ROSALINA ALVES SIMÕES DE MESQUITA

ANÁLISE DA ORGANIZAÇÃO DO TRABALHO NA PESQUISA \& DESENVOLVIMENTO DE INOVAÇÕES COM FOCO NAS QUALIFICAÇÕES DOS PROFISSIONAIS:

UM ESTUDO DE MÚLTIPLOS CASOS 
ROSALINA ALVES SIMÕES DE MESQUITA

\title{
ANÁLISE DA ORGANIZAÇÃO DO TRABALHO NA PESQUISA \& DESENVOLVIMENTO DE INOVAÇÕES COM FOCO NAS QUALIFICAÇÕES DOS PROFISSIONAIS: UM ESTUDO DE MÚLTIPLOS CASOS
}

\author{
Tese apresentada à Escola Politécnica da \\ Universidade de São Paulo para obtenção do \\ título de Doutor em Engenharia.
}

São Paulo 
ROSALINA ALVES SIMÕES DE MESQUITA

\section{ANÁLISE DA ORGANIZAÇÃO DO TRABALHO NA PESQUISA \& DESENVOLVIMENTO DE INOVAÇÕES COM FOCO NAS QUALIFICAÇÕES DOS PROFISSIONAIS: UM ESTUDO DE MÚLTIPLOS CASOS}

Tese apresentada à Escola Politécnica da Universidade de São Paulo para obtenção do título de Doutor em Engenharia.

Área de Concentração: Engenharia de Produção Orientador: Prof. Dr. João Furtado

São Paulo 
FICHA CATALOGRÁFICA

Mesquita, Rosalina Alves Simões de

Análise da organização do trabalho na pesquisa e desenvolvimento de inovações com foco nas qualificações dos profissionais: um estudo de múltiplos casos / R.A.S. de Mesquita. -São Paulo, 2014.

$194 \mathrm{p}$.

Tese (Doutorado) - Escola Politécnica da Universidade de São Paulo. Departamento de Engenharia de Produção.

1.Organização do trabalho 2.Inovações tecnológicas 3.Competência organizacional I.Universidade de São Paulo. Escola Politécnica. Departamento de Engenharia de Produção Il.t. 
Dedico este trabalho à minha família 


\section{AGRADECIMENTOS}

Primeiramente, agradeço ao Prof. João Furtado, pela competência, apoio e valiosa orientação durante todo o período de realização do doutorado.

Aos Professores Renato Garcia e Alceu Salles Camargo, pelas críticas e sugestões valiosas, na banca de qualificação.

Aos membros da banca examinadora, pela disponibilidade em participar e contribuir para o meu desenvolvimento.

Aos colegas do Projeto GEID, pelos momentos de discussão e de trabalho, que agregaram muitas ideias e conhecimento.

Agradeço à CAPES, pela concessão da bolsa, que possibilitou o desenvolvimento da pesquisa.

Aos professores do Departamento de Engenharia de Produção, pela disponibilidade em me atender e pelos valiosos conhecimentos transmitidos. Aos funcionários do departamento, em especial, à Lidia, Olívia e Samy, pela atenção e disponibilidade.

Aos profissionais das Organizações pesquisadas, pelas valiosas contribuições, ao participarem das entrevistas e disponibilizarem informações muito relevantes e ricas, que possibilitaram o aprofundamento das análises e questões propostas nesta pesquisa.

À Daniela Bertoloti e Sônia Scharan pelo excelente trabalho na transcrição das entrevistas.

À Sônia Salvi pela dedicação na revisão do texto.

A todos os colegas da sala de pós, pela convivência, apoio e amizade.

Agradeço aos meus familiares por todo apoio e carinho durante a realização desta pesquisa, em especial, ao Marco, companheiro de todas as horas e meus queridos filhos, Renata e André. 


\section{RESUMO}

Esta tese analisa o processo de organização do trabalho de pesquisa e desenvolvimento de inovações, com foco nas competências requeridas dos diferentes profissionais envolvidos, tanto no ambiente interno como externo das organizações. Assim, o objetivo desta tese é analisar como a organização do trabalho de pesquisa e desenvolvimento de inovações se relaciona com as competências requeridas para realizar as atividades, exigindo, em muitos casos, que as empresas busquem as competências não desenvolvidas internamente, junto a empresas e instituições externas, para garantir o alcance de resultados. A metodologia adotada envolveu primeiramente a revisão da literatura nos temas de P\&D de inovações, modelos de organização do trabalho, gestão de competências, aprendizagem organizacional, para entender a relação entre os construtos. Escolheu-se uma abordagem exploratória de natureza descritivo-qualitativa, com análise de múltiplos casos. Os dados foram obtidos por meio de entrevistas em profundidade, aplicadas de forma presencial, através de roteiro semi-estruturado, junto a diretores, gestores e coordenadores da área de inovação, que foram analisados através de cruzamento com a teoria. Para compor um quadro mais abrangente sobre a questão de pesquisa foi realizado um survey com profissionais da área de P\&D de diferentes empresas através de questionário autoaplicado. Buscou-se analisar como as empresas procedem na combinação de diferentes competências para organizar o processo de P\&D de inovações, um processo extremamente complexo e que envolve grandes investimentos por parte das empresas. Os resultados apontam que há vantagens e desvantagens em buscar competências externas através de parcerias, contratos, acordos de cooperação, com instituições públicas e privadas. A pesquisa também revelou que as parcerias ou acordos de cooperação variam entre os setores e entre as empresas, dependendo da cultura própria de cada organização; de forma geral as dificuldades são maiores nas parcerias com instituições públicas. Por fim, os resultados mostram que as competências requeridas na P\&D de inovações podem mudar ao longo do tempo e por isso, as empresas não conseguem desenvolver todas as competências internamente ou acham mais oportuno buscar estas competências já desenvolvidas por outros atores do ambiente externo, complementando as competências internas de seus pesquisadores. Além disso, as empresas conseguem ganho de escala e redução de custos com pessoal e com a estrutura.

Palavras-Chave: Pesquisa \& Desenvolvimento; Gestão de Competências; Organização do Trabalho; Gestão da Inovação 


\begin{abstract}
This thesis examines the process of work organization in research and development of innovations, focusing on the required competencies of the different professionals engaged in both the internal and external environment of the organization. The objective of this work is to analyze how the work organization of the research and development of innovations is related to the competencies required to perform activities. It requires, in many cases, that companies search for the skills not developed internally in other companies and institutions to ensure the achievement of results. The research begins with a review of the literature in the areas of Research and Development (R\&D), models of work organization, competencies management and organizational learning, to understand the relationship between the constructs. An exploratory and descriptive research method of multiple cases study was chosen. Data were gathered through in-depth interviews, apply in person, through semistructured script, along with directors, managers and coordinators in the area of innovation, which were analyzed by crossing with the theory. To form a more comprehensive picture of the research question a survey was conducted with professionals in R\&D of different companies through self-administered questionnaire. We sought to analyze how companies are making the combination of different skills to organize the process of R\&D innovation, a highly complex and that involves large investments by companies. The results show that there are advantages and disadvantages to search external expertise through partnerships, contracts and cooperative agreements with public and private institutions. The survey also revealed that partnerships or cooperation agreements vary between sectors and between firms, depending on the particular culture of the organization. Generally, the difficulties are greater in partnerships with public institutions. Finally, the results show that the required competences in $R \& D$ innovations can change over time and therefore companies cannot develop all the skills internally or find it appropriate to seek these skills already developed by other actors in the external environment, complementing internal expertise of its researchers. In addition, companies can gain scale and reduce costs with personnel and structure.
\end{abstract}

Key-Words: Research \& Development; Competencies Management; Work Organization; Innovation Management 


\section{LISTA DE TABELAS}

Tabela 1 Número de pesquisadores alocados nas Instituições do país .....................75

Tabela 2 Distribuição dos serviços tecnológicos nas receitas brasileiras (\%) ............77

Tabela 3 Faturamento líquido da indústria química brasileira por segmentos ..........94

Tabela 4 Participação do Brasil no faturamento da indústria química mundial .........94 


\section{LISTA DE FIGURAS}

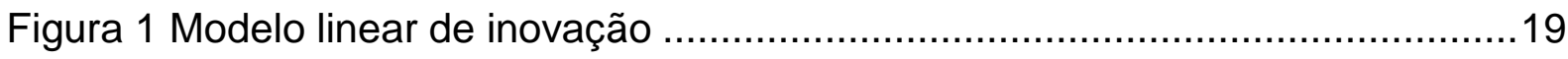

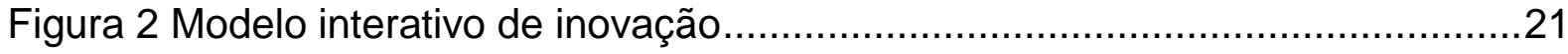

Figura 3 Principais conexões tecnológicas entre diferentes categorias de empresas

Figura 4 Modelo de quadrante da pesquisa científica ...........................................

Figura 5 Modos de conversão do conhecimento ................................................ 41

Figura 6 Características estruturais de organizações tradicionais e inovadoras .......55

Figura 7 Tipos de estruturas para organização de pesquisa e desenvolvimento ......59

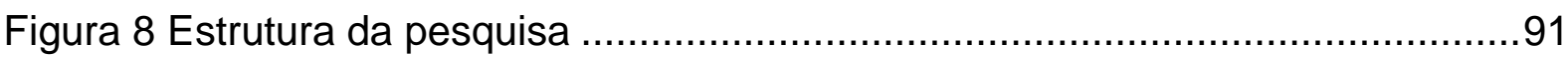

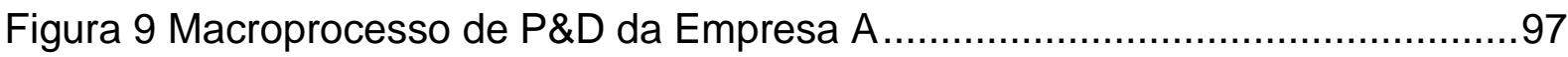

Figura 10 Macroprocesso de P\&D da Empresa B ............................................106

Figura 11 Macroprocesso de P\&D da Empresa C ..............................................114

Figura 12 Estágios da cadeia produtiva farmacêutica.........................................120

Figura 13 Macroprocesso de P\&D da Empresa D...........................................123

Figura 14 Processo de extração de minério de ferro...........................................133

Figura 15 Macroprocesso de P\&D da Empresa E..........................................136

Figura 16 Porcentagem de esforço de inovação ...................................................149 


\section{LISTA DE GRÁFICOS}

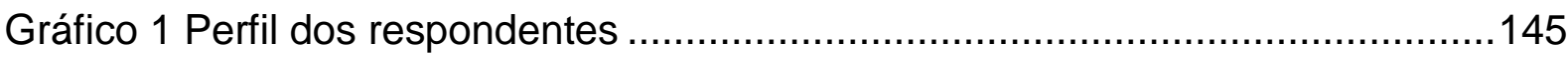

Gráfico 2 Empresas que possuem área de P\&D ..............................................146

Gráfico 3 Tipos de inovações desenvolvidas pelas empresas .............................147

Gráfico 4 Diferença nas médias de inovações radicais e inovações aprimoradas .. 148 Gráfico 5 Proporção de esforços em inovações de produto, processo e tecnologia 148

Gráfico 6 Tipos de inovações das empresas que não possuem área de P\&D........149

Gráfico 7 Rede de cooperação das empresas .................................................150

Gráfico 8 Motivos para busca de cooperação externa ........................................151

Gráfico 9 Instituições com as quais cooperam as empresas que realizam inovações

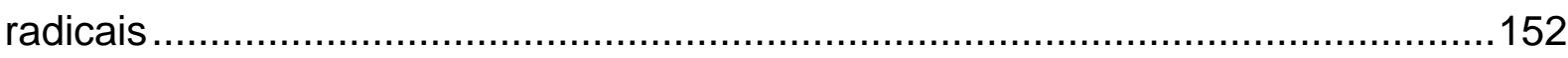

Gráfico 10 Motivos para busca de cooperação externa .......................................152

Gráfico 11 Instituições com as quais cooperam as empresas que realizam inovações

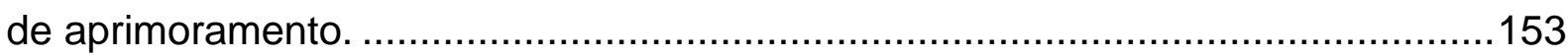

Gráfico 12 Motivos para busca de cooperação externa ......................................153

Gráfico 13 Tipos de inovações das empresas que não possuem equipe de P\&D ..155

Gráfico 14 Tipos de inovações das empresas com até 3 profissionais no P\&D......155

Gráfico 15 Tipos de inovações das empresas com 04 até 10 profissionais no P\&D 155

Gráfico 16 Tipos de inovações das empresas com 11 até 50 profissionais no $P \& D$ 156

Gráfico 17 Tipos de inovações das empresas com 51 até 100 profissionais no P\&D 156

Gráfico 18 Tipos de inovações das empresas com mais de 100 profissionais no P\&D

Gráfico 19 Tipo de inovação por tamanho do P\&D - produto novo .......................157

Gráfico 20 Tipo de inovação por tamanho do P\&D - processo novo .......................158

Gráfico 21 Tipo de inovação por tamanho do P\&D - tecnologia nova ....................158

Gráfico 22 Tipo de inovação por tamanho do P\&D - produto aprimorado ...............159 
Gráfico 23 Tipo de inovação por tamanho do P\&D - processo aprimorado. 159

Gráfico 24 Tipo de inovação por tamanho do P\&D - tecnologia aprimorada 160

Gráfico 25 Competências esperadas da área de P\&D 161

Gráfico 26 Competências esperadas da área de Marketing e Comercial 162 Gráfico 27 Competências esperadas da área de Produção e Operações 162

Gráfico 28 Competências esperadas da área de Gestão da Inovação 163

Gráfico 29 Competências esperadas da área Jurídica 163 


\section{LISTA DE QUADROS}

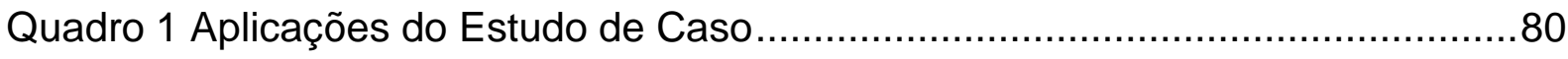

Quadro 2 Proposições do estudo e questões da pesquisa ..................................... 86

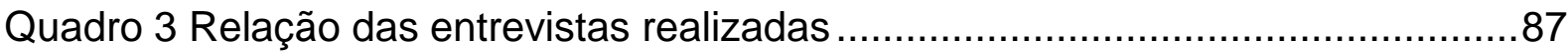

Quadro 4 Classificação CNAE - atividades da indústria de transformação ...............89

Quadro 5 Classificação das empresas participantes por setor..............................144

Quadro 6 Perfil dos respondentes da pesquisa...................................................145

Quadro 7 Tipos de Inovações desenvolvidas pelas empresas (\%) ........................146

Quadro 8 Organizações com as quais as empresas mais cooperam (\%) ...............150

Quadro 9 Motivos para buscar cooperação externa............................................151

Quadro 10: N de Profissionais alocados no Laboratório de P\&D de Inovações ....154

Quadro 11 Principais competências das áreas envolvidas com P\&D .....................160 


\section{LISTA DE ABREVIATURAS E SIGLAS}

ABIFINA Associação Brasileira das Indústrias de Química Fina, Biotecnologia e suas Especialidades

ABIQUIFI Associação Brasileira da Indústria Farmoquímica e de Insumos Farmacêuticos

ABIQUIM Associação Brasileira da Indústria Química

ANPEI Associação Nacional de Pesquisa, Desenvolvimento e Engenharia das Empresas Inovadoras

BNDES Banco Nacional de Desenvolvimento Econômico e Social

CAPES Coordenação de Aperfeiçoamento de Pessoal de Nível Superior

CDI Conselho de Desenvolvimento Industrial

CNAE Classificação Nacional de Atividade Econômica

CNPQ Conselho Nacional de Desenvolvimento Científico e Tecnológico

C,T\&I Ciência, Tecnologia e Inovação

FAPESP Fundação de Amparo à Pesquisa do Estado de São Paulo

FINEP Financiadora de Estudos e Projetos

FNDCT Fundo Nacional de Desenvolvimento Científico e Tecnológico

FUNDEP Fundação de Desenvolvimento da Pesquisa

IBBD Instituto Brasileiro de Bibliografia e Documentação

IBGE Instituto Brasileiro de Geografia e Estatística

ICT Instituto de Ciência e Tecnologia

IEA Instituto de Energia Atômica

IMPA Instituto de Matemática Pura e Aplicada

INPA Instituto Nacional de Pesquisas da Amazônia

INT Instituto Nacional de Tecnologia

IPT Instituto de Pesquisas Tecnológicas do Estado de São Paulo

MCTI Ministério da Ciência, Tecnologia e Inovação

OECD Organisation for Economic Co-operation and Development

PINTEC Pesquisa de Inovação Tecnológica

PITCE Política Industrial, Tecnológica e de Comércio Exterior

PITE Programa de Apoio à Pesquisa em Parceria para Inovação Tecnológica

SBPC Sociedade Brasileira para o Progresso da Ciência

SENAI Serviço Nacional de Aprendizagem Industrial

UNIDO United Nations Industrial Development Organization 


\section{SUMÁRIO}

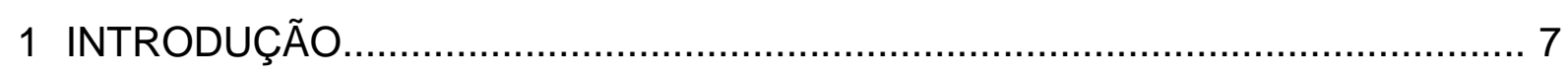

1.1 Apresentação e relevância do estudo .......................................................

1.2 Formulação do problema e objetivos ...........................................................11

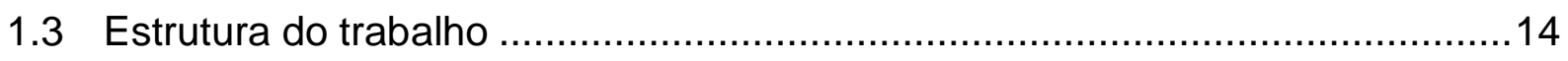

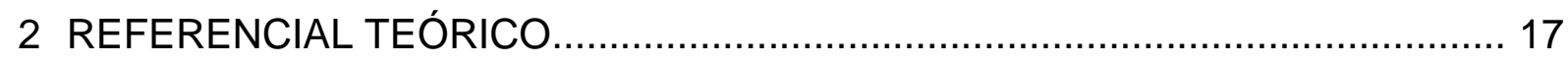

2.1 A inovação segundo os modelos linear e interativo …....................................17

2.2 O surgimento dos laboratórios de Pesquisa \& Desenvolvimento.......................26

2.3 O papel do conhecimento e dos processos de aprendizagem na inovação .....36

2.4 A importância das competências para o desenvolvimento de inovações ..........43

2.5 Estruturas organizacionais e organização do trabalho na P\&D de inovações ..51

2.6 O papel das Instituições no desenvolvimento tecnológico .................................66

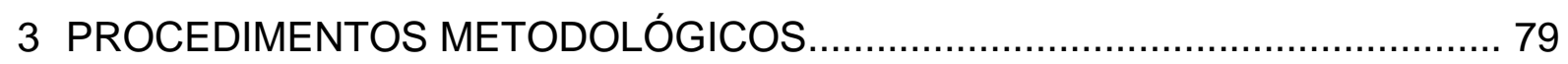

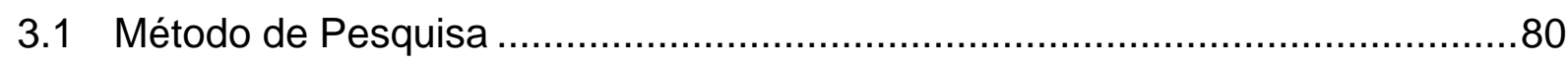

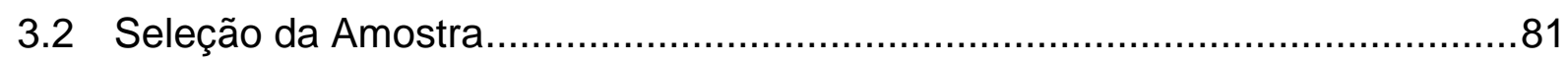

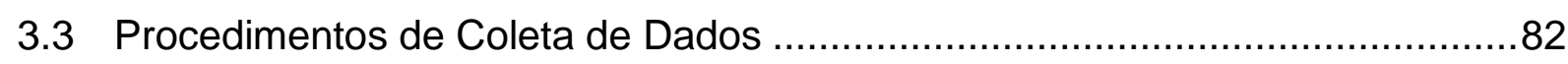

3.4 Apresentação do Instrumento de Coleta de Dados .........................................89

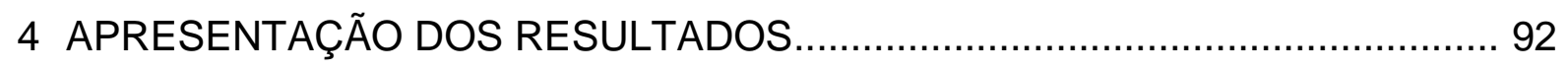

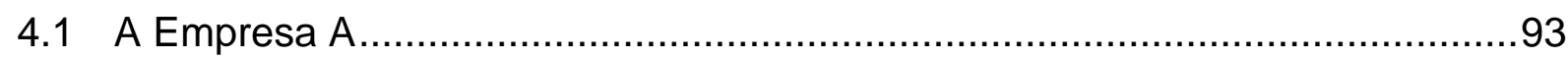

4.1.1 Análise das competências organizacionais da Empresa A ….........................95

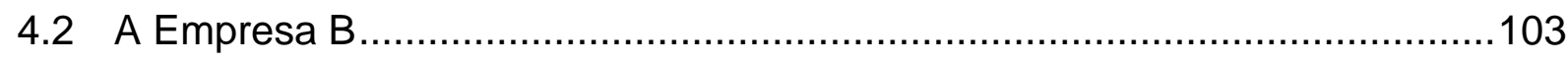

4.2.1 Análise das competências organizacionais da Empresa B..........................103

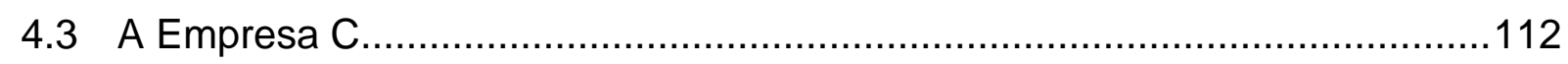

4.3.1 Análise das competências organizacionais da Empresa C...........................113 


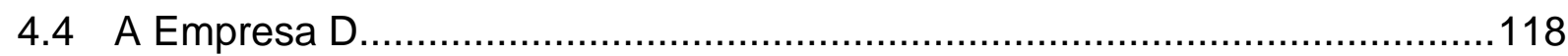

4.4.1 Análise das competências organizacionais da Empresa D...........................119

4.5 A Empresa E

4.5.1 Análise das competências organizacionais da Empresa E............................131

4.6 Apresentação e análise dos resultados do Survey .......................................144

5 ANÁLISE E DISCUSSÃO DOS CASOS E DAS PROPOSIÇÕES...................... 164

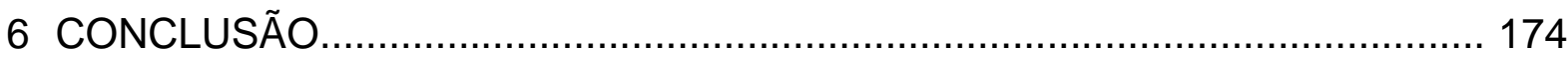

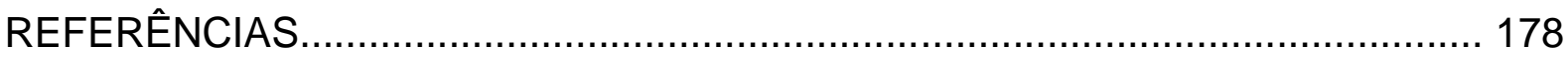

APÊNDICE 


\section{INTRODUÇÃO}

Nesta tese busca-se analisar a organização do trabalho de Pesquisa de Desenvolvimento (P\&D) de inovações e entender o papel das competências dos diferentes atores para a cooperação e interações na realização das diferentes atividades. Estas interações ocorrem tanto no ambiente interno quanto externo das organizações.

\subsection{Apresentação e relevância do estudo}

No cenário atual, a inovação e o conhecimento tornam-se cada vez mais importantes para a competitividade e sobrevivência das organizações produtivas. A inovação pode ser de tecnologia, produto, processo, incluindo ainda, o modelo de negócio.

Empresas que são muito especializadas podem perder mercado e tornaremse vulneráveis em um ambiente complexo e com grande variabilidade de demanda.

Para aumentar a vantagem competitiva, uma empresa depende da diversificação de produtos, mesmo que possa representar uma perda da eficiência produtiva num primeiro momento. Esta diversificação ocorre via processo de inovação, que depende da capacidade de geração de conhecimentos da empresa.

Mecanismos de destruição da concorrência, por meio de competição desigual ou monopólio conseguido através de mecanismos protecionistas, geram resultados num período de tempo determinado, mas não garantem a sobrevivência destas empresas no longo prazo (PENROSE, 1959).

A concorrência através da inovação vem substituir formas de concorrência tradicionais, processo que Schumpeter (1942) chamou de "destruição criativa". Esta forma de concorrência tem impulsionado o crescimento das empresas e o desenvolvimento econômico em diferentes países.

Penrose (1959) já relatava que este processo de "competição de criatividade" tornou-se dominante no comportamento de muitas indústrias dos EUA, garantindo o crescimento das mesmas. 
A diversificação, que ocorre quando as firmas buscam novas áreas de mercado para uma linha nova ou antiga de produtos, é capaz de gerar competitividade às empresas, ao agregar novas competências (PENROSE, 1959).

Neste contexto, a pesquisa industrial passou a ter lugar destacado e o aparecimento de novos laboratórios de pesquisa industrial é um fenômeno que data do início da década de 80, mostrando a importância da pesquisa de novos materiais ou de máquinas e equipamentos para a produção, que podem gerar melhorias nos produtos existentes ou nos processos de produção, bem como gerar novos produtos (PENROSE, 1959).

Diversos autores destacam que a inovação tecnológica é de fundamental importância para a geração de conhecimento, para o desenvolvimento de novas competências e para o desenvolvimento econômico de um país. (DOSI, 1988; ROSENBERG, 1982; NELSON; WINTER, 1982; SCHUMPETER,1942).

Rosenberg (1982) destaca que uma mudança técnica traz contribuições para a produtividade de uma empresa e para o crescimento econômico de um país, mas que essa mudança não pode ser analisada de forma isolada e sim de maneira sistêmica. Há que se considerar que uma invenção específica é viável porque está inserida em uma rede de relacionamentos tecnológicos, ou seja, a mudança técnica possui esse caráter sistêmico ao envolver diversos atores que contribuem com "insumos" ou outras invenções que complementam uma invenção maior.

Surge a necessidade de investigar os ambientes em que são gerados novos conhecimentos e inovações tecnológicas, tais como organizações produtivas, universidades, institutos públicos e privados de pesquisa voltados para a inovação tecnológica.

Um dos desafios das parcerias entre organizações produtivas e organizações de pesquisa está no fato de que possuem missões distintas no processo de inovação, mas que são também complementares (PLONSKI, 1999).

Organizações produtivas e instituições de pesquisa podem ter objetivos diferentes, pois as primeiras buscam a difusão da tecnologia para fins comerciais e as instituições de pesquisa têm um caráter mais científico. Além disso, esses dois 
tipos de organização apresentam estruturas distintas, pois em geral, as organizações produtivas apresentam formas mais hierárquicas, em que o comando e o controle impulsionam as mudanças e as instituições de pesquisa apresentam formas mais orgânicas de trabalho, com estruturas matriciais e trabalhos por projeto, que distribuem o poder e proporcionam autonomia aos pesquisadores (MINTZBERG, 2003).

As organizações produtivas também visam reter novos conhecimentos, transformando em conhecimento tácito ou buscam outras formas de proteção contra as imitações como as patentes, com o objetivo de se manterem no mercado e de conseguirem o retorno do investimento feito em novas pesquisas. Já as instituições de pesquisa visam divulgar as novas descobertas no meio científico, com objetivos mais sociais do que econômicos. No entanto, estas parcerias são fundamentais para o desenvolvimento econômico e social do próprio país, representando oportunidades de geração de emprego e renda e de melhorias na capacitação e na qualidade de vida da população.

Esta tese tem como objetivo analisar e entender como a organização e gestão das atividades de Pesquisa e Desenvolvimento (P\&D), realizadas muitas vezes de forma cooperativa e além das fronteiras organizacionais, por profissionais com diferentes qualificações e competências compartilhadas, influenciam no sucesso das inovações. Buscou-se entender a organização do trabalho de P\&D a partir de uma abordagem sistêmica e evolucionária do processo de desenvolvimento de inovações.

A cooperação, entendida aqui como a interação, integração e articulação de talentos específicos de diferentes pessoas possibilitando o compartilhamento de conhecimentos diferentes (Dejours,1997; Valléry, 2004), é fundamental para que o trabalho de P\&D se desenvolva. Através da cooperação, as pessoas conseguem coordenar as diversas tarefas e negociar a solução de problemas (VALLÉRY, 2004).

Buscou-se investigar os reflexos dessa interação, para a organização do trabalho de P\&D e por consequência, para a própria configuração da estrutura organizacional. Foram analisadas as estratégias das empresas para identificar novas tecnologias e novos conhecimentos no mercado e buscou-se entender como 
os profissionais das empresas absorvem estes novos conhecimentos e criam competências para gerar as inovações de forma cooperativa. Este fenômeno é descrito por Cohen e Levinthal (1990) como capacidade de absorção e pode, segundo os autores, ser crucial para o sucesso no desenvolvimento de inovações.

Foram analisadas algumas características apontadas por Barthe (2003), como específicas de trabalho coletivo ou cooperativo: 1- a divisão dos objetivos dos operadores dentro do trabalho coletivo; 2- a divisão do lugar de trabalho; 3- a articulação temporal das ações dos operadores; 4- a divisão do objeto de trabalho pelos diferentes operadores (podendo ocorrer ou não simultaneamente); 5- o papel das competências compartilhadas e distribuídas na equipe e 6- os processos sociais no grupo (como a normalização ou as relações socioafetivas).

A cooperação faz a integração das diferenças entre as pessoas, articulando os talentos específicos de cada trabalhador e compensando as possíveis falhas singulares (DEJOURS, 1997). Segundo Dejours (1997), a qualidade do trabalho, a confiabilidade e a segurança estão diretamente ligadas à qualidade da cooperação, podendo compensar as falhas da organização do trabalho prescrito e as restrições dos desempenhos humanos.

Pretendeu-se analisar as questões apresentadas em casos de grandes empresas consideradas inovadoras, de diferentes setores como eletrônico, petroquímico, farmacêutico e mineral. Buscou-se contribuir para os estudos e análises sobre organização do trabalho em P\&D, revelando estratégias de sucesso no processo de desenvolvimento de inovações encontradas nestes casos e que podem ser de interesse por parte de outras empresas, do governo e da sociedade em geral.

O estudo assume relevância por aproximar e fundir dois objetos muito estudados separadamente, mas que raramente são tratados em conjunto: Organização do Trabalho e Pesquisa \& Desenvolvimento de Inovações. Além disso, o estudo foi realizado junto a empresas que possuem centros de pesquisa que em geral estão localizados no Estado de São Paulo, que se destaca como centro econômico do país, apresentando alta concentração de atividades industriais e ampla infraestrutura. 
Gonçalves (2007), ao estudar a distribuição espacial da inovação no Brasil através da análise de patentes, classificou regiões do Estado de São Paulo como de alta atividade tecnológica e de inovação, devido à existência de economias de aglomeração. Segundo o autor há cidades no estado de São Paulo que fazem parte de uma rede, capaz de absorver os transbordamentos de conhecimento tecnológico que podem surgir em empresas inovadoras e instituições públicas ou privadas de pesquisa.

\subsection{Formulação do problema e objetivos}

Esta pesquisa pretendeu investigar como a organização e gestão das atividades de P\&D, realizadas por profissionais com diferentes qualificações e competências compartilhadas, influenciam no sucesso das inovações, utilizando-se a abordagem da Teoria Evolucionária. Buscou-se contribuir para os estudos e análises sobre organização do trabalho em P\&D, revelando estratégias de sucesso no processo de desenvolvimento de inovações verificadas em grandes empresas.

Para atender este objetivo, o presente trabalho procurou analisar casos de empresas consideradas inovadoras, orientado pela seguinte questão:

\section{Por que as empresas buscam competências e conhecimentos necessários para a geração de inovações, nas interações com agentes do ambiente externo?}

As formas de aprendizagem, as competências e as qualificações dos profissionais envolvidos no processo de geração de inovações são de grande relevância para as empresas inovadoras e por isso, deve-se aprofundar os estudos e pesquisas relativos a estas temáticas.

Segundo Malerba (1992), as fontes de conhecimento para a inovação estão tanto no ambiente interno quanto externo das organizações. No ambiente interno a aprendizagem ocorre a partir das interações entre as diversas áreas envolvidas no processo de inovação, tais como design, produção, engenharia, marketing e P\&D. No ambiente externo, as fontes de conhecimento podem ser os fornecedores, os clientes, outras empresas de uma mesma indústria e a partir de novos avanços na ciência e tecnologia. 
Outro objetivo desta pesquisa era analisar estas interações, ou seja, como profissionais com diferentes qualificações interagem e cooperam nas diversas etapas do processo de desenvolvimento de inovações, compartilhando ideias, conhecimentos e competências, no ambiente interno e externo das organizações, envolvendo outros agentes de diferentes instituições, como universidades, institutos de pesquisa, clientes, usuários de produtos e outros.

Estas organizações possuem interesses diversos e até conflitantes, mas acabam cooperando e obtendo sucesso na geração de inovações.

Rosenberg (1990) ao analisar as relações e interesses das empresas nos EUA para investirem no desenvolvimento de inovações, salienta que o setor privado não está disposto a fazer investimentos em pesquisa básica, devido ao alto custo deste tipo de pesquisa no longo prazo para ter retorno dos investimentos, à baixa adequação dos resultados e ao alto grau de risco e incerteza envolvidos.

Os fatores inibidores dos investimentos do setor privado em pesquisa básica podem explicar em parte, porque os profissionais buscam interações com outras instituições, como universidades e institutos de pesquisa, que possuem pesquisadores com qualificações e pesquisas financiadas com recursos públicos, podendo contribuir para a geração de inovações no setor privado.

As universidades e institutos de pesquisa geram conhecimento científico, que é disseminado no meio acadêmico, mas que também é transferido às empresas produtivas por outras vias. Por outro lado, as empresas possuem um conhecimento tácito acumulado que também pode gerar inovação e avanços na ciência, despertando interesse das instituições públicas de pesquisa.

Há dessa forma, um fluxo e compartilhamento de dados e informações, que no Brasil são práticas relativamente recentes, compatíveis com a realidade do país e que ainda são pouco exploradas pelos meios acadêmico e empresarial.

O Sistema Nacional de Inovação do país ainda está sendo construído e estas formas de cooperação estão se consolidando e não são muito conhecidas. Há ainda muitos impedimentos para que as empresas cheguem a um processo competitivo e de inovação mais saudável, como por exemplo, o não favorecimento de 
determinados grupos produtivos, que detêm vantagens absolutas de financiamento e crédito (FURTADO, 2008).

Stal (1999) afirma que no Brasil, muitas empresas não querem investir em desenvolvimento tecnológico ou em estruturas de P\&D para realizar pesquisa básica e que por isso, estariam se aproximando de institutos de pesquisa e de universidades, como forma mais viável e rápida para obter competitividade, ao invés de montarem laboratórios de P\&D ou contratarem profissionais mais especializados.

As interações entre organizações produtivas e outras instituições tendem a aumentar no país pela relevância das atividades desenvolvidas de forma conjunta, que além das pesquisas, incluem testes de novos produtos, capacitações, cursos diversos, desenvolvimento de protótipos, entre outras.

Outro aspecto apontado por Stal (1999), para que estas relações se intensifiquem seria a viabilidade financeira, tanto para as empresas quanto para as instituições de pesquisa, pois ambas podem sofrer restrições de recursos, o que faz com que procurem novas fontes de financiamento. A autora acrescenta que a manutenção de uma pesquisa de ponta incorre em custos cada vez mais elevados e que por esse motivo, a pesquisa vem se tornando multidisciplinar, uma estratégia tecnológica importante para o próprio país.

Nesta pesquisa considerou-se que inovações de maior ou menor intensidade tecnológica possuem particularidades e complexidades específicas que requerem formas organizacionais diferentes e dependem de várias qualificações e competências, que podem estar interna ou externamente à organização.

Estas particularidades interferem na distribuição de tarefas e grau de coesão entre os profissionais e regulação de suas ações, seja em estruturas funcionais, matriciais ou por projeto. Os canais de comunicação e formas de difusão de conhecimento e informações também devem ser adaptados aos diferentes tipos de estruturas e considerar as diversas interações entre os profissionais. A própria localização do objeto do trabalho ou da inovação pode variar e não ser fixa ou pode estar dividida entre os diferentes agentes, em ações individuais ou coletivas que requerem recursos intelectuais, competências e experiências diversas. 
A partir da revisão da literatura foram levantados os seguintes objetivos específicos desta pesquisa:

- Entender como diferentes empresas organizam os processos de trabalho de pesquisa e desenvolvimento de inovações.

- Identificar as competências requeridas nas diferentes etapas de P\&D de inovações e como o desenvolvimento dessas competências modifica a estrutura ou o processo de inovação.

- Entender como os profissionais identificam oportunidades tecnológicas e novos conhecimentos no mercado e como transformam em novas competências para desenvolver inovações.

- Identificar as características organizacionais e estruturais das empresas bem sucedidas no lançamento de inovações.

- Entender como se dá a coordenação das atividades de P\&D de inovações nos ambientes interno e externo das empresas e quais são os mecanismos utilizados para garantir a coesão e sinergia entre os profissionais.

Estas questões visavam aprofundar o conhecimento sobre o processo de pesquisa e desenvolvimento de inovações, tendo como foco as competências requeridas nas diferentes etapas do processo, a partir de uma abordagem sistêmica e evolucionária. As inovações envolvem a cumulatividade de conhecimento e a acessibilidade a novos conhecimentos, que ocorre no ambiente externo. Dessa forma verificou-se que há uma relação muito forte com atores do ambiente externo, cada qual contribuindo com competências distintas que se complementam para o sucesso das inovações.

\subsection{Estrutura do trabalho}

A seguir apresenta-se a estrutura dos capítulos que compõem a tese:

O capítulo um situa a presente pesquisa no contexto em que foram desenvolvidos os estudos de casos e o survey junto aos profissionais de P\&D, 
apresenta o problema e os objetivos específicos do estudo, a delimitação da pesquisa, a justificativa e por fim a estrutura do trabalho.

O capítulo dois traz o referencial teórico pertinente ao estudo que foi desenvolvido, abordando conceitos gerais referentes ao processo de inovação e são detalhados os modelos linear e sistêmico. A seguir, faz-se uma revisão histórica sobre o surgimento dos laboratórios profissionais de P\&D e discutem-se algumas abordagens sobre a classificação da pesquisa básica e aplicada. São apresentadas e discutidas as classificações e conceitos referentes às atividades de Pesquisa, Desenvolvimento e Geração de Inovações, adotadas pela OECD no Manual de Oslo e no Manual Frascati.

Em seguida faz-se uma discussão sobre diferentes abordagens referentes ao papel do conhecimento, dos processos de aprendizagem e do desenvolvimento de competências individuais e organizacionais para o sucesso das inovações. São apresentadas as estruturas encontradas nas organizações envolvidas com P\&D de inovações e formas de organização das atividades de P\&D. Por fim, faz-se uma análise teórica sobre o papel das instituições no desenvolvimento tecnológico e sobre a relação das instituições com o desenvolvimento da ciência e tecnologia no Brasil.

O capítulo três traz os procedimentos metodológicos adotados com o objeto de estudo, a questão da pesquisa, as proposições, os objetivos geral e específicos, elaborados e revisados a partir da revisão da literatura e da pesquisa empírica. Em seguida, discute-se a seleção da amostra de empresas pesquisadas na Etapa I e das empresas participantes do survey na Etapa II e os procedimentos de coleta de dados adotados.

O capítulo quatro traz os resultados da pesquisa empírica, com dados e informações das empresas pesquisadas, obtidos através das entrevistas com gestores da área de P\&D das empresas e da análise de informações levantadas em fontes secundárias. Em seguida são apresentados os resultados obtidos através do survey com profissionais da área de P\&D de empresas de diferentes setores.

No capítulo cinco são discutidos os resultados obtidos com a pesquisa empírica qualitativa, em relação aos objetivos e proposições iniciais do estudo. 
O capítulo seis traz as conclusões deste trabalho, as contribuições do estudo, as limitações da pesquisa e as sugestões para possíveis desdobramentos.

Por fim, são apresentadas as referências bibliográficas utilizadas neste trabalho. No apêndice há o roteiro de entrevista semi-estruturado utilizado na Etapa I e o formulário e carta de apresentação que foram enviados eletronicamente para as empresas que participaram do survey na Etapa II da pesquisa. 


\section{REFERENCIAL TEÓRICO}

Este capítulo traz uma revisão teórica e conceitual a cerca do tema e objetivos deste trabalho, anteriormente apresentados, que visa analisar a importância e o papel das qualificações no processo de organização do trabalho em ambientes de pesquisa e desenvolvimento de inovações.

$\mathrm{Na}$ seção 2.1 são apresentados os conceitos e abordagens referentes ao processo de inovação. Discutem-se os diferentes modelos de inovação, como o modelo linear de inovação e outros modelos não lineares, interativos e sistêmicos. Neste trabalho considerou-se o processo de inovação como um processo dinâmico, sistêmico e inserido num contexto social.

$\mathrm{Na}$ seção 2.2 faz-se uma revisão histórica sobre o surgimento dos laboratórios profissionais de P\&D e discutem-se algumas abordagens sobre a classificação da pesquisa em básica e aplicada.

A seção 2.3 traz uma discussão sobre diferentes abordagens referentes ao papel do conhecimento e dos processos de aprendizagem para a inovação e a seção 2.4 trata do desenvolvimento de competências voltadas para a inovação.

Na seção 2.5 são apresentadas as estruturas encontradas nas organizações envolvidas com P\&D de inovações e formas de organização do trabalho de P\&D.

Por fim, na seção 2.6 faz-se uma análise teórica sobre o papel das instituições no desenvolvimento tecnológico e sobre a relação das instituições com o desenvolvimento da ciência e tecnologia no Brasil.

\subsection{A inovação segundo os modelos linear e interativo}

Há uma ampla discussão sobre a importância do inventor independente ou individual, pois quando surgiram os grandes laboratórios de pesquisa acreditava-se que a inovação não ficaria sob o domínio de um único agente, mas surgiria de um esforço conjunto, em um novo modo de produção mais fragmentado, em que cada pesquisador acabaria se especializando em uma parte do processo de pesquisa, tal qual ocorreu com o modo de produção de bens e serviços. 
Segundo Mees (1920), uma inovação depende muito de pesquisa científica, que por sua vez pode adquirir diferentes formas, segundo a área de conhecimento envolvida. Para o autor, muitas pesquisas são desenvolvidas por um único pesquisador, que não necessita necessariamente de um laboratório bem equipado (por exemplo, nas ciências matemáticas).

Pesquisas mais complexas que requerem aparelhos mais sofisticados e que dependem de conhecimentos diversos são em geral, desenvolvidas em laboratórios especiais.

Para Mees (1920), há uma relação muito forte entre a pesquisa científica básica, que visa um avanço no conhecimento puro e a pesquisa voltada para a produção industrial, que visa gerar ganhos financeiros. Segundo o autor, não é possível prever qual será o retorno de uma pesquisa, pois ela pode gerar um avanço no conhecimento ou mostrar-se de grande aplicação industrial.

A importância da pesquisa científica, tanto para as indústrias quanto para o desenvolvimento dos países, passou a ser reconhecida a partir de 1914, quando houve um aumento dos estímulos à geração de conhecimento (MEES, 1920). Neste ano, foi criado nos EUA, o Comitê dos Cem (Committee of One Hundred), através da Associação Americana para o Progresso da Ciência, que visava encontrar formas de estimular a pesquisa científica nesse país. Esses esforços também ocorreram em outros países, como Inglaterra, França, Austrália e Canadá. O governo britânico criou um Comitê para tratar da pesquisa científica. A França criou um laboratório de larga escala. A Austrália criou um departamento ligado ao governo, para organizar o desenvolvimento de pesquisas e o Canadá passou a investigar assuntos relacionados à pesquisa científica, no mesmo ano. As grandes indústrias também começaram a investir em instalações para desenvolver pesquisas, enquanto as pequenas empresas que não dispunham de capital para investir, acabaram se organizando de forma associativa para manter laboratórios que gerassem pesquisas para o setor das mesmas (MEES, 1920).

Nesse contexto, surgiu o modelo linear de inovação, amplamente difundido a partir do final da Segunda Guerra Mundial, entre pesquisadores que buscavam explicar o processo de inovação. Este modelo tomou como base as ideias contidas 
no relatório "Science - The Endless Frontier" de Vannevar Bush, diretor do Office of Scientific Research and Development, elaborado em 1945. Vannevar Bush defendia a premissa de que novos conhecimentos e inovações surgiam a partir da ciência básica e que somente investindo na ciência básica seria possível obter progresso tecnológico. Esta visão da ciência retomava na verdade, as ideias de Francis Bacon de 1635 e exerceram grande influência nas políticas científicas por duas décadas após o ano de 1945 (METCALFE, 2003).

Este modelo traz uma visão mais simples do processo de inovação e considera que o processo traz etapas distintas e definidas, sequenciais e num único sentido, iniciando com a pesquisa básica, desenvolvimento, produção e comercialização, conforme Figura 1.

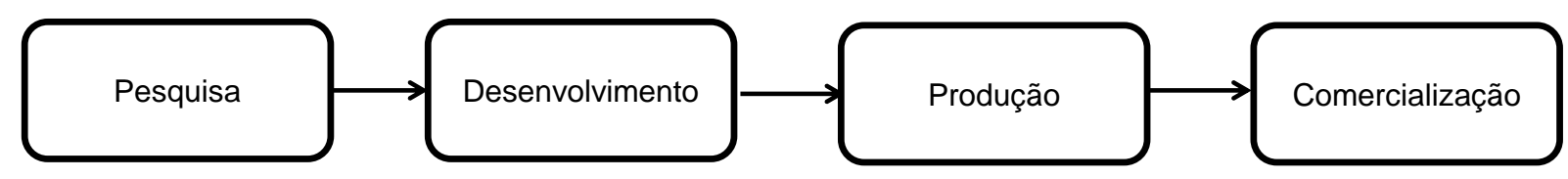

Figura 1 Modelo linear de inovação

Fonte: Adaptado de Kline \& Rosenberg (1986, p. 286).

O modelo linear apresenta controvérsias e uma delas é que a tecnologia teria hierarquicamente menos importância que a ciência e, segundo este modelo, a tecnologia é considerada ciência aplicada. Segundo as premissas desse modelo, novos conhecimentos científicos surgiriam na proporção da aplicação de recursos em pesquisa básica (METCALFE, 2003).

O modelo linear ainda é muito utilizado em análises e discussões, particularmente em questões políticas. Segundo Kline e Rosenberg (1986), uma das falhas do modelo linear é que ele não considera a importância dos feedbacks do mercado em qualquer etapa do processo de inovação (como as opiniões e expectativas dos clientes, fundamentais nas análises do desempenho de produtos e na revisão do projeto ou do design) e as diferentes fontes de inovação existentes, que não necessariamente estão relacionadas com a pesquisa básica ou científica. 
Segundo Kline e Rosenberg (1986), a tese de que uma inovação inicia com a pesquisa é equivocada, na maioria dos casos. Para os autores, a etapa do projeto ou design é considerada a etapa inicial do processo de inovação e não a ciência. Os reprojetos geram a inovação e dependem em muitos casos, da contribuição de outras áreas do conhecimento. A pesquisa pode contribuir ao gerar uma solução para um problema que impede que uma inovação seja completada. Muitas pesquisas sobre novos materiais foram geradas a partir de problemas encontrados na criação de novos produtos, como por exemplo, os semicondutores, as baterias de energia solar, as turbinas de vapor e outras. Thomas Edison ao desenvolver o sistema de iluminação elétrica precisou da análise de um matemático para solucionar problemas referentes ao circuito paralelo (KLINE; ROSENBERG, 1986).

Os exemplos visam mostrar que os feedbacks são fundamentais e que há uma forte interação entre inovação e ciência. Segundo Kline e Rosenberg (1986), a inovação força o desenvolvimento da ciência e o processo de aprendizagem acontece através da experiência acumulada na produção de produtos já estáveis.

Kline e Rosenberg (1986) definem ciência como "a criação, descoberta, verificação, cotejo, reorganização e disseminação de conhecimento sobre a natureza biológica, física e social". Os dois componentes principais da ciência que afetam a inovação são: (1) a totalidade atual do conhecimento humano armazenado sobre a natureza e (2) o processo pelo qual se corrige e adiciona novos conhecimentos à ciência. Inovações importantes ocorrem devido à acumulação de conhecimento científico nas diferentes áreas, mas muitas inovações surgem dentro das organizações, a partir do conhecimento das pessoas que realizam o trabalho e de informações que estão acessíveis a elas.

Aos poucos o modelo linear foi superado por outros modelos mais interativos e sistêmicos, considerados mais adequados para a análise do processo de inovação das empresas.

Um destes modelos com abordagem mais sistêmica do processo de inovação é o modelo interativo (chain-linked model), proposto por Kline e Rosenberg (1986). Este modelo considera os feedbacks entre as diversas fases do processo de inovação. Considera também que a firma é a principal fonte geradora de inovação e 
não a universidade ou os institutos de pesquisa. Há também interação com outras empresas e com a ciência e tecnologia do ambiente em que a empresa atua. A Figura 2 ilustra este modelo interativo:

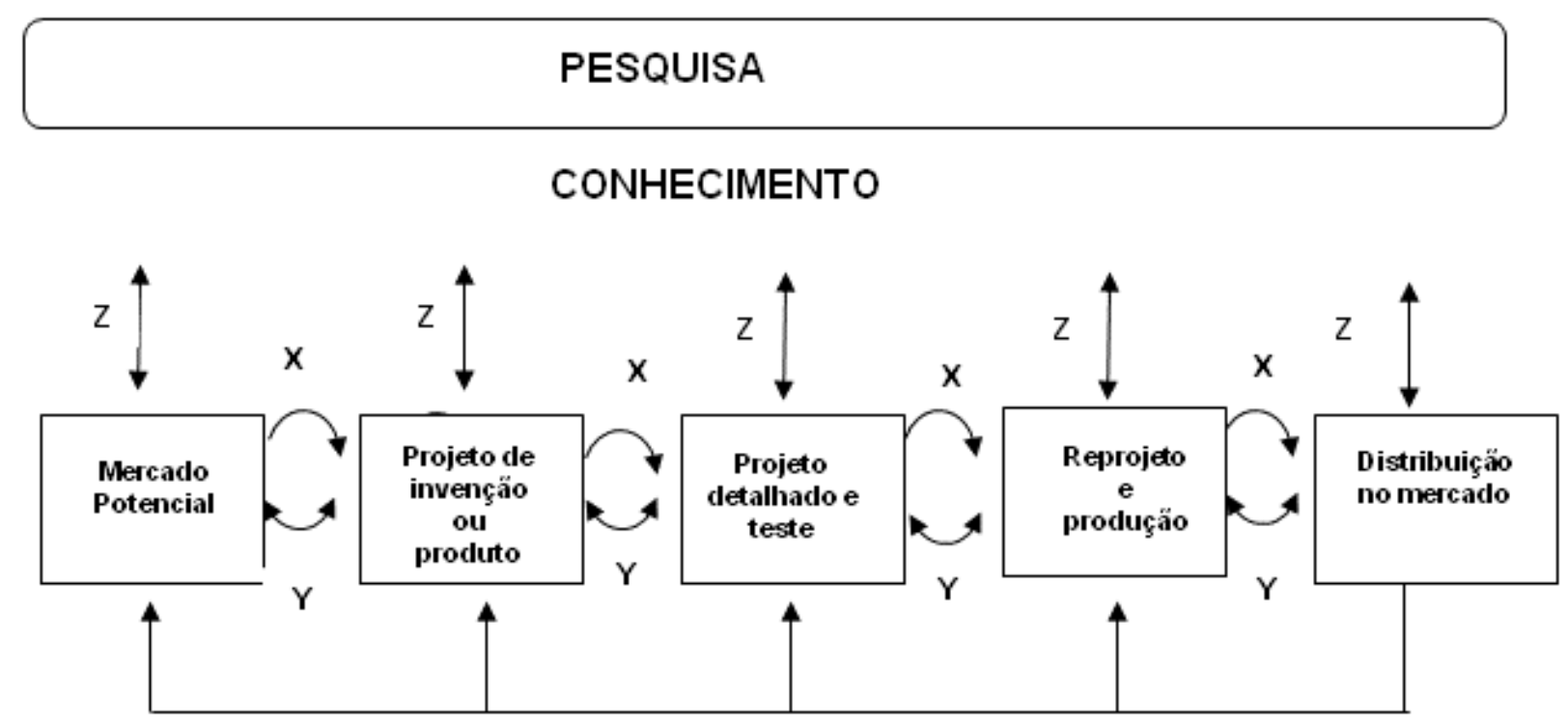

Figura 2 Modelo interativo de inovação

Fonte: Adaptado de Kline \& Rosenberg (1986)

De acordo com o modelo, a relação entre a firma e a pesquisa pode ocorrer em qualquer etapa do processo de inovação. Os autores identificam alguns caminhos possíveis da inovação: (1) um caminho central começando no projeto de uma invenção, passando pelas outras etapas até chegar ao mercado (letra $\mathrm{x}$ ), (2) um caminho dos feedbacks que podem ocorrer em cada etapa do processo (a montante e a jusante) e a partir do mercado (letra y), (3) um caminho partindo da pesquisa para ser incorporada pela firma ou ao contrário, partindo de uma demanda da firma para gerar uma nova pesquisa (letra $\mathrm{z}$ ).

Neste modelo, o início da inovação não ocorre sempre a partir da pesquisa básica para se chegar ao desenvolvimento tecnológico, tal qual ocorre no modelo linear. No modelo interativo há relações internas à empresa, interações externas 
com as demais empresas e também interações entre a ciência e as empresas de forma isolada, para desenvolver produtos, processos ou serviços. A empresa busca oportunidades de inovação a partir das necessidades levantadas no mercado, quando utiliza os conhecimentos científicos já disponíveis internamente ou então, se necessário, aciona o meio científico dando início a uma nova pesquisa.

Segundo Nelson e Rosenberg (1993), inovação não significa apenas que pessoas fazem pesquisa e desenvolvimento. Os autores destacam que a inovação difere de invenção, pois a inovação de produtos ou processos busca atender características de desempenho desejáveis, sujeitas ainda a restrições de custos, dado que as atividades de desenho de novos produtos são muito sofisticadas e muito caras.

A inovação é tratada de forma abrangente, como "um processo pelo qual as firmas dominam e transformam na prática, os protótipos de produtos e processos de produção que são novos para os mesmos e não necessariamente para o universo ou uma nação" (NELSON; ROSENBERG,1993, p. 4).

O processo de inovação passa a ser tratado como um processo social, com a contribuição de diferentes atores e organizações, portadores de conhecimentos e competências que se complementam para gerar a inovação. Esta abordagem interativa e dinâmica do processo de inovação é uma abordagem neoschumpeteriana, que considera melhor toda a complexidade envolvida na dinâmica da inovação e é a abordagem adotada no presente trabalho.

Schumpeter foi o precursor da abordagem que considera que a inovação gera vantagem competitiva para a empresa que introduz a inovação e é a base da evolução e da mudança econômica em um país (FURTADO, 2006).

Nelson e Rosenberg (1993), ao analisarem o processo de inovação em diferentes setores, destacam que em alguns deles os avanços tecnológicos dependiam muito dos avanços na ciência, como no caso dos equipamentos e sistemas eletrônicos, da química e da aviação. No entanto, os autores apontam que os avanços tecnológicos em diferentes áreas, dependem de vários campos da ciência e que as conexões entre a ciência e a tecnologia são complexas e variam de campo para campo. Segundo os autores, em alguns casos uma nova tecnologia 
pode surgir dos avanços científicos e em outros, a nova tecnologia passa a ser objeto de estudos científicos, para que possam ser feitas novas melhorias. A termodinâmica, por exemplo, surgiu a partir de interesses teóricos sobre o funcionamento do trem a vapor, na primeira metade do século dezenove. A engenharia química também surgiu dos avanços da moderna indústria química, com uma aplicação prática da ciência química, envolvendo ainda a engenharia mecânica, para a produção em larga escala dos produtos químicos. Os autores destacam que tanto as universidades, quanto os laboratórios particulares são partes essenciais de um sistema de inovação. Em muitos casos, a tecnologia avança juntamente com os avanços na ciência, como por exemplo, o surgimento do laser nos anos de 1960 e o uso da fibra no campo da ciência ótica.

Seguindo esta linha de discussão, Metcalfe (2003) afirma que a ciência e a tecnologia são ramos do conhecimento distintos, porém interdependentes. Uma característica principal do processo moderno de inovação é a combinação da multidisciplinaridade de conhecimentos com múltiplas fontes institucionais do conhecimento relevante. O alinhamento efetivo dos dois ramos requer a criação de suporte tecnológico adequado e sistemas de inovação que muitas vezes ultrapassam fronteiras nacionais.

É importante destacar aqui que o conceito de inovação não se refere apenas a produtos e segundo Kline e Rosenberg (1986) pode envolver: 1) um novo processo de produção; 2) a substituição de um componente por um material mais barato, recém-desenvolvido para uma determinada função, em um produto essencialmente idêntico e sem alterar sua funcionalidade; 3) a reorganização da produção, funções internas ou arranjos na distribuição que geram aumento da eficiência e um suporte melhor para um dado produto e 4) melhoria nos instrumentos ou métodos para gerar a inovação.

Schumpeter (1939) propôs uma classificação de vários tipos de inovações, incorporadas no Manual de Oslo, que traz as diretrizes para a coleta e uso de dados nas pesquisas sobre inovação tecnológica na indústria (OECD, 1997). Na classificação de Schumpeter, os tipos de inovações são: 
- Introdução de um novo produto ou mudança qualitativa em produto já existente;

- Inovação de processo que seja novidade para uma indústria;

- Abertura de um novo mercado;

- Desenvolvimento de novas fontes de suprimento de matéria-prima ou de outros insumos;

- Mudanças na organização industrial.

A inovação também é classificada segundo a sua dimensão em termos de grau de novidade, como incremental ou radical (TIDD; BESSANT; PAVITT, 2005). Segundo Tidd, Bessant e Pavitt (2005), a inovação incremental ocorre quando um produto ou serviço já existente passa por melhorias ou atualizações e a inovação é radical quando um produto ou serviço inteiramente novo surge no mercado, envolvendo mudanças na forma de pensar e utilizar estes produtos ou serviços.

Tidd, Bessant e Pavitt (2005) apresentaram o modelo classificado como dos "4Ps",em que definem inovação em termos de produto, processo, posição e paradigma, considerando também as inovações em serviços:

- Inovação de produto - mudanças em produtos ou serviços que uma organização oferece;

- Inovação de processo - mudanças na forma como os produtos ou serviços são criados e distribuídos,

- Inovação de posição - mudanças no contexto em que os produtos ou serviços são introduzidos;

- Inovação de paradigma - mudanças nos modelos mentais que servem de base ao trabalho das organizações.

No contexto da abordagem interativa é possível distinguir ou separar as empresas, entre aquelas que produzem inovações e aquelas que apenas fazem aquisição dessas inovações no mercado. Esta distinção é feita por Pavitt (1984) em sua taxonomia sobre a produção e difusão de inovações. De acordo com o autor, a trajetória tecnológica das empresas é determinada pela atividade principal que 
desenvolvem. Em seu estudo envolvendo 2000 inovações de empresas manufatureiras da Grã-Bretanha no período de 1945 até 1979, o autor demonstrou que existem padrões setoriais de mudança técnica.

Em sua taxonomia, o autor classifica as empresas em: (1) empresas dominadas por fornecedores, (2) empresas intensivas em escala, (3) empresas baseadas em ciência e (4) fornecedores especializados (Figura 3).

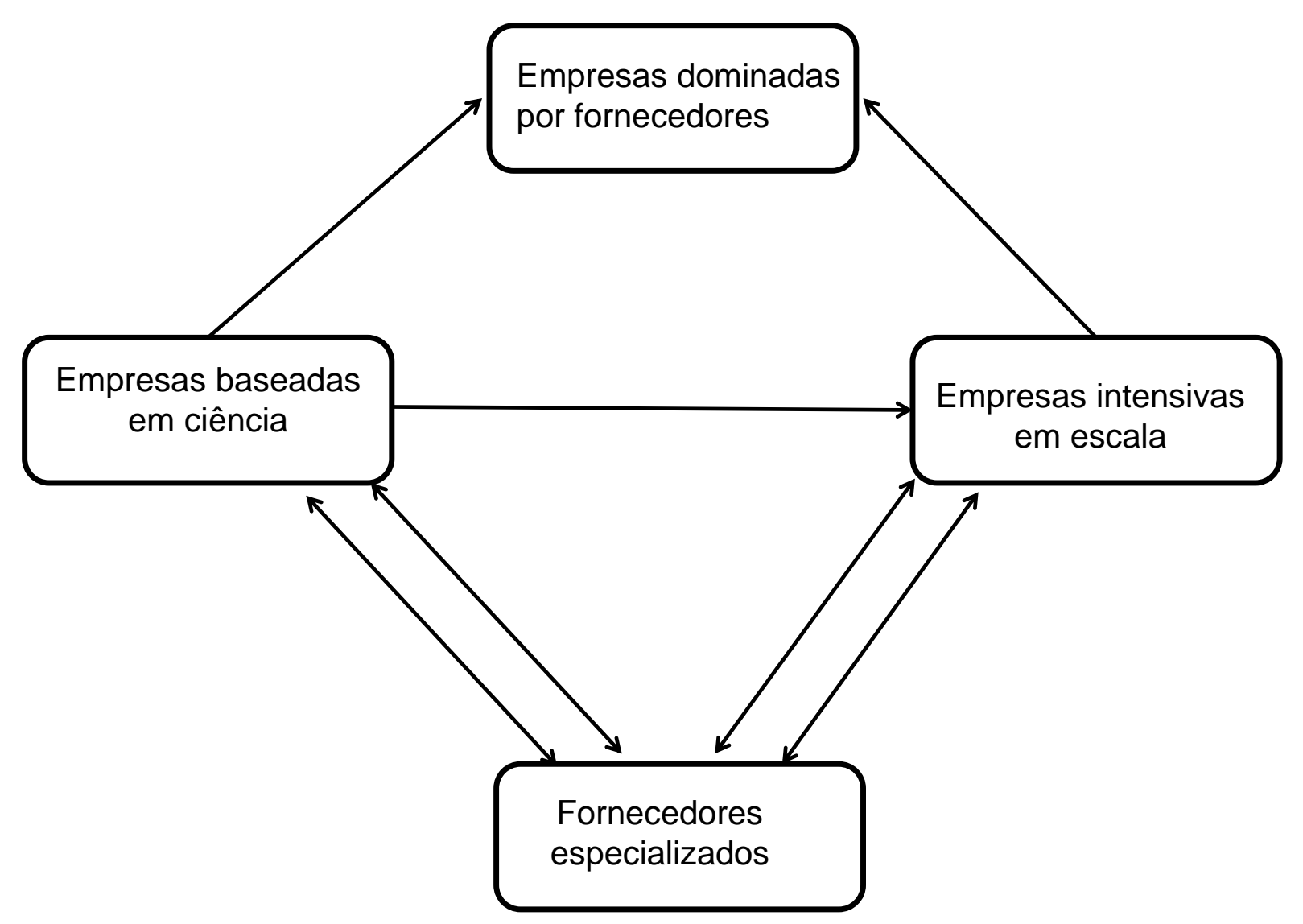

Figura 3 Principais conexões tecnológicas entre diferentes categorias de empresas Fonte: Adaptado de Pavitt (1984) 
Segundo a classificação de Pavitt (1984), as empresas dominadas por fornecedores fazem aquisição de tecnologias das empresas intensivas em escala e das baseadas em ciência. As empresas baseadas em ciência também transferem tecnologia para as empresas intensivas em escala. Empresas baseadas em ciência e empresas intensivas em escala podem adquirir tecnologias dos fornecedores especializados, mas também podem criar inovações e transferir para estes fornecedores.

\subsection{O surgimento dos laboratórios de Pesquisa \& Desenvolvimento}

Quando surgiram as primeiras indústrias técnicas, a pessoa responsável pelas inovações era muitas vezes, o próprio dono da empresa, que gerava novas descobertas. Muitos cientistas possuíam o domínio do conhecimento teórico e prático em diferentes áreas do conhecimento, contribuindo para o desenvolvimento de ramos industriais (MEES, 1920). De acordo com Mees (1920), à medida que as indústrias foram expandindo e tornaram-se mais complexas, surgiram os grandes laboratórios de pesquisa industrial, dada a grande quantidade de informações técnicas e científicas requeridas no trabalho de investigação. Dessa forma o trabalho de pesquisa, que antes era realizado por um único indivíduo, tornou-se fragmentado, especializado e foi transferido para os laboratórios.

Há três tipos de laboratórios industriais, segundo Mees (1920):

a) De trabalho - que visam controlar materiais, processos e produtos;

b) Industriais - que buscam melhorar produtos e processos visando redução de custos de produção e introdução de novos produtos no mercado;

c) De teoria pura e das ciências básicas associadas a um setor.

Mees (1920) aponta que o futuro de um setor industrial depende do trabalho do laboratório de pesquisa, com o desenvolvimento básico da área de interesse da empresa como um todo e não basta apenas aperfeiçoar processos ou reduzir custos. 
A partir de 1870, as grandes empresas químicas da Alemanha passaram a estruturar os departamentos de P\&D industriais, quando perceberam que a pesquisa de novos produtos e o desenvolvimento de novos processos químicos, de maneira regular, sistemática e profissional poderia tornar-se um negócio lucrativo (FREEMAN, 1995).

Segundo Nelson e Rosenberg (1993), o avanço técnico nos setores químico e elétrico passou a depender da pesquisa e desenvolvimento dos laboratórios industriais, na criação de novos produtos e melhoria dos já existentes.

Empresas como Hoechst, Bayer e BASF passaram a contratar diversos cientistas e engenheiros para os laboratórios de P\&D e a indústria química da Alemanha ocupou a liderança antes e no pós Primeira Guerra Mundial, com inovações importantes em materiais sintéticos, fibras e borrachas (FREEMAN, 1995).

Segundo Freeman (1995), o enorme sucesso da indústria química alemã impulsionou as inovações nos departamentos de P\&D de empresas químicas de outros países e os laboratórios de P\&D in-house também surgiram em outras indústrias, que necessitavam ter acesso aos resultados de pesquisa básica das universidades e outras instituições de pesquisa, para desenvolver novos produtos.

Mees (1920) destaca que a pesquisa realizada nos laboratórios industriais é de fundamental importância, podendo garantir que um país controle um determinado ramo industrial. $\mathrm{O}$ autor menciona o caso do surgimento da indústria de lâmpadas incandescentes nos EUA e a importância do laboratório de pesquisa da General Electric Company, para a manutenção da liderança no setor, uma vez que surgiam aperfeiçoamentos e melhorias incrementais em empresas de outros países, que poderiam comprometer e transferir esta liderança para fora dos EUA. A perda de liderança dos grandes fabricantes britânicos de lentes fotográficas ocorreu dessa forma. Apesar dos britânicos terem o domínio das teorias sobre a óptica das lentes, acabaram perdendo a liderança dessa indústria para os alemães, que continuaram e aprofundaram o trabalho científico de pesquisa sobre lentes fotográficas. Os britânicos, graças às pesquisas sobre a fabricação de espectroscópios, conseguiram 
depois levar a fabricação desses instrumentos de volta para a Inglaterra (MEES, 1920).

A ciência mostrou sua importância juntamente com os laboratórios profissionais de P\&D, com as grandes descobertas pós Segunda Guerra Mundial, tais como o radar, os computadores e os explosivos, que resultaram de grandes projetos de P\&D, envolvendo a mobilização do governo, engenheiros industriais e cientistas da academia. Nesta época, a P\&D profissional ganhou enorme prestígio, impulsionando o crescimento de diferentes países industriais desenvolvidos e também de países em desenvolvimento, interessados em armas nucleares, tais como Índia, Argentina, Israel, Brasil e lugoslávia (FREEMAN, 1995).

O sistema de P\&D passou a ser visto como uma fonte para a inovação e as medições adotadas consideravam, sobretudo, as descobertas deste sistema, que passaram a ser padronizadas com a criação do manual Frascati em 1963, pela Organisation for Economic Co-operation and development (OECD). O Manual Frascati estabeleceu um conjunto de princípios básicos relativos à medição das atividades científicas e tecnológicas (OECD, 2002).

Segundo o Manual Frascati (OECD, 2002), o trabalho de Pesquisa e Desenvolvimento (P\&D) engloba o trabalho criativo desenvolvido de forma sistemática para aumentar o estoque de conhecimento, incluindo o conhecimento do homem, da cultura e da sociedade, e a utilização desse estoque de conhecimento para criar novas aplicações.

O termo P\&D abrange três atividades: pesquisa básica, pesquisa aplicada e desenvolvimento experimental.

A pesquisa básica consiste de trabalhos experimentais ou teóricos empreendidos para aquisição de novos conhecimentos sobre os fundamentos subjacentes aos fenômenos e fatos observáveis, sem que haja uma aplicação prática.

Segundo Stokes (2005), a pesquisa básica visa buscar um entendimento mais amplo de fenômenos de um campo do conhecimento. 
A pesquisa básica visa a formulação e teste de hipóteses, teorias ou leis e para isso são analisadas estruturas, propriedades e relações. O pesquisador muitas vezes não conhece uma aplicação real para a sua descoberta e os resultados são publicados no meio científico, como revistas ou congressos. Outras pesquisas são consideradas sigilosas e muitas vezes não são publicadas, aguardando o momento certo para divulgação.

Neste tipo de pesquisa há certa liberdade quanto à fixação dos objetivos por parte do pesquisador. $\mathrm{O}$ espaço onde ocorre a pesquisa pode ser a universidade ou uma organização pública, mas as empresas privadas também podem realizar pesquisa básica, para se prepararem para a próxima geração de tecnologia. Além disso, a pesquisa pode estar direcionada para grandes áreas do conhecimento com interesse mais geral, visando o seu uso no futuro, como por exemplo, as pesquisas em nanotecnologia.

A pesquisa básica divide-se ainda em pesquisa básica pura e pesquisa básica orientada. A pesquisa básica pura é aquela que busca o avanço do conhecimento, sem ter intenção de obter vantagens econômicas ou sociais no longo prazo ou de transferir os resultados para outros setores interessados na aplicação e sem o interesse de aplicar os resultados encontrados. Já a pesquisa básica orientada busca produzir uma base de conhecimento que permita a resolução de problemas já formulados ou que possam surgir. Esta pesquisa ajuda a identificar a pesquisa estratégica ou voltada para a elaboração de políticas.

A pesquisa aplicada abrange trabalhos originais realizados para adquirir novos conhecimentos, porém está direcionada para um objetivo prático específico. Este tipo de pesquisa busca utilizações viáveis para as descobertas da pesquisa básica ou para encontrar novos métodos ou formas de atingir objetivos específicos pré-determinados. A pesquisa aplicada busca aprofundar os conhecimentos existentes para a resolução de problemas específicos. É também um meio de tornar as ideias mais operacionais e os conhecimentos ou informações obtidas são geralmente patenteadas ou permanecem em segredo.

A pesquisa experimental abrange trabalhos sistemáticos baseados nos conhecimentos obtidos na investigação e na experiência prática para produção de 
novos materiais, produtos ou dispositivos, bem como instalação de novos procedimentos, sistemas e serviços ou melhoria dos já existentes. A P\&D engloba tanto a P\&D formal realizada nas unidades de P\&D, como a P\&D informal ou ocasional realizada em outros locais.

O manual destaca que essas categorias geram alguns problemas teóricos e práticos, pois estas separações e sequências não existem no mundo real.

Segundo Stokes (2005), o modelo linear de inovação trazia a ideia de um espectro de pesquisa estático que partia da pesquisa básica até a pesquisa aplicada, ou seja, os progressos científicos seriam convertidos para ter aplicação prática, por meio de um fluxo dinâmico que partiria da ciência e iria até a tecnologia. A abordagem interativa da inovação critica esta visão estática do processo de inovação.

Segundo o Manual Frascati (OECD, 2002), um projeto de P\&D pode estar na fase de pesquisa aplicada e/ou experimental e pode ser necessário fazer um investimento financeiro para realizar pesquisas teórica ou experimental adicionais para conhecer melhor os mecanismos dos fenômenos estudados.

Alguns projetos de pesquisa podem pertencer a mais de uma categoria, como por exemplo, um estudo para identificar as variáveis que influenciam os resultados escolares de crianças com diferenças sociais e étnicas, que pode ser classificado tanto como pesquisa básica quanto aplicada.

Outro exemplo seria de uma pesquisa teórica básica para identificar os fatores que determinam as diferenças regionais de crescimento econômico. Porém, se esta pesquisa for realizada para a criação de uma política pública sobre o tema, torna-se uma pesquisa aplicada. Pode-se ainda neste caso realizar uma pesquisa experimental, se forem desenvolvidos programas operativos, baseados nos conhecimentos anteriormente obtidos, para reduzir os desequilíbrios regionais.

Stokes (2005) propôs um modelo de quadrante para a pesquisa científica, em que classifica as pesquisas quanto ao grau de avanço na fronteira do conhecimento e grau de aplicação prática da descoberta (Figura 4). 
Considerações de uso?

N Considerações de uso?

\begin{tabular}{|c|c|c|c|}
\hline Busca de & Sim & $\begin{array}{l}\text { Pesquisa básica } \\
\text { pura (Bohr) }\end{array}$ & $\begin{array}{l}\text { Pesquisa básica } \\
\text { inspirada pelo uso } \\
\text { (Pasteur) }\end{array}$ \\
\hline fundamental? & Não & & $\begin{array}{l}\text { Pesquisa aplicada } \\
\text { pura (Edison) }\end{array}$ \\
\hline
\end{tabular}

Figura 4 Modelo de quadrante da pesquisa científica

Fonte: Stokes (2005)

Stokes (2005) organizou as pesquisas em quatro quadrantes e classificou-as com os nomes dos pesquisadores Bohr, Pasteur e Edison que geraram importantes contribuições tecnológicas. No quadrante de Bohr estariam as pesquisas básicas puras ou a ciência pura, sem interesse de aplicação prática. No quadrante de Edison estariam pesquisas com interesses de aplicação e que não buscam avançar no entendimento de fenômenos da ciência. O quadrante de Pasteur incluiria as pesquisas que buscam avançar no entendimento dos fenômenos, mas que também buscam uma aplicação ou uso. O quadrante vazio incluiria as pesquisas que exploram fenômenos particulares, porém sem buscar explicações ou aplicações práticas dos resultados.

Segundo as diretrizes do Manual de Oslo, criado em 1997 para análise das inovações de empresas do setor privado, as atividades de inovação tecnológica de produto ou de processo são todas as etapas científicas, tecnológicas, comerciais, 
organizacionais e financeiras que visam implantar produtos ou processos tecnologicamente novos ou melhorados (OECD, 2002).

Em muitos casos há dificuldades para identificar atividades de P\&D, pois há uma separação tênue entre atividades de P\&D e atividades rotineiras, mas que muitas vezes estão relacionadas com atividades de inovação. Uma inovação deve gerar um avanço científico ou tecnológico e apresentar uma solução para um problema que pode ser científico ou tecnológico (OECD, 2002).

O Manual não considera algumas atividades como de P\&D embora sejam atividades afins, com uma base científica e tecnológica. Essas atividades, em muitos casos, têm uma ligação muito próxima com $P \& D$, com fluxos de informações e em termos operacionais ou institucionais, mas quando é possível identificá-las, estas devem ser excluídas. O Manual relaciona algumas dessas atividades:

1) Ensino e Formação - das áreas de ciências naturais, engenharia, medicina, agricultura, ciências sociais e humanidades, praticado em universidades e instituições especializadas de ensino superior;

2) Outras atividades científicas e tecnológicas correlacionadas - atividades especializadas de pessoal científico e técnico, serviços bibliográficos, serviço de patentes, serviços de difusão de informação científica e técnica, bem como de aconselhamento e conferências científicas. Estas atividades são excluídas exceto quando são realizadas para apoiar a $\mathrm{P} \& \mathrm{D}$, como por exemplo, a preparação do relatório sobre os resultados de P\&D;

3) Compilação de dados de interesse geral - efetuada por órgãos públicos, ao coletarem dados de fenômenos naturais, biológicos ou sociais, de interesse público geral. Se a compilação de dados for exclusiva de um projeto de P\&D então é incluída como atividade de P\&D. Por exemplo, os dados sobre a trajetória e características das partículas de um reator nuclear. Nas ciências sociais há muitas coletas de informações relativas à sociedade como, por exemplo, nos censos, inquéritos por amostragem e outros. Se a coleta ou tratamento forem para fins de pesquisa científica, então são consideradas atividades de $P \& D$, mas quando os dados são 
coletados para outros objetivos, como pesquisas frequentes sobre desemprego, não devem ser classificados como atividades de P\&D.

4) Ensaios e atualização de normas nacionais - referentes à atualização ou manutenção de normas nacionais; testes e análises rotineiras de materiais, componentes, produtos, processos, solos, atmosfera etc.;

5) Estudos de viabilidade em projetos de engenharia - quando as pesquisas utilizam técnicas já existentes para obter informação adicional antes de decidir sobre a implementação, não são consideradas atividades de P\&D. Nas ciências sociais, os estudos de viabilidade são pesquisas de características socioeconômicas e as consequências de determinadas situações, como por exemplo, um estudo de viabilidade de um complexo petroquímico para uma determinada região e não são atividades de P\&D. NO entanto, os estudos de viabilidade de projetos de pesquisa são parte de P\&D;

6) Assistência médica especializada - envolve os estudos e aplicação de conhecimentos médicos especializados rotineiros. No entanto, quando a assistência médica especializada é realizada em hospitais universitários, pode haver algumas atividades de P\&D;

7) Trabalhos de patentes e licenciamentos - todo o trabalho administrativo e legal relacionado com as patentes e licenças. No entanto, os trabalhos sobre patentes diretamente relacionados com projetos de P\&D são considerados atividades de P\&D;

8) Estudos relacionados com política - refere-se não só à política nacional como também à política regional e local, assim como à política das empresas para concretizar uma atividade econômica. Os estudos de caráter político cobrem uma série de atividades tais como análise e avaliação de programas existentes, políticas e operações de departamentos governamentais, o trabalho de unidades que fazem análise e monitoramento contínuo de fenômenos externos, como defesa e segurança nacional e o trabalho de comissões parlamentares de inquérito 
relativo ao governo em geral ou à política departamental e suas operações;

9) Atividades de rotina no desenvolvimento de software - estas atividades não são consideradas como atividades de P\&D e envolvem melhorias de sistemas ou programas específicos que já estavam disponíveis no mercado anteriormente. Incluem-se ainda nestas atividades, os problemas técnicos resolvidos em projetos anteriores nos mesmos sistemas operacionais e arquiteturas computacionais e ainda as tarefas rotineiras de manutenção de informática. Muitas atividades são problemas de fronteira entre desenvolvimento de software e P\&D.

10) Outras atividades industriais - todas as etapas científicas, técnicas, comerciais e financeiras que não são $P \& D$, mas que são necessárias para o funcionamento de produtos e serviços novos ou melhorados, assim como a exploração comercial de processos novos e melhorados. Inclui a aquisição de tecnologia, ferramentas e engenharia industrial, desenho industrial, outras aquisições de capital, o start-up de produção e comercialização de produtos novos e melhorados;

11) Produção e atividades técnicas afins - abrangem atividades que antecedem a produção industrial, a produção e distribuição de bens e serviços, diversos serviços técnicos ligados ao setor empresarial e à economia em geral, assim como atividades afins que utilizam disciplinas das ciências sociais como as pesquisas de mercado.

12) Gestão e outras atividades de apoio - as atividades de financiamento de P\&D e as atividades de apoio indiretas.

O Manual Frascati ressalta que um critério básico que permite distinguir as atividades de P\&D das atividades afins é a existência de um elemento de novidade e a resolução de uma incerteza científica e/ou tecnológica, ou seja, quando a resolução de um problema não é evidente para uma pessoa que tenha o domínio básico de conhecimentos e técnicas comuns da área em questão. 
Outros critérios suplementares para diferenciar P\&D e outras atividades científicas, tecnológicas e industriais afins são:

1) Quais são os objetivos do projeto?

2) Existe um elemento novo ou inovador no projeto? Procura previamente fenômenos, estruturas ou relações desconhecidas? Aplica conhecimentos ou técnicas de uma forma nova? Existe uma probabilidade significativa de que resulte um novo (maior e mais profundo) conhecimento de fenômenos, relações ou princípios de manipulação que podem interessar a mais do que somente uma organização? Os resultados podem ser patenteados?

3) Quem trabalha no projeto?

4) Quais são os métodos utilizados?

5) Que programa financia o projeto?

6) Em que medida as conclusões ou resultados do projeto podem ter um caráter geral?

7) O projeto seria melhor classificado como outra atividade científica, tecnológica ou industrial?

Seguindo esta linha de classificação pode-se citar como exemplo, os exames de rotina, tais como as análises de sangue ou bacteriológicas realizadas por médicos, que não são atividades de P\&D. Porém se um programa especial de análise de sangue for realizado com o lançamento de um novo fármaco, então estas atividades serão consideradas como de P\&D.

Outro exemplo pode ser observado na indústria mecânica, cujas atividades de $P \& D$ estão associadas às tarefas de desenho ou como estudos e projetos, no caso de pequenas e médias empresas. As atividades consideradas como P\&D são todas aquelas que envolvem cálculos, projetos, planos e instruções de funcionamento, se forem executadas para a construção e lançamento de instalações piloto e de protótipos. Porém, se estas atividades forem executadas para uma produção normalizada, envolvendo a preparação, execução e manutenção (nas máquinas 
ferramenta por exemplo) ou na promoção de venda de produtos (por exemplo os folhetos, brindes e catálogos de peças), elas não serão consideradas como atividades de $P \& D$.

O Manual de Oslo considera a difusão de inovações tecnológicas de produto ou de processo, como a forma pela qual as inovações se espalham pelos canais de mercado ou não necessariamente através deles, a partir do surgimento em diferentes países e regiões e para diferentes indústrias, mercados e empresas.

Para entender como se dá a organização das atividades de inovação numa indústria e compreender os determinantes das trajetórias de inovação encontradas nos diferentes países, faz-se necessário explorar o papel do conhecimento e como se dá a sua difusão e absorção por parte das empresas, levando ao sucesso ou fracasso das mesmas.

Na próxima seção, estes conceitos serão aprofundados e discutidos à luz das principais abordagens encontradas na literatura.

\subsection{O papel do conhecimento e dos processos de aprendizagem na inovação}

A visão interativa da dinâmica da inovação ressalta dois importantes fatores que podem nortear as trajetórias de inovação tecnológica nas empresas ou mesmo nos setores industriais ao longo do tempo: a acessibilidade a novos conhecimentos no ambiente externo da empresa e a cumulatividade de conhecimento, ou seja, o grau de dependência da construção de novos conhecimentos a partir de conhecimentos já existentes (MALERBA; ORSENIGO, 2000). Os autores destacam que para entender como as empresas e as indústrias evoluem é necessário analisar e entender algumas dimensões do conhecimento e suas relações com os processos de aprendizagem e as competências.

A diversidade no estoque de conhecimento acumulado pelas firmas e a variedade de processos de aprendizagem direcionam as mudanças técnicas das firmas e geram as diferenças de trajetórias (MALERBA, 1992).

Malerba (1992) identifica seis tipos principais de processos de aprendizagem encontrados nas empresas, cada um dos quais ligados a diferentes fontes de 
conhecimento, que podem ser internas ou externas às empresas. A aprendizagem interna está relacionada com atividades da empresa nas diferentes áreas como P\&D, produção e marketing, que o autor classificou como learning by doing, learning by using e learning by searching. O aprendizado externo está relacionado com as relações estabelecidas com outras empresas, com fornecedores, com universidades e com outras instituições, classificadas pelo autor como learning by interacting, learning from advances in science and technology e learning from inter-industry spillover.

Os seis tipos de processos de aprendizagem criados na taxonomia de Malerba (1992) são apresentados em seguida:

- Aprendizagem pelo fazer (Learning by doing) - relacionadas com experiências nas atividades de produção;

- Aprendizagem pelo uso (Learning by using) - relacionadas com o uso de produtos, máquinas e insumos;

- Aprendizagem por avanços em ciência e tecnologia (Learning from advances in science and technology) - relacionadas com a absorção de novos desenvolvimentos em ciência e tecnologia.

- Aprendizagem por transbordamentos entre indústrias (Learning from interindustry spillover) - relacionadas aos transbordamentos entre indústrias, envolvendo o que os concorrentes e outras empresas estão fazendo.

- Aprendizagem por interação (Learning by interacting) - relacionado com a interação com fontes de conhecimento a jusante e a montante, tais como fornecedores e usuários ou através da cooperação com outras empresas da indústria;

- Aprendizagem por pesquisa (Learning by searching) - relacionadas principalmente às atividades formais de $P \& D$, visando geração de novos conhecimentos.

Malerba e Orsenigo (2000) destacam que o conhecimento é um conceito complexo e não pode ser definido ou tratado como informação. O conhecimento possui diferentes graus de acessibilidade e de cumulatividade. Os autores 
consideram que a partir das propriedades da tecnologia, ou seja, o grau de cumulatividade do conhecimento tecnológico, as oportunidades e condições de apropriação e também as características da base de conhecimento, pode-se entender a diversidade nos padrões de inovação nos setores. Estas propriedades da tecnologia são definidas como regime tecnológico e na verdade é uma noção retomada de Nelson e Winter (1982).

A acessibilidade refere-se às oportunidades de obter conhecimento externo às firmas. Este conhecimento pode estar interno a uma indústria favorecendo a imitação por parte de outras empresas pertencentes a essa indústria ou no ambiente externo da indústria. Se a acessibilidade ao conhecimento for alta, a apropriabilidade (os mecanismos de proteção das inovações) será baixa resultando em baixa concentração na indústria, pois os competidores podem ter acesso ao conhecimento sobre novos produtos e processos e podem copiar esses produtos ou processos, resultando numa distribuição uniforme das competências nessa indústria (MALERBA; ORSENIGO, 2000).

A acessibilidade ao conhecimento no ambiente externo de uma indústria está relacionada com as oportunidades científicas e tecnológicas. Malerba e Orsenigo (2000) destacam que o ambiente externo pode afetar as empresas de duas formas: através do capital humano que possui certo nível e tipo de conhecimento e através do conhecimento científico e tecnológico desenvolvido nas empresas ou outras organizações, tais como universidades ou laboratórios de pesquisa. As oportunidades tecnológicas diferem entre as indústrias e tecnologias.

As condições de oportunidades refletem a abundância de conhecimento externo à firma e podem surgir de formas diferentes entre as indústrias. Em alguns casos, as oportunidades podem surgir da demanda transmitida na relação entre usuários e produtores ou do próprio conhecimento externo dos fornecedores. Em outros casos, as condições de oportunidades estão relacionadas com rupturas científicas nas universidades. As oportunidades para inovação podem surgir ainda de avanços em P\&D externo, em equipamentos ou instrumentos (NELSON, 1982).

Nem todo conhecimento externo é de fácil uso e transformação em novos produtos, pois depende da acessibilidade. Se houver acessibilidade ao 
conhecimento externo, significa que outros fornecedores poderão gerar novos produtos ou serviços, a partir do uso desse conhecimento. Esta característica diferencia as estruturas de atividades de inovação apontadas por Schumpeter, denominadas Schumpeter Mark I e Schumpeter Mark II ou "destruição criativa" e "acumulação criativa" (MALERBA; ORSENIGO, 2000).

Na estrutura caracterizada pela "destruição criativa" ou Schumpeter Mark I, as barreiras à entrada são fracas, permitindo que novas firmas e empreendedores realizem atividades de inovação. Nesta fase há muitas oportunidades, baixa cumulatividade e a base de conhecimento encontra-se externa à firma, permitindo acessibilidade. Além disso, esta base de conhecimento é nova e precisa ser explorada. A baixa cumulatividade ao nível da firma abre espaço para a imitação e para a entrada de novas firmas inovadoras.

Na estrutura caracterizada pela "acumulação criativa" ou Schumpeter Mark II há grandes firmas estabelecidas e há muitas barreiras à entrada para novas firmas inovadoras e muitas oportunidades para a inovação. Neste regime, poucas firmas dominam o conhecimento, com alta cumulatividade deste, ao nível da firma. Segundo Malerba e Orsenigo (2000), as propriedades da base de conhecimento e das competências das firmas afetam significativamente a organização de uma indústria. As firmas poderão apresentar diferentes graus de integração e a indústria poderá mostrar diferentes mecanismos de coordenação das complementaridades, como por exemplo, desde a integração vertical na indústria de computadores mainframe nos anos de 1960 ou as interfaces tácitas no Silicon Valley, até os sistemas complexos de subcontratação na indústria aeroespacial e automobilística ou a divisão vertical do trabalho regulada pelas trocas de mercado (MALERBA; ORSENIGO, 2000).

As trajetórias tecnológicas das firmas estão relacionadas com o grau de cumulatividade de conhecimento, pois a geração de novos conhecimentos é feita a partir de conhecimentos pré-existentes nas firmas e em tecnologias específicas (MALERBA; ORSENIGO, 2000).

Malerba e Orsenigo (2000) identificam três tipos diferentes de cumulatividade: 
1) relacionada aos processos de aprendizagem e retornos crescentes e dinâmicos ao nível tecnológico. A natureza cognitiva dos processos de aprendizagem e do conhecimento passado pode limitar a pesquisa corrente, mas também pode gerar novas questões e novos conhecimentos;

2) relacionada com capacitações organizacionais específicas das firmas, que podem ser melhoradas apenas gradualmente ao longo do tempo. Estas capacitações definem o que uma firma aprende e o que pode ser alcançado no futuro;

3) relacionada aos retornos do mercado, pois o retorno de um sucesso da inovação pode ser reinvestido em $\mathrm{P} \& \mathrm{D}$, aumentando assim a probabilidade de se gerar mais inovações.

O conhecimento de base refere-se às dimensões do conhecimento, consideradas relevantes para as atividades de inovação de uma indústria. As dimensões do conhecimento de base que são relevantes para a inovação são o conhecimento tácito e o conhecimento codificado. Estas dimensões influenciam nas escolhas dos meios de transmissão desses conhecimentos, que por sua vez, diferem também entre os setores (MALERBA; ORSENIGO, 2000). Se o conhecimento se apresenta mais na forma tácita, a transmissão do mesmo será feita mais através de meios informais, como conversas face a face, treinamentos personalizados ou através da contratação de novos funcionários. Estes meios de transmissão do conhecimento são extremamente sensíveis à distância entre os agentes.

Se o conhecimento for mais padronizado, modular ou codificado, sua transmissão ocorrerá mais por meios formais, tais como publicações, licenças e patentes. Nestes casos, a proximidade geográfica não é importante na transmissão do conhecimento entre os agentes.

Para Nonaka e Takeuchi (1997), é possível converter os conhecimentos tácito e explícito e em seu modelo denominado SECl, o autor explica que o conhecimento tácito pode ser compartilhado através de contatos interpessoal e social. Conforme proposto pelo modelo $\mathrm{SECl}$, os quatro padrões de conversão do conhecimento aparecem na figura 5 : 


\begin{tabular}{|c|c|c|c|}
\hline & \multicolumn{2}{|l|}{ Para } \\
\hline & & $\begin{array}{l}\text { Conhecimento } \\
\text { tácito }\end{array}$ & $\begin{array}{c}\text { Conhecimento } \\
\text { explícito }\end{array}$ \\
\hline $\mathrm{De}$ & $\begin{array}{c}\text { Conhecimento } \\
\text { tácito }\end{array}$ & Socialização & Externalização \\
\hline $\mathrm{De}$ & $\begin{array}{c}\text { Conhecimento } \\
\text { explícito }\end{array}$ & Internalização & Combinação \\
\hline
\end{tabular}

Figura 5 Modos de conversão do conhecimento

Fonte: Nonaka e Takeuchi (1997, p. 69).

Em seguida, faz-se uma descrição resumida dos quatro modos de conversão do conhecimento, segundo Nonaka e Takeuchi (1997):

1) Socialização: conversão que ocorre na interação do conhecimento tácito entre indivíduos;

2) Externalização: conversão do conhecimento tácito em conhecimento explícito, com registro e documentação do conhecimento para disponibilização formal para outras pessoas;

3) Combinação: junção de conhecimentos explícitos disponíveis, que combinados geram novos conhecimentos. A troca e combinação de conhecimentos ocorrem em reuniões, conversas, redes de comunicação informatizadas;

4) Internalização: conversão do conhecimento explícito em conhecimento tácito, com aquisição do conhecimento através de meios formalizados e registrados.

Cohen e Levinthal (1990) destacaram a importância dos conhecimentos novos, gerados e transmitidos no ambiente externo, para as atividades de inovação das empresas, o qual os autores denominaram "capacidade de absorção". Para os autores, esta "capacidade de absorção" é a habilidade da empresa em reconhecer o 
valor de uma informação nova gerada no ambiente externo, assimilá-la e aplicá-la para fins comerciais.

Os autores destacam a importância do conhecimento base, que é o conhecimento acumulado ao longo do tempo pelas empresas ao realizarem suas atividades rotineiras de produção e de resolução de problemas. Realizar diretamente as atividades de produção é importante para desenvolver a habilidade em reconhecer e explorar um novo conhecimento no ambiente externo e que está relacionado com o que a empresa já conhece. Outras características importantes são as habilidades individuais dos funcionários, o grau de investimento anterior em P\&D e a estrutura organizacional interna responsável pela transmissão de informações.

Cohen e Levinthal (1990) destacam o papel dos funcionários na capacidade de absorção das firmas. Segundo os autores, a capacidade de absorção da firma depende da capacidade de absorção dos próprios funcionários envolvidos com pesquisa e produção, pois eles é que percebem, absorvem e aplicam os conhecimentos externos. Porém, nem sempre estes funcionários possuem o conhecimento prévio necessário para o entendimento do novo conhecimento. Este conhecimento prévio é fundamental para facilitar a assimilação do novo conhecimento e tem impacto direto no desempenho da inovação das firmas no longo prazo (COHEN; LEVINTHAL, 1990)

Essa cumulatividade de conhecimento anterior tem implicações para o desenvolvimento da capacidade de absorção ao longo do tempo. Se a firma tiver desenvolvido alguma capacidade de absorção em uma área particular, terá maior facilidade para acumular conhecimentos adicionais de que necessita num período próximo, disponíveis no ambiente externo. A cumulatividade de conhecimento específico que é dominado pela firma leva a capacidade de absorção a uma forte dependência de trajetória (path dependence) ou dependência histórica, ou seja, há uma relação direta com as escolhas das firmas em relação aos investimentos ao longo do tempo, que orientarão os tipos de conhecimentos externos novos que serão absorvidos. A expertise em uma área também permite que a firma avalie melhor as oportunidades tecnológicas relativas ao campo de conhecimento das 
mesmas e avaliar as potencialidades comerciais de um avanço tecnológico (COHEN; LEVINTHAL, 1990).

Cohen e Levinthal (1990) salientam que se a firma deixar de investir na sua capacidade de absorção terá dificuldades para assimilar e utilizar futuros conhecimentos, pois a firma não conseguirá mais identificar a importância de novos conhecimentos gerados no mercado, fenômeno denominado "lockout".

\subsection{A importância das competências para o desenvolvimento de inovações}

O desenvolvimento de inovações depende de competências individuais e de competências organizacionais que são desenvolvidas ao longo da trajetória das empresas e se modificam em ambientes dinâmicos (PRAHALAD; HAMEL, 1990; ZARIFIAN, 2001). É importante entender o conceito de competências, como elas se desenvolvem nos indivíduos e nas organizações e entender porque as competências geram vantagens competitivas para algumas empresas e não para outras, relativas ou não ao mesmo setor.

Nos anos 70, McClelland iniciou o debate sobre competência entre psicólogos e administradores nos Estados Unidos, quando fez uma revisão sobre as práticas de seleção e contratação de pessoas, ao constatar que as medidas tradicionais para avaliar o desempenho das pessoas no trabalho, como os testes de aptidão, inteligência e de desempenho não eram eficientes, levando ainda à discriminação das minorias. Em seu artigo, propôs que fossem identificadas as atitudes, habilidades e conhecimentos de funcionários com desempenhos superiores aos demais e estas características seriam reunidas em um modelo de competências que orientaria os processos de seleção, considerando ainda as necessidades das organizações. McClelland (1973) definiu as competências como as características observáveis no indivíduo que permitem que tenha desempenho superior na realização de uma tarefa ou em uma dada situação.

Outros autores marcaram as discussões sobre o conceito de competências na literatura americana, defendendo que deveriam ser incluídas características de personalidade dos indivíduos como motivos, aptidões e valores, pois estes fatores seriam fundamentais para identificar os funcionários de excelente desempenho, 
embora admitissem a dificuldade em desenvolver estas características nos indivíduos através de treinamento (BOYATZIS; MCCLELLAND, 1982; DUBOIS,1993; MCLANGAN, 1997).

Nessa perspectiva, a competência é um conjunto de conhecimentos, atitudes e habilidades, que implicam em alto desempenho e assim, o conceito de competência tem como referência as tarefas prescritas do cargo. Para Lawler (1994), esta perspectiva baseia-se nos requisitos do cargo, seguindo os princípios do taylorismo-fordismo e este modelo não atende as necessidades das organizações complexas e em constantes mudanças.

Os debates e pesquisas sobre competência se iniciaram na França também na década de 1970, com contribuições importantes para as discussões e modelos de competências.

A corrente francesa buscou ampliar o conceito baseado nos requisitos do cargo, incorporando a capacidade da pessoa em assumir iniciativas e buscar soluções para as novas situações profissionais (ZARIFIAN, 2001). Para Zarifian (2001), a competência individual é "tomar iniciativa" e "assumir responsabilidade" diante de situações profissionais que o indivíduo encontra. $O$ autor destaca a importância da autonomia e da automobilização do indivíduo, mas também a importância da mobilização coletiva, pois o indivíduo constrói sua competência ao longo de seu percurso profissional e pessoal, a partir de diferentes fontes de conhecimentos, de especialidades e de experiências, que irá combinar de maneira própria desenvolvendo suas competências.

Le Boterf (1995) define competência como um saber agir responsável que envolve a mobilização, integração e transferência de conhecimentos, recursos e habilidades numa dada situação de trabalho.

Le Boterf (2010) considera que o indivíduo depende de outros recursos e de pessoas para desenvolver suas competências. Segundo o autor, um profissional não pode ser competente sozinho, pois ele depende dos suportes organizacionais, dos colegas a quem ele pode consultar, dos recursos do meio em que está inserido e deve saber combinar e mobilizar estes recursos nas situações de trabalho. 
Já a competência coletiva não é simplesmente a soma das competências individuais, pois deve haver sinergia entre as competências e as interações sociais do grupo que também interferem na construção das competências coletivas; se o grupo tem uma boa relação, seu funcionamento será mais eficiente e com resultados melhores (ZARIFIAN, 2001). Zarifian (2001) destaca que é importante "prestar uma forte atenção à constituição desses coletivos e à preservação de seu bom funcionamento". Por outro lado, quanto mais forte for a competência coletiva, mais difícil será a substituição das competência individuais, ou seja, ficará mais difícil trocar ou repor um trabalhador que já desenvolveu as competências necessárias no grupo e dessa forma as organizações devem prestar atenção no processo de renovação do quadro de pessoal.

As competências organizacionais identificadas por Zarifian (2001) são:

- Competências sobre processos: referem-se aos conhecimentos do processo de trabalho, de suas etapas e fluxos;

- Competências técnicas: referem-se aos conhecimentos específicos de um trabalho que é capaz de produzir desempenho econômico;

- Competências sobre a organização: é a capacidade de organizar e otimizar os fluxos de trabalho;

- Competências de serviço: referem-se à competência de identificar e prever o impacto de um produto ou serviço para o cliente ou consumidor final;

- Competências sociais e do saber ser: referem-se à maneira como o indivíduo se comporta e suas atitudes diante da realidade em geral. Possui três domínios: autonomia, responsabilização e comunicação.

A competência de uma empresa também envolve a capacidade de combinar e integrar recursos para conseguir desenvolver, produzir e entregar produtos ou serviços aos clientes e consumidores (PRAHALAD; HAMEL, 1990). Prahalad e Hamel (1990) definiram como competência essencial da empresa (core 
competence), a competência que é específica de uma empresa, que agrega habilidades internas da organização e o aprendizado coletivo.

A empresa poderá obter vantagem competitiva quando identifica, desenvolve e mantém uma competência essencial, seja ela de marketing, produção, operações, etc. e a partir de um conjunto de habilidades e tecnologias consegue entregar um produto, uma tecnologia ou um serviço ao cliente.

Alguns pesquisadores têm buscado identificar quais são as competências que as empresas devem possuir para inovar ou quais as competências mais desenvolvidas por empresas consideradas inovadoras (FRANÇOIS et al., 1999; MUNIER, 1999). François et al. (1999) através de ampla pesquisa realizada junto a empresas industriais na França, identificaram e desenvolveram uma classificação das principais competências que uma empresa deve possuir para inovar. As competências identificadas pelos autores estão relacionadas à gestão de recursos humanos, organização e gestão de tecnologias e materiais e gestão de operações. As competências identificadas pelos autores são competências que já existem nas empresas, ou seja, são rotinas já criadas no processo de inovação. Essa noção de competência é similar ao conceito de rotinas das empresas para inovar, proposto por Nelson e Winter (1982). François et al. (1999) não analisaram as competências que são desenvolvidas ou requeridas durante o processo de inovação.

Para François et al. (1999) há uma hierarquia das competências em que uma é mais importante que outra, porém há uma diferença no grau de importância das competências entre os setores e uma competência poderá ser crítica para um setor e não ser relevante para outro. Segundo os autores, uma empresa pode buscar uma competência que é critica e que não possui internamente, no seu ambiente externo junto aos fornecedores, parceiros e outras instituições, por exemplo, a gestão da propriedade intelectual, que é uma das competências mais importantes na inovação.

As competências identificadas por François et al. (1999) são agrupadas em:

- Gestão e organização da pesquisa de inovações;

- Gestão da comunicação entre diferentes níveis da estrutura da organização; 
- Avaliação das habilidades da empresa em transformar novas ideias;

- Identificação de novas necessidades e de oportunidades relacionadas a produtos e processos;

- Identificação e apropriação de tecnologias externas;

- Gestão da propriedade intelectual;

- Introdução e rápida difusão de uma inovação;

- Monitoramento de atualizações e desenvolvimentos de produtos concorrentes no mercado;

- Comercialização da inovação;

- Identificação de formas de financiamento das inovações.

Munier (1999) realizou um estudo sobre práticas de inovação com empresas na França e identificou quatro grupos de competências que uma empresa deve possuir para inovar: 1- Competências Técnicas, 2- Competências Organizacionais, 3- Competências Relacionais e 4- Competências de Meios.

Munier (1999) e Munier e Rondé (2001) agrupam as competências conforme apresentado em seguida:

1) Competências Técnicas - são aquelas relacionadas à habilidade de fazer uso de conhecimento tecnológico e de gerenciar o processo de produção.

2) Competências Organizacionais - são as que estão relacionadas à criação de novos conhecimentos e formas de aprendizagem;

3) Competências Relacionais - são as relacionadas à capacidade da empresa em formar alianças, cooperar e se apropriar de tecnologias externas e estabelecer relações com a concorrência;

4) Competências de Meios - são aquelas relacionadas à infraestrutura e que permitem realizar o P\&D, buscar financiamentos e recursos para desenvolver a inovação e para comercializá-la. 
O grupo de Competências Técnicas envolve:

- Controle da qualidade e eficiência da produção.

- Avaliação tecnológica dos produtos que a empresa é capaz de produzir.

- Avaliação dos processos que a empresa é capaz de implantar.

- Avaliação das técnicas de gestão que a empresa pode adotar.

- Realização de um balanço das tecnologias da empresa.

- Teste operacional de inovações de produtos e processos.

- Análise de falhas e fracassos de novos processos.

- Rápida adoção de novas tecnologias.

- Rápida adoção de novos equipamentos.

- Teste de tecnologias externas.

- Subcontratação de componentes tecnológicos.

- Absorver os conhecimentos incorporados em equipamentos e componentes inovadores.

O grupo de Competências Organizacionais envolve:

- Fazer levantamento das competências da empresa.

- Criar visão global da empresa em cada funcionário.

- Estruturar a empresa em torno de projetos de inovação.

- Envolver todas as áreas no projeto de inovação.

- Trabalhar coletivamente a inovação.

- Criar mobilidades entre áreas para inovar.

- Dar autonomia aos funcionários para inovar.

- Incentivar a geração de novas ideias. 
- Valorizar a criatividade e originalidade dos funcionários.

- Aceitar criatividade em outras áreas não ligadas à produção.

- Recompensar ideias originais.

- Motivar os lançamentos

- Compartilhar conhecimentos.

- Avaliar a geração de conhecimento coletivo em relação à concorrência.

- Avaliar a contribuição individual de cada funcionário para a produção de conhecimento.

- Identificar o conhecimento estratégico e de know-how.

- Identificar pessoas com conhecimento estratégico.

- Conscientizar as pessoas sobre conhecimentos estratégicos e segredos.

- Controlar a comunicação do conhecimento estratégico.

- Motivar as pessoas que possuem conhecimento estratégico.

- Identificar especialistas no mercado.

- Avaliar a capacidade de trabalhar em equipe.

- Avaliar a propensão para inovar.

- Transparência na avaliação de cada colaborador e premiar os melhores.

- Transparência nas regras de mobilidade.

- Avaliação das necessidades individuais de capacitação.

- Sensibilizar as pessoas para a capacitação adequada.

- Avaliar o impacto da capacitação para a inovação.

- Recompensar as pessoas com capacitação essencial. 
O grupo de Competências Relacionais envolve:

- Analisar produtos dos concorrentes.

- Analisar patentes registradas pelos concorrentes.

- Analisar publicações dos profissionais da concorrência.

- Analisar a segmentação e necessidades dos clientes.

- Analisar as reações dos clientes junto ao pós venda e distribuição.

- Usar a entrega do produto como suporte de informação sobre a satisfação do cliente.

- Identificar necessidades emergentes e comportamentos dos consumidores.

- Conhecer tecnologias dos concorrentes.

- Cooperar em P\&D com outras empresas.

- Cooperar em P\&D com instituições públicas de pesquisa.

- Participar de joint ventures, alianças estratégicas e outras formas de cooperação para inovar.

O grupo de Competências de Meios envolve:

- Pesquisa e desenvolvimento

- Subcontratação ou aquisição de P\&D

- Uso de invenções de terceiros (patentes e licenças).

- Recrutamento de funcionários de alta qualificação científica para inovação.

- Aquisição de empresas com expertise de inovação.

- Prever todos os custos relacionados com a inovação.

- Avaliação dos custos de inovações anteriores. 
- Conhecimento de fontes privadas e públicas de financiamento da inovação.

- Prover informações para potenciais financiadores da inovação.

- Criar estratégias específicas de promoção do novo produto.

- Determinar o tipo de anúncio do novo produto, o veículo e público alvo.

- Promover imagem inovadora da empresa.

As competências relacionais são muito importantes no processo de inovação, pois a inovação não é realizada apenas pelo $P \& D$, mas depende das redes de relacionamentos existentes entre firmas e profissionais, que diferem de acordo com o tamanho e o setor de cada empresa (MUNIER, 1999). Segundo Munier (1999), para que uma empresa desenvolva, mantenha e aprimore suas competências, ela deve desenvolver relacionamentos com terceiros, como empresas competitivas, instituições e universidades. As empresas maiores estão mais capacitadas para desenvolver cooperação para gerar inovação, beneficiar-se das oportunidades tecnológicas externas e também para buscar fontes de financiamento e comercialização da inovação, do que as empresas menores. As atividades de marketing também são importantes para a geração de inovação e são competências que estão mais desenvolvidas nas grandes empresas (MUNIER, 1999).

\subsection{Estruturas organizacionais e organização do trabalho na P\&D de inovações}

Diferentes pesquisas já foram realizadas para identificar os tipos de estruturas utilizadas nas mais variadas organizações, tanto no setor industrial quanto no setor de serviços (LARSON; GOBELI, 1988; JOHNE; SNELSON, 1988; MINTZBERG, 1995; VASCONCELLOS; HEMSLEY, 1997).

A forma estrutural de uma organização pode revelar aspectos importantes sobre como o trabalho é realizado, assim como outros aspectos relativos à distribuição de autoridade, formas de comunicação de regras e informações, coordenação de atividades, formas de cooperação, entre outros. 
A forma mais tradicional é a departamentalização, que apresenta diversas unidades em diferentes níveis dentro da organização. Os critérios utilizados para a formação destas unidades podem ser: funcional, geográfico, por processo, por produtos, por período, por clientes e pela amplitude de controle (VASCONCELLOS; HEMSLEY, 1997).

As estruturas tradicionais são encontradas quando as atividades são muito repetitivas e o ambiente é estável. Vasconcellos e Hemsley (1997) destacam as principais características das estruturas tradicionais:

1) Alto nível de formalização - em que são detalhas as descrições das atribuições, os níveis de autoridade e responsabilidade dos diferentes departamentos. A estrutura aparece detalhada nos organogramas;

2) Unidade de comando - em que um grupo de subordinados fica sob o comando de um único chefe;

3) Especialização elevada - quando os funcionários realizam uma atividade de forma contínua e já conhecem todos os problemas que podem ocorrer e soluções possíveis. A especialização pode estar relacionada com uma área técnica, região, fase de um processo produtivo ou características dos clientes.

4) Comunicação vertical - a comunicação ocorre seguindo a cadeia de autoridade, ou seja, entre chefe e subordinados e todas as informações devem passar por este chefe, o que acaba reforçando sua autoridade;

5) Utilização de formas tradicionais de departamentalização - com formas tradicionais de departamentalização, podendo ser funcional, geográfica, por processo, por clientes, por produtos, por período ou por amplitude de controle.

Segundo Johne e Snelson (1988), a estrutura funcional é ideal para atividades mais estáveis e não para atividades que envolvem mudanças contínuas, como as atividades de inovação.

Para ambientes complexos e de grandes mudanças, como este em que as organizações estão inseridas no presente momento, as estruturas tradicionais não 
são tão adequadas, dando lugar a arranjos mais flexíveis ou orgânicos, como as estruturas matricial e por projetos.

Larson e Gobeli (1988) alisaram os tipos de estruturas organizacionais encontradas no processo de P\&D de novos produtos. Os autores identificaram cinco tipos de estruturas tomando como referência a obra de Galbraith de 1971. As estruturas relacionadas pelos autores são: a estrutura funcional, a matriz funcional, a matriz balanceada, a matriz por projeto e a equipe de projeto.

Larson e Gobeli (1988) fazem uma breve descrição dos arranjos organizacionais encontrados nas equipes de P\&D de produtos:

a) Funcional - O projeto é dividido em segmentos e atribuído a áreas funcionais relevantes e/ou grupos dentro de áreas funcionais. O projeto é coordenado por gerentes de níveis superiores.

b) Matriz funcional - Um gerente com autoridade limitada coordena o projeto através de áreas funcionais diferentes e/ou grupos. Os gerentes funcionais têm responsabilidade e autoridade por suas áreas de atuação no projeto.

c) Matriz balanceada - Um gerente de projeto supervisiona o projeto e divide a responsabilidade e a autoridade pela conclusão do projeto, com o gerente funcional. Os gerentes funcionais e de projeto dirigem juntos as áreas de trabalho e tomam decisões.

d) Matriz por projeto - Um gerente de projeto supervisiona o projeto e tem responsabilidade e autoridade pela conclusão do mesmo. O gerente funcional é encarregado de alocar pessoal com conhecimento técnico.

e) Equipe de projeto - Um gerente de projeto é responsável pela equipe, composta por profissionais de diversas áreas funcionais e/ou grupos, que atuam fora das fronteiras organizacionais para concluir um projeto. O gerente funcional não tem nenhum envolvimento formal.

Para Vasconcellos e Hemsley (1997) as principais características das estruturas de inovação são: 
1) Baixo nível de formalização - não detalha as atividades por função e nível de autoridade porque em ambientes complexos surgem muitos problemas novos;

2) Utilização de formas avançadas de departamentalização - abrange a departamentalização por centros de lucro ou unidades com grande autonomia, geralmente em grandes conglomerados com atividades ou produtos muito diversificados; abrange também a departamentalização por projetos que é uma estrutura muito flexível e de grande eficácia frente a mudanças ambientais e que permite alocar as pessoas rapidamente entre os projetos ou ao término de um deles; a departamentalização matricial que utiliza simultaneamente dois ou mais tipos de departamentalização para um grupo de pessoas, como o tipo funcional e por projetos ou por produtos; a estrutura celular que é totalmente flexível e com grande informalidade e a estrutura para "novos empreendimentos" que separa atividades novas como uma nova fábrica, das atividades de rotina ou operacionais.

3) Multiplicidade de comando - quando um ou mais projetos integrados envolvem especialistas de várias áreas técnicas, gerando dupla ou múltipla subordinação destes especialistas aos respectivos gerentes.

4) Diversificação elevada - os profissionais não são especialistas e possuem conhecimento diversificado de várias áreas técnicas.

5) Comunicação horizontal e diagonal - em ambientes dinâmicos há necessidade de comunicação mais frequentemente e é utilizada a comunicação horizontal entre especialistas de diferentes áreas, sem envolver pessoas de níveis hierárquicos superiores.

A figura 6 apresenta um comparativo das características estruturais de organizações tradicionais e inovadoras. 


\begin{tabular}{|c|c|c|}
\hline $\begin{array}{l}\text { CARACTERÍSTICAS } \\
\text { ESTRUTURAIS }\end{array}$ & $\begin{array}{l}\text { ESTRUTURAS } \\
\text { TRADICIONAIS }\end{array}$ & $\begin{array}{l}\text { ESTRUTURAS } \\
\text { INOVADORAS }\end{array}$ \\
\hline Formalização & $\begin{array}{c}\text { Elevada com autoridade e } \\
\text { responsabilidades } \\
\text { definidas }\end{array}$ & $\begin{array}{l}\text { Baixa devido ao } \\
\text { dinamismo do } \\
\text { ambiente }\end{array}$ \\
\hline Departamentalização & $\begin{array}{l}\text { Tradicional (funcional, por } \\
\text { processo, por cliente, } \\
\text { geográfica e por produto }\end{array}$ & $\begin{array}{c}\text { Por projeto, matricial, } \\
\text { por centros de lucro e } \\
\text { celular }\end{array}$ \\
\hline Unidade De Comando & Respeitada e obedecida & $\begin{array}{c}\text { Não é } \\
\text { necessariamente } \\
\text { obedecida }\end{array}$ \\
\hline Especialização & Mais elevada & Mais baixa \\
\hline Padrão De Comunicação & Vertical & $\begin{array}{l}\text { Vertical, horizontal e } \\
\text { diagonal }\end{array}$ \\
\hline
\end{tabular}

Figura 6 Características estruturais de organizações tradicionais e inovadoras

Fonte: Adaptado de Vasconcellos e Hemsley (1997)

Um tipo de estrutura apontada por vários autores como uma das mais encontradas em atividades de P\&D é a estrutura por projetos, com maior diversificação dos técnicos, o que permite ainda reduzir a ociosidade entre os projetos. Neste tipo de estrutura, os técnicos trocam experiências e cooperam com técnicos de diferentes áreas, podendo assim conhecer as inter-relações entre as áreas e ter uma visão de conjunto do projeto, que a estrutura funcional não possibilita (LARSON; GOBELI, 1988; VASCONCELLOS; HEMSLEY, 1997; NAKANO; FLEURY, 1998).

$\mathrm{Na}$ estrutura por projetos há mudança na composição das equipes a cada novo projeto, o que possibilita maior variabilidade de atividades e maior interação entre diferentes pessoas de áreas afins. Segundo Vasconcellos e Hemsley (1997), 
estas características da estrutura por projetos gera maior satisfação para os técnicos, além de ser uma oportunidade de aprimoramento.

Para Vasconcellos e Hemsley (1997), uma das maiores desvantagens da estrutura funcional é a separação entre áreas funcionais com a especialização dos técnicos, que não permite o trabalho em conjunto. Na estrutura por projetos, a equipe é multidisciplinar e trabalha conjuntamente, com alta interação durante toda a execução do projeto.

$\mathrm{Na}$ estrutura por projetos, a comunicação e o processo decisório são facilitados e há maior agilidade na resolução de problemas internos e externos aos projetos (RABECHINI; CARVALHO, 2010).

Outro tipo de estrutura encontrada em atividades de P\&D é a estrutura matricial, que combina aspectos das estruturas funcionais e por projetos. Este tipo de estrutura possibilita otimizar o uso dos recursos organizacionais, embora possa gerar duplicidade de comando e possíveis conflitos (NAKANO; FLEURY, 1998; RABECHINI; CARVALHO, 2010).

Vasconcellos e Hemsley (1997) identificam várias estruturas matriciais, que combinam diferentes estruturas. Os autores identificaram e classificaram os tipos de estruturas matriciais em: balanceada, funcional, por projetos e funcional-produto. Os tipos de estruturas matriciais são descritos em seguida:

1) Matriz balanceada ou matriz pura - os gerentes de projetos e os gerentes funcionais têm o mesmo nível hierárquico e o mesmo grau de autoridade, cada um em sua área de atuação e com atividades bem específicas. O gerente de projeto comunica-se com a equipe técnica diretamente, sem ter que contatar o gerente funcional.

2) Matriz funcional - o gerente de projetos está num nível hierárquico inferior ao do gerente funcional e subordina-se a um dos gerentes funcionais. Este tipo de estrutura é muito comum nas organizações, pois garante uma hierarquia de autoridade ao gerente funcional e não representa uma transformação muito radical para quem trabalhava nos moldes de uma estrutura funcional e de repente precisa adaptar-se a uma estrutura matricial. 
3) Matriz por projeto - o gerente de projeto está num nível hierárquico maior do que o gerente funcional. É muito comum quando os projetos interdisciplinares são prioritários para a organização. Neste tipo de estrutura pode ocorrer transferência de especialistas para trabalharem no local onde o projeto é executado, embora seja uma estrutura não muito comum nas organizações. Caracteriza-se por grande volume de recursos envolvidos e por ter prazo de execução mais longo do que os anteriores.

4) Matriz funcional por produto - a matriz está organizada por produtos e há um gerente para cada produto ou para um grupo de produtos. O gerente é o responsável pelo sucesso do produto ou da linha de produtos e desta forma, busca maior contato com as diversas unidades funcionais da empresa e que podem impactar no sucesso do produto, tais como vendas, crédito, propaganda, produção.

A figura 7 traz os tipos de estruturas para organização de pesquisa e desenvolvimento. 


\begin{tabular}{|c|c|c|c|}
\hline TIPO & CARACTERÍSTICAS & $\begin{array}{c}\text { CONDIÇÕES QUE FAVORECEM A } \\
\text { UTILIZAÇÃO }\end{array}$ & CONSEQUÊNCIAS DA UTILIZAÇÃO \\
\hline 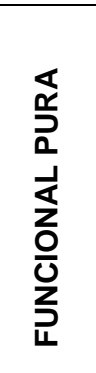 & $\begin{array}{l}\text { Pesquisadores } \\
\text { agrupados em áreas } \\
\text { técnicas conforme a } \\
\text { especialidade }\end{array}$ & $\begin{array}{l}\text { - Pesquisa básica. } \\
\text { - Recursos orçamentários ou contratos } \\
\text { a fundo perdido. } \\
\text { - Pesquisas individuais ou realizadas } \\
\text { em grupos de } 2 \text { ou } 3 \text {. } \\
\text { - Pesquisas unidisciplinares, isto é, } \\
\text { envolvem pesquisadores de uma } \\
\text { mesma área de especialização. } \\
\text { - Existência de pesquisadores de várias } \\
\text { especialidades. }\end{array}$ & $\begin{array}{l}\text { - Formação de capacitação científica. } \\
\text { - Especialização. } \\
\text { - Bom aproveitamento de recursos } \\
\text { humanos e materiais. } \\
\text { - Com o tempo forma unidades } \\
\text { estanques dificultando trabalhos } \\
\text { integrados. }\end{array}$ \\
\hline 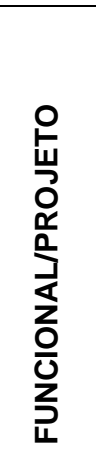 & $\begin{array}{l}\text { Abaixo do gerente de } \\
\text { cada área de } \\
\text { especialização } \\
\text { técnica, há gerentes } \\
\text { de projetos que } \\
\text { coordenam equipes } \\
\text { de pesquisadores. }\end{array}$ & $\begin{array}{l}\text { - Pesquisa básica ou aplicada. } \\
\text { - Projetos contratados externamente } \\
\text { havendo necessidade de controle de } \\
\text { prazos e custos. } \\
\text { - Pesquisas realizadas em equipes. } \\
\text { - Pesquisas interdisciplinares. } \\
\text { - Existência de pesquisadores de várias } \\
\text { especialidades. } \\
\text { - Existência de capacitação para } \\
\text { gerenciar projetos. } \\
\text { - Existência de capacitação para o } \\
\text { trabalho em equipe. }\end{array}$ & $\begin{array}{l}\text { - Formação de capacitação científica e } \\
\text { tecnológica. } \\
\text { - Formação de capacitação na área de } \\
\text { gerência de projetos. } \\
\text { - Conduz à eficiente integração de } \\
\text { pesquisadores da mesma área para } \\
\text { obtenção de um mesmo produto. } \\
\text { - Boa utilização de recursos humanos e } \\
\text { materiais. } \\
\text { - Com o tempo torna um deles } \\
\text { estanque dificultando trabalhos } \\
\text { integrados. }\end{array}$ \\
\hline 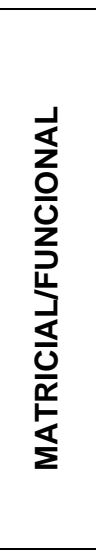 & $\begin{array}{l}\text { Abaixo do gerente da } \\
\text { área há gerentes de } \\
\text { projetos integrados } \\
\text { que utilizam } \\
\text { colaboração de } \\
\text { pesquisadores de } \\
\text { outras áreas. }\end{array}$ & $\begin{array}{l}\text { - Pesquisa aplicada. } \\
\text { - Projetos contratados externamente. } \\
\text { - Pesquisas realizadas em equipe. } \\
\text { - Existência de pesquisas } \\
\text { interdisciplinares. } \\
\text { - Existência de capacitação para } \\
\text { gerenciar projetos interdisciplinares no } \\
\text { esquema matricial. } \\
\text { - Existência de pesquisadores com } \\
\text { habilidades humanas para operar no } \\
\text { esquema matricial com condições de } \\
\text { suportar ambiguidade de múltipla } \\
\text { chefia. }\end{array}$ & $\begin{array}{l}\text { - Formação de capacitação } \\
\text { tecnológica. } \\
\text { - Formação de capacitação na área de } \\
\text { gerência de projetos interdisciplinares. } \\
\text { - Conduz à eficiente integração de } \\
\text { pesquisadores de áreas técnicas } \\
\text { diferentes e ao mesmo tempo mantém } \\
\text { esses pesquisadores em contato com } \\
\text { outros da mesma especialidade. } \\
\text { - Boa utilização de recursos humanos e } \\
\text { materiais. } \\
\text { - Permite atingir prazos do projeto } \\
\text { integrado do orçamento com eficiência } \\
\text { e com alta qualidade técnica. } \\
\text { - Aumenta o nível de conflitos. }\end{array}$ \\
\hline 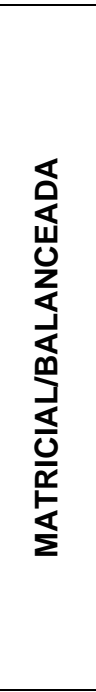 & $\begin{array}{l}\text { Gerente do projeto } \\
\text { integrado tem nível } \\
\text { hierárquico igual ao } \\
\text { gerente funcional. }\end{array}$ & $\begin{array}{l}\text { - Pesquisa aplicada. } \\
\text { - Projetos contratados externamente. } \\
\text { - Pesquisas realizadas em equipes. } \\
\text { - Pesquisas realizadas em equipe. } \\
\text { - Existência de pesquisas } \\
\text { interdisciplinares. } \\
\text { - Existência de capacitação para } \\
\text { gerenciar projetos interdisciplinares no } \\
\text { esquema matricial. } \\
\text { - Existência de pesquisadores com } \\
\text { habilidades humanas para operar no } \\
\text { esquema matricial em condições de } \\
\text { suportar ambiguidade advinda da } \\
\text { múltipla chefia. } \\
\text {-Importância dos projetos } \\
\text { interdisciplinares para a instituição } \\
\text { justifica a constituição de uma gerência } \\
\text { com nível hierárquico igual ao dos } \\
\text { gerentes funcionais. }\end{array}$ & $\begin{array}{l}\text { - Formação de capacitação } \\
\text { tecnológica. } \\
\text { - Formação de capacitação em } \\
\text { gerência interdisciplinar. } \\
\text { - Conduz à eficiente integração entre } \\
\text { as áreas. } \\
\text { - Boa utilização de recursos humanos e } \\
\text { materiais. } \\
\text { - Permite atingir prazos do projeto } \\
\text { dentro do orçamento com eficiência e } \\
\text { com alta qualidade técnica. } \\
\text { - Aumenta o nível de conflitos. }\end{array}$ \\
\hline
\end{tabular}




\begin{tabular}{|c|c|c|c|}
\hline TIPO & CARACTERISTICAS & $\begin{array}{c}\text { CONDIÇÕES QUE FAVORECEM A } \\
\text { UTILIZAÇÃO }\end{array}$ & CONSEQUÉNCIAS DA UTILIZAÇÃO \\
\hline 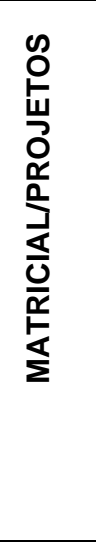 & $\begin{array}{l}\text { Gerente do projeto } \\
\text { integrado tem nível } \\
\text { hierárquico superior } \\
\text { ao gerente funcional. }\end{array}$ & $\begin{array}{l}\text { - Pesquisa aplicada. } \\
\text { - Projetos contratados externamente. } \\
\text { - Pesquisas realizadas em equipe. } \\
\text { - Existência de projetos } \\
\text { interdisciplinares. } \\
\text { - Existência de capacitação para } \\
\text { gerenciar projetos interdisciplinares. } \\
\text { - Existência de pesquisadores com } \\
\text { habilidades humanas para gerenciar } \\
\text { projetos interdisciplinares. } \\
\text { - Existência de projetos } \\
\text { interdisciplinares prioritários, o que } \\
\text { justifica o nível hierárquico de seus } \\
\text { gerentes ser superior ao nível dos } \\
\text { gerentes funcionais. }\end{array}$ & $\begin{array}{l}\text { - Formação de capacitação } \\
\text { tecnológica. } \\
\text { - Formação de capacitação em } \\
\text { gerência interdisciplinar. } \\
\text { - Conduz à eficiente integração entre } \\
\text { áreas. } \\
\text { - Boa utilização de recursos humanos e } \\
\text { materiais. } \\
\text { - Permite atingir prazos do projeto, } \\
\text { orçamento e qualidade. } \\
\text { - Permite dar atenção especial a } \\
\text { projetos interdisciplinares prioritários. } \\
\text { - Aumenta o nível de conflitos. }\end{array}$ \\
\hline 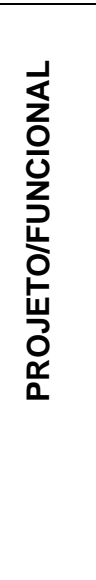 & $\begin{array}{l}\text { Os projetos são } \\
\text { independentes } \\
\text { possuindo grande } \\
\text { número de } \\
\text { pesquisadores } \\
\text { agrupados por } \\
\text { especialidade } \\
\text { técnica. }\end{array}$ & $\begin{array}{l}\text { - Pesquisa aplicada. } \\
\text { - Projetos contratados externamente. } \\
\text { - Pesquisa realizada por equipes. } \\
\text { - Existência de projetos } \\
\text { interdisciplinares. } \\
\text { - Existência de capacitação para } \\
\text { gerenciar grandes projetos } \\
\text { interdisciplinares. } \\
\text { - Existência de projetos } \\
\text { interdisciplinares de longa duração } \\
\text { envolvendo grande volume de recursos } \\
\text { humanos e materiais em tempo } \\
\text { integral. } \\
\text { - Localização física dos projetos } \\
\text { distantes umas das outras e distante da } \\
\text { organização Matriz. }\end{array}$ & $\begin{array}{l}\text { - Formação de capacitação em } \\
\text { gerência interdisciplinar. } \\
\text { - Atenção, prioridade e integração } \\
\text { dentro do projeto é maximizada. } \\
\text { - Permite a eficiente integração entre } \\
\text { áreas de um mesmo projeto. } \\
\text { - Duplicação de recursos humanos e } \\
\text { materiais, custos altos. } \\
\text { - Ineficiente formação de capacitação } \\
\text { tecnológica. }\end{array}$ \\
\hline 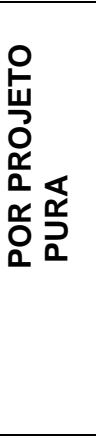 & $\begin{array}{l}\text { Os pesquisadores } \\
\text { são agrupados } \\
\text { conforme o projeto } \\
\text { nos quais estão } \\
\text { alocados. Ficam } \\
\text { subordinados ao } \\
\text { Gerente de Projeto } \\
\text { até o seu término. }\end{array}$ & $\begin{array}{l}\text { - Pesquisa aplicada. } \\
\text { - Projetos contratados externamente. } \\
\text { - Projetos de pequena dimensão, } \\
\text { envolvendo poucos pesquisadores. } \\
\text { - Existência de capacitação para } \\
\text { gerenciar projetos. } \\
\text { - Instituições de pequena dimensão } \\
\text { com pouca diversificação tecnológica. }\end{array}$ & $\begin{array}{l}\text { - Formação de capacitação em } \\
\text { gerência de projetos. } \\
\text { - Eficiente integração na equipe do } \\
\text { projeto, atingimento dos prazos e } \\
\text { custos. } \\
\text { - Duplicação de recursos humanos e } \\
\text { materiais. } \\
\text { - Capacidade ociosa de recursos } \\
\text { humanos e materiais. } \\
\text { - Ineficiente formação de capacitação } \\
\text { tecnológica. } \\
\text { (conclusão) }\end{array}$ \\
\hline
\end{tabular}

Figura 7 Tipos de estruturas para organização de pesquisa e desenvolvimento

Fonte: Adaptado de Vasconcellos e Hemsley (1997)

O tipo de estrutura organizacional adotado por uma empresa impacta em alguns indicadores de eficiência, pois algumas estruturas geram maior flexibilidade do que outras, possibilitando redução de custos, maior comunicação entre as pessoas, maior autonomia aos profissionais, agilidade na tomada de decisões e na solução de problemas, entre outras. 
Há na literatura diversos estudos sobre impactos das estruturas organizacionais na pesquisa e desenvolvimento de inovações e muitos modelos com enfoque nas etapas do processo de desenvolvimento. Em geral, os estudos estão voltados para fatores determinantes do desempenho financeiro e do sucesso das inovações, focando aspectos de melhoria das etapas do processo, redução de custos, melhoria da comunicação entre os membros das equipes, mecanismos e estratégias de coordenação das atividades (BROWN; EISENHARDT, 1995).

A organização do processo de P\&D é apontada como um fator de extrema importância para o sucesso de lançamento de uma inovação, em vários trabalhos analisados para esta pesquisa, dentre os quais destacam-se: Cooper (1979), Cooper e Kleinschmidt (1986), Takeuchi e Nonaka (1986), Brown e Eisenhardt (1995), Griffin (1997), Kahn; Barczak e Moss (2006).

A pesquisa de Cooper (1979) é uma das primeiras a identificar os fatores críticos de sucesso no desenvolvimento de um novo produto, o autor mapeou as principais atividades envolvidas no processo de PDP.

Tomando como referência o trabalho de Cooper (1979), os autores Cooper e Kleinschmidt (1986) identificaram as atividades mais importantes no processo de desenvolvimento de um novo produto, pois as empresas bem sucedidas utilizam processos formais e critérios claros. Kahn; Barczak e Moss (2006) também destacam a organização do processo de P\&D, como um dos fatores de sucesso das empresas inovadoras.

Cooper e Kleinschmidt (1986), com o estudo denominado NewProd Fase II, buscaram identificar as atividades mais importantes e essenciais no processo de desenvolvimento de um novo produto, pois as empresas bem sucedidas utilizam processos formais e critérios claros. No estudo extensivo e detalhado, com 123 empresas canadenses, os autores consideraram apenas os dados dos projetos lançados no mercado, num total de 203 projetos, incluindo 123 sucessos comerciais e 80 fracassos.

Para Cooper e Kleinschmidt (1986), o sucesso de um novo produto depende de algumas atividades e de quão bem essas atividades são executadas e integradas ao processo, ou seja, as pessoas são o ativo mais importante para o sucesso do 
novo produto. O tipo de tecnologia, a natureza do mercado ou a sinergia entre 0 projeto e a empresa são importantes, mas não bastam, pois são as pessoas que executam as atividades e que contribuem fortemente para o sucesso do projeto e do novo produto. Para os autores, as atividades relacionadas ao processo de desenvolvimento de um novo produto são:

1) Seleção inicial - decisão inicial sobre a ideia de um novo produto que terá recursos alocados.

2) Avaliação preliminar do mercado - análise inicial rápida e não científica do mercado.

3) Avaliação técnica preliminar - avaliação inicial dos méritos técnicos e dificuldades do projeto.

4) Estudo detalhado do mercado - pesquisa de mercado envolvendo uma amostra considerável de respondentes, com procedimentos consistentes de coleta de dados.

5) Análise financeira ou de negócio - análise que conduz a uma decisão antes do desenvolvimento de produtos.

6) Desenvolvimento do produto - o projeto efetivo e o desenvolvimento do produto resultando em um protótipo ou amostra.

7) Teste interno do produto - teste no laboratório ou sob condições controladas.

8) Teste do produto pelo cliente - teste do produto sob condições reais.

9) Teste de mercado/venda experimental - teste de mercado ou venda a um número limitado de clientes.

10) Produção experimental - produção experimental para testar as instalações de produção.

11) Análise de negócio na pré-comercialização - análise financeira após o lançamento do produto e antes da comercialização em larga escala.

12) Início da produção - produção comercial completa. 
13) Lançamento no mercado - lançamento do produto no mercado, de forma comercial.

Os autores apontam que o processo de desenvolvimento de novos produtos é deficiente em muitas empresas. Embora os gestores digam que possuem um processo de planejamento sistemático, os autores identificaram muitos gaps e deficiências. Algumas atividades críticas são omitidas e outras atividades-chave são parcialmente desenvolvidas.

Segundo Cooper e Kleinschmidt (1986), uma análise dos resultados sobre o que realmente acontece nos 203 projetos revela que muitas atividades ou estágios aceitos ou prescritos no projeto, são omitidos completamente no processo real. Apenas $1,9 \%$ dos projetos executaram as 13 atividades no processo de novos produtos. A maioria dos projetos apontou que menos de 9 das 13 atividades foram executadas.

Em outro trabalho de destaque, Cooper e Kleinschmidt (1995), apontam que é importante focar nas atividades de pré-desenvolvimento, com destaque para os estudos técnicos, de mercado e análise de viabilidade do produto. Já Griffin (1997) destaca que as atividades mais importantes são as de geração e análise de ideias, o desenvolvimento técnico e a introdução no mercado.

Para Cooper; Edgett e Kleinschmidt (2004), todas as atividades de prédesenvolvimento, desenvolvimento e pós-desenvolvimento são fundamentais para o sucesso de um novo produto.

Takeuchi e Nonaka (1986), ao analisarem o processo de desenvolvimento de novos produtos, destacaram a importância dos fatores flexibilidade e velocidade para o desenvolvimento de inovações e afirmam que algumas estruturas e formas de organizar as atividades de P\&D comprometem a eficiência destes fatores, como a forma tradicional sequencial.

$\mathrm{Na}$ abordagem tradicional de desenvolvimento de produtos, um projeto tem várias fases e há um grupo de especialistas funcionais trabalhando em cada uma das etapas do projeto (desenvolvimento do conceito, teste, desenho do produto, 
desenvolvimento, produção piloto e produção para o mercado). Quando um grupo termina sua etapa, passa o trabalho ao grupo seguinte para dar continuidade (TAKEUCHI; NONAKA, 1986).

Vários autores destacam a importância das equipes dos projetos de $P \& D$, para a melhoria do desempenho do processo, troca de informações, aumento de competências e integração das diferentes atividades envolvidas (EDMONDSON; NEMBHARD, 2009; KAHN; BARCZAK; MOSS, 2006; GRIFFIN, 1997; BROWN; EISENHARDT, 1995; TAKEUCHI; NONAKA, 1986; ).

Brown e Eisenhardt (1995), enfatizam a importância dos times de projetos para o desempenho do P\&D, com times multifuncionais (cross-functional), pois são os responsáveis pelo desenvolvimento de todas as atividades do processo de P\&D. São eles que transformam conceitos, ideias vagas e especificações de produto, em novos produtos. Segundo as autoras, a composição, o processo de grupo e a organização do trabalho nas equipes de projeto afetam as informações, os recursos e o estilo de solução de problemas das equipes, que por sua vez, influenciam o desempenho do processo, ou seja, a velocidade e a produtividade do processo. A composição dos times, com pessoas de diferentes qualificações, a figura de um facilitador nos times e o bom relacionamento entre os membros são apontados como fundamentais para o desempenho do processo (BROWN; EISENHARDT, 1995; GRIFFIN, 1997).

Takeuchi e Nonaka (1986), ao pesquisarem empresas dos EUA e Japão, apontam que estas empresas começaram a tratar o desenvolvimento de produtos com um método holístico, que os autores comparam com o jogo de "rugby", em que o time trabalha unido, indo e voltando de acordo com a tática escolhida e não por etapas ou sequencialmente. No método "rugby" há uma integração constante num grupo multidisciplinar e os membros trabalham juntos do começo ao fim e não por etapas estruturadas e definidas, mas sobrepostas. Assim, um grupo de engenheiros poderia iniciar o design do produto, antes que os testes tivessem terminado. As empresas Honda, Canon e Fuji-Xerox trabalhavam com este método que busca encorajar o experimento e o erro, desafiando o status quo. Segundo os autores, este 
método estimula novas formas de aprendizagem e pensamento nas empresas, em diferentes níveis e funções, podendo quebrar a rigidez das empresas.

Takeuchi e Nonaka (1986) examinaram novas abordagens na gestão do processo de desenvolvimento de produtos em empresas como NEC, Honda, Epson, Brother, 3M, Xerox e HP. Os autores identificaram seis características na gestão do processo de desenvolvimento de produtos:

1) Construção da instabilidade - os gestores estabelecem metas desafiadoras e dão liberdade para o grupo em projetos de importância estratégica para a empresa, como forma de gerar criatividade.

2) Equipes de projeto auto-organizados - as equipes começam o trabalho sem ter informações iniciais, tomando riscos, como se fosse um start-up. Num certo momento as equipes acabam criando conceitos próprios. Estas equipes adquirem capacitação quando exibem três condições: autonomia (a equipe tem liberdade para estabelecer a direção dos esforços), autotranscendência (a alta gestão estabelece os parâmetros e a equipe estabelece suas próprias metas ao longo do processo) e fertilização cruzada (equipes com alta diversidade, grande variedade de conhecimentos, processo de pensamento e padrões de comportamento. A FujiXerox, por exemplo, formou equipes com pessoas do planejamento, da produção, do design, de vendas, da distribuição e da avaliação, que trabalhavam juntas em uma sala grande. Desta forma, intensificou o comportamento de grupo, a cooperação, a iniciativa e o compartilhamento de informações que antes eram individuais).

3) Sobreposição de fases do desenvolvimento - as equipes trabalham em ritmos sincronizados e embora a equipe de P\&D tenha o maior horizonte de tempo e a equipe de produção tenha o menor, eles terão que atingir juntos o prazo final. Há uma sobreposição do ritmo individual e do ritmo do grupo e um compartilhamento de informações e conhecimentos técnicos e de mercado. Esta sobreposição ajuda a diminuir a vibração e os ruídos gerados no processo de desenvolvimento ou os conflitos entre integração e diferenciação. $\mathrm{Na}$ empresa Honda, os autores observaram que os membros da equipe de projeto não mudavam até o final de todas as etapas, tal como num time de rugby e eram responsáveis por todas as etapas. 
A abordagem da sobreposição gera responsabilidade compartilhada e cooperação, estimula o envolvimento e o comprometimento, foca na solução de problemas, encoraja a tomada de decisão, desenvolve habilidades diversas, aumenta sensibilidade sobre as condições do mercado, desestimula a divisão do trabalho. Os pontos negativos desta abordagem envolvem: gerenciamento de um processo intensivo, problemas de comunicação com todas as equipes de projeto, preparação de diversos planos contingenciais, geração de tensão e/ou conflitos nos grupos.

4) Aprendizagem múltipla - estímulo ao "aprender fazendo" em que os membros das equipes envolvem-se num processo contínuo de experimentação e erro. Eles também adquirem conhecimento amplo e habilidades diversas, que os ajudam a criar uma equipe versátil, capaz de solucionar diferentes problemas rapidamente.

O "aprender fazendo" ocorre em duas dimensões: através de múltiplos níveis (individual, grupo e corporativo) e através de múltiplas funções. Estas duas dimensões foram classificadas pelos autores como aprendizagem múltipla.

A aprendizagem corporativa muitas vezes ocorre com a implantação de um novo programa ou método, como por exemplo, o movimento do TQC (Total Quality Control) que ajudou a mudar o pensamento corporativo.

$\mathrm{Na}$ aprendizagem multifuncional, os técnicos são estimulados a acumularem experiências em outras áreas diferentes de suas formações. $\mathrm{Na}$ Epson, por exemplo, os membros do projeto de uma mini-impressora, eram engenheiros mecânicos que conheciam pouco de eletrônica. O líder do projeto estimulou os técnicos a estudarem eletrônica, para obter domínio desta outra área do conhecimento.

5) Controle sutil - as equipes de projeto têm muita autonomia, mas também são controladas. $O$ gestor estabelece pontos de verificação suficientes para evitar que ambiguidade, instabilidade e tensão se transformem em caos. $O$ gestor evita o tipo de controle rígido, que prejudica a criatividade e a espontaneidade. Dá ênfase no autocontrole, no controle "por meio de pressão" e no controle "pelo amor", que os autores classificaram como controle sutil. 
6) Transferência organizacional de aprendizagem - os membros dos projetos encorajam a transferência de conhecimentos para outros que não pertencem aos grupos, como por exemplo, os fornecedores. A transferência de conhecimentos para membros de novos projetos ou para pessoas de outras divisões das empresas é frequente.

O conhecimento também é transmitido nas organizações, quando as atividades de projeto são convertidas em práticas padronizadas ou quando as práticas bem sucedidas são institucionalizadas pelas empresas (TAKEUCHI; NONAKA, 1986).

A abordagem holística do desenvolvimento de produtos não se aplica a todas as situações e apresenta algumas limitações, segundo Takeuchi e Nonaka (1986):

- exige esforço extraordinário de todos os membros do projeto durante todo o processo de desenvolvimento;

- pode não se aplicar a projetos revolucionários que requerem uma inovação revolucionária, como biotecnologia e química;

- não se aplica aos projetos grandes como aeroespacial, onde a escala do projeto limita as discussões face a face;

- não se aplica às organizações em que o desenvolvimento de produtos depende de um gênio, que faz a invenção e passa as especificações para as pessoas subordinadas a ele.

\subsection{O papel das Instituições no desenvolvimento tecnológico}

Diferentes autores têm analisado o papel das instituições nas relações de mercado, no ambiente social em que as organizações estão inseridas e no próprio desenvolvimento econômico, pois as instituições podem determinar as diferentes trajetórias de desenvolvimento encontradas entre os países (NORTH, 1990; NELSON; WINTER, 1982; RODRIK, 2003; ACEMOGLU et al., 2004; PANDE; UDRY, 2005; HODGSON, 2006).

Hodgson (2006) destaca o papel das instituições na vida social e para ele são as regras sociais, muitas vezes embutidas em hábitos compartilhados de 
pensamento e comportamento, que regem as interações sociais e este sistema para o autor é considerado instituição, tais como costumes, leis, moeda, língua dominante, entre outras.

North (1990) salienta que os indivíduos atuam num ambiente de incertezas, com capacidades limitadas para processar e analisar todas as variáveis envolvidas na tomada de decisão e têm que fazer escolhas nas interações, desta forma, as instituições ajudam a restringir essas escolhas, diminuindo as incertezas, norteando o jogo, ditando as regras e os incentivos para as ações. Para o autor, as instituições baseadas em relações formais impessoais são as mais importantes, pois podem regular os contratos de maneira mais imparcial, especificando os direitos de propriedade e o enforcement para cumprimento das regras. Ao reduzir as incertezas das interações humanas, as instituições fornecem também incentivos para que os indivíduos cooperem entre si e desta forma pode ocorrer o desenvolvimento econômico.

Para os autores Acemoglu et al. (2004) as instituições políticas são mais importantes, pois determinam e alocam o poder político na sociedade (o poder de jure) e o poder político pode escolher e mudar as instituições, com o intuito de aumentar o poder político de determinados grupos já dominantes. Para estes autores, o crescimento econômico depende das instituições econômicas, pois são estas que definem os atores-chave da economia e moldam seus incentivos, além de determinar o potencial de crescimento da economia e a distribuição de recursos no futuro. Para os autores, a escolha das instituições econômicas é determinada coletivamente e por isso surgem conflitos de interesse sobre a distribuição de recursos e sobre as instituições, pois nem todos os indivíduos preferem as mesmas instituições. Não há acordo, segundo os autores, porque há problemas de compromisso.

As condições e restrições locais de cada país implicam em estruturas institucionais diferentes, mesmo tendo como referência um modelo de país mais desenvolvido e dessa forma, as políticas públicas devem considerar o contexto específico em que serão aplicadas (RODRIK, 2003). 
Para Rodrik (2003), as estratégias de desenvolvimento envolvem ainda a forte regulação dos mercados. Segundo o autor, a regulação forte dos mercados pode: reduzir os abusos de poder, internalizar as externalidades, gerenciar as assimetrias de informação, estabelecer padrões de segurança e de produtos entre outros.

Pande e Udry (2005) destacam ainda, que a qualidade das instituições é muito importante e impacta no crescimento econômico de um país. Segundo os autores, as mudanças institucionais são importantes e são respostas às pressões de diferentes atores para uma dada época. A qualidade das instituições depende também, da situação econômica e política dos indivíduos em um determinado país. As mudanças impactam na melhoria dos direitos de propriedade, na burocracia, no enforcement da lei e na confiança sobre ações do Estado.

As escolhas institucionais têm que encontrar um equilíbrio entre os objetivos concorrentes ou conflitantes, por exemplo, no caso das inovações em que há competição entre atores. A competição deve garantir a eficiência alocativa de recursos, mas também deve garantir os ganhos esperados com inovações, quando uma empresa investe altos valores em P\&D (RODRIK, 2003).

O Estado é um dos atores principais para promover o crescimento econômico, através das políticas industriais adequadas e do controle de outras instituições (NELSON; ROSENBERG, 1993). Deve por isso, ser imparcial nas avaliações e na destinação de verbas e programas em Ciência, Tecnologia e Inovação, para que haja grandes contrastes dentro de um território. O Estado pode mediar os conflitos entre instituições, transformar regras informais em leis, decidir quais são os interesses mais importantes e definir muitas vezes, qual será a trajetória de um país no processo de desenvolvimento, quando gera incentivos ou proteção para sua indústria e estimula áreas fundamentais.

No Brasil, a influência das instituições nas políticas e atividades de C,T\&l também têm gerado impactos e norteado o desenvolvimento econômico do país.

A literatura destaca principalmente o período pós Segunda Guerra Mundial, quando os interesses e esforços sobre o desenvolvimento de pesquisas se intensificam no Brasil, assim como em outros países como os EUA, sobretudo para 
pesquisas de tecnologias voltadas para guerra, como energia nuclear, aviação, defesa nacional e a construção da bomba atômica (KRIEGER et al., 1993).

Krieger et al. (1993) destacam que grande parte do Sistema de Ciência \& Tecnologia do país foi criada entre 1968 e 1980, durante o regime militar.

Nos anos 50, os cientistas brasileiros iniciaram um movimento para criação de instituições voltadas para a regulação das atividades científicas. Neste contexto foi criada a Sociedade Brasileira para o Progresso da Ciência (SBPC), que é uma sociedade sem fins lucrativos nem interesses político-partidários, voltada para 0 desenvolvimento científico, educacional, cultural e tecnológico do país (KRIEGER et al., 1993).

A criação do Conselho Nacional de Pesquisas (CNPq) que ocorreu em 1951, no final do governo Dutra foi um marco para o desenvolvimento científico nacional e ainda é uma das mais importantes agências de fomento à pesquisa. (KRIEGER et al., 1993; ANPEI, 2004).

A lei de criação do Conselho estabelecia suas finalidades: "(...) promover e estimular o desenvolvimento da investigação científica e tecnológica, mediante a concessão de recursos para pesquisa, formação de pesquisadores e técnicos, cooperação com as universidades brasileiras e intercâmbio com instituições estrangeiras". Em 1972, o CNPq passou a ser o órgão central do chamado Sistema Nacional de Desenvolvimento Científico e Tecnológico, que visava consolidar programas e projetos, bem como incentivar a pesquisa no setor privado e nas chamadas economias mistas (CNPq, 2013).

O CNPq concedeu recursos para pesquisadores e instituições, e também financiou a implantação de vários institutos de pesquisa, como o Instituto de Matemática Pura e Aplicada (IMPA) e o Instituto Nacional de Pesquisas da Amazônia (INPA) em 1952, o Instituto Brasileiro de Bibliografia e Documentação (IBBD) em 1954 e o Instituto de Energia Atômica (IEA) em 1956 (CNPq, 2013).

Outro marco para a ciência que ocorreu em 1951, no segundo governo Vargas, foi criação da Campanha Nacional de Aperfeiçoamento de Pessoal de Nível Superior (atual Capes), pelo Decreto n. 29.741 para apoiar a formação e 
aperfeiçoamento de especialistas e pesquisadores no ambiente acadêmico (CNPq, 2013).

Em 1960 a pesquisa científica passa a ter o apoio do Estado, com a criação da Fundação de Amparo à Pesquisa do Estado de São Paulo (FAPESP), pela Lei Orgânica 5.918 e. A Fundação recebia 0,5\% do total da receita tributária do Estado, percentual elevado para 1\% pela Constituição de 1989, para financiar pesquisas e estimular novas áreas do conhecimento (FAPESP, 2013).

Em 1967 foi criada a Financiadora de Estudos e Projetos (FINEP), que está vinculada ao MCTI e a sua fundação visava institucionalizar o Fundo de Financiamento de Estudos de Projetos e Programas. Posteriormente a FINEP passou a financiar a implantação de programas de pós-graduação nas universidades brasileiras, que era atribuição do BNDES com o fundo FUNTEC. Na década de 70 fez várias ações para estimular a articulação entre universidades, centros de pesquisa, empresas de consultoria e contratantes de serviços, produtos e processos. Financiou importantes projetos, como o do desenvolvimento do avião Tucano pela Embraer, vários projetos da EMBRAPA e de Universidades, programas de formação de recursos humanos do país e da Petrobrás em parceria com Universidades, entre outros. Em 1969 foi criado o Fundo Nacional de Desenvolvimento Científico e Tecnológico (FNDCT), que tinha o objetivo de financiar a expansão do sistema de Ciência \& Tecnologia, sendo que a FINEP era a sua Secretaria Executiva (FINEP, 2013).

A FINEP, CNPq e CAPES são agências federais de fomento e respondiam por 40 a 50\% dos recursos do orçamento federal para C,T\&l e a FAPESP possuía um orçamento de $2 \%$ da receita de impostos do Estado de São Paulo, segundo Krieger et al. (1993).

Em 1974, o CNPq fica subordinado diretamente à SEPLAN (Secretaria de Planejamento) e passa a chamar-se Conselho Nacional de Desenvolvimento Científico e Tecnológico, quando sua sede foi transferida para Brasília. Nessa época iniciam-se estudos setoriais em empresas públicas, aproximando o conhecimento científico ao segmento empresarial. Em 1973 é criado o primeiro Plano Básico de Desenvolvimento Científico e Tecnológico (I PBDCT) que visava apoiar o 
desenvolvimento científico e tecnológico e em 1975 foi criado o II PBDCT, tendo a FINEP como responsável por administrar o fundo criado para apoiar os planos de desenvolvimento Sociais (TOLMASQUIM; DOMINGUES, 1998).

Nos anos 70, o ambiente econômico e institucional favoreceu a estruturação da indústria no país, devido a alguns fatores, tais como forte proteção do mercado, incentivos governamentais, alta da demanda no mercado interno e aos investimentos dos empresários em novas indústrias. Destacam-se os dois grandes gestores dos incentivos, o Conselho de Desenvolvimento Industrial (CDI) e o Banco Nacional de Desenvolvimento Econômico (BNDE). Estes fatores foram responsáveis pelas altas taxas de rentabilidade para a indústria (ANPEI, 2004).

$\mathrm{Na}$ década de 80 houve alguns avanços e criação de outras instituições, como o Ministério da Ciência e Tecnologia (MCT) em 1985 e as Fundações de Amparo à Pesquisa (FAPs) e Secretarias Estaduais de C,T\&I. Atualmente é o Ministério da Ciência, Tecnologia e Inovação (MCTI) que controla a política nacional de pesquisa científica, tecnológica e de inovação, além das políticas de desenvolvimento de informática e automação, biossegurança, espacial e nuclear, entre outras. O MCTI incorporou as duas agências de fomento do país, a FINEP e o CNPq (MCT, 2013).

Na década de 1980, a área de Ciência e Tecnologia não teve grandes mudanças nas políticas ou no próprio sistema, dadas a recessão econômica, a crise fiscal que se seguiu e o impasse junto aos credores externos, que afetaram o repasse de recursos do Tesouro (KRIEGER et al., 1993).

Nos anos 80, questões macroeconômicas levaram as indústrias a perderem competitividade, tais como altas taxas de inflação, altos custos de produção, crises econômicas, desequilíbrios econômicos, entre outras. Além disso, os empresários se adaptaram ao modelo baseado na substituição de importações que visava atender o mercado interno e não houve motivação para que as empresas gerassem inovações e buscassem exportar para novos mercados. A indústria era pouco dinâmica na geração e incorporação de progresso técnico, pelo isolamento interno (ANPEI, 2004). 
Em 1988, a Constituição brasileira incluiu um capítulo referente à Ciência e Tecnologia, estabelecendo as diretrizes de desenvolvimento para o setor de ciência e tecnologia. O Art. 218 menciona: "O Estado promoverá e incentivará o desenvolvimento científico, a pesquisa e capacitação tecnológicas". Ainda no $\S 1^{\circ}$ diz que "a pesquisa científica básica receberá tratamento prioritário do Estado, tendo em vista o bem público e o progresso das ciências", e no $\S 4^{\circ}$ diz que "a lei apoiará e estimulará as empresas que invistam em pesquisa, criação de tecnologia adequada ao país, formação e aperfeiçoamento de seus recursos humanos (...)" (BRASIL, 1988).

Nos anos 90 ocorreram grandes mudanças institucionais no país, com liberalização econômica e abertura comercial, redução da intervenção do Estado na economia e privatizações de empresas. Além destas mudanças, a política econômica gerou taxas de crescimento muito baixas para o país, que levou à reestruturação da indústria brasileira. As empresas passaram a buscar maior competitividade, focaram em outros mercados e introduziram inovações de produtos e também organizacionais. As mudanças organizacionais e melhorias dos produtos geraram ganhos de produtividade e de qualidade, que compensaram em parte as perdas pela crise econômica. Contudo, as inovações geradas não foram substanciais, apenas pequenas modificações em produtos e processos, sem grandes rupturas tecnológicas (ANPEI, 2004). Na análise da ANPEI, a abertura econômica não pressionou as empresas para que gerassem inovações de produtos e processos, tornando-as mais competitivas e inovadoras, pois não houve apoio do governo para criar condições e uma política industrial, para que as empresas nacionais pudessem concorrer com as empresas de países mais avançados.

Para Krieger et al. (1993), o sistema fracassou porque não houve articulação com a política econômica e industrial. Para os autores, o sistema de C,T\&l das décadas de 80 e 90, foi o mesmo do final dos anos 70, destacando-se somente 0 fato de que os recursos humanos ganharam mais titulação, dado o avanço e desempenho do subsistema de pós-graduação, porém com infraestrutura mais sucateada devido à crise no financiamento das universidades no período. 
A partir de 2000, o país busca implementar políticas mais eficazes de estímulo a inovação tecnológica, que ganham força em 2001, com a Conferência Nacional de Ciência, Tecnologia e Inovação. Deu-se também o lançamento pelo Governo Federal, da Política Industrial, Tecnológica e de Comércio Exterior (PITCE), plano que visa aumentar a capacidade de inovação das empresas do país e a eficiência produtiva, cuja principal medida é a Lei no. 10.973-04, conhecida como 'Lei da Inovação' (PLONSKI, 2005).

Dados da Pesquisa de Inovação Tecnológica (PINTEC) de 2005, revelam que a intensidade média de P\&D da indústria de transformação do país era de 1,5\% naquele ano, número muito baixo se comparado com a média de países desenvolvidos, como dos países da OCDE, que era de 7,7\%. Esse indicador é muito importante e mostra a fragilidade da indústria brasileira em termos de inovação, segundo análise da FAPESP (FAPESP, 2010-C).

Em 2005, duas leis constituíram um marco na legislação ligada à Política de C,T\&I, a Lei 10.973, denominada Lei da Inovação, aprovada em 2004 e a Lei 11.196 de 2005, conhecida como Lei do Bem.

A Lei do Bem institui incentivos fiscais automáticos às empresas que realizam pesquisa tecnológica e desenvolvimento de inovação tecnológica, além de subvenções econômicas incorporadas ao financiamento FINEP Inova Brasil, concedidas às empresas que contratam pesquisadores mestres ou doutores, como empregados para realizarem atividades de pesquisa, desenvolvimento e inovação tecnológica. Há ainda um incentivo adicional às empresas que financiarem projetos e pesquisas de Instituições Científicas e Tecnológicas - ICTs, cujos projetos são aprovados pelo MEC (BRASIL, 2005).

A Lei de Inovação é um marco regulatório que dispõe sobre incentivos à inovação e à pesquisa científica e tecnológica no ambiente produtivo e abrange três vertentes: "Vertente I- Constituição de ambiente propício às parcerias estratégicas entre as universidades, institutos tecnológicos e empresas; Vertente II - Estímulo à participação de instituições de ciência e tecnologia no processo de inovação e Vertente III - Incentivo à inovação na empresa" (BRASIL, 2004). 
A Lei da Inovação visa aproximar governo, empresas, universidades e centros de pesquisa e dessa forma, deu-se a necessidade de aprimorar as políticas, práticas, organizações e mecanismos de controle dessas interações, ou seja, aprimorar as instituições do país envolvidas com Ciência, Tecnologia e Inovação (C,T\&l). Os interesses são muitas vezes conflitantes e acabam gerando novas mudanças nas práticas e procedimentos, num processo cíclico e sistêmico, com o envolvimento de diferentes atores.

Segundo pesquisa PINTEC de 2005, a taxa de cooperação para a inovação no Brasil era de 2,9\%, inferior a países como a França e o Reino Unido, ambos com taxa de $10 \%$, a Alemanha com $8 \%$ e a Itália com 5\%. O Estado de São Paulo possuía a maior parte da P\&D industrial do país, com $58,4 \%$ do total nacional, mais concentrados nos setores automobilístico e aeroespacial.

Uma pesquisa realizada pela FAPESP sobre número de publicações de cientistas do Brasil, em comparação com outros países da América Latina, para o período de 2008-2010, revela que o país lidera a produção de artigos científicos, com a publicação de 94.622 trabalhos em periódicos científicos internacionais indexados pelo Web of Science. Segundo a pesquisa FAPESP o número de publicações brasileiras foi $25 \%$ maior do que o total de trabalhos do México, Argentina, Chile, Colômbia e Venezuela juntos, com um total de 75.665 artigos. O Estado de São Paulo produziu $46 \%$ da produção nacional e 25,5 da produção da América Latina, com publicações nas áreas de química, física, agricultura, engenharia, farmacologia e farmácia, medicina, psicologia e odontologia, entre outras, enquanto no âmbito nacional aparecem mais produções na área agrícola (FAPESP, 2011-A).

O indicador referente ao desenvolvimento de recursos humanos envolvidos com C,T\&l é um dos que refletem o retorno dos investimentos feitos pelo país nessa área, como é possível observar na Tabela 1, com dados do Brasil: 
Tabela 1 Número de pesquisadores alocados nas Instituições do país

\begin{tabular}{lccc}
\hline SETOR E NATUREZA ADMINISTRATIVA & $\mathbf{1 9 9 5}$ & $\mathbf{2 0 0 1}$ & $\mathbf{2 0 0 8}$ \\
\hline Total & 124.751 & 155.742 & 229.121 \\
Instituições de Ensino Superior & 86.932 & 113.380 & 152.519 \\
$\quad$ Estaduais & 25.932 & 34.618 & 44.870 \\
Federais & 44.486 & 51.765 & 66.122 \\
Privadas e municipais & 1.383 & 2.586 & 5.287 \\
Bolsistas de pós-doutorado & 2.992 & 3.597 & 6.704 \\
$\quad$ Bolsistas de doutorado & 12.139 & 20.814 & 29.536 \\
Institutos de Pesquisa & 4.740 & 4.652 & 6.855 \\
Empresas & 33.079 & 37.710 & 69.747 \\
\hline
\end{tabular}

Fonte: Adaptado de FAPESP (2010-B)

Segundo o relatório FAPESP, em 2006 havia aproximadamente um estoque de 21,4 milhões de pessoas, com 6 milhões ou 28\% residentes em São Paulo, da área de C,T\&I, porém são resultados ainda inferiores aos outros países como Reino Unido (38,9\%), Alemanha $(40,7 \%)$, Suíça $(47,1 \%)$, entre outros. O Estado de São Paulo chegou ao número de quase 63 mil pesquisadores, que é $66 \%$ maior que o estimado para 1995, considerando os bolsistas do CNPq, CAPES, Fundações Estaduais e pessoas de P\&D de empresas com nível superior (FAPESP, 2010-B).

Quanto ao registro de patentes no Escritório de Patentes dos EUA, USPTO, o Brasil ocupava a $28^{\underline{a}}$ posição no ranking de patenteadores em 1974 , caindo para $27^{\text {a }}$ em 1990 e 29a posição em 1998 e em 2006, indicando que em 32 anos, o país esteve praticamente na mesma posição no ranking, embora em 1974 tenham sido depositadas 44 patentes, subindo para 341 patentes depositadas em 2006, um número oito vezes maior, porém os depósitos de outros países também aumentaram muito no período. Países que estavam atrás do Brasil em 1974, como Taiwan, Coreia do Sul, China, Índia e Malásia, passaram o Brasil em 2006, com exceção de Taiwan. O Estado de São Paulo manteve a liderança de depósito de patentes no INPI, para todo o período de 1980 a 2005 e os seis estados líderes no depósito de 
patentes são: São Paulo, Rio G.do Sul, Rio de Janeiro, Minas Gerais, Paraná e Santa Catarina (FAPESP, 2011-B).

A Petrobrás lidera quanto ao total de pedidos de patentes entre 1980 e2005 e as instituições de ensino e pesquisa estão aumentando a participação, com seis líderes no total do país, com destaque para a UNICAMP que é a líder entre 2000 2005, tendo superado a Petrobrás em 2002 e 2003. Entre as vinte instituições líderes estão ainda USP, FAPESP, UFMG, UFRJ, CNPq, CDTN, UNESP e Embrapa. (FAPESP, 2011-B).

A produção e exportação de itens com maior valor agregado e/ou de maior conteúdo tecnológico são consideradas indicadores de impacto, pois medem o grau de evolução das tecnologias ou mesmo da ciência, entre os países. Na pesquisa FAPESP de 2010 foi possível perceber que os países em desenvolvimento estão aumentando o peso percentual das exportações de itens de maior intensidade tecnológica, com redução dos países desenvolvidos nesses segmentos. O Brasil se destacou com o aumento das exportações de produtos de média tecnologia (que incorpora produtos primários agrícolas e agroindustriais), com aumento de US\$37,3 bilhões de 2002 para 2005 (FAPESP, 2010-A).

No balanço de pagamentos tecnológico, o principal item gerador de receita para o país está relacionado com serviços técnicos profissionais, sendo que respondeu por $67,76 \%$ das receitas brasileiras com a venda de serviços tecnológicos em 2008, representando $R \$ 3,6$ bilhões, conforme se observa na Tabela 2 (FAPESP, 2010-A). 
Tabela 2 Distribuição dos serviços tecnológicos nas receitas brasileiras (\%)

\begin{tabular}{|c|c|c|c|c|}
\hline TIPOS DE SERVIÇOS TECNOLÓGICOS & 2005 & 2006 & 2007 & 2008 \\
\hline Serviços Técnicos Profissionais & 89,33 & 66,34 & 64,99 & 67,76 \\
\hline Marcas e Patentes & 2,34 & 1,73 & 2,45 & 2,35 \\
\hline Aquisição de Software & 1,71 & 1,64 & 2,23 & 2,39 \\
\hline $\begin{array}{l}\text { Projetos e desenhos de modelos } \\
\text { industriais }\end{array}$ & 1,42 & 0,79 & 0,59 & 0,70 \\
\hline Montagem de equipamentos & 1,40 & 4,62 & 2,30 & 3,20 \\
\hline Serviços de assistência técnica & 1,29 & 18,42 & 17,88 & 10,60 \\
\hline $\begin{array}{l}\text { Projetos e desenhos de modelos de } \\
\text { engenharia }\end{array}$ & 0,97 & 2,66 & 5,52 & 7,14 \\
\hline Direitos Autorais & 0,79 & 1,21 & 0,91 & 1,03 \\
\hline Outras montagens sob encomenda & 0,27 & 0,61 & 0,33 & 0,41 \\
\hline $\begin{array}{l}\text { Implantação e instalação de projetos de } \\
\text { engenharia }\end{array}$ & 0,25 & 1,11 & 1,28 & 1,51 \\
\hline $\begin{array}{l}\text { Fornecimento de serviços e despesas } \\
\text { complementares }\end{array}$ & 0,13 & 0,49 & 0,65 & 0,90 \\
\hline Fornecimento de tecnologia & 0,05 & 0,17 & 0,13 & 0,74 \\
\hline
\end{tabular}

Fonte: FAPESP com base em dados do Bacen

No entanto, segundo dados referentes às despesas do país com fluxos de tecnologia, 60\% são de aquisição de software e serviços técnicos profissionais, representando quase US $\$ 4,4$ bilhões. O país apresenta um déficit referente aos fluxos de tecnologia, que na análise da FAPESP pode apontar competências que o país não possui ou que são insuficientes para atender a demanda interna, dentro de segmentos específicos.

A legislação, regulamentações e políticas públicas relacionadas à $\mathrm{C}, \mathrm{T} \& \mathrm{I}$ avançaram muito no período analisado, com o surgimento de importantes instituições como MCT, MDIC, CNPq, CAPES, FAPESP, FINEP, ANPEI e Receita Federal entre outras. Foi possível perceber como o ambiente econômico, político e social interferiu na qualidade das instituições, ao longo dos anos analisados e 
perceber que houve uma evolução das nossas instituições, inseridas hoje num ambiente mais democrático, embora dados tenham revelado que o país avançou muito na área de C,T\&I, durante o período de governo militar, dada a política desenvolvimentista da época, mas também devido ao cenário mais favorável em termos econômicos, oposto do que o país vem passando atualmente, inserido num cenário globalizado, em que a concorrência está muito mais acirrada e são necessários esforços e cooperação entre as instituições para garantir a competitividade da nossa indústria.

No próximo capítulo são apresentados os procedimentos metodológicos adotados na elaboração da tese, com justificativas da escolha das empresas que foram analisadas em profundidade e da seleção da amostra de empresas para as quais foi enviado o link do questionário autoaplicado. Em seguida é apresentado um quadro com as proposições analisadas na pesquisa e principais conceitos utilizados. Ao final do capítulo encontra-se a estrutura geral da Tese. 


\section{PROCEDIMENTOS METODOLÓGICOS}

Neste capítulo são apresentados os procedimentos metodológicos empregados na elaboração da tese.

O objetivo geral desta tese é entender como as competências e conhecimentos de diferentes profissionais se combinam para organizar o trabalho de P\&D, tanto no ambiente interno como externo e como influenciam no sucesso das inovações, utilizando-se a abordagem da Teoria Evolucionária. Busca-se contribuir para os estudos e análises sobre organização do trabalho em P\&D, revelando práticas de sucesso na geração de inovações, a partir de casos de empresas que mais inovam no país, pertencentes a diferentes setores como químico, petroquímico, extrativo mineral e farmacêutico.

Para atender este objetivo, o presente trabalho pesquisou casos de empresas bem sucedidas no desenvolvimento e geração de inovações, orientando-se pela seguinte questão:

"Por que as empresas precisam buscar conhecimentos e competências necessários para a geração de inovações, no ambiente externo da organização?"

A elaboração da questão de pesquisa para guiar a coleta de dados, é uma etapa essencial na construção de um estudo de caso (VOSS et al., 2002).

A partir da revisão da literatura levantaram-se os seguintes objetivos específicos desta pesquisa:

- Entender como as empresas organizam os processos de trabalho de pesquisa e desenvolvimento de inovações.

- Identificar as competências e qualificações requeridas nas diferentes etapas de P\&D de inovações e como essas competências modificam a estrutura ou o processo de inovação.

- Identificar as características organizacionais e estruturais das empresas bem sucedidas no lançamento de inovações. 
- Entender como se dá a coordenação das atividades de P\&D de inovações nos ambientes interno e externo das empresas e quais são os mecanismos utilizados para garantir a coesão e sinergia entre os profissionais.

\subsection{Método de Pesquisa}

Foi adotada uma abordagem exploratória de natureza descritivo-qualitativa, com análise de múltiplos casos. A pesquisa exploratória é indicada quando se investiga objetos, fenômenos e sistemas complexos, podendo abranger pessoas, processos e eventos, em que se tem pouco conhecimento ou que podem gerar diferentes perspectivas de interpretação (LEEDY, 1997). Segundo Leedy (1997), a abordagem descritivo-qualitativa é adequada para explicar a ocorrência de um fenômeno, com o propósito de descrevê-lo e entendê-lo, considerando ainda o ponto de vista dos participantes envolvidos no contexto da pesquisa.

Para Yin (1981), o estudo de caso possibilita o estudo de um fenômeno contemporâneo em seu contexto real, especialmente quando as fronteiras entre 0 fenômeno e o contexto em que está inserido não são claras.

Para Eisenhardt (1989), o estudo de caso é uma estratégia de pesquisa onde se procura entender a dinâmica, presente no espaço em que se investiga um fenômeno ou problema.

Voss, Tsikriktsis e Frohlich (2002) destacam que os estudos de casos contribuem de várias maneiras para pesquisas em gestão, conforme Quadro 1:

Quadro 1 Aplicações do Estudo de Caso

\begin{tabular}{|l|l|}
\hline \multicolumn{1}{|c|}{ Aplicações } & \multicolumn{1}{c|}{ Características } \\
\hline Exploratório & $\begin{array}{l}\text { Possibilita o desenvolvimento de ideias e questões de pesquisa, sendo que } \\
\text { muitas pesquisas de doutorado iniciam com um ou mais estudos de casos, } \\
\text { gerando uma lista de questões para pesquisas futuras. }\end{array}$ \\
\hline $\begin{array}{l}\text { Construção } \\
\text { de Teoria }\end{array}$ & $\begin{array}{l}\text { O estudo de caso ajuda a construir teoria, em áreas onde os casos são } \\
\text { contundentes. }\end{array}$ \\
\hline $\begin{array}{l}\text { Testar a } \\
\text { Teoria }\end{array}$ & $\begin{array}{l}\text { Apesar de suas limitações para testar teoria, o estudo de caso tem sido } \\
\text { utilizado em pesquisas na área de gestão para testar questões } \\
\text { complicadas. }\end{array}$ \\
\hline $\begin{array}{l}\text { Refinamento } \\
\text { de Teoria }\end{array}$ & $\begin{array}{l}\text { Os estudos de casos também podem ser usados para aprofundar e validar } \\
\text { resultados empíricos já encontrados. }\end{array}$ \\
\hline
\end{tabular}

Fonte: Elaborado a partir de Voss, Tsikriktsis e Frohlich (2002). 


\subsection{Seleção da Amostra}

Nesta pesquisa foram selecionadas grandes empresas com forte inserção internacional, que possuem laboratórios de P\&D no Brasil ou outros países e que desenvolvem inovações de forma cooperativa com universidades, institutos de pesquisa, instituições, empresas brasileiras e do exterior. Foram selecionadas empresas de diferentes setores, como químico, petroquímico, extrativo mineral e farmacêutico. Buscaram-se empresas com diferentes características, incluindo empresas de capital nacional, que desenvolvem inovação tecnológica, de produtos e de processos. Considera-se que as grandes empresas têm o processo de inovação bem organizado, com estrutura já consolidada e gestão eficiente da área de inovação, o que lhes confere vantagem em relação às demais empresas. Esta pesquisa originou-se de um projeto firmado com a UNICAMP, intitulado "Interações de Universidades/ Institutos de Pesquisa e Empresas no Brasil", em parceria com pesquisadores da EPUSP, cujo tema era investigar o padrão atual de interações entre a dimensão científica e a dimensão tecnológica no Brasil, focalizando universidades/instituições públicas de pesquisa e empresas, para analisar o relacionamento entre as duas instituições para o sistema nacional de inovação.

A definição da amostra da presente pesquisa considerou que há um vasto campo de estudo e pela necessidade de delimitação do escopo e de sua viabilidade, foram adotados os seguintes critérios para escolha dos casos:

- São empresas de grande e médio porte;

- Possuem laboratórios de P\&D bem estruturados;

- As empresas geram inovações de produto, processo e/ou tecnológica;

- São empresas conhecidas como muito inovadoras;

- Realizam investimentos consideráveis em P\&D;

- Possuem cooperação externa com outras organizações.

Para Eisenhardt (1989) é importante definir inicialmente a questão da pesquisa e nesse ponto há uma concordância com Mintzberg (1979), quando ele afirma que em pesquisas organizacionais não importa se a amostra é pequena, mas 
ter um foco bem definido para que sejam coletados dados específicos sistematicamente.

Segundo Eisenhardt (1989) e Yin (1981), o estudo de caso possibilita a combinação de métodos de coleta de dados como entrevistas, questionários, observações e arquivos. As evidências podem ser qualitativas, quantitativas ou ambas.

Foram selecionadas cinco empresas e a escolha das mesmas partiu de levantamento de informações através da mídia como jornais e revistas, indicações de pesquisadores com trabalhos realizados na área de inovação e de profissionais de empresas. Outras fontes utilizadas envolveram publicações em jornais especializados e notícias extraídas de sítios da internet. Destaca-se que o contato e acesso a pessoas-chave nestas empresas foi decisivo para a pesquisa e no resultado final.

A escolha de múltiplos casos é indicada quando se pretende construir modelos e teorias, com análises mais consistentes e que permitem maiores generalizações dos resultados, embora envolvam mais recursos e tempo por parte do pesquisador (VOSS; TSIKRIKTSIS; FROHLICH, 2002).

A unidade de análise escolhida foi a área de Pesquisa e Desenvolvimento de Inovações (P\&D).

\subsection{Procedimentos de Coleta de Dados}

As análises realizadas nesta tese basearam-se em fontes primárias e secundárias.

As fontes primárias utilizadas para explorar 0 assunto inicialmente envolveram: reuniões com especialistas, entrevista piloto com profissionais de uma empresa do ramo químico e observações no campo. As fontes secundárias utilizadas envolveram informações produzidas por órgãos públicos, instituições especializadas e mídia, abrangendo: jornais, revistas, livros, relatórios, teses, periódicos científicos, estudos e informações disponíveis em portais da internet. Iniciou-se a revisão bibliográfica por um levantamento de publicações da área de 
gestão e inovação. As referências bibliográficas clássicas e mais recentes pesquisadas através de portais de busca como EBSCO, PROQUEST, SCHOLAR GOOGLE, bases de teses e dissertações, permitiram resgatar muitas indicações. Também foram obtidos dados complementares sobre as empresas pesquisas em fontes secundárias, tais como documentos e publicações na mídia e sítios da internet.

Após definir o escopo do estudo, nos meses de dezembro de 2011 e janeiro de 2012 foram realizadas entrevistas preliminares (piloto) com profissionais de uma grande empresa do setor químico. Foram entrevistados o coordenador e um analista da área de P\&D, obtendo-se informações prévias que possibilitaram a revisão dos instrumentos de coleta de dados e avaliação sobre a viabilidade do estudo.

Neste piloto foi possível perceber a importância da entrevista com diferentes profissionais, gerando pontos de vista diversos e que através de uma triangulação, complementaram o levantamento e análise dos dados.

Segundo Lakatos e Marconi (2004), a técnica de triangulação permite ampliar uma descrição, explicação e compreensão de um fato estudado. A triangulação pode ser de fontes de informação, de metodologias de pesquisa, de investigadores e de teorias.

Foram então coletados dados primários junto às empresas, através de entrevistas com roteiro semi-estruturado com profissionais estratégicos das mesmas, tais como diretores, gestores e pesquisadores que atuam na área de P\&D. O roteiro foi enviado previamente aos entrevistados e as entrevistas foram realizadas pessoalmente, tiveram duração mínima de uma hora, com gravações que depois foram transcritas para análise e interpretação. As respostas foram checadas quando surgia alguma dúvida ou diferença e foram comparados os diferentes pontos de vista, eliminando riscos de respostas enviesadas por interesses pessoais.

Voss; Tsikriktsis; Frohlich (2002) destacam que o estudo de caso implica múltiplas fontes de dados obtidas através de entrevistas estruturadas, observações in loco, conversas informais, participação em eventos e encontros, consulta a documentos e arquivos. Deve-se seguir um protocolo de pesquisa bem desenhado e sua base essencial está nas questões a serem usadas nas entrevistas, que podem, 
por exemplo, seguir o conhecido modelo de funil. Inicia-se com questões gerais e mais abertas e com o progresso da entrevista, faz-se perguntas mais específicas e mais detalhadas. Os autores destacam ainda que é importante enviar o esboço do roteiro da entrevista previamente, para que os entrevistados possam se preparar.

O roteiro de entrevista visava explorar em profundidade, algumas questões relacionadas à influência das qualificações e competências na organização do trabalho de P\&D de inovações. Foram contemplados temas como: práticas gerenciais adotadas para cobrir lacunas na base de conhecimento interno das empresas, práticas e recursos utilizados na cooperação com outras instituições para desenvolver inovações, estratégias de busca de novos conhecimentos no mercado e novas tecnologias para criar novas competências, práticas de aprendizagem e gestão do conhecimento. O roteiro é apresentado no Apêndice A.

Buscou-se analisar a importância das competências técnicas, organizacionais, relacionais, de regulação e de meios, para o sucesso na geração das inovações e analisar também, se há diferenças no grau de importância das competências para empresas de diferentes setores e tamanho. Outra característica de interesse do estudo foi a regulação das ações, no ambiente interno e externo da organização, para que os diferentes atores atingissem metas e objetivos que poderiam divergir. Verificou-se ainda, o grau de autonomia e de cooperação dos profissionais para a geração de ideias e desenvolvimento de competências.

A abordagem adotada para análise das competências é a desenvolvida por Munier e Rondé (2001), já apresentada anteriormente e adaptada para esta pesquisa, juntamente com a taxonomia de Pavitt (1984).

Para a análise dos casos, além da questão de pesquisa, foram formuladas três proposições que direcionaram a análise:

1‥Proposição: uma rede de cooperação forte é um fator importante para viabilizar o sucesso na geração de uma inovação e assim a competência relacional dá sustentação às demais competências. 
2a -Proposição: as empresas buscam competências externas devido às especificidades de cada inovação, que exige competências complementares para o alcance de resultados.

3ㄹ. Proposição: a competência de negócios vem ganhando importância em muitas empresas, evidenciando que a competência técnica não tem primazia no processo de inovação, inclusive por causa dos estímulos gerados por programas institucionais de incentivo.

As proposições do estudo e questões utilizadas para análise das mesmas durante as entrevistas são apresentadas no Quadro 2: 


\section{Quadro 2 Proposições do estudo e questões da pesquisa}

\begin{tabular}{|c|c|c|c|c|}
\hline Objetivos & Questão e proposições de pesquisa & Conceitos / Variáveis & $\begin{array}{l}\text { Questões } \\
\text { Roteiro }\end{array}$ & $\begin{array}{c}\text { Questões } \\
\text { Questionário }\end{array}$ \\
\hline $\begin{array}{l}\text { Objetivo geral: Investigar como a } \\
\text { organização e gestão das atividades de } \\
\text { P\&D, realizadas por profissionais com } \\
\text { diferentes qualificações e competências } \\
\text { compartilhadas, influenciam no sucesso } \\
\text { das inovações. }\end{array}$ & $\begin{array}{l}\text { Questão principal: Por que as } \\
\text { empresas buscam competências e } \\
\text { conhecimentos necessários para a } \\
\text { geração de inovações, nas interações } \\
\text { com agentes do ambiente externo? }\end{array}$ & $\begin{array}{l}\text { Competência - Munier e Rondé, 2001; Munier, 1999; Zarifian, } \\
\text { 2001; François et al., 1999; Malerba e Orsenigo, 2000; Le } \\
\text { Boterf, 1995, 2010; Lawler, 1994; Prahalad e Hamel, 1990. } \\
\text { Inovação - Schumpeter, 1939; Nelson e Rosenberg, 1993; } \\
\text { Kline e Rosenberg, 1986; Malerba e Orsenigo, 2000; Tidd, } \\
\text { Bessant e Pavitt, 2005. } \\
\text { Cumulatividade de Conhecimento - Malerba e Orsenigo, } 2000\end{array}$ & $\begin{array}{l}1,2,3,5,6 \\
7,9,12,13 \\
14,16\end{array}$ & $2,4,6$ \\
\hline \multicolumn{5}{|l|}{ Objetivos específicos: } \\
\hline $\begin{array}{l}\text { (a) entender como diferentes empresas } \\
\text { organizam os processos de trabalho de } \\
\text { pesquisa e desenvolvimento de inovações. }\end{array}$ & $\begin{array}{l}\text { 1‥ Proposição: uma rede de } \\
\text { cooperação forte é um fator importante } \\
\text { para viabilizar o sucesso na geração de } \\
\text { uma inovação e assim a competência } \\
\text { relacional dá sustentação às demais } \\
\text { competências. }\end{array}$ & $\begin{array}{l}\text { Processo de P\&D Inovação - Cooper, 1979; Cooper e } \\
\text { Kleinschmidt, 1986; Takeuchi e Nonaka, 1986; Brown e } \\
\text { Eisenhardt, 1995; Griffin, 1997; Kahn, Barczak e Moss, 2006; } \\
\text { Cooper, Edgett e Kleinschmidt, 2004. } \\
\text { Rede de Relacionamentos - Rosenberg, 1982; Kline e } \\
\text { Rosenberg, 1986; Metcalfe, } 2003 .\end{array}$ & $\begin{array}{l}1,2,4,5,7 \\
12,13,14 \\
16,23\end{array}$ & $1,3,4,5$ \\
\hline $\begin{array}{l}\text { (b) identificar as competências requeridas } \\
\text { nas diferentes etapas de P\&D de } \\
\text { inovações e como o desenvolvimento } \\
\text { dessas competências modifica a estrutura } \\
\text { ou o processo de inovação. } \\
\text { (c) entender como se dá a coordenação } \\
\text { das atividades de P\&D de inovações nos } \\
\text { ambientes interno e externo das empresas } \\
\text { e quais são os mecanismos utilizados para } \\
\text { garantir a coesão e sinergia entre os } \\
\text { profissionais. }\end{array}$ & $\begin{array}{l}\text { 2a . Proposição: as empresas buscam } \\
\text { competências externas devido às } \\
\text { especificidades de cada inovação, que } \\
\text { exige competências complementares } \\
\text { para o alcance de resultados. }\end{array}$ & $\begin{array}{l}\text { Cooperação - Dejours, 1997; Valléry, 2004; Barthe, } 2003 . \\
\text { Complementaridades - Rosenberg, 1982; Pavitt, 1984; } \\
\text { Nelson e Rosenberg, 1993. } \\
\text { Conhecimento - Nonaka e Takeuchi, 1997; Cohen e Levinthal, } \\
\text { 1990; Malerba e Orsenigo, 2000; Metcalfe, 2003. } \\
\text { Autonomia - Zarifian, 2001; Mintzberg, 2003; Takeuchi e } \\
\text { Nonaka, 1986. } \\
\text { Processos de Aprendizagem - Malerba e Orsenigo, 2000; } \\
\text { Malerba, 1992. }\end{array}$ & $\begin{array}{c}1,2,3,5,6 \\
7,8,10,11 \\
12,13,18 \\
19,22\end{array}$ & $2,3,4,6$ \\
\hline $\begin{array}{l}\text { (d) entender como os profissionais } \\
\text { identificam oportunidades tecnológicas e } \\
\text { novos conhecimentos no mercado e } \\
\text { transformam em novas competências para } \\
\text { desenvolver inovações. } \\
\text { (e) identificar as características } \\
\text { organizacionais e estruturais das } \\
\text { empresas bem sucedidas no lançamento } \\
\text { de inovações. }\end{array}$ & $\begin{array}{l}\text { 3a. Proposição: a competência de } \\
\text { negócios vem ganhando importância } \\
\text { em muitas empresas, evidenciando que } \\
\text { a competência técnica não tem } \\
\text { primazia no processo de inovação, } \\
\text { inclusive por causa dos estímulos } \\
\text { gerados por programas institucionais } \\
\text { de incentivo. }\end{array}$ & $\begin{array}{l}\text { Capacidade de absorção - Cohen e Levinthal, 1990; Malerba, } \\
1992 . \\
\text { Oportunidades tecnológicas - Pavitt (1984) } \\
\text { Estrutura Organizacional - Mintzberg, 1995, 2003; Cohen e } \\
\text { Levinthal, 1990; Larson e Gobeli, 1988; Johne e Snelson, } \\
\text { 1988; Vasconcellos e Hemsley, 1997; Nakano e Fleury, 1998; } \\
\text { Rabechini e Carvalho, 2010. }\end{array}$ & $\begin{array}{l}2,3,4,8,12 \\
13,14,15 \\
16,17,18 \\
19,20,21 \\
\quad 22,23\end{array}$ & $2,3,4,6$ \\
\hline
\end{tabular}


O quadro 3 apresenta a relação das entrevistas realizadas junto aos gestores das áreas de P\&D das cinco empresas pesquisadas, aqui denominadas empresas A, B, C, D e E, com datas de realização das entrevistas, cargos dos entrevistados e o tempo de duração das entrevistas.

Quadro 3 Relação das entrevistas realizadas

\begin{tabular}{|c|c|c|c|}
\hline Empresa & Data da entrevista & $\begin{array}{c}\text { Cargo do } \\
\text { Entrevistado }\end{array}$ & $\begin{array}{c}\text { Duração da } \\
\text { Entrevista }\end{array}$ \\
\hline A & Dez/2011 (piloto) & Coordenador P\&D & 1h40min \\
\hline A & Dez/2012 & Gerente de P\&D & 1h50min \\
\hline B & Out/2013 & Diretor & 1h10min \\
\hline B & Nov/2013 & Gerente de P\&D & 1h20min \\
\hline C & Dez/2013 & Gerente de P\&D & 1h50min \\
\hline C & Dez/2013 & Pesquisador P\&D & 1h10min \\
\hline D & Set/2013 & Diretor & 1h10min \\
\hline D & Set/2013 & Gerente & 1h25min \\
\hline E & Jan/2014 & Assessor & 1h45min \\
\hline E & Jan/2014 & Gerente P\&D & 1h15min \\
\hline
\end{tabular}

Para compor um quadro mais abrangente sobre a questão de pesquisa foi aplicado um questionário, através de um survey com várias empresas, para coletar mais respostas e reforçar as conclusões preliminares levantadas com as entrevistas. A amostra é composta por empresas associadas à Associação Nacional de Pesquisa, Desenvolvimento e Engenharia das Empresas Inovadoras (ANPEI). São empresas de diversos portes e setores, líderes de importantes cadeias produtivas do país. 
Segundo Voss; Tsikriktsis; Frohlich (2002), a aplicação de questionários pode complementar e ampliar as análises sobre um fato estudado, sendo uma forma de coleta de dados muito usada na técnica de triangulação.

A partir dos objetivos da pesquisa e das evidências extraídas das entrevistas, foram definidos os dados que seriam coletados através do Survey e criou-se o instrumento de coleta de dados que é apresentado no Apêndice 3 - um questionário autoaplicado desenvolvido com a utilização do software do Google Drive. Além deste software, também foi analisada a funcionalidade do software Survey Monkey, porém optou-se pelo Google Drive pela facilidade de utilização pelos respondentes. Este software possui algumas funcionalidades que permitem controlar as respostas, identificar respondentes, geração de algumas tabulações e gráficos, além de permitir diferentes formatações dos dados e envio dos resultados aos respondentes.

O software possui facilidades como permitir a inclusão de comentários ou observações nas questões e agregar respostas em blocos por temas. O uso do software é bem fácil para quem elabora e também para quem responde a pesquisa, permitindo ainda, cadastrar o endereço eletrônico dos respondentes se tiver acesso a essa informação ou obter anonimato dos respondentes, caso seja enviado através de uma associação ou cadastro de terceiros.

Após elaboração do instrumento de coleta de dados foi feita uma validação junto a duas empresas, sendo uma de desenvolvimento de software e outra de fabricação de produtos eletrônicos. Após a validação junto a estas empresas foram feitos ajustes no questionário, referentes à interpretação dos enunciados das questões e escalas utilizadas.

Ao término dos ajustes no questionário foram levantados dados de empresas associadas à ANPEI, disponíveis no site da associação. Foi possível identificar e contatar 200 empresas associadas, para as quais foi enviado um e.mail endereçado aos profissionais responsáveis pela área de $P \& D$, convidando para participarem da pesquisa e explicando os objetivos. Com o retorno afirmativo dos responsáveis das áreas de P\&D das empresas foi enviado um e.mail com carta contendo instruções e link da pesquisa. 
Tomou-se como base a Classificação Nacional de Atividade Econômica (CNAE), para caracterizar as empresas representadas na amostra. Há empresas com atividades de diferentes divisões, porém grande maioria pertencente à Seção $C$ - Indústrias de Transformação, conforme Quadro 4.

Quadro 4 Classificação CNAE - atividades da indústria de transformação

\begin{tabular}{|c|c|}
\hline \multicolumn{2}{|r|}{ Hierarquia } \\
\hline Seção: & INDÚSTRIAS DE TRANSFORMAÇÃO \\
\hline \multicolumn{2}{|c|}{ Esta seção contém as seguintes divisões: } \\
\hline 10 & FABRICAÇÃO DE PRODUTOS ALIMENTÍCIOS \\
\hline 11 & FABRICAÇÃO DE BEBIDAS \\
\hline 12 & FABRICAÇÃO DE PRODUTOS DO FUMO \\
\hline 13 & FABRICAÇÃO DE PRODUTOS TÊXTEIS \\
\hline 14 & CONFECÇÃO DE ARTIGOS DO VESTUÁRIO E ACESSÓRIOS \\
\hline 15 & $\begin{array}{l}\text { PREPARAÇÃO DE COUROS E FABRICAÇÃO DE ARTEFATOS DE COURO, ARTIGOS PARA } \\
\text { VIAGEM E CALÇADOS }\end{array}$ \\
\hline 16 & FABRICAÇÃO DE PRODUTOS DE MADEIRA \\
\hline 17 & FABRICAÇÃO DE CELULOSE, PAPEL E PRODUTOS DE PAPEL \\
\hline 18 & IMPRESSÃO E REPRODUÇÃO DE GRAVAÇÕES \\
\hline 19 & $\begin{array}{l}\text { FABRICAÇÃO DE COQUE, DE PRODUTOS DERIVADOS DO PETRÓLEO E DE } \\
\text { BIOCOMBUSTÍVEIS }\end{array}$ \\
\hline 20 & FABRICAÇÃO DE PRODUTOS QUÍMICOS \\
\hline 21 & FABRICAÇÃO DE PRODUTOS FARMOQUÍMICOS E FARMACÊUTICOS \\
\hline 22 & FABRICAÇÃO DE PRODUTOS DE BORRACHA E DE MATERIAL PLÁSTICO \\
\hline 23 & FABRICAÇÃO DE PRODUTOS DE MINERAIS NÃO-METÁLICOS \\
\hline 24 & METALURGIA \\
\hline 25 & FABRICAÇÃO DE PRODUTOS DE METAL, EXCETO MÁQUINAS E EQUIPAMENTOS \\
\hline 26 & FABRICAÇÃO DE EQUIPAMENTOS DE INFORMÁTICA, PRODUTOS ELETRÔNICOS E ÓPTICOS \\
\hline 27 & FABRICAÇÃO DE MÁQUINAS, APARELHOS E MATERIAIS ELÉTRICOS \\
\hline 28 & FABRICAÇÃO DE MÁQUINAS E EQUIPAMENTOS \\
\hline 29 & FABRICAÇÃO DE VEÍCULOS AUTOMOTORES, REBOQUES E CARROCERIAS \\
\hline 30 & $\begin{array}{l}\text { FABRICAÇÃO DE OUTROS EQUIPAMENTOS DE TRANSPORTE, EXCETO VEÍCULOS } \\
\text { AUTOMOTORES }\end{array}$ \\
\hline 31 & FABRICAÇÃO DE MÓVEIS \\
\hline 32 & FABRICAÇÃO DE PRODUTOS DIVERSOS \\
\hline 33 & MANUTENÇÃO, REPARAÇÃO E INSTALAÇÃO DE MÁQUINAS E EQUIPAMENTOS \\
\hline
\end{tabular}

Fonte: IBGE (2013)

\subsection{Apresentação do Instrumento de Coleta de Dados}

O questionário autoaplicado apresentado no Apêndice $C$ é formado por 6 questões do tipo múltipla escolha. Na primeira questão buscava-se identificar o tamanho da empresa e o quanto ela estava organizada para a P\&D de inovações.

$\mathrm{Na}$ segunda questão, o objetivo era explorar o tipo de inovação que a empresa desenvolvia prioritariamente e também outros tipos desenvolvidos. O objetivo era investigar se a empresa estava produzindo inovações radicais ou 
incrementais, que têm influência diferente sobre os tipos de competências desenvolvidas e requeridas nas etapas do processo de desenvolvimento da inovação e em toda estrutura da empresa voltada para a inovação.

$\mathrm{Na}$ terceira questão visava-se identificar as fontes de cooperação para desenvolver a inovação e também fontes de conhecimento para o desenvolvimento de competências. Esta questão também ajuda a perceber os relacionamentos entre as organizações tomando-se como base a tipologia de Pavitt (1984).

$\mathrm{Na}$ quarta questão foram explorados os principais motivos pelos quais as empresas buscam cooperação externa.

A quinta questão identificava o tamanho da equipe envolvida com P\&D de inovações nas empresas, o que caracteriza também o tamanho da empresa.

A sexta questão explorava as competências requeridas nas principais áreas envolvidas com P\&D de inovação e as atribuições dessas áreas, que podem ser diferentes em cada empresa, dada a importância atribuída à área no processo de inovação.

Foi possível manter o contato direto com os respondentes para esclarecer possíveis dúvidas e fazer o reenvio da pesquisa aos associados que não haviam retornado o e.mail inicial. A pesquisa ficou disponível durante três meses e foi encerrada com 42 respostas e aproveitamento de todas as respostas.

A Figura 8 apresenta a estrutura da pesquisa, os objetivos e abordagens do estudo. 


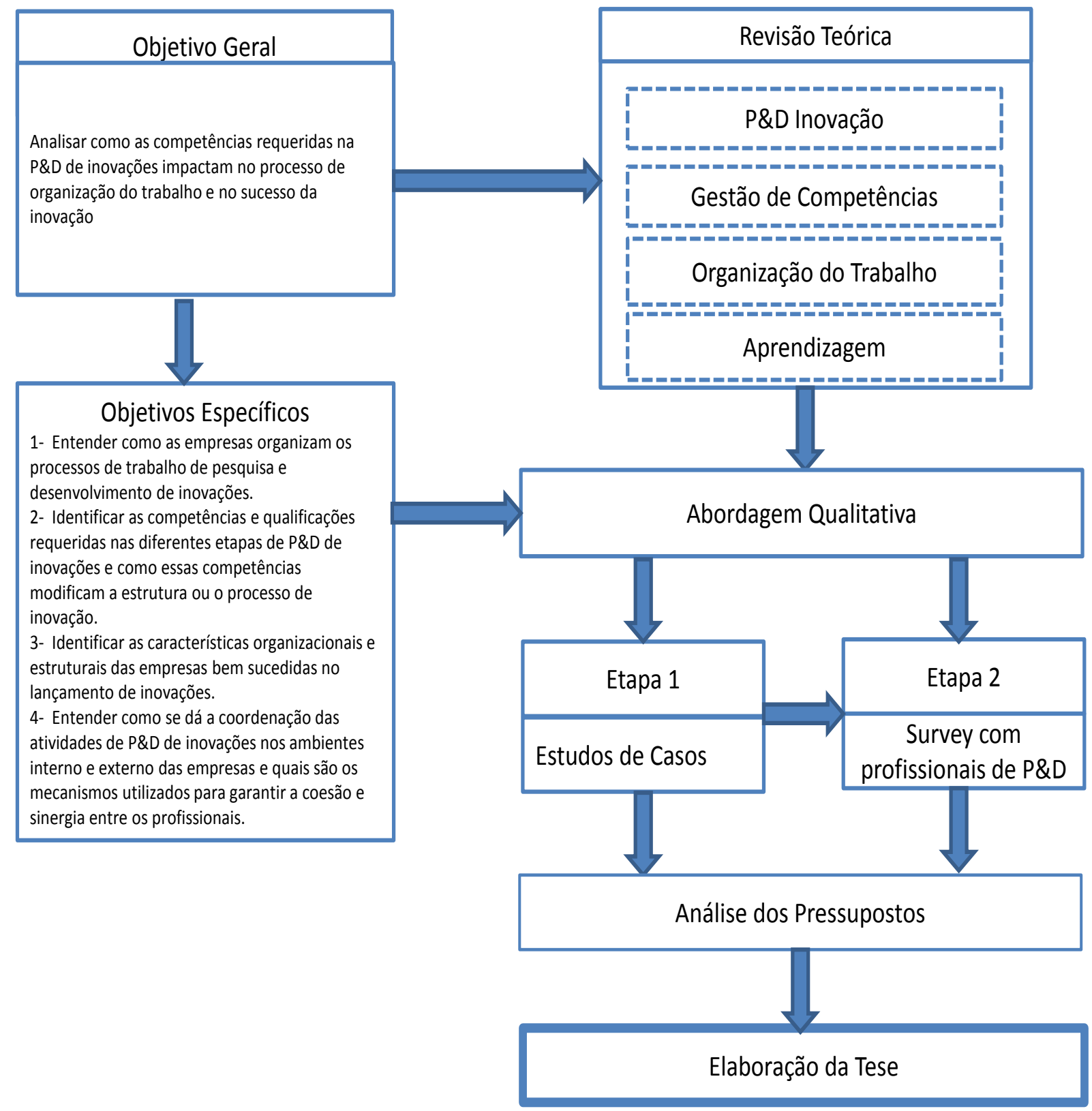

Figura 8 Estrutura da pesquisa

Fonte: Elaboração própria

A seguir são apresentados e discutidos os resultados da Pesquisa obtidos através das entrevistas presenciais e da aplicação do survey junto aos profissionais diretamente envolvidos com P\&D. 


\section{APRESENTAÇÃO DOS RESULTADOS}

Este capítulo apresenta a análise dos dados e informações levantados através da Etapa 1 da pesquisa que envolvia entrevistas em profundidade com profissionais responsáveis pela área de $P \& D$ de cinco empresas de grande porte consideradas inovadoras e do Survey com aplicação de questionário autoaplicado via web, junto a uma amostra de empresas consideradas inovadoras. Os resultados deste Survey são oriundos das análises das respostas do questionário autoaplicado.

A análise dos resultados foi feita através dos cruzamentos das questões e pressupostos da pesquisa com os dados que foram obtidos. Ao todo, onze perguntas do roteiro exploraram a questão principal (Por que as empresas buscam competências e conhecimentos necessários para a geração de inovações, nas interações com agentes do ambiente externo?), seis perguntas são referentes à $1^{\text {a }}$. Proposição (uma rede de cooperação forte é que viabiliza o sucesso na geração de uma inovação e assim a competência relacional dá sustentação às demais competências); sete perguntas analisaram a $2^{\mathrm{a}}$. Proposição (as empresas buscam competências externas devido às especificidades de cada inovação, que exige competências técnicas complementares para que o lançamento da inovação se concretize) e nove perguntas estão relacionadas à $3^{a}$. Proposição (a competência de negócios vem ganhando importância em muitas empresas, evidenciando que pode haver perda de foco da competência técnica, devido aos estímulos gerados por programas institucionais de incentivo).

As empresas objeto de estudo da Etapa 1 são empresas de grande porte, com faturamento acima de $R \$ 1,0$ bilhão, possuem laboratórios de $P \& D$ de inovações bem estruturados com mais de 100 profissionais alocados diretamente em pesquisa e possuem parcerias com outras organizações. Foi realizada análise de cinco empresas com forte inserção internacional, que desenvolvem inovações de forma cooperativa com outras organizações e que aqui são denominadas empresas A, B, C, D e E.

As empresas $A$, B e $C$ pertencem ao setor petroquímico, a empresa $D$ é do setor farmacêutico e a empresa $E$ é do setor extrativista mineral. 


\subsection{A Empresa A}

A empresa $A$ é uma multinacional de grande porte, pertencente à cadeia petroquímica, com unidades industriais no Brasil e em outros países e escritórios para comercialização de seus produtos. A empresa atua na primeira e segunda geração da cadeia petroquímica.

A cadeia petroquímica é constituída de unidades ou empresas de primeira geração, que produzem os básicos petroquímicos - olefinas (eteno, propeno e butadieno) e aromáticos (benzeno, tolueno e xilenos) e secundariamente são produzidos solventes e combustíveis. Na cadeia há também as empresas de segunda geração, que produzem resinas termoplásticas (polietilenos e polipropilenos) e produtos intermediários que são transformados em produtos finais petroquímicos, como PVC, poliestireno, ABS, resinas termoestáveis, polímeros para fibras sintéticas, elastômeros, bases para detergentes sintéticos e tintas etc. As empresas de terceira geração ou de transformação plástica transformam os produtos das empresas de segunda geração, fornecendo embalagens, peças e utensílios para outros segmentos como o automotivo, alimentício, eletrônico, elétrico, de embalagens e construção civil. As empresas de terceira geração estão próximas ao mercado consumidor de maneira geral (GOMES et al., 2005).

Segundo Gomes et al. (2005), a indústria petroquímica global e a nacional se organizam em polos para melhor eficiência logística, de infraestrutura e de integração operacional e as unidades que formam um polo petroquímico são as de primeira e segunda geração, que podem estar empresarialmente integradas ou não. No país há quatro polos petroquímicos em operação, localizados em São Paulo, Bahia, Rio de Janeiro e Rio Grande do Sul.

O faturamento líquido total da indústria química brasileira em 2013 foi de US\$162,3 bilhões e é apresentado por segmentos na Tabela 3: 
Tabela 3 Faturamento líquido da indústria química brasileira por segmentos

\begin{tabular}{lc}
\hline Segmento & US\$ Bilhões \\
\hline Produtos químicos de uso industrial & 72,2 \\
Produtos Farmacêuticos & 26,5 \\
Fertilizantes & 16,1 \\
Sabões e detergentes & 14,8 \\
Higiene pessoal, perfumaria e cosméticos & 14,7 \\
Defensivos agrícolas & 10,4 \\
Tintas, esmaltes e vernizes & 4,2 \\
Outros & 2,2 \\
Fibras artificiais e sintéticas & 1,2 \\
\hline Total & 162,3 \\
\hline
\end{tabular}

Fonte: ABIQUIM (2013)

O país estava na $6^{\circ}$ posição em 2011 , na participação do faturamento líquido da indústria química mundial, conforme se observa na Tabela 4:

Tabela 4 Participação do Brasil no faturamento da indústria química mundial

\begin{tabular}{|c|c|}
\hline País & US\$ Bilhões \\
\hline $1^{\circ}$ China & 1.286 \\
\hline $2^{\circ}$ EUA & 759 \\
\hline 3ำ Japão & 382 \\
\hline $4^{\circ}$ Alemanha & 261 \\
\hline $5^{\circ}$ Coreia & 172 \\
\hline 6ํㅗㄱil & 166 \\
\hline 7ํ Índia & 152 \\
\hline $8^{\circ}$ França & 151 \\
\hline 9ํItália & 115 \\
\hline 10ํRússia & 114 \\
\hline 11ํ Reino Unido & 103 \\
\hline $12^{\circ}$ Taiwan & 90 \\
\hline $13^{\circ}$ Holanda & 83 \\
\hline 14ํㅡspanha & 82 \\
\hline 15 Suíça & 73 \\
\hline Total & $4.998,4$ \\
\hline
\end{tabular}

Fonte: ABIQUIM (2013) 


\subsubsection{Análise das competências organizacionais da Empresa A}

\section{Competência técnica}

O processo de P\&D de inovações está muito estruturado e parte inicialmente das estratégias tecnológicas da empresa, que tem um foco na pesquisa de novos produtos, processos ou tecnologias, voltados para uma área específica, a petroquímica. A empresa possui unidades de negócios e estas unidades é que definem os orçamentos para projetos de novos produtos e principalmente para aprimoramento de produtos já existentes e de tecnologia. Não há estímulo para geração de inovações em outra área do conhecimento, pois as competências foram desenvolvidas ao longo do tempo e há um acúmulo do conhecimento que é importante e permite acompanhar os avanços no mercado e projetar o que terá que ser modificado no longo prazo, por exemplo, a escassez de recursos naturais. As pesquisas de novas matérias primas, por exemplo, recebem orçamento maior se for justificada uma demanda futura que será gerada pelo mercado, pelas mudanças no cenário global que impactam nas tendências de consumo dos clientes ou numa limitação futura de um componente.

Os processos estão formalizados e estruturados, para o monitoramento e busca de oportunidades tanto no ambiente interno quanto externo, devido à adoção do modelo de inovação aberta. A empresa desenvolveu uma rede de inovação, a partir de parcerias com Institutos de Ciência e Tecnologia (ICT's), universidades, fornecedores, instituições certificadoras e clientes. Os profissionais realizam diversos contatos e viagens para prospectar novos negócios e novas tecnologias, formando parcerias com várias organizações de outros países.

A empresa possui centros de inovação tecnológica e possui mais de 100 profissionais trabalhando diretamente nos laboratórios de P\&D. São desenvolvidas principalmente inovações incrementais de produtos, processos e de tecnologia e secundariamente, desenvolve novos produtos e tecnologia nova. Embora não desenvolvam produtos novos, a mudança ou descoberta de uma matéria-prima pode ter grande impacto nos processos e na própria competitividade da empresa e de seus clientes. A melhoria incremental de produtos, processos e tecnologia é muito importante, para que não corram risco de perder mercado para os concorrentes e 
assim, há desenvolvimento das competências já existentes, que foram obtidas ao longo do tempo mas que não podem ficar estáticas, tem que acompanhar as mudanças de mercado. A empresa investe hoje em pesquisas sobre novas características dos produtos que já possui em carteira, para encontrar novas aplicações no mercado. Possuem lançamentos de inovações que são anuais e também metas de prospecção de novos projetos mais de longo prazo, para até 10 anos. No momento da pesquisa, a empresa apresenta mais de 200 projetos, sendo alguns para aplicação em 6 meses e outros em até 3 anos.

A área de inovação faz a prospecção e analisa cada projeto, sendo que há uma equipe para analisar projetos muito complexos e outra equipe para analisar projetos de menor complexidade. Os projetos complexos são os considerados inéditos no mercado e pode ser um produto, uma matéria prima, uma tecnologia. Nesses projetos complexos pode haver a necessidade de realizar testes, simulações, montar uma planta piloto ou uma planta de demonstração, dimensionar um equipamento. Cada etapa é analisada dentro das competências dos diferentes profissionais, porém estes projetos mais complexos exigem maior atenção e esforço, pois os riscos são maiores. Os projetos considerados mais simples são aqueles dentro da área de conhecimento de uma tecnologia já dominada pela empresa, então exigem menor esforço e atenção.

A priorização de projetos de $P \& D$ é orientada pelo mercado, pelas necessidades dos clientes, mas têm que atender também a estratégia da empresa e as metas de retorno econômico.

Os profissionais das equipes são separados por competências, mas isso não significa que uma equipe tenha mais capacidade do que a outra, pois o que ocorre é que há exigências de competências diferentes para projetos simples e para complexos. Há uma equipe para fazer o acompanhamento mercadológico, outra que tem conhecimento do mercado e faz a precificação, outra que realiza modelagens quando necessário, outra que realiza as atividades de marketing e outra que avalia projetos complexos. Os profissionais das diferentes equipes estão inclusive nas mesmas faixas salariais, não tendo muita diferenciação entre eles. O macroprocesso de P\&D da Empresa A é apresentado na figura 9: 


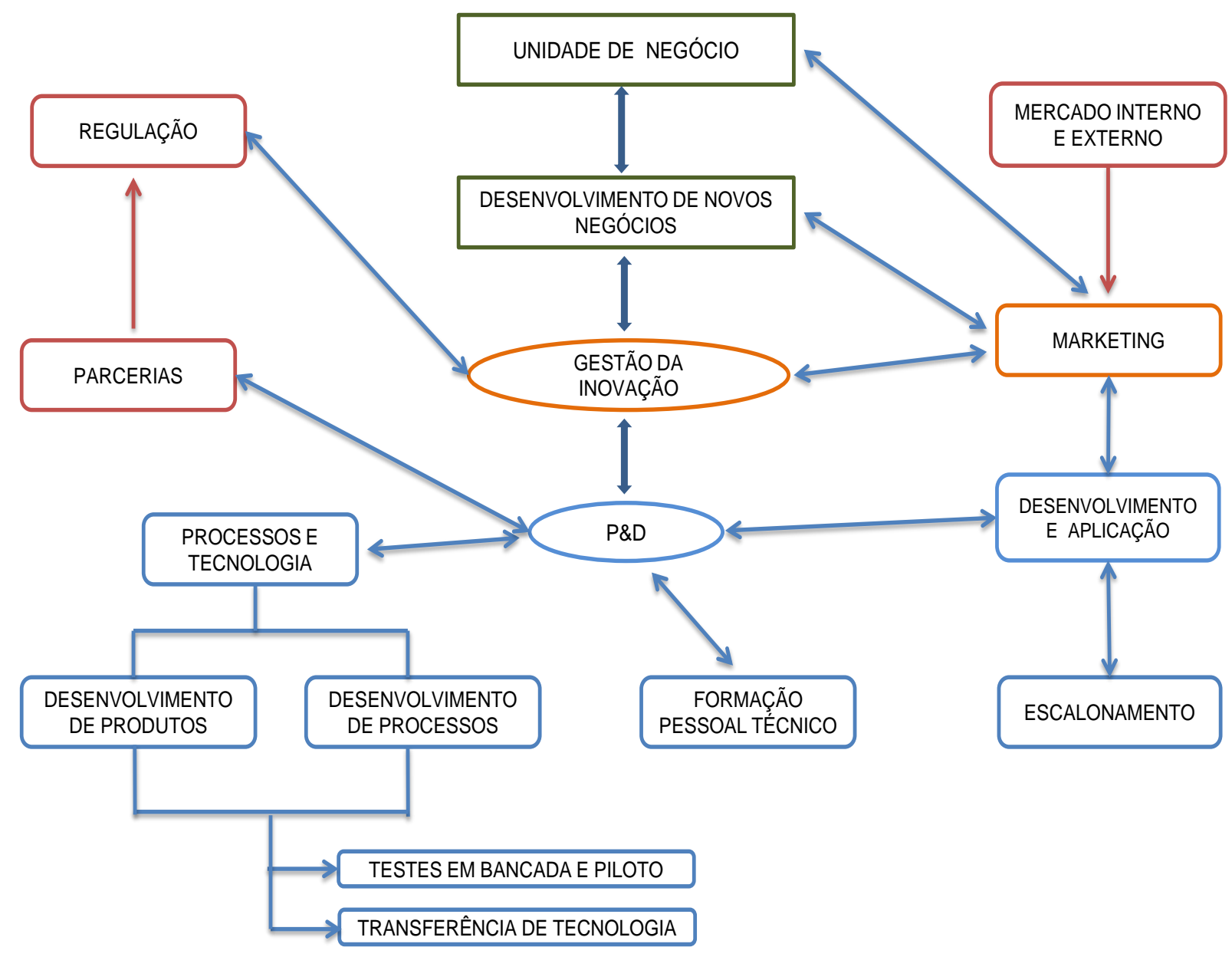

Figura 9 Macroprocesso de P\&D da Empresa A

Fonte: elaboração própria com base nas entrevistas

Há uma interdependência entre as áreas de conhecimento no processo de P\&D de inovações e uma divisão clara das atividades. O profissional de uma equipe não consegue fazer o trabalho do profissional da outra equipe, pois há competências diferentes.

\section{Competência relacional}

Em relação a esta competência, a área de marketing tem papel fundamental para a empresa, pois realiza as atividades de estudo e análise dos mercados e dos riscos mercadológicos, seja para produtos novos, para desenvolver um mercado para um produto já existente ou para estudar a viabilidade do lançamento de um produto em determinado mercado. As unidades de negócio dependem dessas competências de marketing 
A inovação aberta permitiu a formação de uma rede de cooperação para pesquisa e desenvolvimento de novas competências.

A empresa desenvolveu parcerias e interações com muitas organizações, principalmente como os Institutos de Ciência e Tecnologia (ICT's), universidades, fornecedores, instituições certificadoras e clientes. As interações com universidades são importantes ao promoverem a formação de novas competências em áreas mais de pesquisa básica e envolvem também a capacitação através de cursos promovidos pela universidade como em nível de pós-graduação. As universidades também têm o importante papel de formar e fornecer novos profissionais para as empresas. Muitos funcionários possuem mestrado completo e alguns possuem doutorado.

As principais parcerias da empresa com instituições de ensino mencionadas nas entrevistas são a USP, UNICAMP, UFRJ e instituições de outros países.

Os congressos e seminários também foram apontados como fontes de conhecimentos e contatos para as parcerias. Nestes congressos e também nas feiras, os profissionais identificam as novidades tecnológicas disponíveis no mercado e também avaliam as publicações das empresas concorrentes em que divulgam novos produtos ou tecnologias. O acompanhamento e controle de registro de patentes também é uma forma de avaliar as pesquisas dos concorrentes.

As interações com os clientes são muito importantes, pois geram ideias de possíveis melhorias nos produtos e novas demandas. A empresa ajuda os clientes a identificarem oportunidades no mercado de atuação dos mesmos e por isso devem ter conhecimentos sobre a indústria em que seus clientes atuam. A partir dessas interações, a empresa realiza os "fóruns de ideação" que são encontros para discutir possíveis novas ideias e muitas vezes os clientes são envolvidos nesses encontros. Segundo relato em entrevista, as dificuldades dos clientes podem virar oportunidades para que a empresa A desenvolva algo específico. Uma das práticas utilizadas pela empresa é a visita frequente aos seus clientes para captar as dificuldades e demandas.

A empresa possui centros de tecnologia em que os profissionais desenvolvem projetos voltados para o tema inovação e tecnologia, interagindo com licenciadores e 
desenvolvedores de tecnologia do país e do exterior. Na equipe há muitos engenheiros pesquisadores e pessoas especificamente de gestão. Estes profissionais detêm competências e conhecimentos específicos da área que os auxiliam na identificação de oportunidades ao participarem de feiras internacionais, congressos e outros eventos.

Internamente realizam ainda encontros em que colaboradores alocados no Brasil, mas também em outros países, trocam conhecimentos, pesquisas e informações, fundamentais para o desenvolvimento das competências. A partir desses encontros são gerados documentos e artigos que são disponibilizados internamente. A empresa permite a divulgação de algumas pesquisas em congressos científicos, após serem analisados os riscos da divulgação.

\section{Competência de negócios}

Uma forma encontrada pela empresa para captação de recursos e financiamentos, com o objetivo de reduzir os altos investimentos em P\&D, tem sido a contratação ou participação em editais que hoje estão mais organizados através do modelo Inova da FINEP. A FINEP vem organizando todas as empresas, universidades, ICTs e outras organizações que têm interesse e também competências em certos temas para que possam participar dos editais. Os editais facilitam a execução de um grande projeto, pois dividem as etapas e cada empresa ou instituição contribui com sua competência específica, além de ter uma redução nos investimentos necessários para todo o projeto completo do começo ao fim. Através dos editais é possível identificar oportunidades e parcerias para novos projetos, embora a questão da propriedade intelectual seja algo que ainda não está totalmente resolvido, depende da sinergia com o parceiro e por isso, conhecer os parceiros, os concorrentes é uma competência essencial.

Os acordos de cooperação com outras empresas também é uma forma de tornar mais eficiente e acelerar o processo de P\&D.

A empresa está dividida por unidades de negócio e estas unidades têm autonomia para definir contratos, operar acordos e parcerias, realizar P\&D e produção, porém há a área corporativa que consolida todas as informações para evitar conflitos de interesse no futuro e um comitê específico de inovação e 
tecnologia que analisa os projetos, os investimentos. As unidades de negócio têm competência para decidir se o escopo de um projeto pode e deve ser ou não ampliado, o que envolve as mudanças no cenário global e na demanda. Dessa forma tem um impacto no orçamento que deverá ser aumentado ou pode também diminuir, impactando no total de investimentos da empresa em P\&D por ano, que nos três últimos anos teve um crescimento considerável. Todas essas decisões são tomadas de maneira bem estruturada pela área corporativa, incluindo o uso de um software para a gestão dos projetos.

A empresa possui ainda uma área de gestão da inovação, que tem como atividades fazer a interface entre os objetivos estratégicos da empresa e os objetivos da área de P\&D, gerenciando os projetos em termos de orçamentos, custos, viabilidade. Esta área tem também o papel de identificar fontes para captar recursos e financiamentos públicos e privados para a $P \& D$ de inovações. A forma como estruturam a inovação depende de todos esses fatores e a área de gestão da inovação vem ganhando importância estratégica.

A gestão de portfólio é feita com vários processos que lhe dão suporte, ou seja, a inovação é feita de maneira estruturada.

\section{Competência de regulação}

A área jurídica da empresa faz toda a parte de regulação que envolve a formalização de contratos e licenciamentos, o controle e monitoramento da propriedade intelectual, o uso de patentes e licenças já existentes no mercado, a análise e controle de riscos dos projetos no aspecto jurídico como, por exemplo, buscar informações sobre o uso ou proibição de uma determinada matéria prima que será usada em cosméticos ou em alimentos, entre outros. Há uma busca e desenvolvimento de competências nesta área que também é um processo muito dinâmico.

A questão da propriedade intelectual é uma área que exige acompanhamento, principalmente nas parcerias com instituições públicas tais como universidades, pois o processo é mais complexo e depende de regras institucionais muito rígidas ou de uma legislação que rege as empresas públicas e que muitas vezes não atendem os 
interesses das empresas. O processo para fechar um contrato com a universidade ou com uma instituição pública é mais lento e afeta o cronograma dos projetos.

Um processo de subvenção, que também é utilizado pela empresa, engloba desde o lançamento do edital até a contratação final, sendo um processo de difícil estruturação e documentação, segundo um dos entrevistados. Pode levar até um ano para finalizar o processo e implica em aprendizado ou desenvolvimento de competências do jurídico, por todas as mudanças e especificações que têm que ser atendidas. A subvenção é dada apenas para uma parte do processo que é a pesquisa e depois para o escalonamento e etapa industrial, a empresa deve obter financiamento que envolve taxas de contratação.

Outro aspecto jurídico referente aos financiamentos diz respeito à propriedade dos projetos e no caso de financiamentos do BNDES ou FINEP, os projetos pertencem à empresa. Já nos projetos financiados pela FAPESP envolve parceiro tecnológico.

Os projetos realizados com as universidades também envolvem questões de propriedade intelectual, pois uma parte da pesquisa é da universidade e uma parte dos resultados poderá ser ou não de interesse da empresa ao final do projeto. Este fator gera incertezas no futuro e dificulta as parcerias.

A empresa vem aumentando o depósito de patentes, como forma de proteger as invenções, porém algumas invenções não são registradas para não detalhar o processo para os concorrentes. Algumas das inovações são protegidas através do sigilo interno.

\section{Competência organizacional}

A organização da empresa em rede integra a matriz com as unidades de negócio, de produção e centros de pesquisa, gerando um fluxo de informações e conhecimentos, alinhando as competências dos profissionais e garantindo que não haja perda de foco do negócio e das estratégias competitivas.

A empresa incentiva e promove o intercâmbio dos profissionais e visitas entre as unidades de negócios e demais áreas, como forma de disseminar o conhecimento e capacitar os colaboradores. A capacitação é feita prioritariamente 
com programas internos de desenvolvimento, mas a empresa também estimula os colaboradores a cursarem um MBA. A empresa difunde entre os colaboradores, o conceito de capacitação "pelo trabalho", ou seja, que as pessoas aprendam lidando com os problemas do dia a dia, com o líder de área fazendo o papel de educador. Incentiva também as visitas a outras instituições e empresas de diferentes países, como Alemanha, Canadá e Estados Unidos.

O quadro de pesquisadores da empresa é composto por engenheiros químicos, engenheiros de materiais, químicos, biólogos, bioquímicos e bioinformáticos. Cerca de $40 \%$ dos pesquisadores possuem título de graduação, mestrado ou doutorado e $60 \%$ são técnicos.

As parcerias com os ICT's também tem o intuito de promover a capacitação profissional, além de realizarem testes e pesquisas mais de longo prazo para projetos novos e radicais.

A empresa utiliza a estratégia de fazer aquisição de empresas que detêm conhecimentos e competências em áreas novas e que podem ser de interesse. Dessa forma, adquire know-how de forma rápida, além de incorporar os mercados atendidos por essas empresas que são adquiridas.

A empresa oferece grande reconhecimento aos pesquisadores, com possibilidades distintas de crescimento na carreira, além de motivar a pesquisa com premiações e bonificações. Há um projeto de implantação de um modo de premiação e reconhecimento das ideias dos colaboradores que virarem inovações e que tenham sucesso de lançamento no mercado, mesmo que o colaborador não faça mais parte do quadro de funcionários, uma vez que todo o processo demora um longo tempo para ser executado.

A mobilidade dos colaboradores é grande e uma unidade de negócios pode perder seu profissional para outras unidades de negócios ou mesmo para o mercado, como a grande perda hoje de profissionais que decidem trabalhar na Petrobrás. Devido a essa mobilidade e risco, uma estratégia utilizada pela empresa para registrar o conhecimento tácito e know-how dos profissionais, tem sido a técnica da filmagem das reuniões, workshops, seminários, encontros e outros eventos, que vem se tornando uma estratégia eficiente. 
Há carência de profissionais altamente qualificados no mercado de trabalho e uma forma de busca de novos profissionais é também através das interações e parcerias com outras instituições e com consultores estrangeiros, ou seja, o networking é uma forma eficiente para encontrar novos profissionais, segundo entrevistado.

\subsection{A Empresa B}

A empresa B é uma multinacional de grande porte, pertencente à cadeia petroquímica que opera na segunda geração da cadeia e possui unidades industriais no Brasil e no exterior, centros de P\&D no Brasil e no exterior e escritórios na América e Europa. Possui uma linha grande de produtos e uma das principais é a de oil \& gas. Entre seus clientes estão empresas da indústria de cosméticos, perfumaria \& higiene pessoal e produtos alimentícios. Uma das principais estratégias da empresa para obter know-how em novas áreas e ampliar mercado em outros países é a aquisição de empresas.

\subsubsection{Análise das competências organizacionais da Empresa B}

\section{Competência técnica}

A empresa estrutura seu processo de P\&D a partir da matriz, que define as estratégias competitivas, os investimentos a serem feitos e as rotinas para P\&D de inovações de produtos e processos. A matriz define as estratégias e as subsidiárias têm que seguir e aplicar o que foi determinado pela matriz. As subsidiárias têm autonomia operacional para a produção, seleção de fornecedores de tecnologia, escolha de sistemas gerenciais, escolha de equipamentos e de matéria-prima.

Os processos de P\&D de inovações estão formalizados e estruturados pela matriz, que controla as subsidiárias quanto aos orçamentos, custos e desempenho através de sistema integrado para maximizar o potencial de retorno dos projetos. As parcerias com outras organizações são formadas in loco, nos países onde estão situadas as subsidiárias e visam atender as demandas e o mercado locais, sem alinhamento com as demandas da matriz. 
A empresa possui unidades de P\&D de inovação no país e no exterior, com mais de 100 profissionais trabalhando diretamente nos laboratórios de P\&D. Desenvolve inovações de produtos, processos, tecnologia e também inovações incrementais de produtos, processos e tecnologia. Dos projetos de inovação, em torno de $70 \%$ são de inovações incrementais e de 20 a 30\% são inovações radicais de maior risco e de longo prazo.

A gestão dos projetos é feita pelo sistema em seis fases, começando com a fase zero que é o pré-projeto onde são definidas as bases conceituais, os objetos, as metas e o projeto passa para aprovação. Então inicia a fase 1 do projeto que é o desenvolvimento do produto, depois a fase 2 com a aprovação do cliente, fase 3 da implementação, fase 4 com o lançamento e fase 5 com a validação.

A empresa está dividida em três grandes áreas, uma dedicada a Home \& Personal Care, outra dedicada a Agrochemicals e a terceira dedicada a Mercados Industriais. Cada uma dessas áreas possui seu próprio gestor e seu laboratório de aplicação onde são reproduzidas as condições de testes e de desenvolvimento dos produtos dos setores. Cada área possui competências específicas para os diferentes produtos. Dentro da área de P\&D há outras áreas técnicas, as áreas transversais, que possuem expertises específicas e atuam de forma matricial com as áreas de negócios.

Uma dessas áreas transversais é a área de Desenvolvimento ou de P\&D de Processos, que é responsável pelo desenvolvimento dos produtos e produção na planta piloto e pela rota química. Estes profissionais desenvolvem competências que envolvem desde a concepção dos testes de bancada do início da rota, até o escalonamento da tecnologia, que é o momento em que se implementa na planta e acompanha as primeiras produções. A maioria desses profissionais é composta por químicos e engenheiros e estão divididos por tecnologia. Cada um dos profissionais desenvolve conhecimentos e competências em uma determinada tecnologia. Uma tecnologia pode ser aplicada a diversos segmentos, então um pesquisador atua matricialmente em projetos com a área de agro, de higiene pessoal ou com a de mercados industriais. 
Outra área transversal é a área Analítica em Qualidade que é composta por especialistas em pesquisas analíticas e técnicas sofisticadas para análise das reações dos produtos, das composições, da concentração dos contaminantes e propriedades físicas dos materiais. Estes profissionais realizam também os procedimentos de qualidade ligados a desenvolvimento e possuem um laboratório especializado para desenvolver o trabalho.

A terceira área transversal é a área de Assuntos Regulatórios que é composta por especialistas em assuntos regulatórios referentes aos produtos químicos. Estes profissionais acompanham a legislação relacionada aos produtos e à aplicação deles e é um trabalho feito por área geográfica do mercado de clientes, uma vez que a legislação muda de um país para outro. Esta área dá suporte à área de P\&D e é um fator crítico para o desenvolvimento de produtos. Quando há um projeto de novo produto é feita uma pesquisa regulatória sobre a legislação a ser atendida e possíveis restrições, antes de dar continuidade ao projeto. Os clientes querem garantias de que o produto da empresa não contém determinados contaminantes e que atendem a legislação específica que muda constantemente e sofre atualizações, por pressão dos consumidores e de ONG's. Além das atividades relacionadas aos projetos, esta área realiza ainda um trabalho de inteligência estratégica, em que fazem análise de tendências em relação ao que está sendo discutido nas ONG's e que ainda não virou lei ou em relação às restrições das empresas que deixam de usar determinados componentes e ainda, análises sobre riscos e oportunidades dos produtos da empresa. Todas essas informações servem de base para o planejamento estratégico. Os profissionais têm formação em química e engenharia química principalmente, mas há também alguns agrônomos, biólogos e farmacêuticos.

Uma última área transversal é a área de Observatório da Inovação que faz prospecção tecnológica para identificar o que está sendo desenvolvido e o que já existente de patentes no mercado e as publicações na literatura. Estas informações servem de base para a estratégia de inovação das áreas. Esta área também faz a busca de fontes de financiamentos, a gestão e intermediação dos contratos desses financiamentos, as contratações de projetos e prospecção tecnológica. $O$ macroprocesso de P\&D da Empresa B é apresentado na figura 10: 


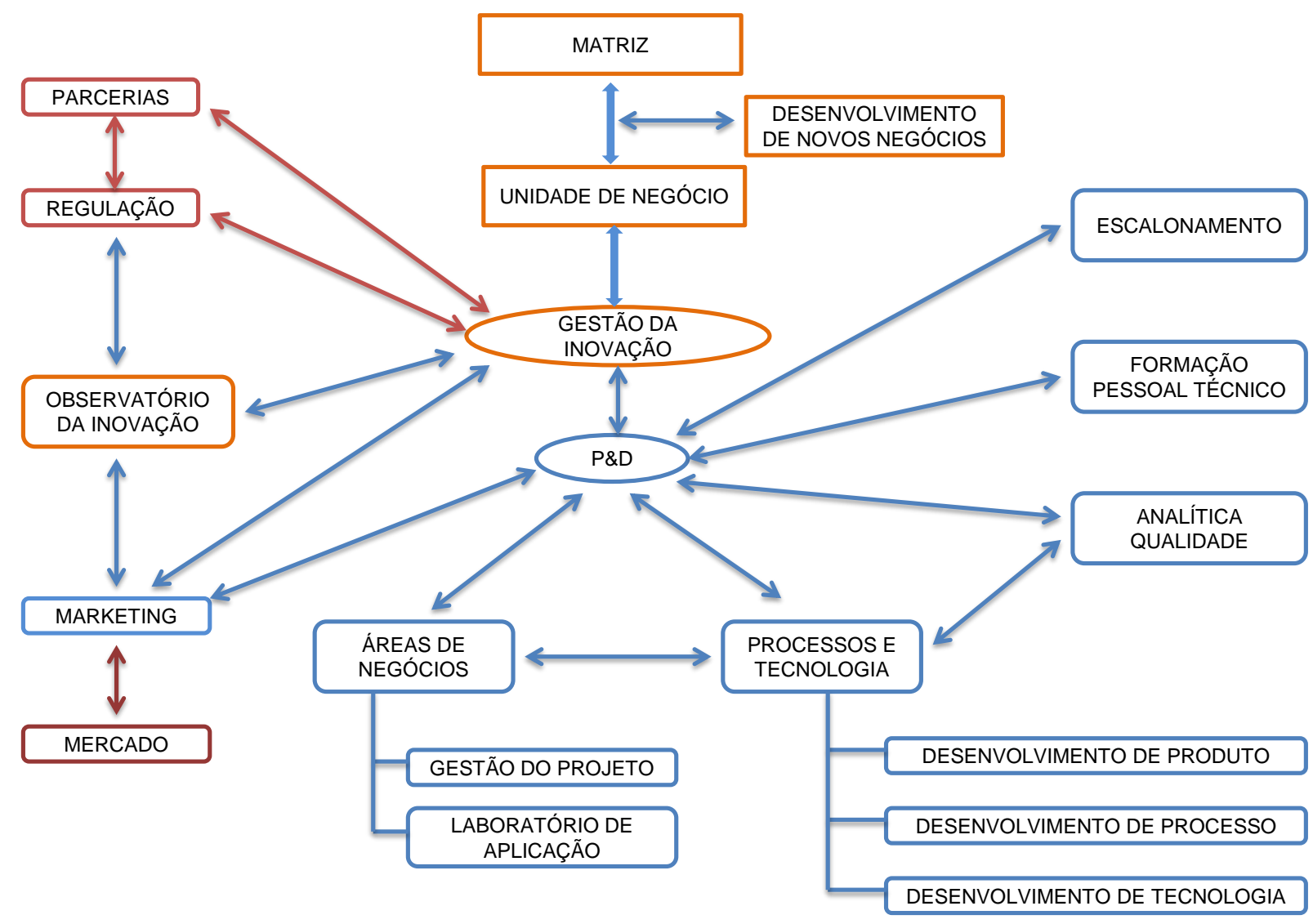

Figura 10 Macroprocesso de P\&D da Empresa B

Fonte: elaboração própria com base nas entrevistas

\section{Competência relacional}

A área de Observatório da Inovação desenvolve muitas competências relacionais como relatado anteriormente, ao realizar análise das patentes e produtos dos concorrentes.

A busca de novas ideias ocorre de duas formas, a partir das necessidades dos clientes levantadas pelas visitas técnicas, denominada "outside in" e a partir das atividades de P\&D interno incluindo informações da área de Observatório, denominada "inside out". Quando este projeto está bem desenvolvido, buscam os clientes potenciais para este novo produto ou solução. Desenvolvem ainda inovações de processo, pois têm que reduzir os custos das inovações de produto. 
Além do atendimento contínuo aos clientes para captar novas ideias, a empresa vem consolidando sua rede global de P\&D e buscando captar as ideias e soluções que surgem das demandas dos clientes das outras unidades do exterior. Dessa forma, a estrutura da empresa vem aumentando para consolidar essa atuação no âmbito internacional.

Os profissionais participam de congressos, encontros e outros eventos, para apresentar artigos, fazer novos contatos, captar ideias e buscar novos conhecimentos.

Outra fonte de captação de ideias apontada pelo entrevistado é a consultoria externa. Além da consultoria, a empresa recebe informações de tendências para a P\&D de inovações, de especialistas que fazem parte do Conselho de Ciência e Tecnologia. Entres os especialistas estão cientistas, ex-executivos de grandes empresas e pessoas que trabalharam em P\&D. Estes profissionais são fontes muito importantes não só de ideias, mas para validação e aferição dos projetos indicando possíveis falhas.

As parcerias com universidades não são consideradas fontes relevantes de ideias, pois normalmente a empresa busca colaboração da universidade quando já tem um projeto e precisa de uma competência que não possui internamente para aprofundar e solucionar um problema. A empresa pode contratar o serviço, a consultoria ou realizar um debate apenas com pessoas da universidade. A empresa busca colaboração de várias universidades do país e algumas do exterior e também do IPT, do INT e do SENAI. Normalmente a empresa realiza um projeto de cooperação externa quando não domina uma expertise necessária na área do projeto. Como os produtos químicos têm aplicação em diferentes indústrias como de alimentos e de higiene \& cosméticos, são necessários conhecimentos em outras áreas como, por exemplo, da biologia, agronomia e botânica. A cooperação ajuda a complementar o conhecimento nos assuntos em que a empresa não tem domínio e também porque não seria eficiente montar uma estrutura interna e um laboratório especializado de alto custo para atender essas demandas. Isto ocorre, por exemplo, na área de agroquímicos, em que são necessários testes em fazendas experimentais e ter toda uma estrutura de alto investimento em uma área que não é 
o core business da empresa. Isto já se justifica para uma empresa da agroindústria, que precisa ter necessariamente as competências desenvolvidas internamente.

Alguns clientes possuem essas competências específicas e podem ajudar, mas não é comum, pois a empresa quer ter independência e autonomia em suas pesquisas e projetos até chegar num nível tecnológico e os clientes querem dirigir as pesquisas para seus próprios interesses que diferem um pouco dos interesses da empresa. É um tipo de parceria não muito consolidada e que ocorre quando é para atender uma demanda do próprio cliente.

\section{Competência de negócios}

O planejamento estratégico é elaborado pela matriz e depois transmitido às subsidiárias que devem fazer a implementação dos objetivos, segundo as determinações da matriz. A matriz faz o controle da implementação estratégica de suas subsidiárias.

A empresa não tem uma área específica de gestão da inovação e por isso todas as áreas estão envolvidas na gestão, com atividades e funções definidas dentro do processo.

Quanto às fontes de financiamentos das atividades de inovação, um dos modelos adotados é o da FINEP, que é uma parceria realizada há pelo menos 9 anos. Atender estas chamadas é um processo complexo, segundo relato de um entrevistado, porque exige que a empresa atenda uma área temática de pesquisa e forme parcerias com universidades num período curto de tempo. Outra fonte utilizada é a Lei do Bem, em que a empresa obtém redução dos impostos sobre as atividades de P\&D. A empresa criou sistemas de coleta e controle de dados para apresentar à auditoria se for necessário comprovar os gastos efetivos da empresa com P\&D, por exemplo, materiais, equipamentos ou horas de treinamento de pessoal. Segundo o entrevistado, a Lei do Bem proporciona um ganho considerável que ajuda a empresa a inovar mais, impulsionando as pesquisas e estimulando os investimentos para ampliar a estrutura. Em um ano, a empresa ampliou em 40\% a estrutura em pessoas e equipamentos, segundo um dos entrevistados. 
Outros tipos de fomentos utilizados estão relacionados a projetos como o da EMBRAPII, a empresa de tecnologia que o governo está criando e dessa forma dá um aporte de recursos, outro aporte é dado pela INT e a empresa paga 1/3 do projeto. Outro modelo já utilizado foi o PITE da FAPESP, que financia projetos de pesquisa desenvolvidos em colaboração com universidades e institutos de pesquisa no Estado de São Paulo. Os projetos com FAPESP têm mais flexibilidade temática, mas por outro lado, só cobre o Estado de São Paulo e se a empresa tem centros de expertises que não estão no Estado fica mais difícil para consolidar a parceria, o que não ocorre com a FINEP que cobre a área de todo o país.

A empresa tem também um financiamento Fundep do BNDES para um projeto disruptivo de alto risco tecnológico desenvolvido em cooperação com a universidade, que é uma regra do BNDES para financiar o projeto, embora a universidade não tenha cultura para projetos de desenvolvimento de produto de escalonamento. Este é um tipo de financiamento que o país dispõe para financiar projetos de alto valor e de alto risco tecnológico, mas é o único existente no Brasil, sendo que no exterior há outras opções e é mais fácil de obter este tipo de financiamento. Este é um problema de escalonamento denominado "vale da morte", justamente pela pior relação entre risco e investimento, quando a empresa tem que construir praticamente uma planta industrial para um projeto cheio de incertezas. Neste sentido, um aporte governamental ajuda a reduzir o risco e depois há um retorno desse aporte, então é um modelo que funciona hoje no país.

Segundo relato de um dos entrevistados, as regras de funcionamento das instituições variam muito e impactam na formação das parcerias e na cooperação, inviabilizando os projetos em alguns casos.

Segundo o entrevistado, a empresa acaba não recorrendo muito às universidades para cooperar em projetos, porque muitas possuem estatutos e regras que são muito defensivos inviabilizando a cooperação. Outro ponto que emperra a cooperação com a universidade é a questão da propriedade intelectual, pois a universidade pode participar da pesquisa de uma inovação, mas essa é apenas uma das primeiras etapas do processo até chegar às etapas de escala e produção industrial, que envolvem grandes investimentos e custos altos, além de alguns 
riscos. É justo que a universidade tenha uma participação nos lucros após venda do produto no mercado, mas o risco maior é sempre da empresa, que tem que ser remunerada e ter retorno de seu investimento. Há algumas parcerias com instituições de ensino e pesquisa no exterior para pesquisa de novas tecnologias e produtos. Nos últimos anos, a empresa ampliou em mais de $20 \%$ o seu portfólio através de pesquisas de inovação.

Os investimentos em P\&D são da ordem de $1 \%$ do faturamento e no mercado químico oscila de $0,5 \%$ a $3 \%$ dependendo da empresa.

\section{Competência de regulação}

A competência de regulação está muito centralizada e desenvolvida na área de Assuntos Regulatórios, dada a natureza dos produtos químicos gerados pela empresa que já envolve riscos de produção, aplicação e de consumo final, tendo legislação específica e determinada pela área geográfica de localização das unidades. A atividade de inteligência estratégica também permite reduzir os riscos dos projetos e do lançamento dos produtos no mercado, uma vez que procura antecipar os futuros problemas e proporcionar ajustes nos projetos.

O monitoramento da propriedade intelectual e da imitação é feito pela área de Observatório da Inovação que faz a busca e controle de patentes existentes no mercado. Esta área também faz a gestão e intermediação dos contratos de financiamentos da inovação.

As parcerias e contratos de cooperação sempre envolvem a questão da propriedade intelectual e geralmente é mais difícil entrar em acordo com as universidades e instituições de pesquisa. As empresas são mais flexíveis na definição da propriedade e da participação nos projetos. Cada projeto tem especificidades e acaba gerando um modelo diferente de cooperação, com acordos e critérios de participação diferentes. Se a empresa já tem a patente, por exemplo, no projeto já fica definido quem tem maior participação nos resultados. Algumas empresas também são muito defensivas e prejudicam as parcerias.

A definição da participação é bastante complexa porque as empresas negociam sobre um valor potencial e se a empresa tem somente uma ideia "bruta" 
fica difícil estabelecer o valor, pois vai depender do projeto. As empresas utilizam os valores investidos no negócio, mas se uma delas teve a ideia, o valor é muito maior então a negociação é muito complexa e sem a ideia não se tem o projeto.

A empresa vem aumentando a quantidade de patentes por ano; produzia anteriormente uma média de 2 a 3 patentes por ano e, no momento da pesquisa, produzia de 5 a 6 patentes por ano, muitas de nível internacional.

A área de Assuntos Regulatórios controla também a negociação das taxas de coparticipação e de intermediação, com as instituições e empresas, uma vez que variam bastante e têm impactos nos custos dos projetos. Algumas instituições chegam a cobrar até $20 \%$, que é uma taxa de administração alta e reduz o valor final da pesquisa. As instituições acabam definindo os valores e é difícil negociar.

\section{Competência organizacional}

A Empresa B faz aquisição de empresas que possuem conhecimentos e competências em áreas de interesse e também busca adquirir matérias primas novas.

Há troca de conhecimentos e informações nas unidades locais e cada unidade faz a gestão dos recursos humanos, proporcionando treinamento e integração dos profissionais. A empresa investe muito em treinamento dentro e fora do país e em viagens para que os profissionais participem de feiras, congressos e outros eventos diversos. Os profissionais realizam visitas às outras unidades fora do país para conhecerem os processos e projetos, com intuito de aproveitar estes conhecimentos e competências para aplicar em outros mercados.

O quadro de profissionais vem aumentando e de um ano para outro teve aumento de 40\%, para acompanhar o crescimento da empresa que também foi alto, incluindo novas aquisições.

A oferta de profissionais com experiência de pesquisa na área química está muito fraca no país e a empresa tem dificuldades para encontrar esses profissionais. A estratégia da empresa tem sido contratar recém-formados nas universidades e capacitá-los internamente. Dentro da empresa estes profissionais têm uma carreira em $\mathrm{Y}$ e em determinada fase da carreira podem optar em seguir carreira de 
pesquisador ou, se tiverem vocação, carreira de gestor técnico, com forte experiência e conhecimento de tecnologia e de gestão tecnológica. Há certo status na carreira gerencial, mas nem todos querem seguir essa opção, somente aqueles que têm vocação para a gerência, para coordenar e motivar equipes, para desenvolver pessoas e lideranças, contatos etc. Em termos salariais não há muita diferença entre a carreira de pesquisador e a de gerente, são as mesmas grades.

\subsection{A Empresa C}

A empresa $\mathrm{C}$ é uma filial brasileira de uma multinacional norte-americana do ramo químico e petroquímico, fabricante de plásticos e intermediários para a indústria automotiva. A multinacional possui unidades industriais em mais de 30 países, onde estão também seus principais clientes. A empresa tem seu foco em tecnologia, inovação voltada para aplicações e na excelência em operações.

A empresa fabrica mais de 200 produtos com foco global e empregava até a data da pesquisa no final de 2011, em torno de 2.000 funcionários. Seus produtos são fornecidos para indústrias de dispositivos médicos, iluminação, automotiva e outras. A unidade em que foi conduzido o estudo de caso possui um dos laboratórios de P\&D da empresa e nessa unidade estão localizadas também as áreas de logística e suporte técnico ao cliente, produção, manutenção e controle de qualidade. Esta unidade fabrica polímeros de engenharia (tipos de polipropilenos) que são matérias-primas já coloridas utilizadas na produção de peças para carros e tem grande importância na estratégia de negócios de duas grandes áreas da empresa, a de plásticos e a automotiva. Além dos polímeros, os produtos da empresa incluem resinas de estireno, borracha sintética e látex.

A equipe de P\&D nesta unidade era composta por 10 profissionais, sendo 4 voltados para um tipo de produto e os demais para outro produto. No total havia mais de 70 funcionários alocados nos laboratório de $P \& D$, dispersos por diferentes países na Ásia, Europa e Américas do Norte e do Sul. Os pesquisadores tem formação em engenharia química, engenharia de materiais e bacharelado em ciências. 


\subsubsection{Análise das competências organizacionais da Empresa $\mathrm{C}$ \\ Competência técnica}

Os clientes são fontes importantes de novas pesquisas e ideias e a empresa possui dois funcionários que atuam junto aos mesmos buscando novos projetos $\mathrm{e}$ também junto à área comercial. Os dois funcionários que trabalham internamente dão suporte de análise dos produtos, realizam testes, averiguação quanto aos requisitos do cliente e aplicação final.

Os cinco funcionários que atuam junto aos clientes são responsáveis pela negociação com os clientes, pela análise financeira e pela elaboração do protótipo. Grande parte da pesquisa é feita no cliente e os demais funcionários trabalham diretamente nas plantas dos clientes. Quando surge uma ideia de novo produto, estes funcionários levantam todos os detalhes e especificações junto ao cliente, antes da entrada como um novo projeto na Empresa C. O cliente tem as competências e a estrutura para iniciar as pesquisas em suas plantas, então quanto o projeto entra na Empresa $C$ já está em etapa avançada. $A$ equipe de $P \& D$ tem uma rotina pesada de ajustes da inovação para adequar aos requisitos do cliente, por exemplo, a formulação de uma nova cor para impressão de embalagens dos produtos de um cliente da indústria de produtos de limpeza. Se surge algum problema, a empresa faz uma checagem detalhada no processo junto ao cliente e quando surge uma dificuldade mais específica, a equipe global de pesquisa é acionada (esta equipe é composta por mais de 30 pesquisadores dedicados exclusivamente para soluções técnicas e pesquisa). Este grupo é acionado somente se não há exigência de prazo, pois pode gerar um atraso no processo de produção. Outra solução mais utilizada pela empresa são as reuniões envolvendo os denominados "focal-points" regionais de cada área da empresa, que são profissionais de diferentes áreas, tais como líderes de produção, de qualidade, de logística, etc. Nestas reuniões, os profissionais conseguem solucionar a grande maioria dos problemas mais complexos e são extremamente direcionados para a solução rápida dos problemas, segundo o entrevistado.

A gerência da unidade está subordinada à diretoria global de pesquisa e todas as ações em P\&D têm que ter aval dessa diretoria. Além da diretoria de 
pesquisa, a empresa possui ainda a diretoria de tecnologia que centraliza as inovações nessa área.

Os projetos são coordenados em reuniões mensais com o líder da área e as equipes têm total autonomia no trabalho, pois a equipe implantou o empowerment na empresa e reduziu o número de líderes necessários. Os membros das equipes da unidade cooperam na execução das tarefas, mas globalmente há competição entre as equipes de outras áreas geográficas e outros negócios. O macroprocesso de P\&D da Empresa $C$ é apresentado na figura 11:

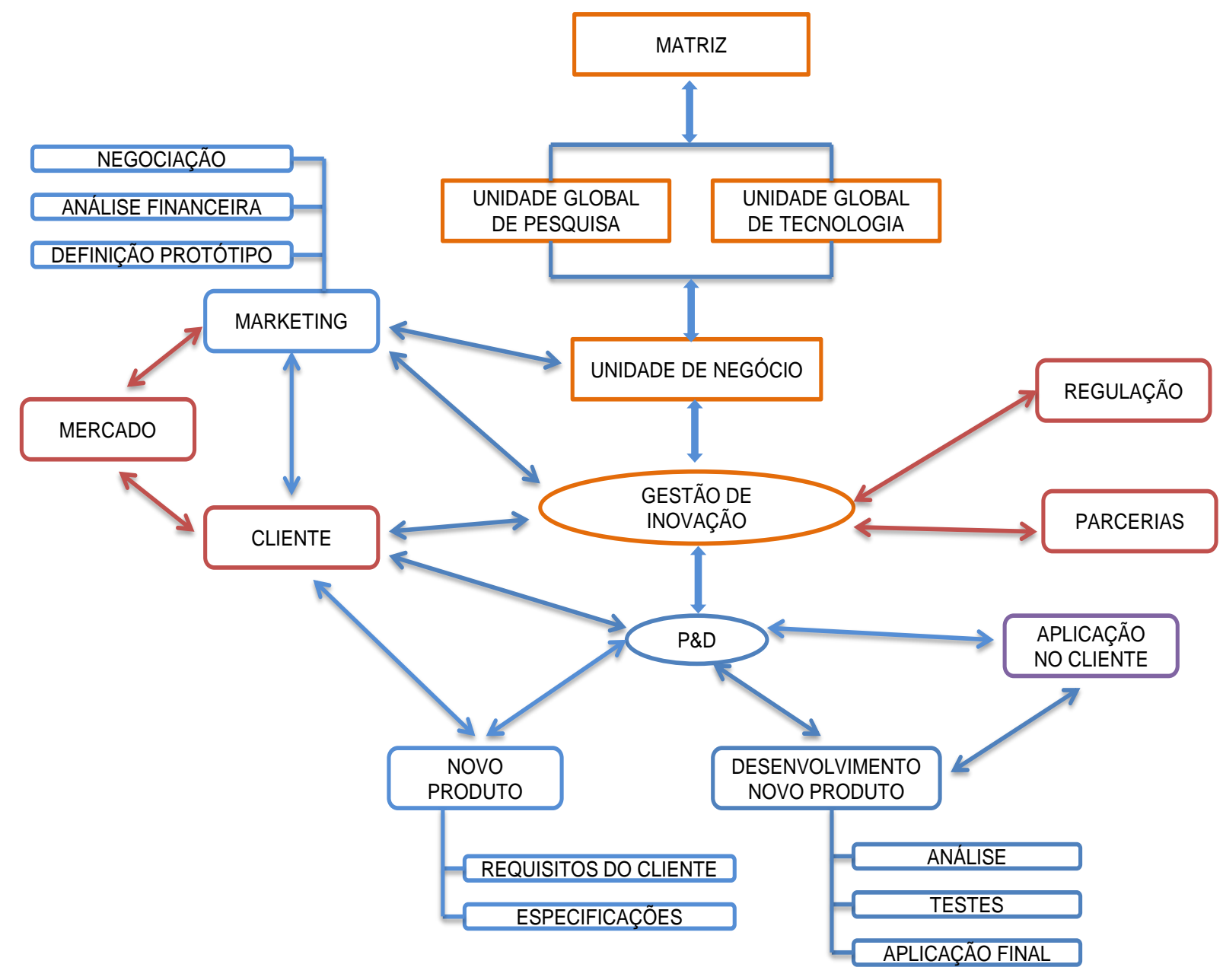

Figura 11 Macroprocesso de P\&D da Empresa C

Fonte: elaboração própria com base nas entrevistas 
Internamente há também prestadores de serviço, como na área de suporte a projetos, que trabalham diretamente na planta.

\section{Competência relacional}

A empresa possui parcerias com instituições de ensino e pesquisa, tais como Universidade Federal de São Carlos, Universidade de São Paulo, IPT, SENAI, entre outras. Estas parcerias são utilizadas para diferentes testes exigidos pelo cliente no projeto ou durante o desenvolvimento do produto, como forma de reduzir também os custos com equipamentos, se a empresa tivesse que fazer a aquisição. Estas parcerias são formadas no longo prazo, envolvendo confiança mútua e checagem dos resultados inter-laboratoriais. As informações geradas são retidas internamente na empresa e tudo é tratado confidencialmente, exceto quando envolve ganho comercial e então fecham um acordo entre as partes. Os pesquisadores podem gerar inovações, mas a patente é da empresa e eles assinam acordo de compromisso sobre esta questão quando são admitidos na empresa. O entrevistado estava cursando mestrado na época desta pesquisa e o resultado seria um produto que poderia ser comercializado pela empresa. Neste caso ele iria negociar a propriedade, pois a inovação foi gerada fora do ambiente da empresa.

As parcerias com os clientes também são muito importantes, pois é uma forma de acompanhar as inovações que são geradas nos setores de atuação dos clientes. Um exemplo é a parceria com um cliente do setor automotivo, que utiliza a engenharia assistida por computador (CAE) para otimizar os projetos. As simulações podem ser usadas para analisar o comportamento dos materiais e de suas modificações, de forma a atender as especificações dos clientes, como a atual necessidade de redução do peso dos veículos. Desta forma, as inovações nos clientes também impulsionam as mudanças e inovações na Empresa C.

A colaboração com os clientes possibilita o acompanhamento das tendências técnicas e as áreas de marketing, vendas e desenvolvimento trabalham cooperativamente para gerar novas ideias. Os serviços prestados aos clientes envolvem o desenvolvimento de protótipos virtuais construídos através o uso da engenharia assistida por computador. Realizam simulações e modelagens que são aplicadas no design do conceito, na otimização do produto e na parte mecânica. $O$ 
uso da prototipagem virtual pela equipe permite que realizem simulações estruturais e de processo, conseguindo definir parâmetros de processo e aplicações para os materiais e realizar demonstrações do produto final.

Há uma equipe que desenvolve inovações e soluções para cores a serem aplicadas nos plásticos e que podem ser usadas em outras unidades de negócio. Esta equipe trabalha em cooperação com outras áreas da engenharia e consegue incluir outras soluções personalizadas aos produtos, como por exemplo, fazer uma simulação virtual de texturas do produto. Desta forma, possuem um portfólio grande de cores e criam conceitos em parceria com projetistas. As alternativas de compostos prontos ou personalizados e resinas coloridas visam redução de custos de estoque, de prazo de entrega e também agilidade de entrega do produto final fabricado pelo cliente.

\section{Competência de negócios}

A maioria dos projetos é de inovações incrementais de produtos e geralmente são alteradas a cor ou algumas propriedades do produto para adaptação aos processos dos clientes. São lançados aproximadamente 20 produtos novos por ano, mas existem projetos que levam até 2 anos para serem lançados e os prazos são determinados pelo próprio cliente, por exemplo, no lançamento de um novo modelo de automóvel que terá aplicação de um tinta especial nas partes plásticas desenvolvidas com material da Empresa C.

A empresa incentiva a busca por inovações e estimula o registro das patentes como forma de proteger as descobertas. As principais fontes de ideias são os clientes e os fornecedores, segundo entrevistado. Seus clientes estão em diferentes setores industriais, tais como construção civil, automotiva, eletrodomésticos, eletroeletrônicos, embalagens, produtos médicos e outros.

A empresa participa de joint ventures e parcerias com empresas fornecedoras em outros países, como forma de ampliar a capacidade de produção e expandir geograficamente seu mercado consumidor, sendo o setor automotivo seu principal mercado estratégico. Outra estratégia que a empresa vem utilizando para ampliar o mercado é a seleção e aquisição de empresas estratégicas para os seus negócios. 


\section{Competência de regulação}

As competências de regulação são centralizadas na área jurídica da empresa com advogados e consultores jurídicos, que formalizam e controlam contratos de prestação de serviço, parcerias, joint ventures, além de fazerem monitoramento da propriedade intelectual e das patentes e acompanharem os segredos industriais da empresa. As inovações e patentes registradas são de propriedade da empresa e não do funcionário que fez, por exemplo, uma composição de um novo material plástico.

A área jurídica faz acompanhamento de legislação específica da área de atuação da empresa, como por exemplo, a legislação sobre eficiência de combustível e emissão de poluentes, afetando indiretamente a empresa que precisa adaptar e melhorar seus produtos de forma que o cliente atenda as especificações da legislação. Esta área deve conhecer também a legislação que regulamenta o comércio internacional e as leis americanas que restringem a venda de produtos $\mathrm{e}$ tecnologia para determinados países, uma vez que a empresa é de origem norteamericana e atua globalmente.

\section{Competência organizacional}

Como a equipe de P\&D da unidade é pequena, não possuem um coordenador responsável e a coordenação das atividades dos profissionais é ditada pelos próprios prazos impostos pelos clientes e depende da urgência de cada projeto.

A divulgação de parte das informações e descobertas é feita em revistas técnicas da área química e também em congressos e conferências da área de negócios como a Conferência Anual do Setor Automotivo, mas como os produtos atendem geralmente nichos determinados, nem tudo pode ser divulgado e há o controle da propriedade pelo cliente e pela empresa.

A busca de informações e conhecimento sobre produtos, serviços e preços é feita em meios públicos disponíveis, como artigos publicados, análises de mercado e relatórios. 
A empresa possibilita a transferência de seus funcionários entre as demais unidades localizadas no Brasil e em outros países e para isso, disponibiliza na intranet as oportunidades de trabalho que surgirem para que todos os interessados que detenham as competências requeridas para as vagas possam participar dos processos de seleção. A empresa não considera que a mobilidade possa gerar concorrência entre as unidades e áreas.

A capacitação e treinamento são incentivados pela empresa, tanto através de cursos internos disponíveis on-line ou promovidos pelos gestores, quanto na realização de pós-graduação como mestrado e doutorado nas instituições de ensino do país.

\subsection{A Empresa D}

A empresa $D$ é uma farmacêutica brasileira de grande porte que fabrica e exporta matérias primas para mais de 30 países e medicamentos genéricos para neurologia, psiquiatria, cardiologia, ginecologia, oftalmologia, dermatologia, entre outros. A empresa produz ainda moléculas em diversas formas farmacêuticas

A empresa possui quatro unidades fabris no país e um centro de pesquisas composto por mais de 100 pesquisadores, sendo que mais da metade possui pósgraduação em nível de doutorado e pós-doutoramento.

O centro de P\&D recebeu grandes investimentos desde 2009 para ampliar a estrutura e centralizar todo o processo de P\&D de medicamentos. Possui parcerias com diferentes instituições de pesquisa, universidades, agências governamentais e profissionais de saúde.

Em relação ao panorama da indústria farmacêutica nacional, diferentes autores apontam que ela não tinha uma cultura de investir em atividades de P\&D de fármacos e medicamentos, concentrando as atividades apenas nas últimas etapas do processo dentro da cadeia farmacêutica. Nos anos 1970 e 1980 foram implantadas políticas governamentais na tentativa de reduzir a dependência das importações de insumos farmoquímicos, visando internalizar no país as atividades 
de P\&D e produção de fármacos e medicamentos. Somente a partir da década de 1990, com algumas mudanças institucionais é que as empresas iniciam algumas atividades mais científicas e tecnológicas na área farmacêutica, uma das áreas consideradas de elevado conteúdo científico e muito desenvolvida em outros países (URIAS, 2009; ANDRADE,2010).

A cadeia produtiva farmacêutica é dividida em indústria de farmoquímicos e indústria de medicamentos. As empresas produtoras de farmoquímicos, uma especialização da indústria de química fina, possuem fortes competências tecnológicas. A indústria farmacêutica mundial é intensiva em capital e ciência (Science based) (CAPANEMA; PALMEIRA FILHO, 2006).

O setor de química fina engloba a produção de produtos de maior valor agregado do que os da indústria química de base, denominados intermediários ou especialidades. A maioria das empresas brasileiras da indústria farmacêutica sempre importou matérias-primas e desenvolveu apenas a etapa de formulação farmacêutica enquanto que as multinacionais sempre foram muito verticalizadas, atuando em toda cadeia, desde a P\&D de matérias-primas, formulação e marketing (BERMUDEZ, 1994).

As economias centrais controlam $80 \%$ do mercado mundial de remédios e produtos de medicina e o Brasil é o $14^{\circ}$ exportador de remédios e outros produtos de saúde, controlando $0,5 \%$ do mercado mundial.

O cenário atual aponta que ainda predominam as importações de produtos acabados, com importação de US\$ 3,590 bilhões de medicamentos acabados em doses, contra o valor de US $\$ 897$ milhões no ano de 2003, um valor quatro vezes menor (ABIFINA, 2013).

\subsubsection{Análise das competências organizacionais da Empresa D}

\section{Competência técnica}

O processo de P\&D de inovações da empresa é bem internalizado, se comparado com outras empresas nacionais do setor, mas depende muito de parcerias externas por ser um processo bastante complexo, que exige competências 
e conhecimentos diversos em várias áreas, como biologia, medicina, química, física, farmácia, engenharia, biotecnologia entre outras.

Na figura 12 são apresentados os estágios da cadeia produtiva farmacêutica e cada estágio envolve questões jurídicas, econômicas e éticas, por envolver seres humanos.

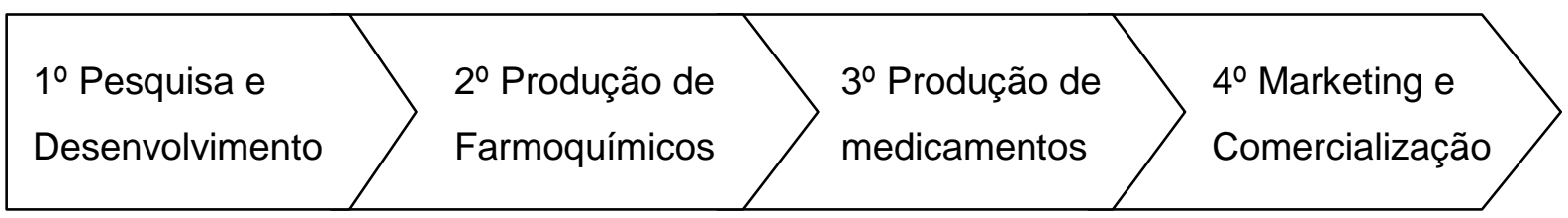

Figura 12 Estágios da cadeia produtiva farmacêutica

Fonte: Capanema e Palmeira filho (2006)

O processo de P\&D de medicamentos da empresa segue dois modelos um pouco diferentes, um em que a empresa desenvolve o projeto internamente e em alguma fase do processo busca parcerias ou cooperação com universidades e institutos de pesquisa, outro em que pesquisadores das universidades procuram a empresa com um projeto, o desenvolvimento passa a ser feito na empresa e o pesquisador tem o apoio da empresa para continuar a fase de descoberta, pois necessita de vários testes de mecanismo de ação. Neste modelo, o pesquisador faz um projeto de desenvolvimento acadêmico com a empresa e a empresa fornece materiais, pessoal e empresta os equipamentos, para que o pesquisador desenvolva seu projeto. Neste caso, o pesquisador trabalha nas atividades de pesquisa e descoberta e a empresa realiza as atividades de desenvolvimento. Dessa parceria saem um ou mais pedidos de patentes e a empresa vem aumentado o depósito de patentes a cada ano, outro diferencial para uma farmacêutica de capital nacional.

Ao longo do tempo, a empresa conseguiu internalizar a cadeia completa de medicamentos e no momento atual consegue executar a concepção do projeto, o desenvolvimento do princípio ativo farmoquímico ou biotecnológico, a prospecção da propriedade intelectual e industrial, os estudos de estabilidade, os testes, a fabricação e a comercialização do produto no mercado. As parcerias externas com 
universidades e institutos de pesquisas são fundamentais nas pesquisas de novos princípios ativos, mas a empresa mantém laboratórios equipados e bem estruturados, com equipe composta por diferentes profissionais para gerar pesquisas de ponta. Destaca-se o investimento da empresa na área de biotecnologia, uma competência importante que as farmacêuticas vêm buscando desenvolver para realizar análises moleculares.

Segundo relato de um entrevistado, as parcerias nesta empresa não são apenas acordos comerciais, mas oportunidades para melhorar o trabalho, trocar conhecimentos e experiências para enriquecer as competências em áreas diversas e necessárias para a cadeia produtiva. Esta empresa difere das demais, que se preocupam com direitos de propriedade, participação nos lucros e royalties, pois a Empresa $\mathrm{D}$ dá todo apoio jurídico para que o pesquisador proteja sua descoberta, entrando com pedido de patente. Na área farmacêutica, a patente é muito importante, tanto pelos altos investimentos envolvidos, quanto pelo longo tempo até que a empresa consiga lançar e comercializar o novo medicamento.

A empresa fabrica princípios ativos para produzir medicamentos novos e genéricos, através de parcerias com centros de pesquisa realiza estudos clínicos, exigidos para que os medicamentos sejam aprovados. Esta é uma competência que poucas empresas possuem no país e têm que recorrer a ensaios clínicos multicentros, ou seja, em diferentes países, em centros certificados com protocolo internacional, esse padrão é uma exigência na área farmacêutica. É um processo que exige altos investimentos e que aumenta o custo do medicamento. A empresa tem que contratar alguns dos serviços referentes a testes clínicos de laboratórios especializados e como há poucos no Brasil, ela tem que contratar laboratórios no exterior. Os pesquisadores da empresa discutem os projetos e monitoram 0 desenvolvimento com essas empresas contratadas tanto no país quanto no exterior, viajando para o país para fazer um acompanhamento mais próximo. Os testes são comportamentais, toxicológicos e farmacológicos. Os testes comportamentais visam avaliar os efeitos das substâncias nos comportamentos. Os testes toxicológicos avaliam os efeitos colaterais dos compostos e efeitos carcinogênicos. Os testes farmacológicos avaliam o modo de ação, efeitos adversos sobre sistemas vitais do 
corpo e também, aspectos de absorção e metabolismo do novo composto, além das interações medicamentosas.

Esta é uma lacuna existente na cadeia, pois a pesquisa pré-clínica deve seguir protocolos rígidos de agências regulatórias e precisam ser aprovadas por uma Comissão de Ética. Eventos recentes envolvendo centros de pesquisa, como o caso do Instituto Royal que teve suas pesquisas destruídas por um grupo de manifestantes, tiveram impacto negativo nas parcerias, com repercussão na mídia, o que inviabiliza os financiamentos para implantação e funcionamento destes centros, que inclusive têm aporte do Governo Federal. A empresa tinha interesse em formar parcerias com estes centros, mas pretende recorrer mais aos centros de outros países, para garantir que não terá a marca e nome da empresa, envolvidos com questões polêmicas. Há um acréscimo destes custos no preço final do medicamento e a empresa perde competitividade com laboratórios estrangeiros.

A empresa investe constantemente em suas plantas, para equipá-las tecnologicamente ou para ampliar a capacidade de produção, garantindo a competitividade no mercado, dado que o setor depende fortemente de tecnologia, para passar do estágio piloto de fabricação até a produção em escala industrial. Esta é uma competência já desenvolvida na empresa e suas tecnologias são as mais modernas e que hoje são as utilizadas nas grandes multinacionais do setor. $O$ macroprocesso de P\&D da Empresa D é apresentado na figura 13: 


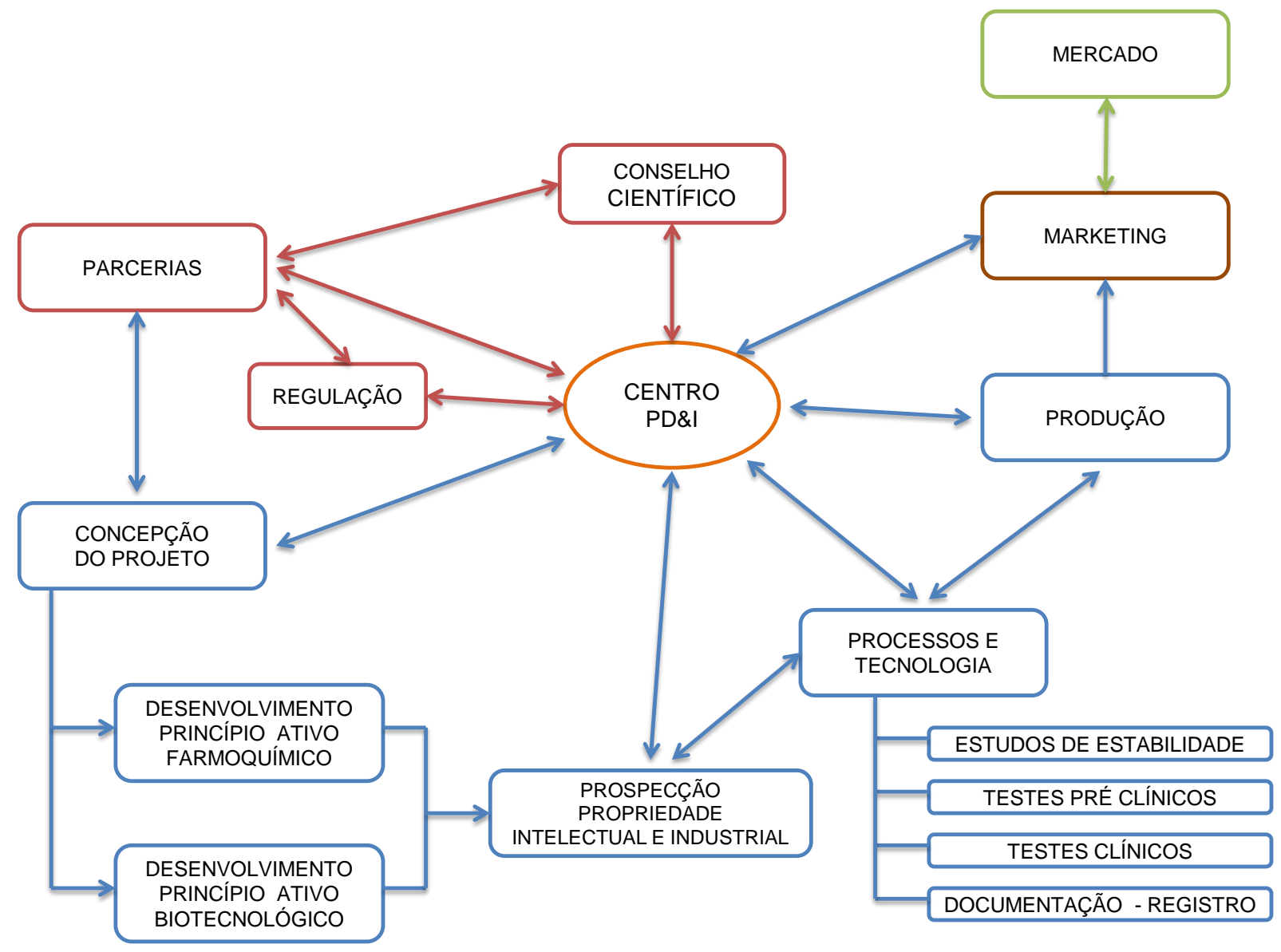

Figura 13 Macroprocesso de P\&D da Empresa D

Fonte: elaboração própria com base nas entrevistas

As competências essenciais da empresa, tal como em outras farmacêuticas, são as relacionadas à pesquisa científica, novas tecnologias e também o marketing para fazer toda a prospecção de mercado. A empresa possui equipes de pesquisadores voltados para estas competências e muitos atuam na empresa e também nas universidades, em atividades de ensino, pesquisa e participando de eventos como congressos e simpósios, onde buscam atualizar os conhecimentos. Possuem contratos de trabalho que permitem esse tipo de atuação conjunta, o que acrescenta novos conhecimentos e amplia as competências, com o que há de mais moderno em pesquisas de ponta da academia. 
Outra competência desenvolvida refere-se às boas práticas de fabricação, pré-requisitos exigidos pela Agência Nacional de Vigilância Sanitária, para garantir a qualidade e segurança dos produtos que são desenvolvidos e comercializados. Recentemente investiu em tecnologia moderna para evitar o contato humano com o processo de fabricação, dessa forma não há contaminação dos produtos e nem dos trabalhadores.

\section{Competência relacional}

Esta é uma competência fundamental para a empresa, uma vez que o processo de P\&D de novos medicamentos é complexo e depende de áreas e conhecimentos diversos.

A estratégia inicial da empresa era a de produzir medicamentos similares aos de grandes multinacionais, para reduzir preços e atender somente o mercado hospitalar do país, mas com o aumento da produção acabou fornecendo também para o mercado externo.

A empresa desenvolve projetos próprios e também realiza inovação aberta em parceria com várias instituições de pesquisa, ligadas ou não a universidades, com o governo, agências de fomento e com vários profissionais de saúde. A empresa faz parte de um Conselho Científico que integra Universidade e Empresa, que visa transformar as ideias dos pesquisadores acadêmicos em inovações, onde todos os profissionais participam dos resultados. Dentre as organizações parceiras destacam-se: Universidade de São Paulo, Universidade Estadual de Campinas, Irmandade da Santa Casa de Misericórdia de São Paulo, Escola Paulista de Medicina, Fundação Oswaldo Cruz, Instituto Butantã, Fundação Zerbini, cinco Universidades Federais, CNPq, FAPESP, CAPES, Ministério da Saúde, Ministério da Ciência e Tecnologia, FINEP e BNDES.

Essas parcerias com outras instituições de pesquisa permitem atualizar os conhecimentos e trocar informações. Os profissionais participam também de eventos divulgando suas inovações e conhecimentos, como feiras, congressos, seminários, simpósios, entre outros. 
Possui vários pedidos de patentes depositados, sendo que $20 \%$ referem-se à tecnologia e possui mais de 50 patentes de invenção. Metade dos projetos de novos medicamentos é de inovações radicais e metade de inovações incrementais. Uma das estratégias atuais é investir na produção de insumos farmacêuticos ativos de alto valor agregado que não estão disponíveis no país ou que possuem cotas muito altas de importação.

As patentes de fármacos estão registradas nos Estados Unidos, Argentina, Europa e Hong Kong. Possui patentes de composição de produtos na Europa, México, Japão, China, Hong Kong e Estados Unidos. Possui também patentes de processos de desenvolvimento de compostos nos Estados Unidos, México, Japão, China, Índia e Hong Kong. Recentemente obteve patente de uma tecnologia relacionada a produto nos Estados Unidos, Europa e no Brasil.

A empresa depende muito das Universidades porque não tem as competências necessárias para montar todas as pesquisas nas diferentes áreas e conduzir internamente. Na visão do entrevistado, a Universidade reduz os gastos com pesquisa se fizer o licenciamento e produz algo que pode contribuir para a melhoria da saúde da população e sem o licenciamento fica só fazendo pesquisa e não produz nada. Por outro lado, a parceria com a Universidade ainda não tem regras claras e, por exemplo, não sabe como aplicar os royalties recebidos das patentes ou tem medo das auditoras acharem algo que não está dentro das normas burocráticas. Segundo o entrevistado, é o que aconteceu numa parceria com a USP e pode comprometer ou inviabilizar projetos futuros. Isto ocorre porque o país não tem cultura de desenvolvimento e como envolve muitos riscos, a parte jurídica não consegue resolver tudo, sendo mais fácil recusar as parcerias do que correr risco de futuros processos.

\section{Competência de negócios}

Os investimentos realizados pela empresa são em grande parte de capital próprio, mas há financiamentos de Agências de Fomento, da FINEP e do Governo Federal. Recentemente obteve financiamento do Governo Federal para ampliar sua capacidade produtiva, sendo que o Governo participou com 25\% e a empresa com $75 \%$ do investimento realizado. 
Possui parcerias com mais de vinte laboratórios públicos e privados, através de programa desenvolvido pelo Ministério da Saúde para produção de medicamentos com transferência de tecnologia. Essas parcerias visam atender a demanda interna por medicamentos nos programas cobertos pelo Sistema Único de Saúde. Essas parcerias permitiram que a empresa dobrasse seu faturamento durante o período do acordo de fornecimento dos medicamentos e a redução dos gastos públicos ao comprar medicamentos nacionais (ANVISA, 2014).

A empresa iniciou suas atividades participando de licitações juntamente com multinacionais de grande porte que ofereciam preços mais competitivos, desta forma a empresa só conseguia participar de licitações de lotes menores que não interessavam aos grandes laboratórios. Focou seu negócio nesses produtos e atualmente consegue competir igualmente com as multinacionais em processos de licitações governamentais. No momento atual, uma parte do faturamento da empresa corresponde ao fornecimento de medicamentos hospitalares através de licitações públicas.

Os acordos de cooperação com outras instituições de pesquisa são fundamentais para o processo de P\&D de novos medicamentos, mas com o objetivo maior de desenvolver novos conhecimentos e obter novas descobertas e não necessariamente com o objetivo de reduzir custos.

A empresa está dividida por linhas de negócio que atendem demandas de hospitais e varejo através das farmácias, para produtos genéricos e também de alto custo nas áreas já mencionadas anteriormente.

O foco da empresa nos últimos anos vem sendo no marketing, com ampliação de sua área comercial que teve seu quadro aumentado em $40 \%$ em um ano, para atender a área de varejo mais especificamente, pois a demanda hospitalar já está sendo atendida. A empresa teve que buscar estes profissionais em outras empresas do setor, mostrando que há uma carência de bons profissionais.

Uma estratégia atual da empresa para ampliar os negócios é a aquisição de empresas, com o objetivo de entrar em novos mercados em outros países ou para atuar em novos segmentos. Desta forma fez nos últimos anos a aquisição de três empresas farmacêuticas seguindo esta estratégia de atuação. 


\section{Competência de regulação}

As competências de regulação são fundamentais no setor farmacêutico, devido à natureza de seus produtos para uso em seres humanos, envolvendo desde o atendimento de normas internacionais para testes pré-clínicos e clínicos, certificação de boas práticas de fabricação, licenças de produção industrial e de proteção ambiental, certificações para atender órgãos que regulamentam o setor, tais como a Organização Mundial da Saúde, a Food and Drug Administration ou a Agência Nacional de Vigilância Sanitária, para poder comercializar e exportar seus produtos e ainda, todas as questões referentes a direitos de propriedade, uso de patentes e direitos de comercialização e exportação, entre outras.

A empresa montou seu departamento jurídico que detém essas competências para auxiliar a empresa, seus pesquisadores e também dá suporte aos novos pesquisadores parceiros que fazem pesquisa conjuntamente com a empresa e que precisam proteger suas ideias, mas não conhecem a legislação ou os procedimentos. A área jurídica gerencia os contratos, projetos e processos de licitação quanto aos aspectos jurídicos, formas de participação, royalties e outros.

As parcerias com universidades e outras instituições públicas também exigem competências específicas da área jurídica e as regras variam de uma instituição para outra, algumas com extremo rigor e outras mais flexíveis, que impactam na parceria e na viabilidade dos projetos. A empresa precisa de garantias de que terá retorno dos altos investimentos que realiza e as instituições querem receber já na fase de licenciamento, porém a participação sobre a comercialização de uma inovação muitas vezes está baseada em previsões, pois é difícil mensurar o retorno futuro de um novo produto. Outro ponto relatado pelo entrevistado é que a fase de desenvolvimento é a que mais envolve riscos para ambas as partes, porém se o projeto não der certo, a empresa perde muito investimento e a universidade não perde nada.

Atualmente a área jurídica vem acompanhando o processo para realizar associações com outras empresas do setor, com o objetivo de explorar novos negócios e ganhar na concorrência com as grandes multinacionais. O processo de 
joint venture é uma tendência e muitas multinacionais estão se associando para competir no setor farmacêutico.

\section{Competência organizacional}

A Empresa D formou seu quadro de pesquisadores com pessoas que atuavam nas instituições de ensino e pesquisa e também os recém-formados de renomadas universidades de todo o país, dando-lhes condições para que se estabelecessem nas localidades próximas dos centros de pesquisa e unidades da empresa. Os pesquisadores são estimulados a continuarem a pós-graduação no mestrado, doutorado e pós-doutoramento.

A empresa busca mapear nas universidades e outras instituições de pesquisas, onde estão localizados os pesquisadores que detêm as competências de que a empresa precisa nas diferentes áreas de negócios. Esse mapeamento é fundamental, pois se precisar fazer um teste mais específico em laboratório, a empresa contata diretamente o profissional. Nessa parceria, a empresa pode pagar pelo serviço ou consultoria, pode convidar o pesquisador para participar do projeto ou pode montar e equipar o laboratório necessário para aquele teste, inclusive contatando o Instituto Nacional de Metrologia para certificar o laboratório quanto aos Princípios de Boas Práticas de Laboratório que é exigido pelo órgão fiscalizador. Enfim, a Empresa $\mathrm{C}$ oferece muitos incentivos para aqueles que quiserem participar da cadeia, pois integra as ações e a empresa acaba sendo beneficiada indiretamente. No longo prazo acaba se beneficiando, pois a empresa ainda importa $50 \%$ de sua matéria-prima e se puder comprar no próprio país, os custos caem e os preços dos medicamentos podem ser menores.

Outra iniciativa da empresa para desenvolver as competências dos pesquisadores é a concessão de bolsas de pesquisa para pessoas da academia que estejam pesquisando na área farmacêutica. É uma iniciativa para que as pesquisas de novos métodos e descobertas se desenvolvam no país e também, no médio ou no longo prazo, podem impactar de alguma forma nos negócios da empresa.

A aquisição de empresas é uma estratégia utilizada pela empresa nos últimos anos, para se apropriar de novos conhecimentos em áreas em que não atua e agregar novas competências ao seu negócio. 
$\mathrm{Na}$ empresa é o pesquisador sênior que orienta a equipe de pesquisadores quanto às atividades de pesquisa e documentação, para alinhar os conhecimentos $e$ as competências dos profissionais. Este pesquisador é responsável também pela transferência de tecnologia para os parceiros externos e pela elaboração e revisão de procedimentos para instrução de trabalho do departamento. As ações são muito padronizadas para atender as especificações e exigências dos órgãos certificadores. Os pesquisadores precisam ter ainda, conhecimento sobre a legislação das agências reguladoras do setor e acompanhar os bancos de dados de patentes e os artigos científicos publicados, para mapear a geração de inovações.

A geração de novas ideias não está limitada apenas para a equipe de pesquisadores e qualquer pessoa da área pode propor uma ideia e será o inventor na patente, sendo que o produto pertencerá à empresa e se for comercializado, o inventor ganhará sua parte em royalties segundo determinado nas cláusulas contratuais.

\subsection{A Empresa E}

A empresa $E$ é uma empresa global do setor de mineração e siderurgia com sede no Brasil. Possui escritórios para comercialização dos produtos em diversos países. Participa de joint ventures com empresas globais para operação e exploração de minas e refinaria em outros diversos países, tais como Canadá, China, Reino Unido, Taiwan, Japão e outros.

A empresa investe muito em tecnologia e logística para exploração dos segmentos minerais em que atua, dentre eles o minério de ferro, níquel, carvão, cobre e manganês, garantindo eficiência e qualidade dos seus produtos, principais insumos da indústria siderúrgica.

A empresa possui um centro de pesquisas de novos processos de extração de minérios, a fim de aumentar a eficiência dos processos, reduzir perdas e viabilizar economicamente a produção. A inovação tecnológica é uma atividade estratégica da empresa para garantir seu crescimento sustentável. 
As equipes da empresa são compostas por geólogos, engenheiros, biólogos, botânicos e outros. Os profissionais buscam técnicas avançadas para coleta de rochas e sondagens do subsolo e análise de imagens de satélite para localizar minerais em diferentes regiões e países, em busca de novas reservas minerais. A descoberta de reservas de minérios com alto valor econômico requer muitos anos de estudos e análises.

A partir do ano 2000 houve aumento da demanda por minerais, devido principalmente ao fortalecimento das economias mundiais e processos de urbanização dos países (IBRAM, 2014).

O país possuía em 2011, o total de 8.879 mineradoras segundo levantamento do Departamento Nacional de Produção Mineral, sendo que 3.609 empresas estavam localizadas na região Sudeste, 2.065 na região Sul, 1.606 na região Nordeste, 1.075 na região Centro-Oeste e 515 na região Norte (IBRAM, 2014).

Segundo dados do Instituto Brasileiro de Mineração, em 2012 a distribuição dos produtos minerais mais significativos no valor da produção brasileira era composta por: $63,30 \%$ de ferro, $4,30 \%$ de ouro, $3,65 \%$ de cobre, $2,00 \%$ de níquel, $1,94 \%$ de alumínio, $1,15 \%$ de fosfato, $0,73 \%$ de carvão mineral e outros minérios com produção abaixo de 0,60 (IBRAM, 2014).

O país produziu em 2012 mais de US\$ 51 bilhões em minérios com participação de $16,68 \%$ da produção mundial e em 2013 produziu mais de US $\$ 44$ bilhões, sendo que o Brasil era o $2^{\circ}$ maior produtor de minério de ferro em $2012 \mathrm{com}$ participação de 16,68\% da produção mundial (IBRAM, 2014).

O setor de mineração gerou 2,2 milhões de empregos diretos no país no ano de 2011, sem considerar as vagas geradas na fase de pesquisa, prospecção e planejamento e a mão de obra ocupada nos garimpos. As principais empresas geradoras desses empregos no país são: a Vale que tem $46 \%$ de participação na produção; a Mineração Maracá com 39\%, a Mineradora Caraíba com 14\% e a Votorantim Metais com 1\% (IBRAM, 2014).

A arrecadação do Governo com a exploração de recursos minerais vem aumentando desde 2010, sendo que em 2012 houve a arrecadação de $R \$ 1,832$ 
bilhão para a Compensação Financeira pela Exploração de Recursos Minerais, um encargo incidente na cadeia de mineração pago ao governo. Em 2011 a arrecadação foi de $R \$ 1,540$ bilhão, ou seja, $42,8 \%$ superior à de 2010 , que foi de R\$ 1,078 bilhão (IBRAM, 2014).

Apesar dessa participação na produção mundial, o país ainda importa minerais que são estratégicos para o país. O país importou, por exemplo, 91\% de potássio e $51 \%$ de fosfato, materiais usados na fabricação de fertilizantes, sendo que o país é o $4^{\circ}$ maior consumidor de fertilizantes do mundo (IBRAM, 2014).

O setor depende muito de inovações na tecnologia, que em geral são introduzidas por fornecedores que estão a montante na cadeia produtiva e por isso, o setor impulsiona o desenvolvimento de atividades tecnológicas em outras atividades econômicas (FURTADO; URIAS, 2013)

\subsubsection{Análise das competências organizacionais da Empresa $\mathrm{E}$ \\ Competência técnica}

A empresa desenvolve muitos processos de $P \& D$ de inovações tecnológicas para encontrar novas reservas em diferentes regiões do país ou no exterior e para explorar as minas com tecnologias de ponta que permitem beneficiar os minérios com maior aproveitamento e qualidade.

O processo de exploração de minérios é um processo complexo que pode envolver várias etapas. A exploração do minério de ferro, por exemplo, segue as seguintes etapas: 1 - preparo das minas para as operações de lavra com diversos equipamentos e toda operação é orientada por sistema de automação que controla via satélite cada etapa de produção; 2- retirada com escavadeiras de toneladas de minérios e outros materiais de bancadas e carregamento de caminhões; 3transporte do material por caminhões até um britador para beneficiamento do minério em partículas pequenas; 4- carregamento do minério britado através de correias transportadoras até uma usina de beneficiamento; 5- peneiramento do minério e separação em três tamanhos diferentes; 6- transporte do minério processado através de correias para ser estocado em pátios; 7- transporte das pilhas de minérios até silos que são descarregados em vagões de trem de carga; 8- 
o trem passa por baixo dos silos para receber o minério e depois de carregado segue até a capital do estado onde se localiza a mina; 9- descarregamento do trem em silos que são levados para estocagem em pátios no porto; 10- colocação do minério do pátio em esteiras para ser levado aos porões de navios do terminal portuário que entregaram a carga aos clientes. O processo está representado de forma resumida na figura 14 : 


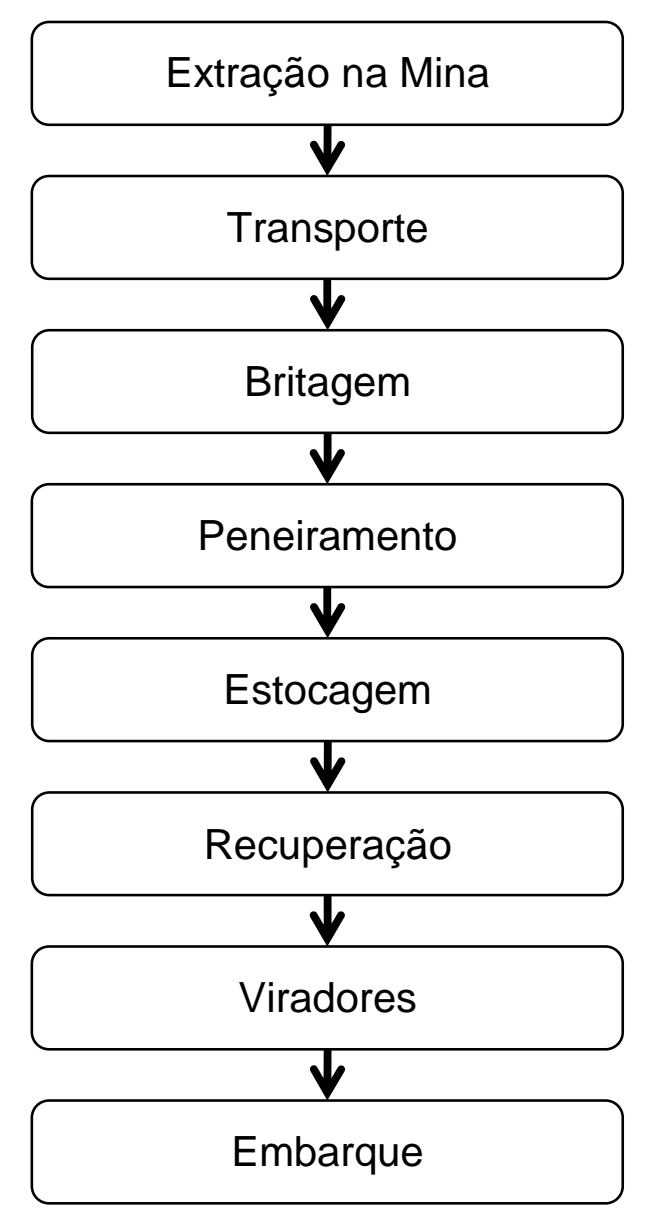

Figura 14 Processo de extração de minério de ferro

Fonte: empresa pesquisada

Para desenvolver suas atividades, a empresa depende muito de tecnologia multisetorial. Envolve as tecnologias propriamente ditas fazer a extração mineral, com máquinas de grande porte e conhecimentos de processos para fragmentar as rochas e fazer o beneficiamento seguindo as etapas do processo anteriormente apresentado. As parcerias com os fornecedores de tecnologia, por exemplo, fabricantes de caminhão especial, são fundamentais para garantir a eficiência do processo de mineração e acaba induzindo o desenvolvimento dessas tecnologias. Envolve também tecnologias relacionadas com eficiência energética, pois a empresa utiliza muita energia em seus processos e precisa ter garantia de suprimento, criando toda infraestrutura necessária. Há um terceiro grupo de tecnologias relacionadas com a dimensão ambiental, pois a empresa abre a mina para ser 
explorada e depois tem que ter um plano de fechamento dessa mina, que engloba a repartição de benefícios com as comunidades locais e o cuidado com o impacto ambiental, pois todos os projetos têm uma dimensão de sustentabilidade que incorpora as comunidades que vivem no entorno das minas.

A estratégia de tecnologia da empresa é definida com base no planejamento estratégico da empresa. Os objetivos estratégicos vão determinar quais serão as tecnologias necessárias para a empresa e também qual será o orçamento disponível. A formação de parcerias dependerá das tecnologias e equipamentos que serão necessários, buscando novas parcerias para tecnologias que a empresa não dispõe, como um tipo específico de caminhão para o transporte. As parcerias também são formadas com pesquisadores da academia ou com uma ONG, para cuidar do aspecto social e ambiental. A mina pode ficar aberta e ser explorada por décadas, então tem que haver uma preocupação com o social e o ambiental daquela determinada região ou determinado país. A mineradora tem licenças outorgadas pelas agências regulatórias, mas a população vê a atividade mineradora como uma atividade primitiva, que não gera desenvolvimento local e dessa forma, pode ser contra a exploração das minas. Devido a estes fatores, a empresa precisa criar ações que demonstrem como pode contribuir efetivamente para o desenvolvimento das populações locais e assim, a dimensão social é muito relevante para as atividades. A empresa busca capacitar e financiar outras áreas de conhecimento que são áreas afins às áreas em que a empresa atua e de instituições em regiões geográficas em que a empresa está instalada. É o caso de projetos de pesquisas em biologia molecular, em que as técnicas utilizadas podem ser relevantes para outros projetos de interesse da empresa no futuro.

Há também projetos de grande risco, em que o investimento é muito alto, com a construção de planta piloto e beneficiamento de produto, porém não recebem aporte das agências governamentais. Se após avaliação da viabilidade técnica e econômica, a empresa conclui que não compensa levar para a etapa de produção em escala, o projeto é interrompido e perde-se todo o investimento feito, o que pode envolver milhões de reais. Na visão do entrevistado, falta este tipo de linha de financiamento não reembolsável para as empresas no Brasil, já disponíveis em outros países, o que acaba inviabilizando novas pesquisas desse porte. 
Embora a empresa seja classificada como produtora de commodities há diferenças na qualidade dos produtos entre as mineradoras concorrentes e essa qualidade é obtida pela tecnologia que é utilizada na exploração e beneficiamento, para atender as especificações dos clientes, por exemplo, na demanda para o alto forno de um cliente. A empresa não tem interesse em desenvolver competências que não estão diretamente relacionadas com o seu negócio principal e estimula o estabelecimento de outras empresas prestadoras de serviços na região da mina, tais como, provedores de tecnologias ou empresas de logística.

A empresa faz o acompanhamento do surgimento de novas tecnologias e novos materiais no mercado, que podem concorrer com os produtos da empresa no futuro, através das patentes registradas, dos artigos científicos e outras publicações e do próprio desenvolvimento da economia no setor. Há novos materiais como a fibra de carbono ou os aços especiais, que são materiais mais resistentes, mais duráveis e que podem concorrer com o ferro, porém não apresentam preço competitivo no momento, nem vantagens de uso. Avalia então o uso desses materiais nos seus equipamentos, como o uso do aço especial nos vagões de carga, tornando-os mais leves e aumentando a capacidade de carregamento ou nos trituradores para torná-los mais resistentes e reduzir os desgastes, mas esbarra novamente na questão do custo e a empresa tem que avaliar as vantagens e desvantagens, o potencial, os riscos etc.

A empresa possui uma estrutura grande e descentralizada de P\&D com mais de 100 profissionais alocados nas pesquisas de novas tecnologias e novos materiais, envolvendo engenheiros, geólogos, biólogos, engenheiros, etc. Fez algumas aquisições de empresas englobando as equipes de P\&D das mesmas e estruturando centros de desenvolvimento por produtos no país e no exterior. Metade dos pesquisadores possui pós-graduação em nível de doutorado e a empresa estimula a especialização de seus funcionários. A empresa trabalha com inovação aberta para estabelecer cooperação e formar rede de colaboração com outras empresas e institutos de pesquisa e ensino. Esta rede permite que a empresa mantenha um quadro mais reduzido de pesquisadores, uma vez que não tem que internalizar todas as competências necessárias para realizar P\&D. Além disso, a rede permite acompanhar o que está sendo pesquisado e desenvolvido no mercado, 
com capacidade para detectar o que é de interesse da empresa e fazer apropriação em outra etapa do desenvolvimento.

Desenvolve principalmente inovações radicais e também incrementais de processos e de tecnologia.

Mantém parcerias para P\&D de inovações principalmente com universidades, instituições de pesquisa, fornecedores e consultorias. Os projetos das parcerias são importantes no desenvolvimento de competências complementares e também para a redução de custos de materiais e equipamentos. O macroprocesso de P\&D da Empresa E é apresentado na figura 15:

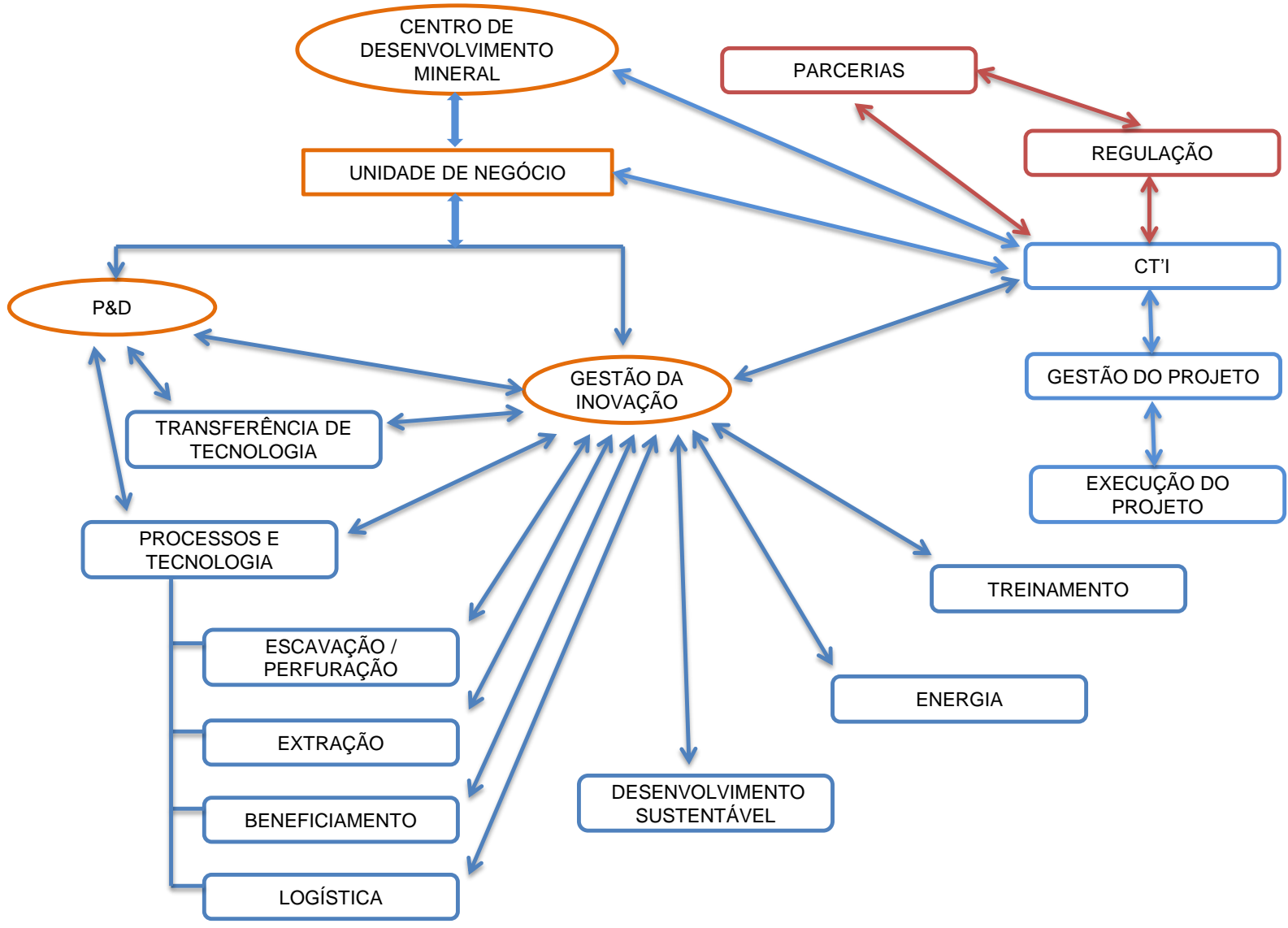

Figura 15 Macroprocesso de P\&D da Empresa E

Fonte: elaboração própria com base nas entrevistas 
A gestão da tecnologia é feita através do acompanhamento de gates específicos de execução dos projetos, com marcos financeiros de execução, de aderência, ou seja, são acompanhados física e financeiramente ao longo do ano para que sejam adequados e alcancem os objetivos do negócio. Cada um dos produtos da empresa tem sua própria gestão e desenvolvimento de tecnologias específicas que buscam aumentar a eficiência do negócio, melhorando a lucratividade, mantendo as margens e diminuindo os custos, por exemplo, algum aperfeiçoamento na ferrovia que vai reduzir o custo por tonelada em $\mathrm{Km}$ percorrido. Cada um dos negócios tem seus próprios indicadores de desempenho que são medidos e acompanhados em todas as etapas do projeto, embora a medição seja mais apurada quando chega na fase de implementação do projeto, quando a tecnologia se aproxima da aplicação.

\section{Competência relacional}

As parcerias são formadas com diferentes instituições de ensino e pesquisa, fornecedores e consultorias, com o intuito de atender as dimensões econômica, tecnológica, social e ambiental dos negócios da empresa. O cliente gera a demanda para a empresa e esta busca desenvolver as competências e parcerias para atender esta demanda. Entre os parceiros estão o Instituto Chico Mendes de Conservação da Biodiversidade e o Instituto Brasileiro do Meio Ambiente e dos Recursos Naturais Renováveis, Instituto Nacional de Pesquisas Espaciais, Universidades Federais e Estaduais, SEBRAE, SENAI, Petrobrás, ONG's, Prefeituras Municipais, Empresas, Instituições de Ensino e Pesquisa de outros países, entre outras. Uma parte dos recursos dos projetos é proveniente da própria empresa e outra parte, de parceiros externos como o BNDES, CNPq, Fundações Estaduais de Amparo à Pesquisa. Estes investimentos contemplam inúmeros projetos e bolsas de pesquisa, com instituições de pesquisa e empresas do país e do exterior.

A empresa possui uma área voltada para ações de ciência, tecnologia e inovação. Esta área é responsável pela formação das parcerias e pela gestão da carteira de projetos, das bolsas concedidas, dos orçamentos e financiamentos da empresa voltados para $P \& D$ de inovações. A criação dessa área impulsionou a $P \& D$ de inovações, através do modelo adotado de inovação aberta para desenvolver 
ideias, processos e produtos em cooperação com os parceiros, além de atrair recursos de terceiros para alavancar as pesquisas.

Para dar sustentabilidade aos projetos, a empresa busca desenvolver e capacitar fornecedores de tecnologias menores das localidades em que atua, para que possam participar da cadeia extrativa mineral. Os clientes participam da seleção dos parceiros fornecedores e tomam decisões sobre as escolhas, direcionando de certa forma, a implementação das tecnologias.

\section{Competência de negócios}

A área de C,T\&I da empresa é responsável pela captação de recursos através das parcerias e dos financiamentos das Instituições Públicas como BNDES, CNPq, Fundações Estaduais de Amparo à Pesquisa, entre outras. Essa área acompanha e controla os orçamentos e a carteira de projetos de inovação.

A área de C,T\&I elabora a agenda estratégica e define quais projetos serão executados, pois acompanha o que a empresa está desenvolvendo e avalia o que poderá ser interessante colocar em prática em outro momento. Os projetos podem surgir em áreas operacionais e tem possibilidade de serem desenvolvidos, mas a área de C,T\&I definirá se são prioritários e se terão orçamento ou não, ou seja, se os projetos terão continuidade ou serão descontinuados. Esses projetos têm que ser "comprados" por alguma área para ter continuidade. Esta área faz uma coordenação transversal e gerencia especificamente projetos de custo e prazos maiores, que envolvem mais riscos, sendo que estes projetos são transferidos para as áreas numa determinada etapa e as áreas passam a fazer a gestão. Os demais centros de tecnologia atendem as necessidades diretas das unidades de negócios.

A área de C,T\&I controla os repasses de orçamento dos projetos para as unidades interessadas e faz uma transição durante as fases do projeto. Inicialmente a área pode cobrir até $70 \%$ do projeto e a unidade cobre o restante dos 30\%, no ano seguinte dividem $50 \%$ para cada parte. Na próxima fase, a área de C,T\&l pode cobrir $30 \%$ e a unidade passa a cobrir $70 \%$ e no final fica $100 \%$ para a unidade responsável por desenvolver o projeto. Segundo o entrevistado, esta prática tem um indicador de sucesso para o desenvolvimento e gerenciamento de tecnologia na empresa. 
A empresa durante muitos anos desenvolveu C,T\&I somente com aportes próprios, sem buscar aportes externos. No início de 2010 começou a buscar aportes de capital externo de maneira mais sistematizada, em instituições do país e do exterior. Uma parte dos aportes era de parcerias com outras empresas, mas hoje recebem aporte para desenvolver projetos internamente e sem parceiros. Os incentivos da Lei do Bem passaram a ser usados mais recentemente pela empresa e esses aportes são importantes no momento, pois os orçamentos estão mais apertados devido às flutuações de preços no mercado terem afetado a margem de lucro. Isto tem impacto no quadro de pesquisadores, acaba reduzindo o número de pessoas alocadas em pesquisa e uma forma de cobrir essa lacuna é formar parcerias na academia, com pessoas que têm competências que interessam para o negócio e que podem fazer as atividades que eram internas.

Os projetos são separados por tipo de minério e por tipo de negócio da empresa, envolvendo as áreas de Logística, Meio Ambiente, Saúde e Segurança e outras. Aproximadamente $38 \%$ dos projetos são voltados para inovações mais incrementais de processos e produtos já existentes e $48 \%$ dos projetos estão voltados para a criação de vantagens competitivas à empresa em termos de custos ou novas oportunidades de mercado. Os demais projetos, que representam $14 \%$ da carteira, são projetos disruptivos, gerando inovações que mudam a estrutura da indústria ou do mercado e recebem volume maior de recursos.

Destaca-se ainda, que $68 \%$ do total de projetos são classificados como de pesquisa aplicada e têm o objetivo de gerar novos conhecimentos para solução de problemas científicos ou tecnológicos específicos dos negócios da empresa, 23\% envolvem pesquisa básica sem aplicação imediata e $9 \%$ são de projetos de desenvolvimento experimental para comprovar a aplicação prática de produtos e equipamentos, alguns de grande porte. Alguns projetos não têm ligação direta com os negócios da empresa, mas visam aproximar das universidades e mudar a antiga relação de 'compra e venda', formando parceiros institucionais importantes para o futuro. As descobertas que são importantes para a empresa são internalizadas e as que não são de interesse, passam por processo de licenciamento e geram recursos para cobrir os investimentos feitos. 
Há mais de 15 projetos internacionais, desenvolvidos em parceria com instituições de ciência e tecnologia e com empresas.

Os investimentos em P\&D no ano de 2013 ficaram acima de $R \$ 2,0$ bilhões e em 2014 o valor é de aproximadamente $\mathrm{R} \$ 1,5$ bilhão. Dentro desses valores há uma parte de prospecção e exploração e não necessariamente de pesquisa. $A$ redução nos investimentos em 2014 visa aumentar a eficiência na gestão dos projetos, com foco na carteira de produtos já existentes e em tecnologias que aumentem a qualidade, produtividade e eficiência de produção. Os investimentos em operações envolvem ampliação das plantas, saúde e segurança dos trabalhadores, manutenções, responsabilidade social corporativa, melhoria dos sistemas de tecnologia da informação, entre outras.

A empresa vem participando de editais, juntamente com instituições federais e estaduais, financiando bolsas de pesquisa de mestrado e doutorado, em que faz acompanhamento das atividades dos bolsistas através de relatórios. Em nova etapa, a empresa busca parceiros institucionais no exterior, para intercâmbio dos pesquisadores dos países envolvidos, internacionalizando a rede de pesquisas. $O$ interesse está em parcerias com países que se destacam ou que estão em graus diferentes de desenvolvimento científico e tecnológico em relação ao Brasil e nos quais a empresa tem interesse numa determinada atividade econômica, tais como China, Austrália, Moçambique, EUA, entre outros.

\section{Competência de regulação}

As competências de regulação são muito importantes para o tipo de negócio da empresa, uma vez que são necessárias muitas licenças para implantação e exploração dos empreendimentos após as análises arqueológicas mais técnicas. A empresa criou um setor específico para dar apoio aos processos de obtenção de licenças, reduzindo o tempo de resposta nos pareceres sobre os projetos junto às instituições regulatórias, envolvendo desde licenças ambientais, licenças para instalação e expansão de ferrovia, operação nos portos, entre outras. A redução de prazo de liberação de licenças tem relação direta com prazos de execução dos projetos e também nos custos envolvidos, uma vez que as atividades só iniciam com a liberação das licenças pelas instituições. Um exemplo é o prazo estimado das 
start-ups (empresas nascentes fornecedoras) que tem que ser revisado devido aos atrasos no licenciamento ambiental.

Aproximadamente $30 \%$ dos projetos de P\&D surgiram a partir de demandas dos clientes, que buscam melhorias de qualidade e custo nos produtos.

A empresa possui mais de 100 patentes de inovações tecnológicas obtidas através de pesquisas de sua equipe multidisciplinar, composta por engenheiros químicos e metalúrgicos, geólogos, físicos, químicos e outros.

O objetivo da empresa não está na geração de patentes, pois o foco está na exploração de produtos que já possui, envolvendo novas tecnologias. A empresa quer preservar o direito de uso dessas tecnologias, sem ter que pagar. Quando a tecnologia é gerada em parceria com uma universidade ou outro parceiro, a empresa tem o direito de primeira compra se tiver interesse, caso contrário o parceiro pode negociar a venda da tecnologia para outros. O retorno da venda será dividido segundo o investimento que foi realizado pelas partes e segundo o acordo de propriedade intelectual que foi firmado. A empresa vem reestruturando a área de propriedade intelectual, com o objetivo de poder patentear o que for relevante para os negócios e de identificar o que não é necessário proteger.

A empresa busca estabelecer uma rede com outras empresas, com as quais tem relação enquanto cliente. Nesse sentido, apoia fortemente um modelo das agências federais e estaduais em que se forma um núcleo de pesquisadores, com um contrato de prazo limitado, para o desenvolvimento de uma solução tecnológica. Quando o projeto é concluído, pode ser incubado em uma empresa nascente, transformando-se em um novo negócio no mercado e vir a ser um fornecedor de tecnologia.

\section{Competência organizacional}

A empresa busca formas para organizar o conhecimento e as informações disponíveis, uma vez que atua globalmente e possui muitos colaboradores dispersos em vários países. Na área de P\&D possui mais de 100 pessoas vinculadas diretamente às atividades. 
Para disseminar os projetos, a empresa realiza workshops com as unidades de negócios e todas as áreas apresentam seus projetos sobre um determinado tema, por exemplo, sobre sustentabilidade ou reaproveitamento de aço. Esta é uma forma rápida e mais eficiente que a empresa encontrou para disseminar o que está sendo desenvolvido no curto e longo prazo, tais como as tecnologias, soluções, novas ideias e conhecimentos, uma vez que possui muitos colaboradores no país e no exterior.

A busca de conhecimentos, ideias e informações também é feita através de visitas dos pesquisadores e dos gestores em outras instituições no exterior e da participação em congressos relevantes nas áreas de atuação dos profissionais.

As parcerias são uma fonte de novas ideias e conhecimentos, principalmente com as universidades e institutos da pesquisa, cobrindo áreas que não estão muito desenvolvidas internamente. Quando há corte no quadro de pesquisadores, a parcerias também têm o papel de cobrir a lacuna na área de conhecimento, mas a empresa sabe que em algum momento terá que internalizar o que está sendo desenvolvido na parceria com a academia e, portanto, tem que ter um número mínimo de pessoas capacitadas em seu quadro de pessoal para acompanhar o que está sendo desenvolvido e dar continuidade ao trabalho no final da parceria. As equipes estão organizadas por produto e se há perda de margem de lucro em um dos produtos, as equipes alocadas para esse produto é que sofrem a redução de custos e de pessoas. As parcerias são voltadas mais para as áreas de tecnologia e processos, uma vez que a empresa não gera produtos novos, aprimorando os já existentes que são os minérios. Possui parcerias com importantes instituições de ensino e pesquisa da Alemanha, China, Japão e Estados Unidos.

A questão do controle e eficiência do processo de P\&D quando externaliza o projeto para os parceiros é apontada como um aspecto de deseconomias de escala, pois o controle do projeto deixa de ser centralizado na empresa e há perda da eficiência da execução, pois o pesquisador da universidade está envolvido com outras pesquisas e não tem um foco só no projeto da empresa, como ocorre com os projetos conduzidos internamente. Então, se por um lado, a empresa tem redução 
de custos nas parcerias, tem também a perda do controle e da eficiência, segundo apontado por um entrevistado.

Quanto à capacitação dos profissionais, a empresa criou um Instituto voltado para pesquisa e ensino de pós-graduação, semelhante a uma universidade corporativa, em que ocorre a pesquisa cientifica e o desenvolvimento de tecnologias voltadas para os negócios da empresa, mas de maneira sustentável. O foco principal é a pesquisa voltada para inovação tecnológica, desenvolvimento sustentável, logística, energia e siderurgia. O Instituto oferece cursos de pós-graduação em nível de doutorado e mestrado, tanto acadêmico quanto profissional, além de atividades de extensão e de iniciação científica.

Outra iniciativa do Instituto é o preparo de pesquisadores como futuros empreendedores de empresas de base tecnológica ou para a transferência de tecnologias oriundas das pesquisas. Oferece ainda curso de especialização profissional na área de negócios da empresa, que envolve a realização de atividades na empresa.

A empresa busca formar pessoal qualificado para atuação nos diferentes negócios, a partir do seu programa de estágio aberto para candidatos do ensino técnico e superior, em diferentes áreas do conhecimento, tais como economia, ciências contábeis e da computação, mecânica, elétrica, entre outras. Além de sua área de atuação, a empresa apoia diversos projetos da área cultural, como apoio à música brasileira e orquestras sinfônicas, bem como da área técnico-institucional, com projetos de investimento em ações de conservação do meio ambiente.

Utilizam softwares e modernos simuladores 3D para treinamento dos técnicos no seu centro de engenharia logística, voltados para operações de ferrovia, portos e também manutenção. A empresa disponibiliza esse treinamento também para profissionais do mercado no Brasil e em Moçambique.

Utilizam vários recursos da tecnologia para treinamentos, testes diversos, programas e ações de segurança, estudos geológicos, geotécnicos e ambientais e, também nas apresentações das pesquisas. A tecnologia é utilizada para a tomada de decisão tanto nas operações quanto nos projetos da empresa, envolvendo desde a definição inicial da área de lavra, dos cenários de licenciamento ambiental, até o 
fechamento da mina. Foram feitos investimentos na montagem de bases de dados geográficos das áreas de atuação da empresa, com o objetivo de montar modelos digitais em 3D para treinamento com realidade virtual portátil.

\subsection{Apresentação e análise dos resultados do Survey}

As empresas que retornaram o questionário autoaplicado são de diferentes setores de atividade. Houve a participação de 42 empresas, o que representa $21 \%$ da amostra de 200 empresas para a qual foi enviada a pesquisa. Para caracterizar as empresas participantes, foi utilizada como referência a Classificação Nacional de Atividade Econômica (CNAE), com atividades da Indústria de Transformação, conforme Quadro 4, anteriormente apresentado. Dois dos respondentes não informaram o nome da empresa e por isso, não foi possível classificá-las.

Das empresas participantes, 70\% apresentaram receita líquida acima de 1 bilhão de reais no ano de 2013. No Quadro 5 são apresentados os tipos de empresas participantes da pesquisa:

Quadro 5 Classificação das empresas participantes por setor

\begin{tabular}{|l|c|}
\hline \multicolumn{1}{|c|}{ Setor } & Respondentes \\
\hline Fabricação de produtos alimentícios & 05 \\
\hline Fabricação de celulose, papel e produtos de papel & 02 \\
\hline Fabricação de produtos químicos & 03 \\
\hline Fabricação de produtos farmoquímicos e farmacêuticos & 01 \\
\hline Extração de minerais não metálicos & 01 \\
\hline Fabricação de componentes eletrônicos & 01 \\
\hline Fabricação de máquinas, aparelhos e materiais elétricos & 01 \\
\hline Fabricação de cosméticos, produtos de perfumaria e de higiene pessoal & 03 \\
\hline Fabricação de veículos automotores & 01 \\
\hline Fabricação de produtos diversos & 01 \\
\hline Atividades dos serviços de tecnologia da informação & 01 \\
\hline Geração, transmissão e distribuição de energia elétrica & 02 \\
\hline Água, esgoto, atividades de gestão de resíduos e descontaminação & 42 \\
\hline Não informou o nome da empresa & 01 \\
\hline Total & 01 \\
\hline
\end{tabular}


O perfil dos respondentes é apresentado no Quadro 6 e verifica-se que apenas $21 \%$ não possuem cargo de gestão:

Quadro 6 Perfil dos respondentes da pesquisa

\begin{tabular}{|l|c|}
\hline \multicolumn{1}{|c|}{ Cargo dos respondentes } & Total \\
\hline Diretor P\&D & 03 \\
\hline Diretor outra área & 02 \\
\hline Coordenador de P\&D & 06 \\
\hline Gestor de P\&D (ou Científico) & 11 \\
\hline Gerente de Inovação & 06 \\
\hline Gerente - (operações, marketing, depto etc.) & 03 \\
\hline Especialista (pesquisador ou analista de P\&D) & 09 \\
\hline Não informou o cargo & 02 \\
\hline Total & 42 \\
\hline
\end{tabular}

O perfil dos respondentes também é apresentado no gráfico 1:

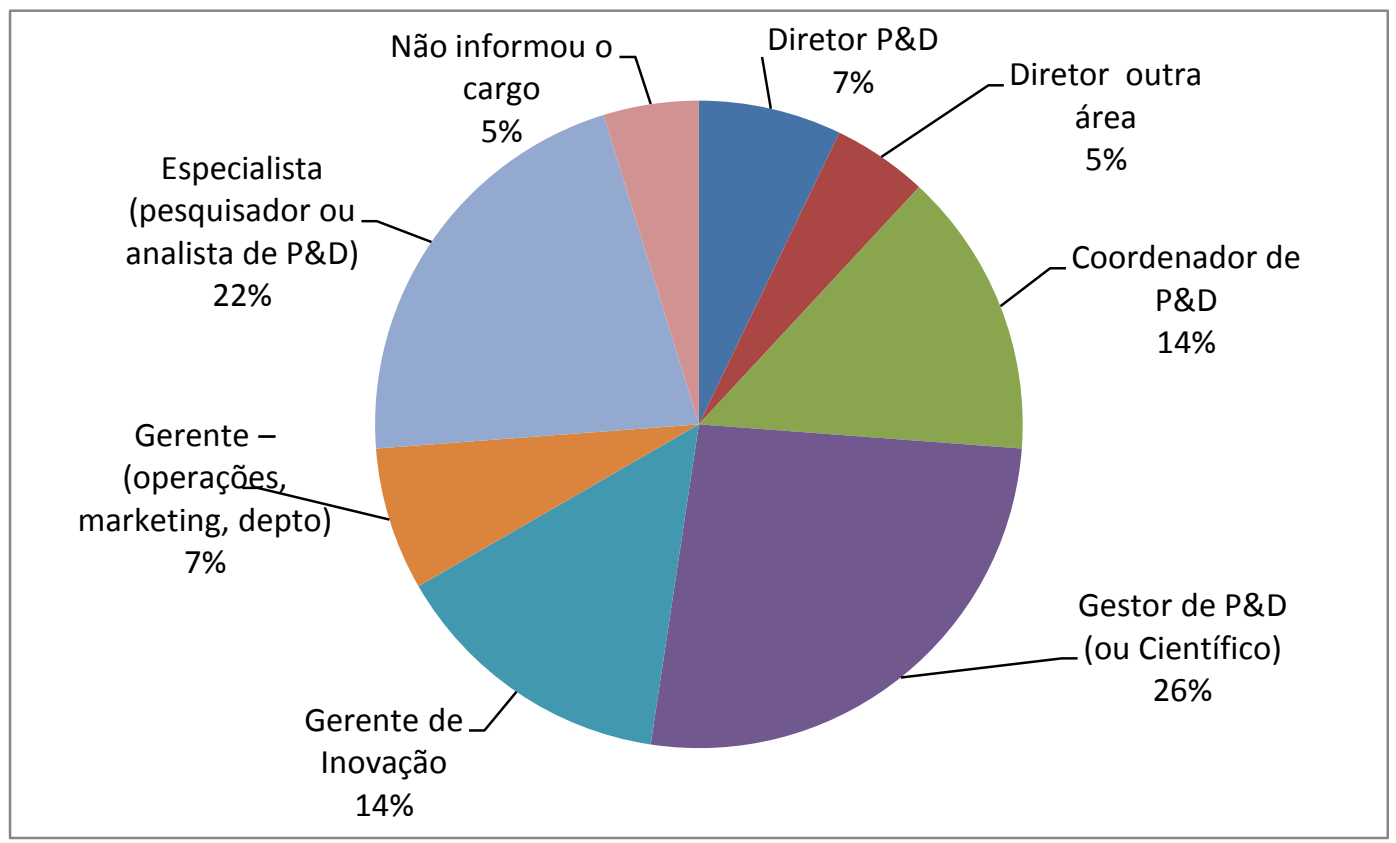

Gráfico 1 Perfil dos respondentes

A questão 1 era uma pergunta simples para identificar se a empresa possuía ou não uma área formal de P\&D e tinha como objetivo identificar o quanto as empresas estavam estruturadas para a P\&D de inovações. Verificou-se que $90 \%$ 
das empresas respondentes possuem uma área formal de P\&D e apenas 10\% não possuem uma área de $P \& D$ estruturada, conforme observa-se no gráfico 2 :

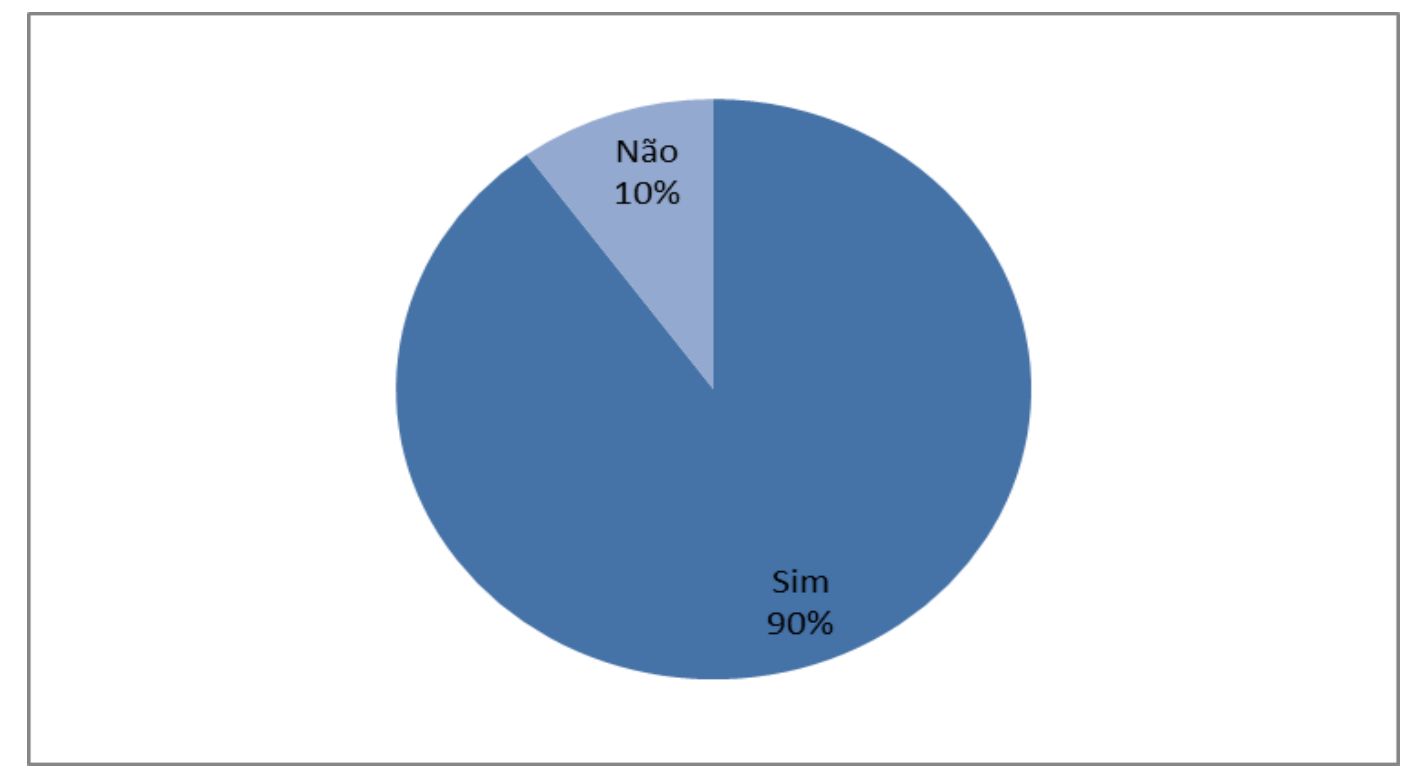

Gráfico 2 Empresas que possuem área de P\&D

$\mathrm{Na}$ questão 2 buscava-se identificar o tipo de inovação desenvolvida por todas as empresas pesquisadas e se era como atividade principal ou secundária. No Quadro 7 observa-se as respostas obtidas:

Quadro 7 Tipos de Inovações desenvolvidas pelas empresas (\%)

\begin{tabular}{|l|c|c|c|}
\hline \multicolumn{1}{|c|}{ Tipo de Inovação } & Atividade Principal & Atividade Secundária & Não se Aplica \\
\hline Produto Novo & 69 & 31 & 0 \\
\hline Produto Aprimorado & 77 & 23 & 0 \\
\hline Processo Novo & 47 & 42 & 11 \\
\hline Processo Aprimorado & 60 & 29 & 11 \\
\hline Tecnologia Nova & 52 & 40 & 8 \\
\hline Tecnologia Aprimorada & 67 & 28 & 5 \\
\hline
\end{tabular}

Das empresas respondentes, observa-se que 100\% delas desenvolvem produtos novos, sendo que para $69 \%$ das empresas esta é considerada uma atividade principal. As inovações incrementais de produtos são realizadas por todas 
as empresas, mas para $23 \%$ das empresas esta é uma atividade secundária. A maioria das empresas realiza inovações de processos num total de $89 \%$, embora $42 \%$ delas realizem como atividade secundária e $90 \%$ das empresas realizam melhorias em processos já existentes. Verifica-se que $92 \%$ das empresas desenvolvem tecnologias novas, embora para $40 \%$ delas esta seja uma atividade secundária. Observa-se ainda, que 95\% das empresas fazem melhorias em tecnologias já existentes e que para $67 \%$ das empresas esta é considerada uma atividade importante. Do total de respondentes há $8 \%$ que não verificaram inovação de tecnologia em suas empresas. Os resultados são apresentados no gráfico 3:

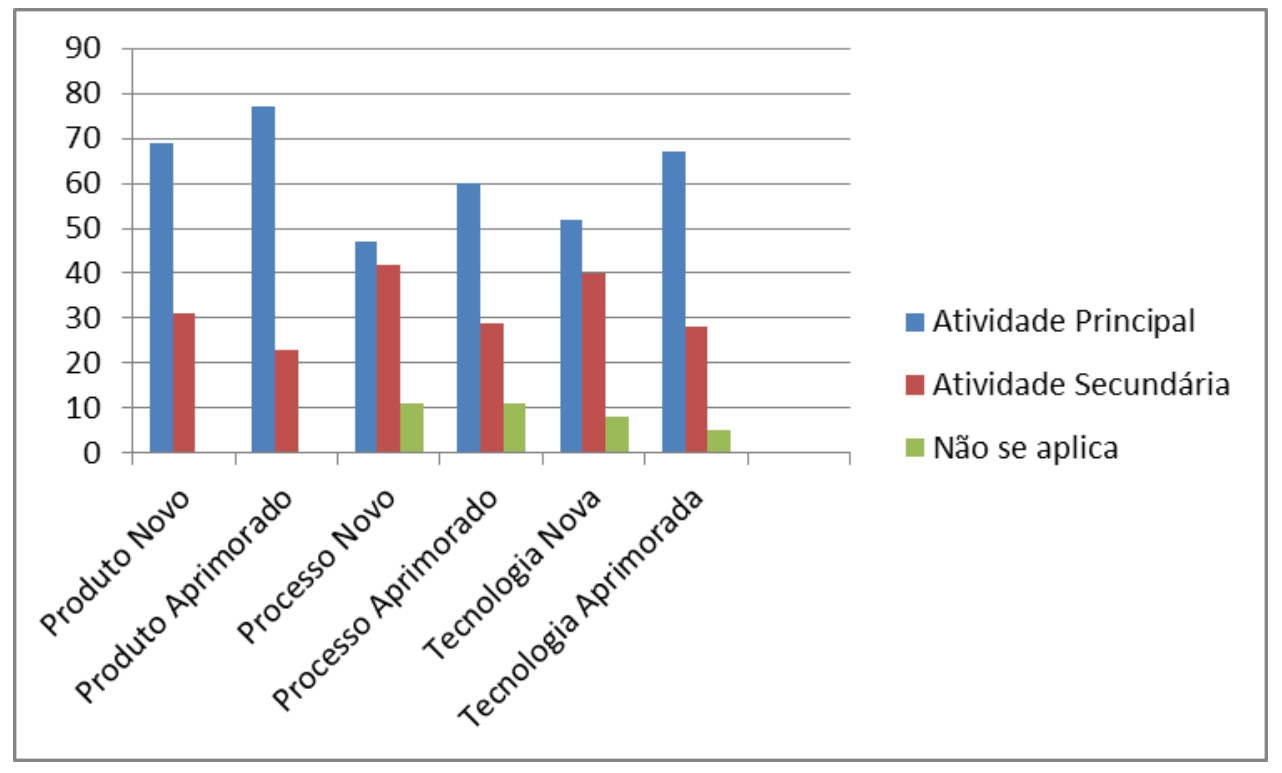

Gráfico 3 Tipos de inovações desenvolvidas pelas empresas

Ao realizar-se a média de inovações radicais e subtrair-se a média de inovações aprimoradas, observa-se que do total de empresas pesquisadas há 8 empresas que têm um foco em inovações radicais e 15 empresas que têm foco em inovações de aprimoramento. Nas demais empresas há um balanceamento entre os tipos de inovações radicais e aprimoradas, conforme observa-se no gráfico 4: 


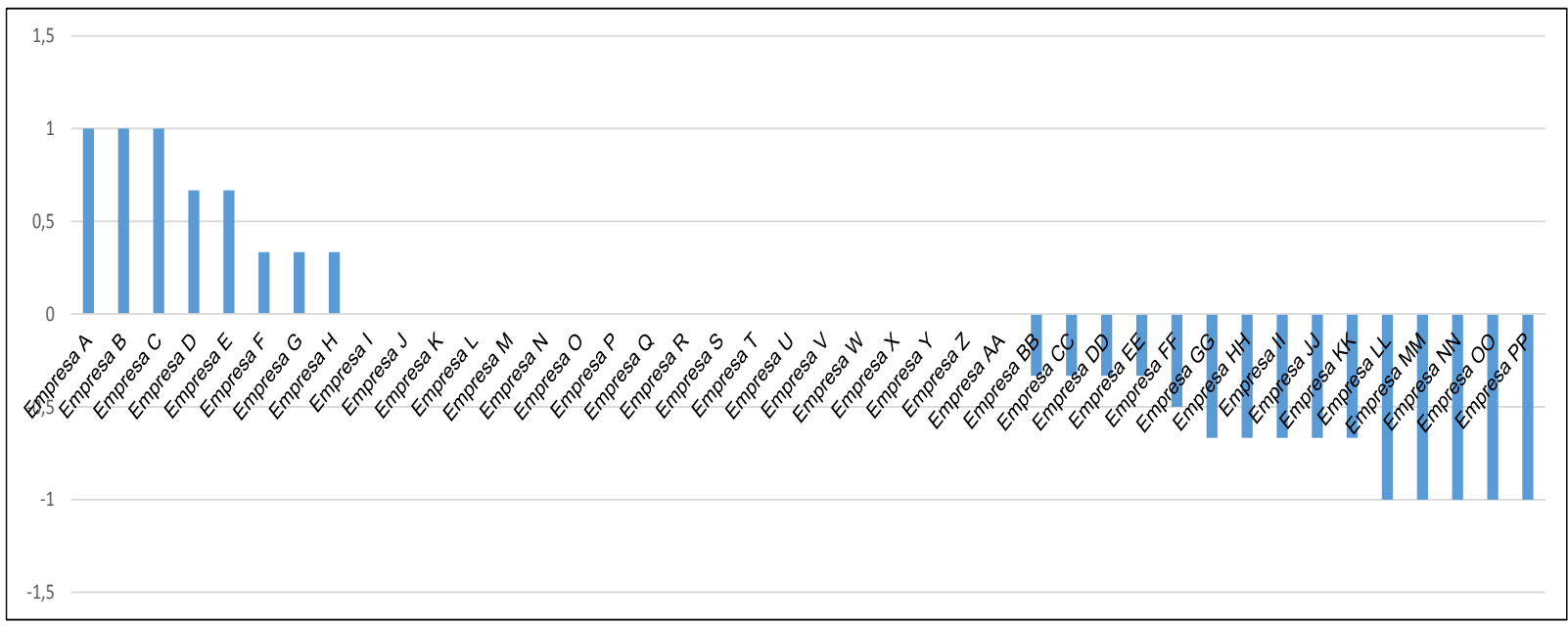

Gráfico 4 Diferença nas médias de inovações radicais e inovações aprimoradas

Ao medir-se a proporção do esforço em inovações de produto, processo e tecnologia verifica-se que os esforços são de $40 \%$ para inovações de produto, $32 \%$ para inovações de tecnologia e $28 \%$ para inovações de processo, conforme figura 16. A partir do gráfico 5 verifica-se que 6 empresas se dedicam unicamente à inovação de produto e apenas uma empresa se dedica unicamente à inovação de processos. As demais realizam os três tipos de inovações.

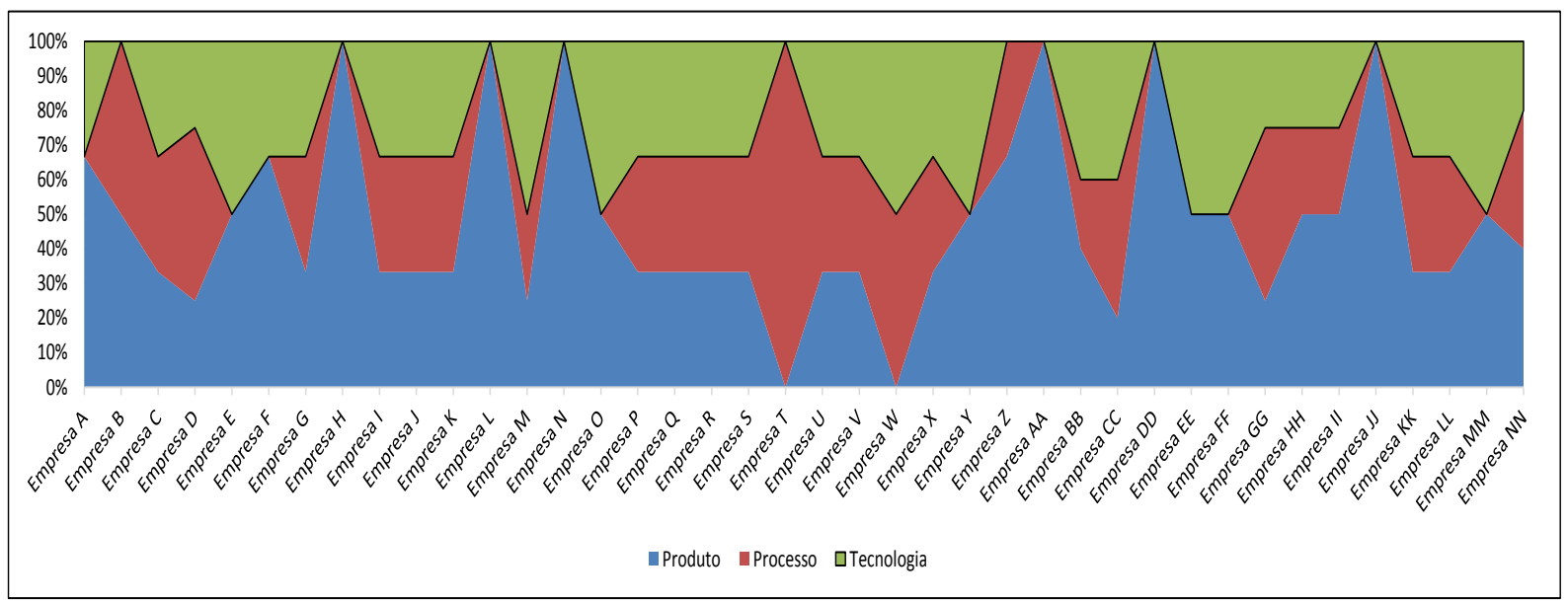

Gráfico 5 Proporção de esforços em inovações de produto, processo e tecnologia 


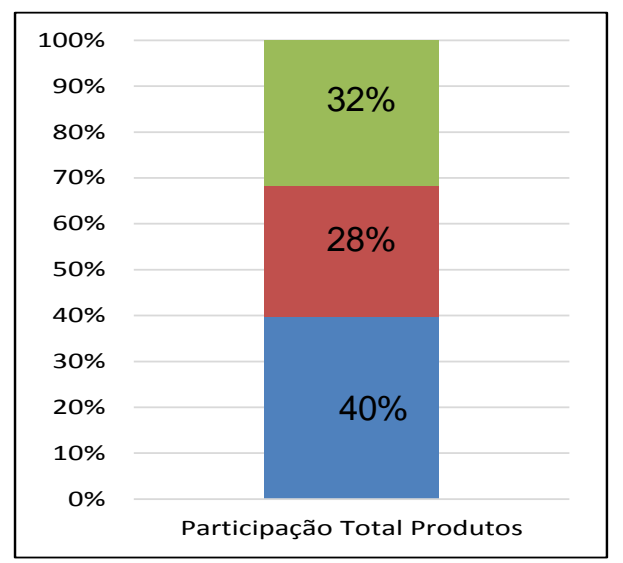

Figura 16 Porcentagem de esforço de inovação

Das empresas que não apresentam área formal de P\&D mediu-se a proporção do tipo de inovação que realizam e foi possível constatar que o foco destas empresas está no aprimoramento de produtos, processos e tecnologia, conforme se observa no gráfico 6 :

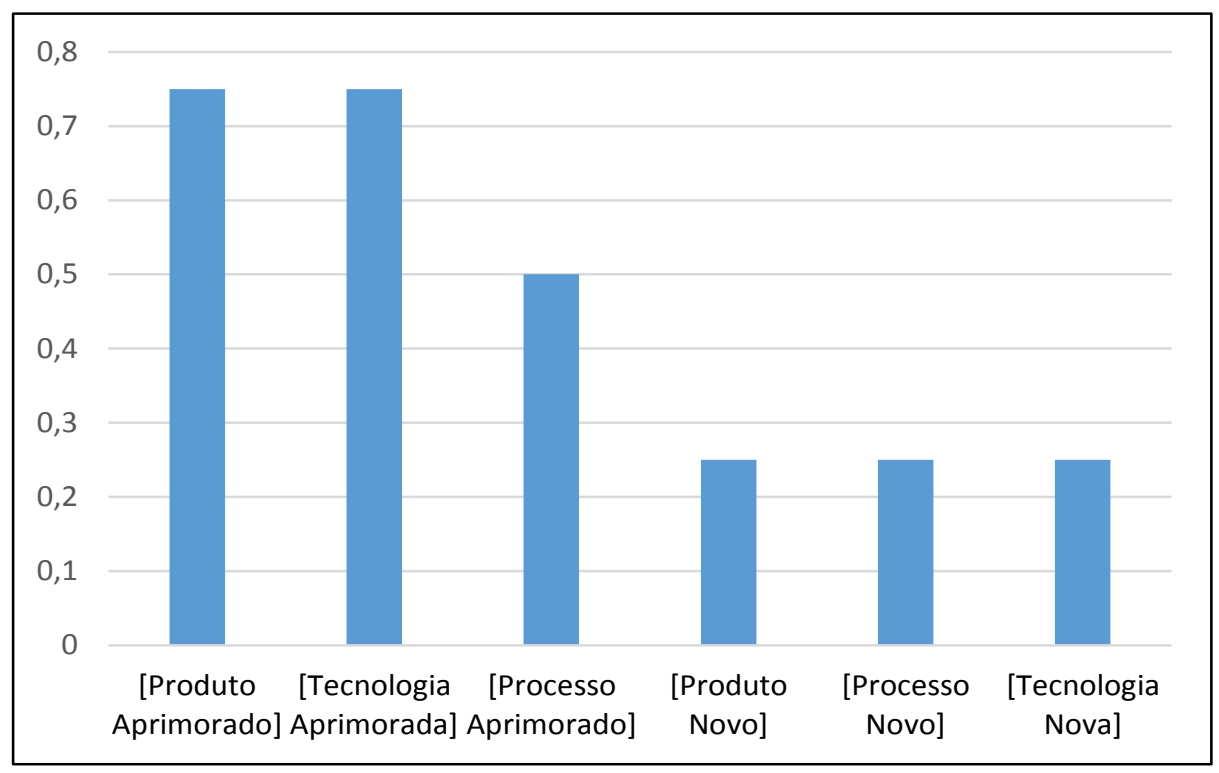

Gráfico 6 Tipos de inovações das empresas que não possuem área de P\&D

$\mathrm{Na}$ questão 3, o objetivo era mapear a rede de cooperação das empresas com os diferentes tipos de organizações. O Quadro 8 e gráfico 7 trazem os resultados encontrados: 
Quadro 8 Organizações com as quais as empresas mais cooperam (\%)

\begin{tabular}{|l|c|c|c|}
\hline Organização & Regularmente & Ocasionalmente & Não se Aplica \\
\hline Universidades & 52 & 40 & 8 \\
\hline Institutos de Pesquisa & 64 & 34 & 2 \\
\hline Clientes & 59 & 34 & 7 \\
\hline Fornecedores & 74 & 21 & 2 \\
\hline Consultorias & 36 & 62 & 15 \\
\hline Concorrentes & 18 & 31 & 13 \\
\hline $\begin{array}{l}\text { Centros de Capacitação } \\
\text { Profissional }\end{array}$ & 26 & 59 & \\
\hline $\begin{array}{l}\text { Instituições certificadoras ou } \\
\text { de testes }\end{array}$ & 47 & 40 & \\
\hline
\end{tabular}

A partir das respostas, verifica-se que as principais fontes de cooperação são os Fornecedores, Institutos de Pesquisa, Clientes e Universidades, com resultados acima de $50 \%$. Os fornecedores aparecem com maior valor entre as principais fontes de cooperação. Verificou-se ainda que há pouca cooperação com as empresas concorrentes, conforme observa-se no gráfico 7 :

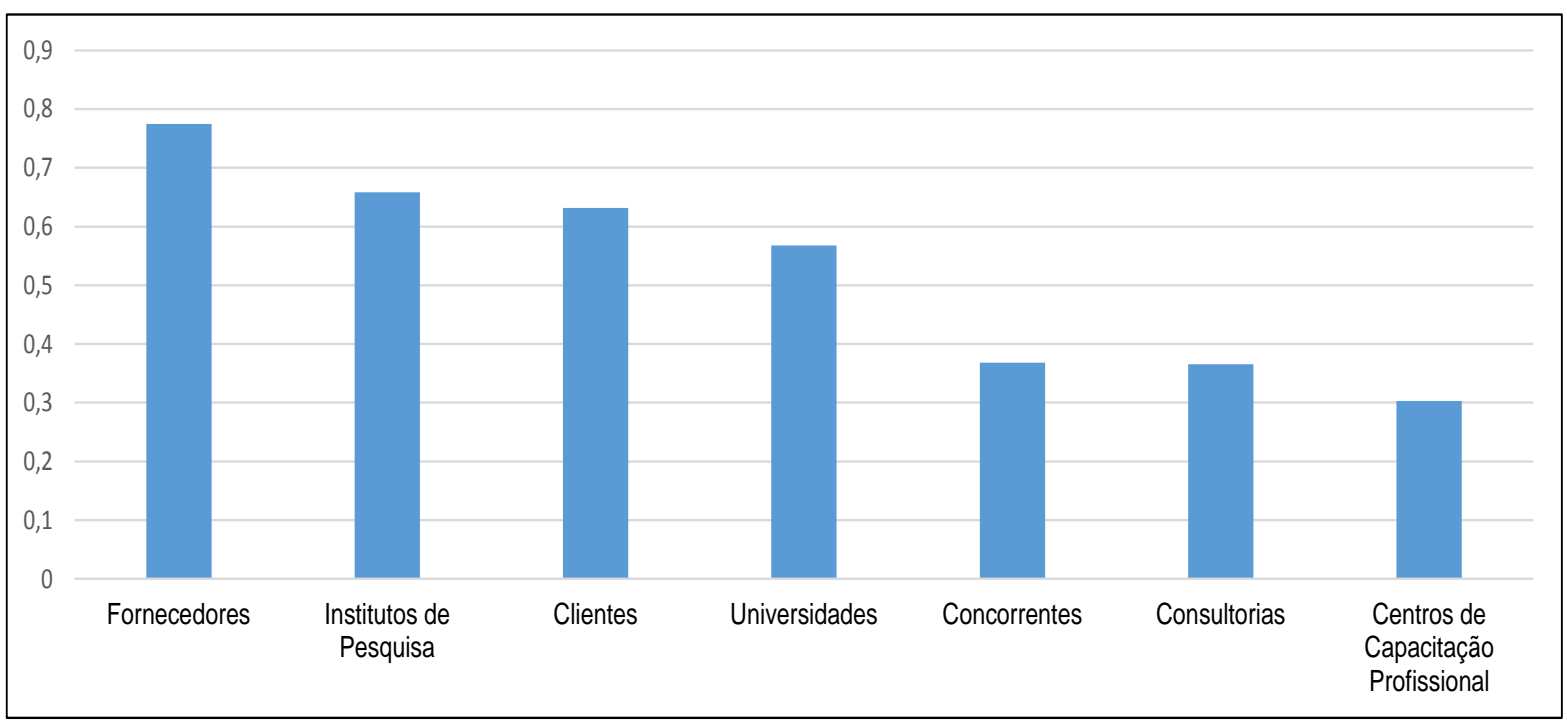

Gráfico 7 Rede de cooperação das empresas 
A questão 4 visava identificar os motivos pelos quais as empresas buscam cooperação externa e os resultados são apresentados no Quadro 9:

Quadro 9 Motivos para buscar cooperação externa

\begin{tabular}{|l|c|}
\hline Motivo da Cooperação & \% de Respostas \\
\hline Busca de competência complementar & 28 \\
\hline Busca de competência específica & 19 \\
\hline Busca de novas ideias & 15 \\
\hline Redução de custos de materiais e equipamentos & 4 \\
\hline Redução de custos com pesquisadores & 5 \\
\hline Outros & 29 \\
\hline
\end{tabular}

Verifica-se que para $57 \%$ de todas as empresas pesquisadas, o principal motivo para buscar cooperação externa é a busca de competências, sendo que $28 \%$ buscam competência complementar e 29\% buscam competência específica, conforme se observa no gráfico 8:

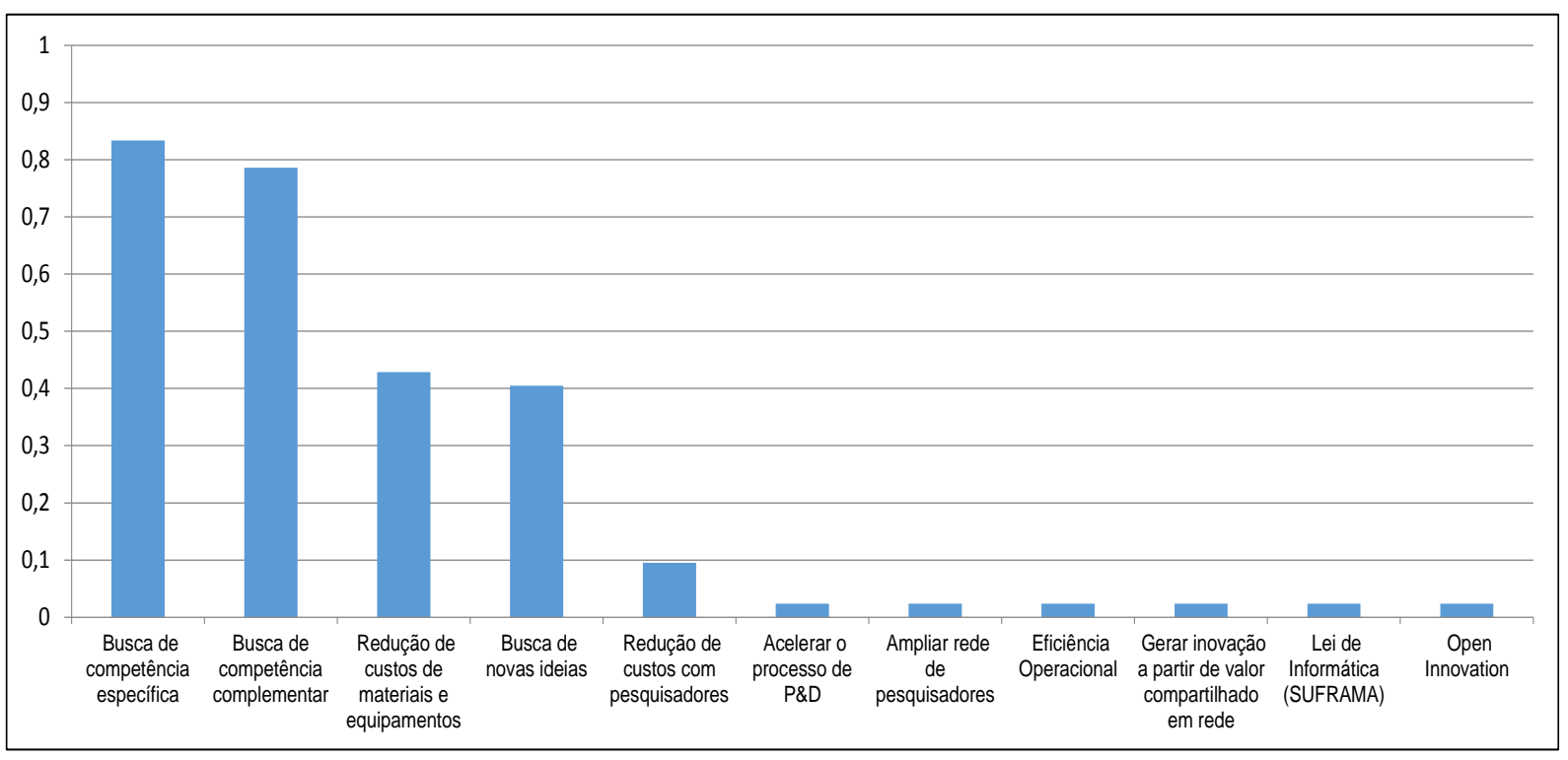

Gráfico 8 Motivos para busca de cooperação externa 
Ao analisar-se as empresas que realizam inovações de produtos, processos e tecnologias observa-se que cooperam mais com Institutos de Pesquisa, concorrentes e Universidades, conforme gráfico 9:

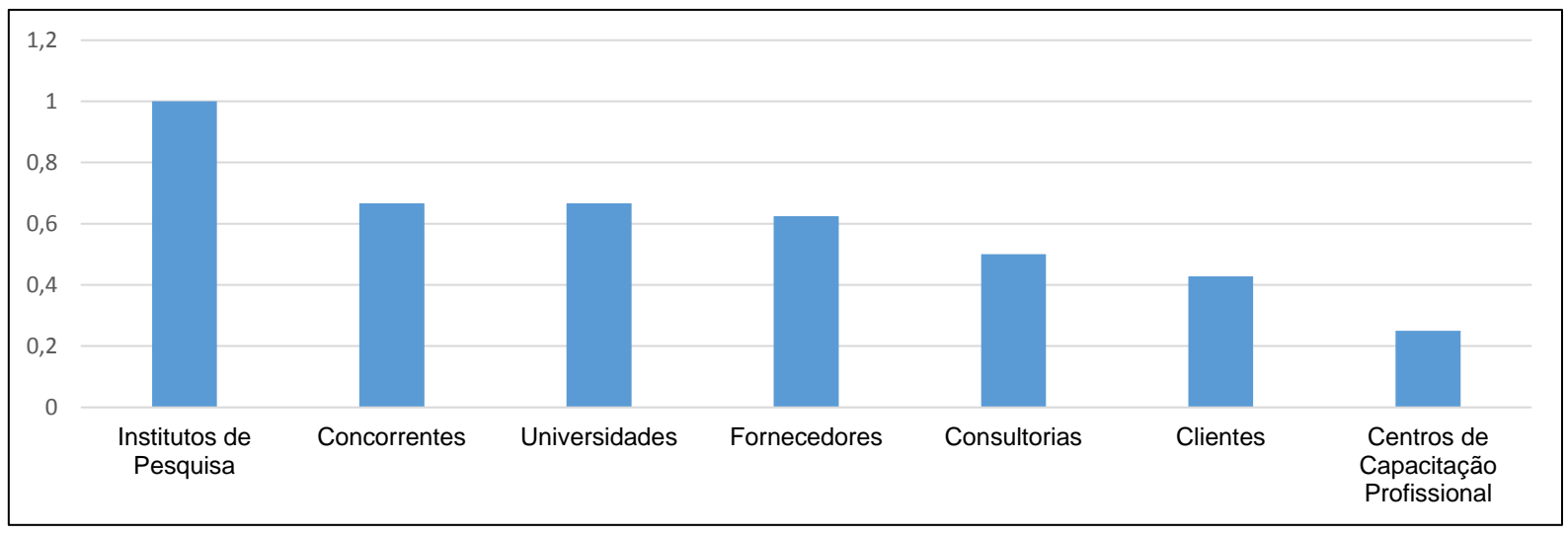

Gráfico 9 Instituições com as quais cooperam as empresas que realizam inovações radicais

Para estas empresas foram analisados os motivos pelas quais buscam cooperação externa e verifica-se que em geral buscam competências específicas ou complementares. A busca de novas ideias apareceu em terceiro lugar, conforme se observa no gráfico 10:

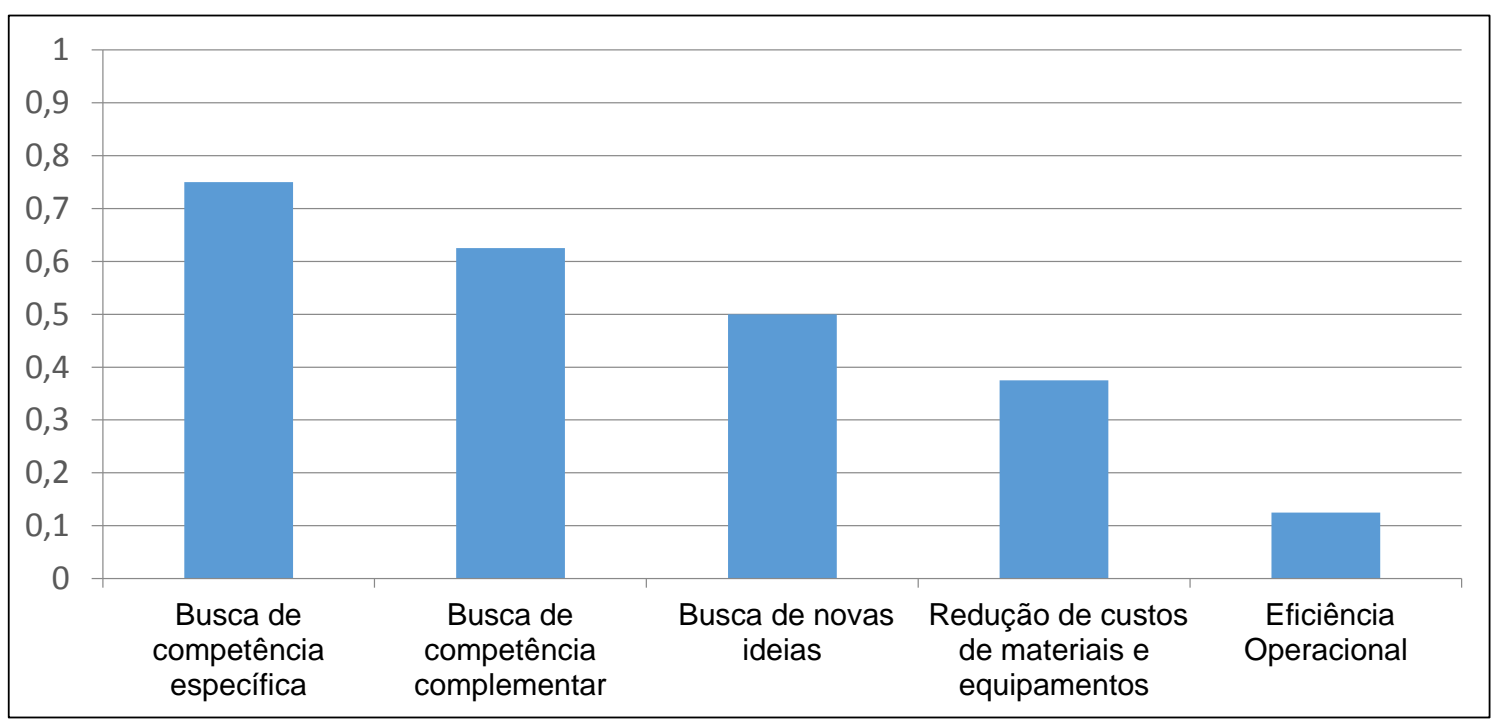

Gráfico 10 Motivos para busca de cooperação externa

Analisando-se as empresas que realizam aprimoramento de produtos, processos e tecnologias observa-se que cooperam mais com Institutos de Pesquisa, concorrentes e Universidades. A interação com concorrentes acontece quando as 
empresas precisam atender legislação e outras normas. Verifica-se ainda que há baixa interação com fornecedores e clientes, conforme gráfico 11:

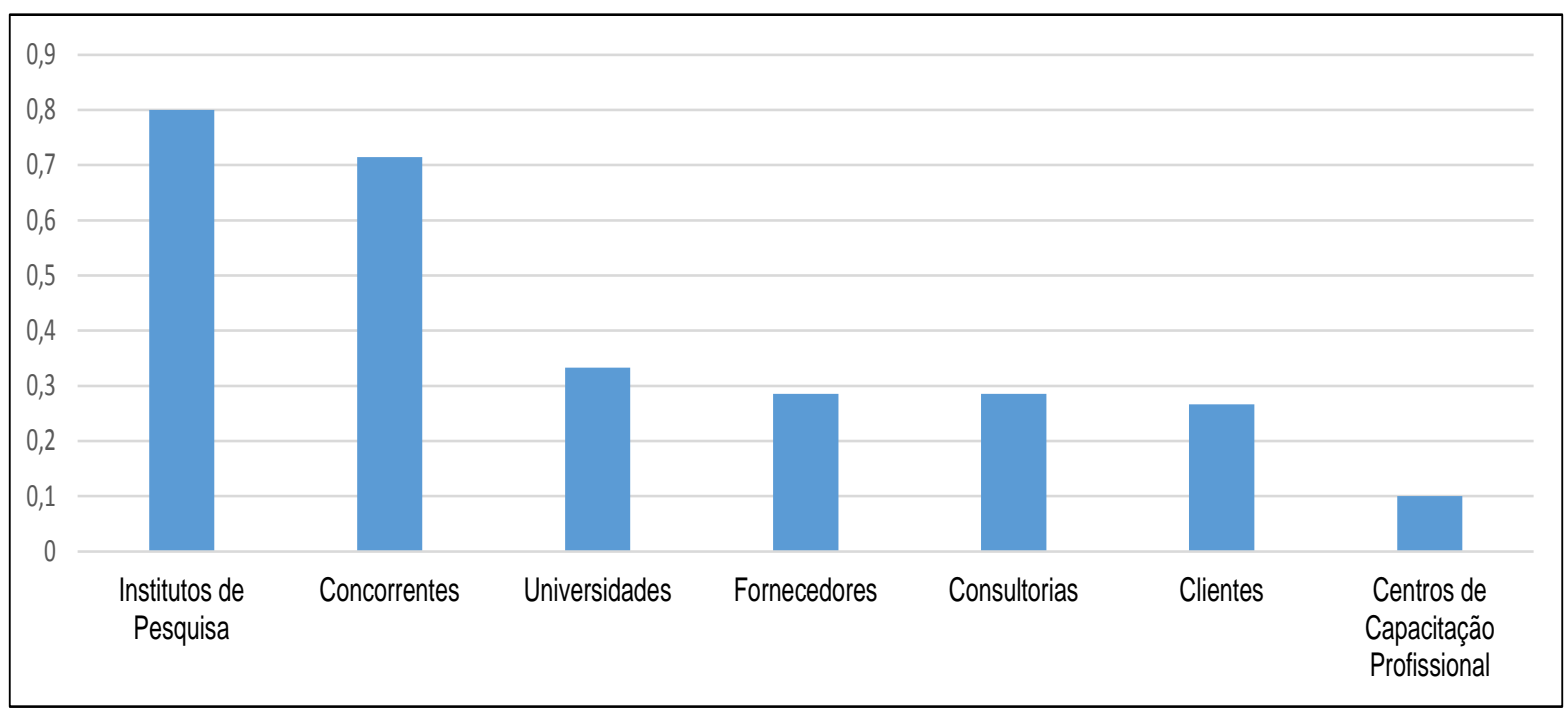

Gráfico 11 Instituições com as quais cooperam as empresas que realizam inovações de aprimoramento.

Para estas empresas foram analisados os motivos pelas quais buscam cooperação externa e verifica-se que em geral buscam competências específicas ou complementares. A redução de custos com materiais e equipamentos é mais relevante do que a redução de custos com pesquisadores, conforme se observa no gráfico 12:

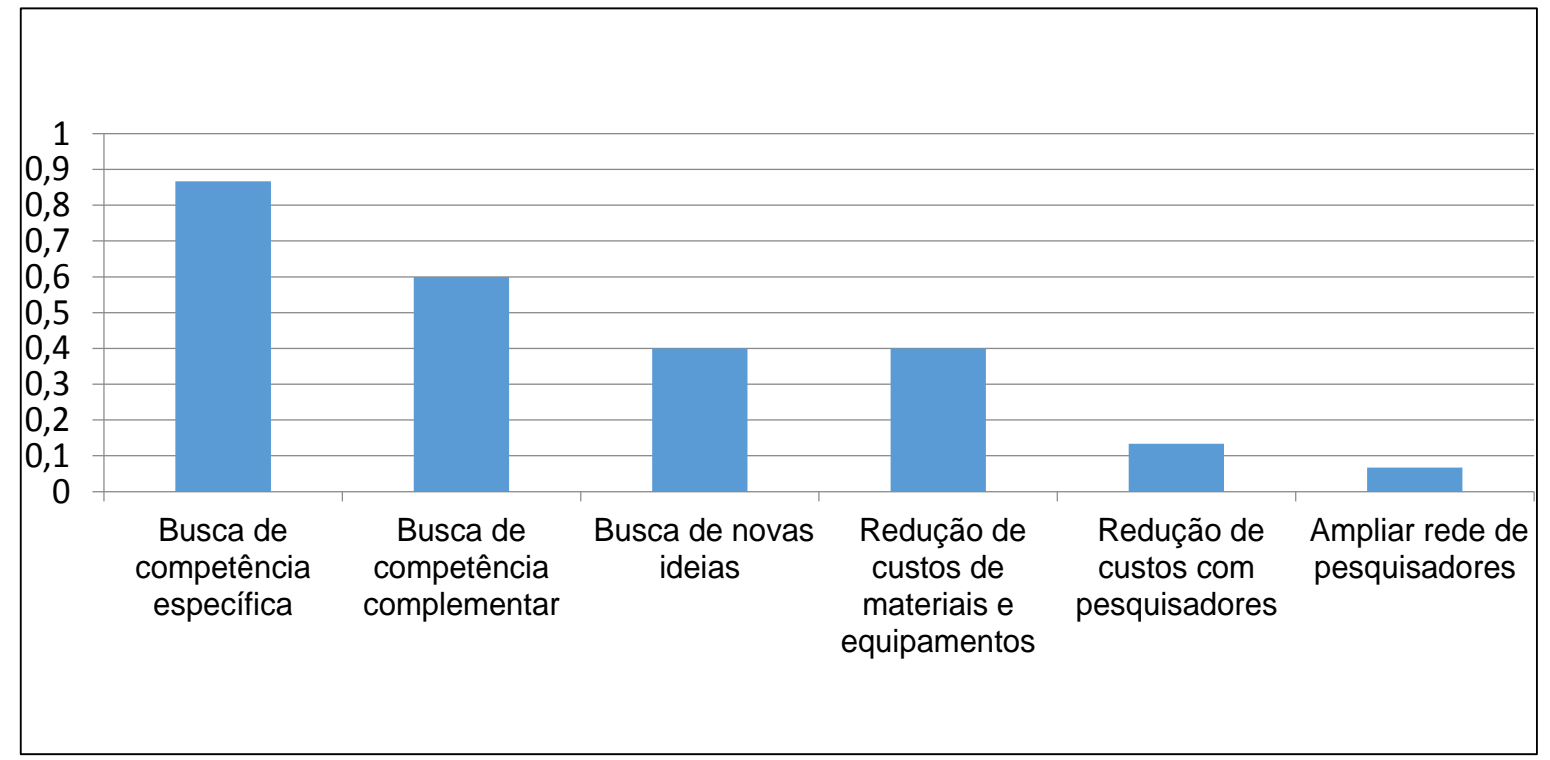

Gráfico 12 Motivos para busca de cooperação externa 
Na questão 5, o objetivo era identificar o tamanho da empresa e o quanto ela estava organizada para P\&D da inovação. Foi possível perceber que das 42 empresas respondentes, um total de $45 \%$ são de empresas que possuem laboratórios grandes de P\&D com mais de 100 profissionais envolvidos diretamente com pesquisa e $12 \%$ são de empresas de tamanho médio, sendo que o restante possui equipes com menos de 50 profissionais, conforme Quadro 10:

Quadro 10: № de Profissionais alocados no Laboratório de P\&D de Inovações

\begin{tabular}{|l|c|}
\hline $\mathbf{N}^{\circ}$ de Profissionais alocados no Laboratório de P\&D & \% de Respostas \\
\hline Não tem equipe de P\&D & 05 \\
\hline Até 3 profissionais & 12 \\
\hline De 4 até 10 profissionais & 10 \\
\hline De 11 até 50 profissionais & 17 \\
\hline De 51 até 100 profissionais & 12 \\
\hline Mais de 100 profissionais & 45 \\
\hline
\end{tabular}

Ao agrupar as empresas por tamanho de equipe de P\&D para verificar os tipos de inovações que desenvolvem foi possível perceber que as empresas menores têm maior foco em aprimoramento de produtos e processos, desenvolvendo pouco as novas tecnologias. As empresas maiores se destacam no desenvolvimento de novos produtos, novos processos e também novas tecnologias. As empresas de tamanho médio também realizam mais o aprimoramento de produtos, processos e tecnologia. As evidências são apresentadas nos gráficos $13 \mathrm{a}$ 18: 


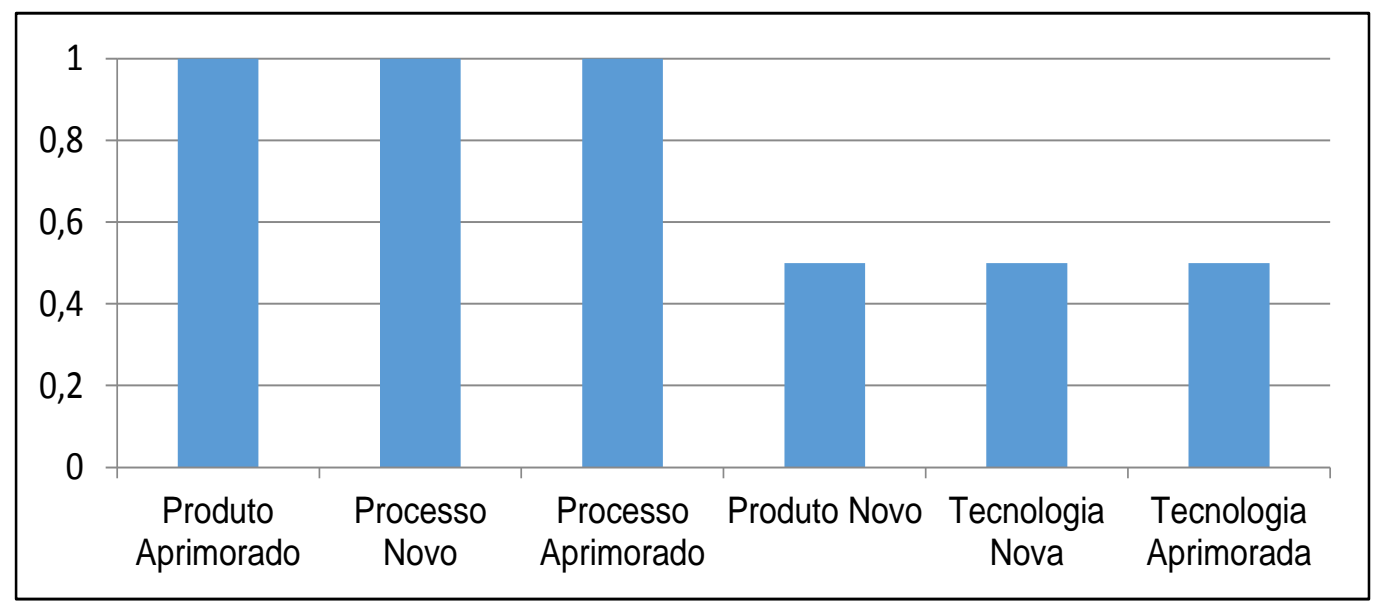

Gráfico 13 Tipos de inovações das empresas que não possuem equipe de P\&D

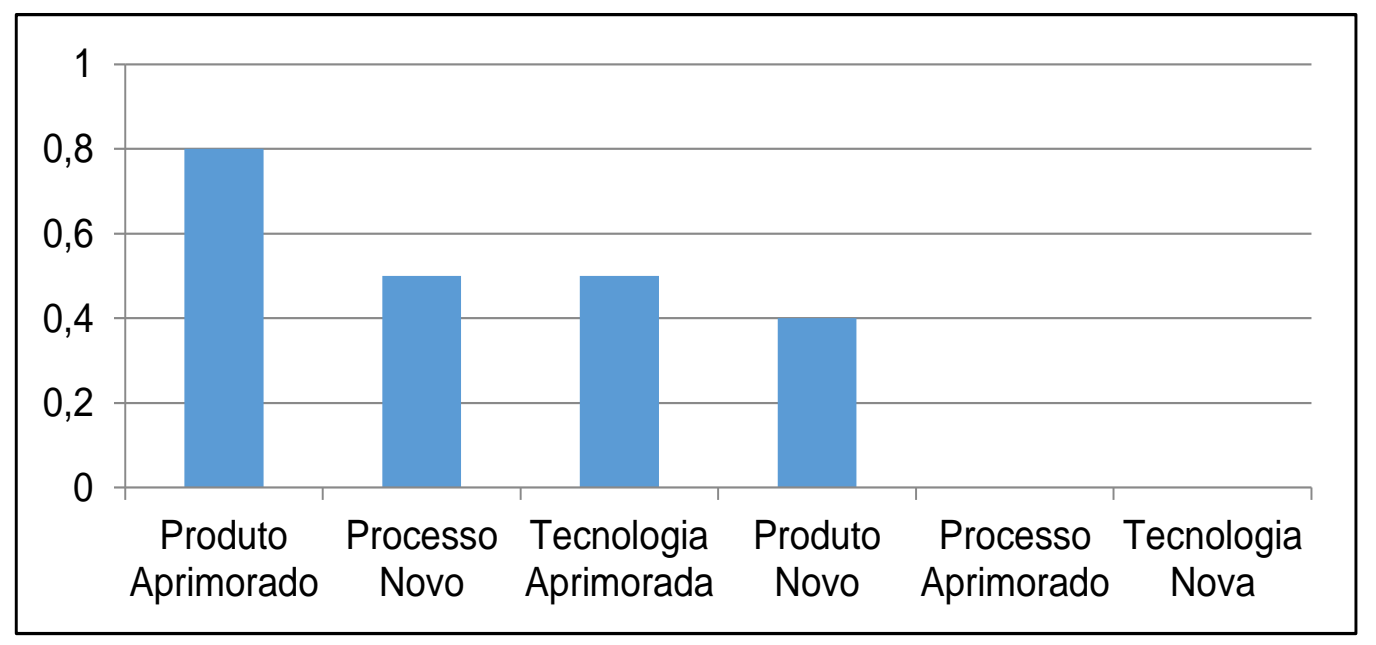

Gráfico 14 Tipos de inovações das empresas com até 3 profissionais no P\&D

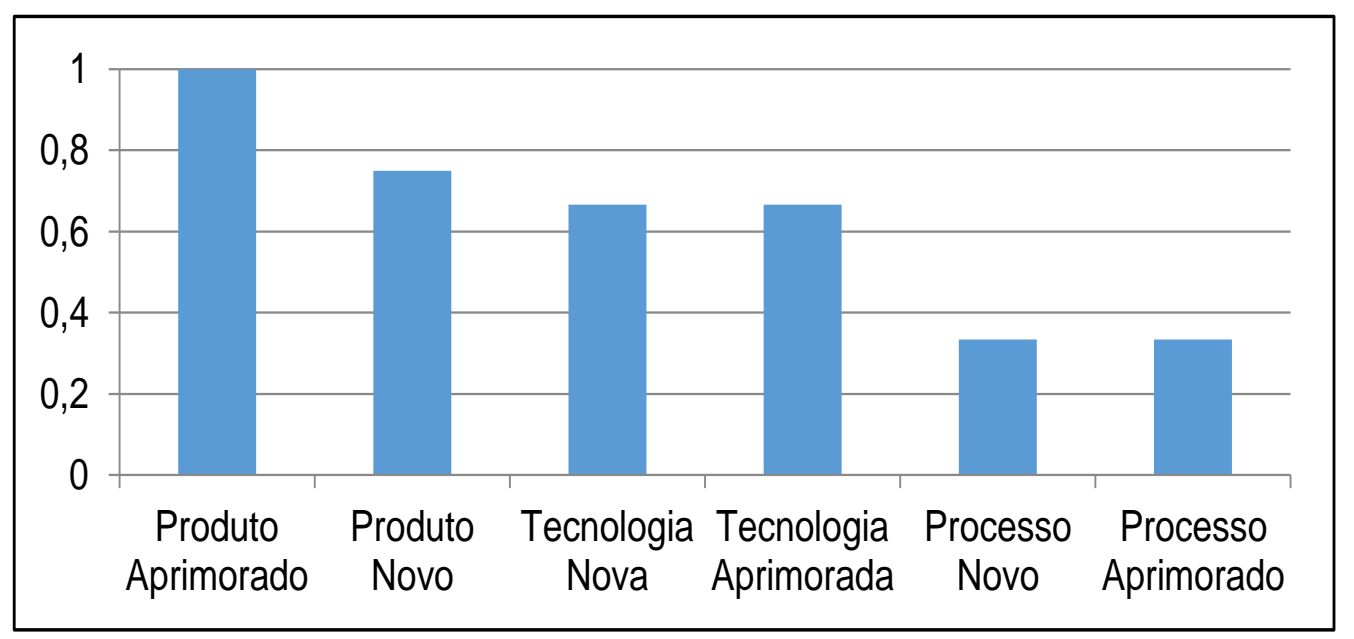

Gráfico 15 Tipos de inovações das empresas com 04 até 10 profissionais no P\&D 


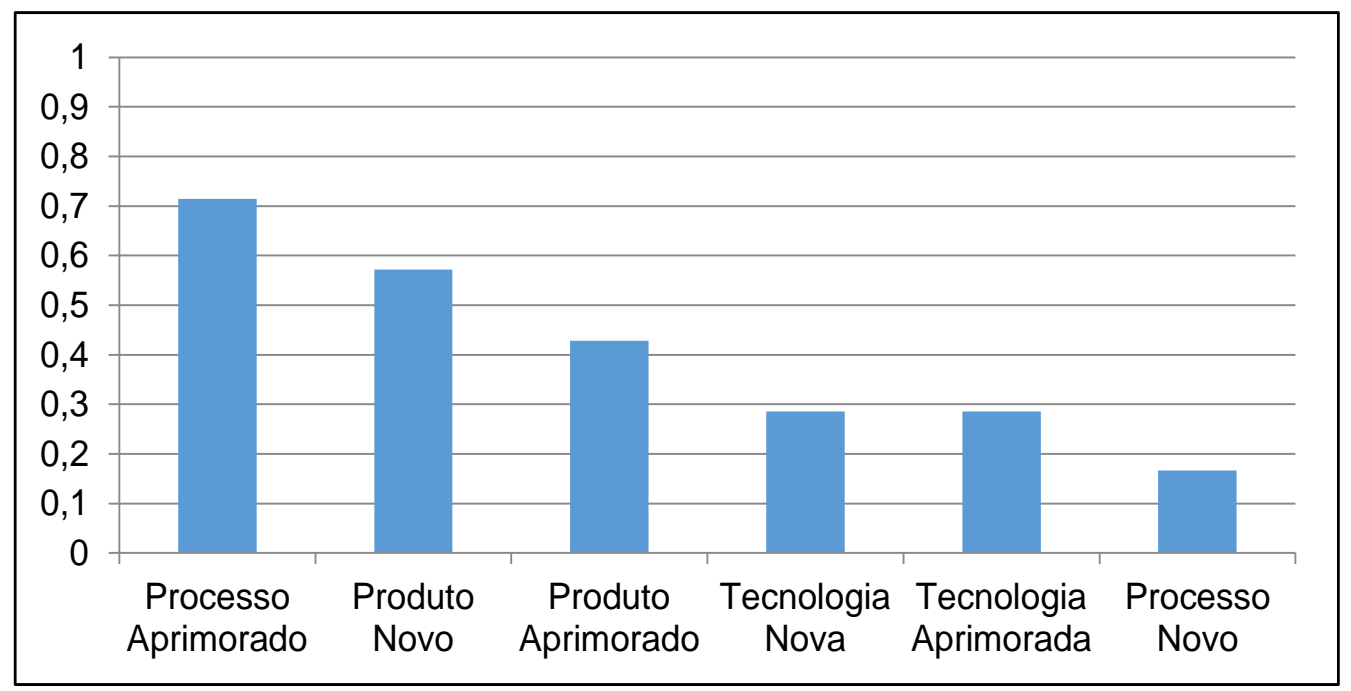

Gráfico 16 Tipos de inovações das empresas com 11 até 50 profissionais no P\&D

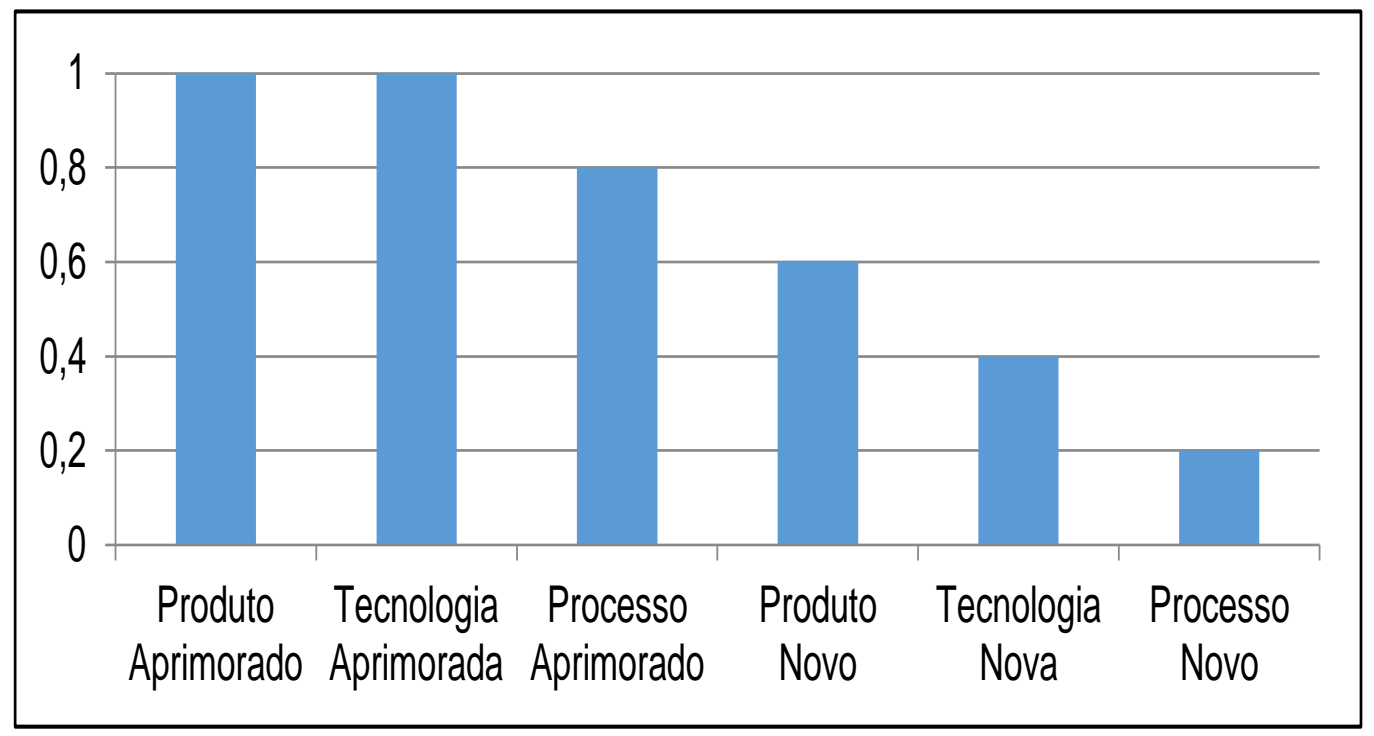

Gráfico 17 Tipos de inovações das empresas com 51 até 100 profissionais no P\&D 


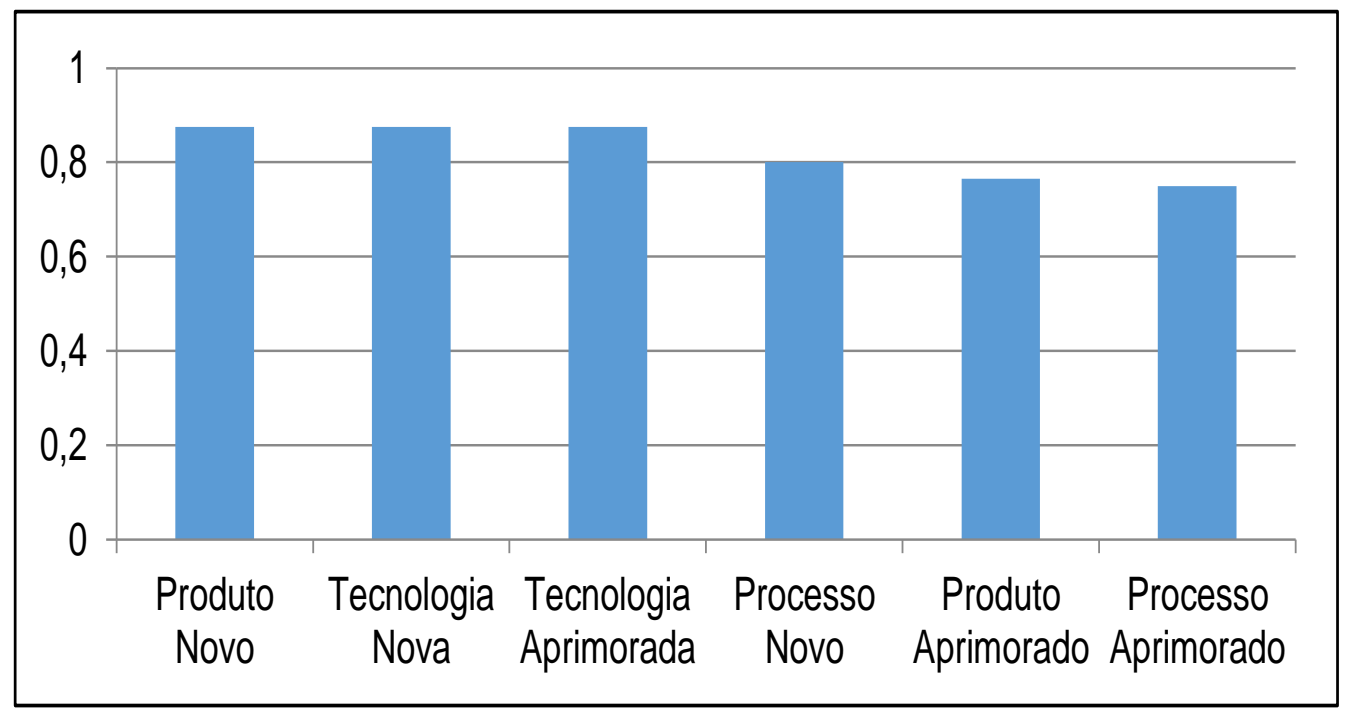

Gráfico 18 Tipos de inovações das empresas com mais de 100 profissionais no P\&D

Ao agrupar as empresas por tipo de inovação produzida, observa-se que as grandes empresas se destacam no desenvolvimento de novos produtos, conforme gráfico 19.

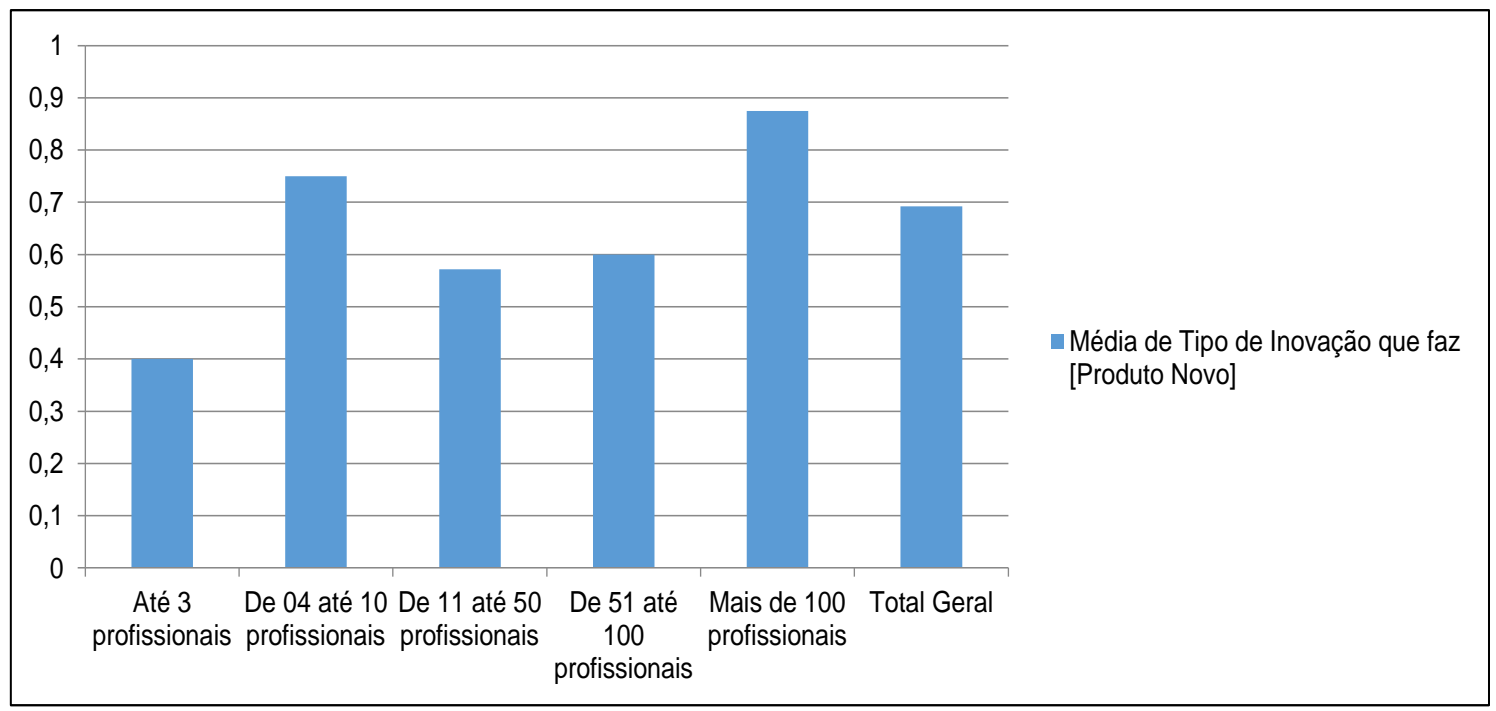

Gráfico 19 Tipo de inovação por tamanho do P\&D - produto novo

Quanto ao desenvolvimento de novos processos, observa-se que todas as empresas fazem algum esforço de desenvolvimento, com exceção das que não têm equipe de P\&D. As empresas maiores também investem mais no desenvolvimento de novos processos, conforme gráfico 20: 


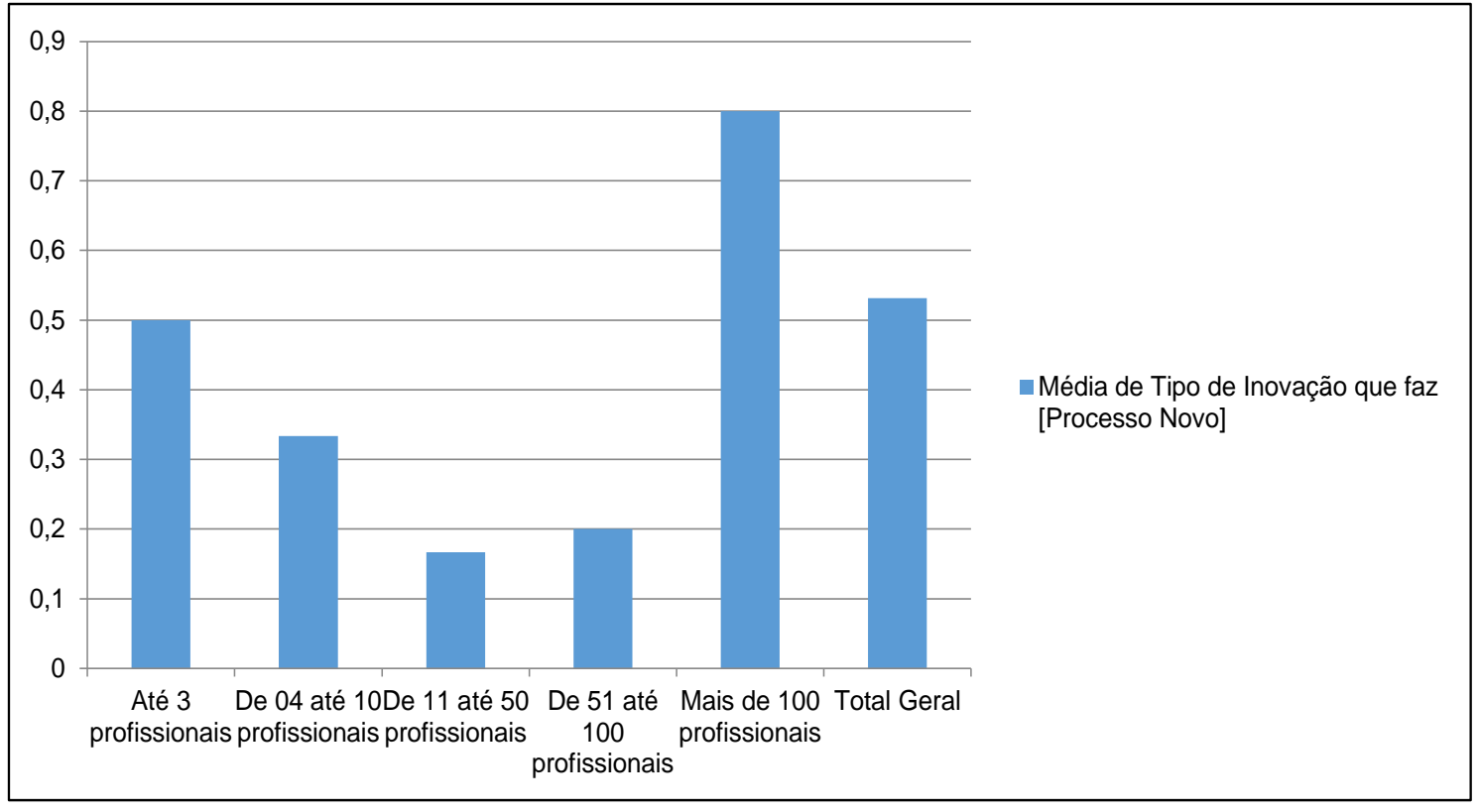

Gráfico 20 Tipo de inovação por tamanho do P\&D - processo novo

Para o desenvolvimento de novas tecnologias, pode-se observar que as grandes empresas investem mais nesse tipo de inovação. As empresas muito pequenas não realizam este tipo de inovação, provavelmente pelo alto custo envolvido, conforme gráfico 21 :

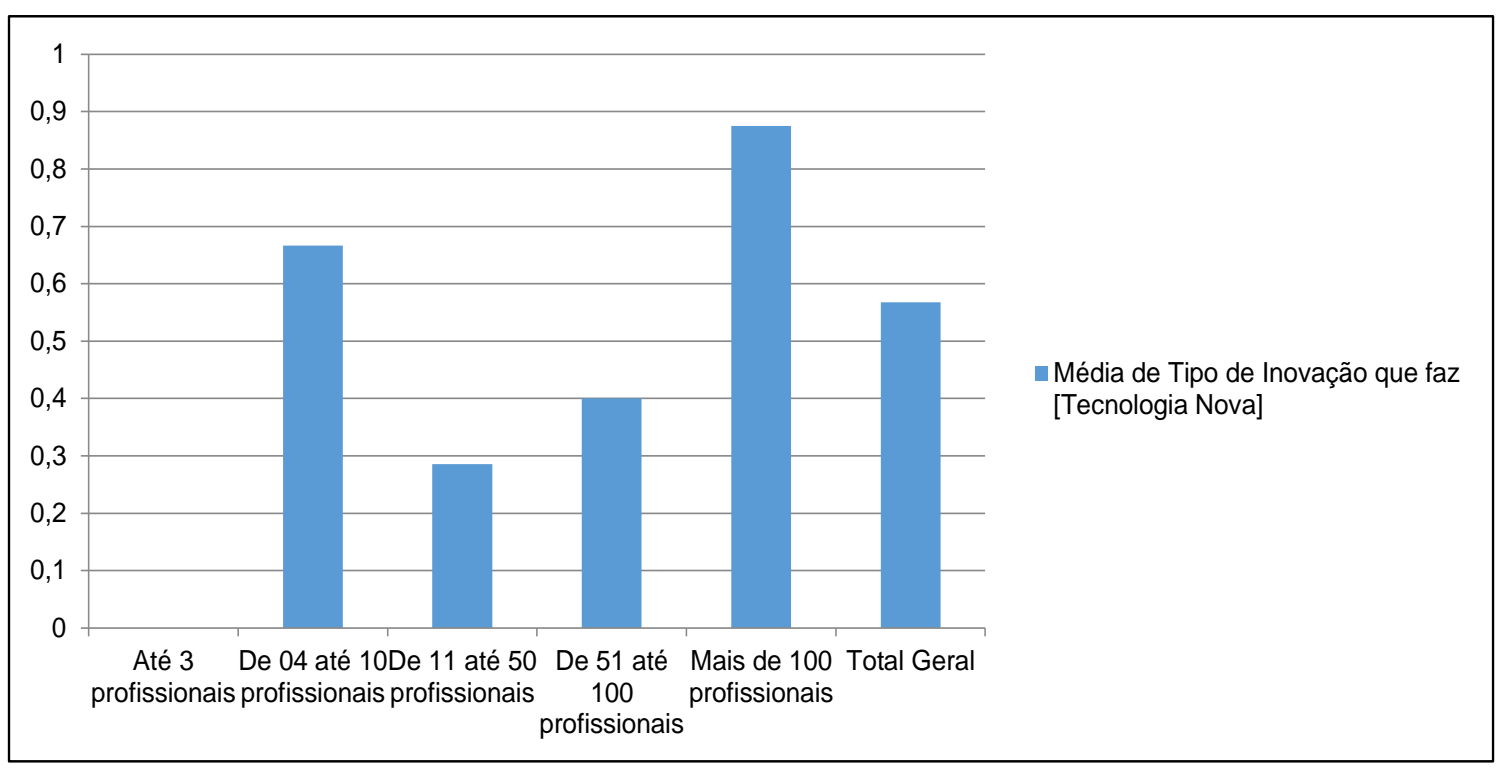

Gráfico 21 Tipo de inovação por tamanho do P\&D - tecnologia nova 
Verifica-se que todas as empresas realizam aprimoramento dos produtos já existentes, inclusive as empresas menores, conforme observa-se no gráfico 22 :

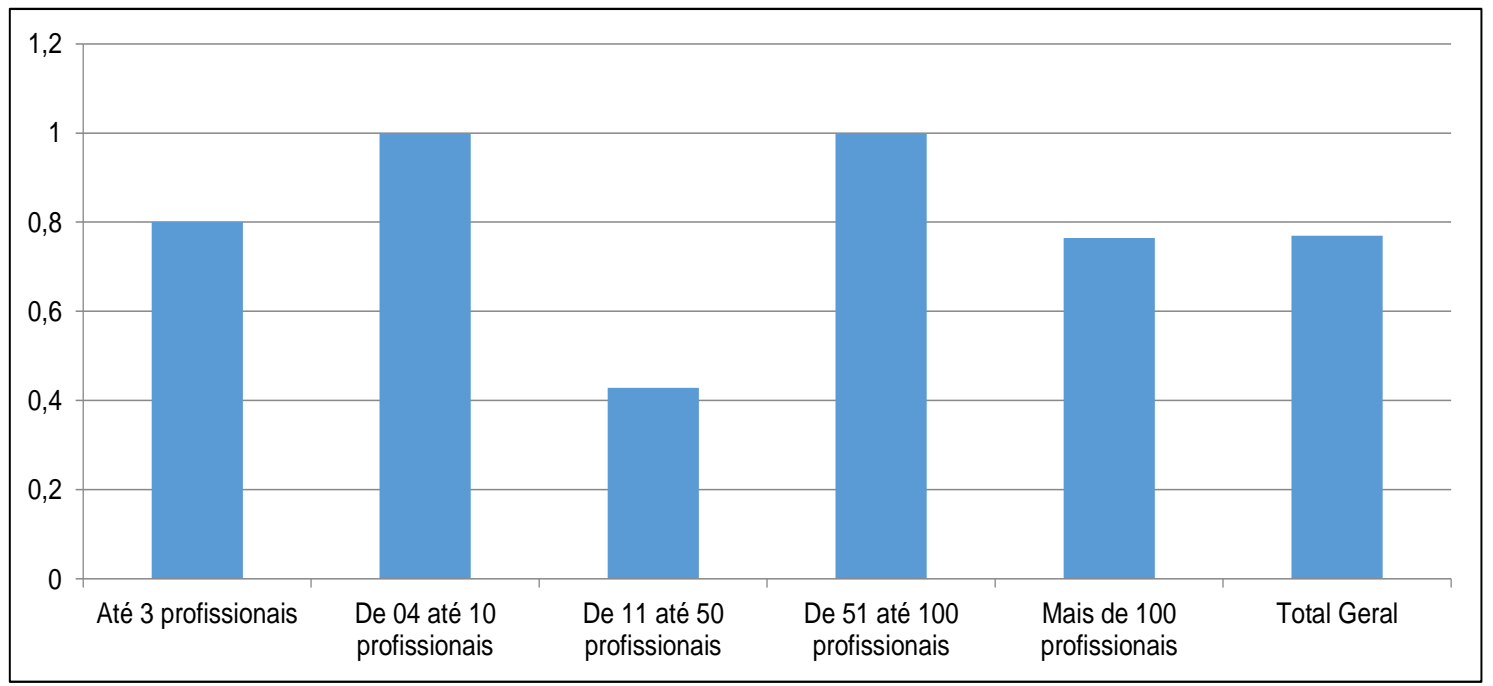

Gráfico 22 Tipo de inovação por tamanho do P\&D - produto aprimorado

Todas as empresas realizam aprimoramento dos processos já existentes, exceto as empresas menores que têm baixo índice de inovação, conforme observase no gráfico 23:

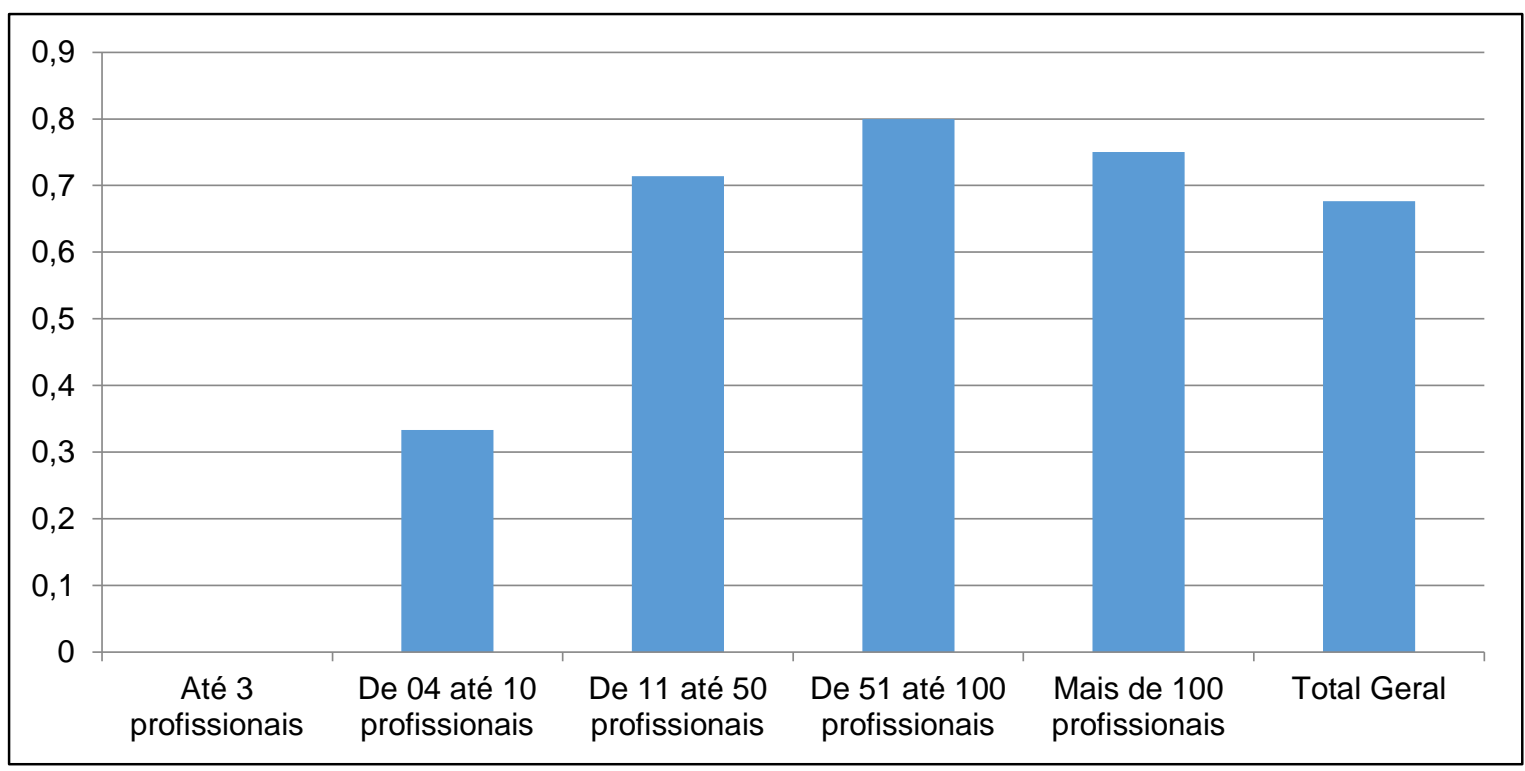

Gráfico 23 Tipo de inovação por tamanho do P\&D - processo aprimorado 
Quanto ao aprimoramento de tecnologias verifica-se que todas as empresas realizam este tipo de inovação, porém as empresas maiores inovam mais, conforme observa-se no gráfico 24 :

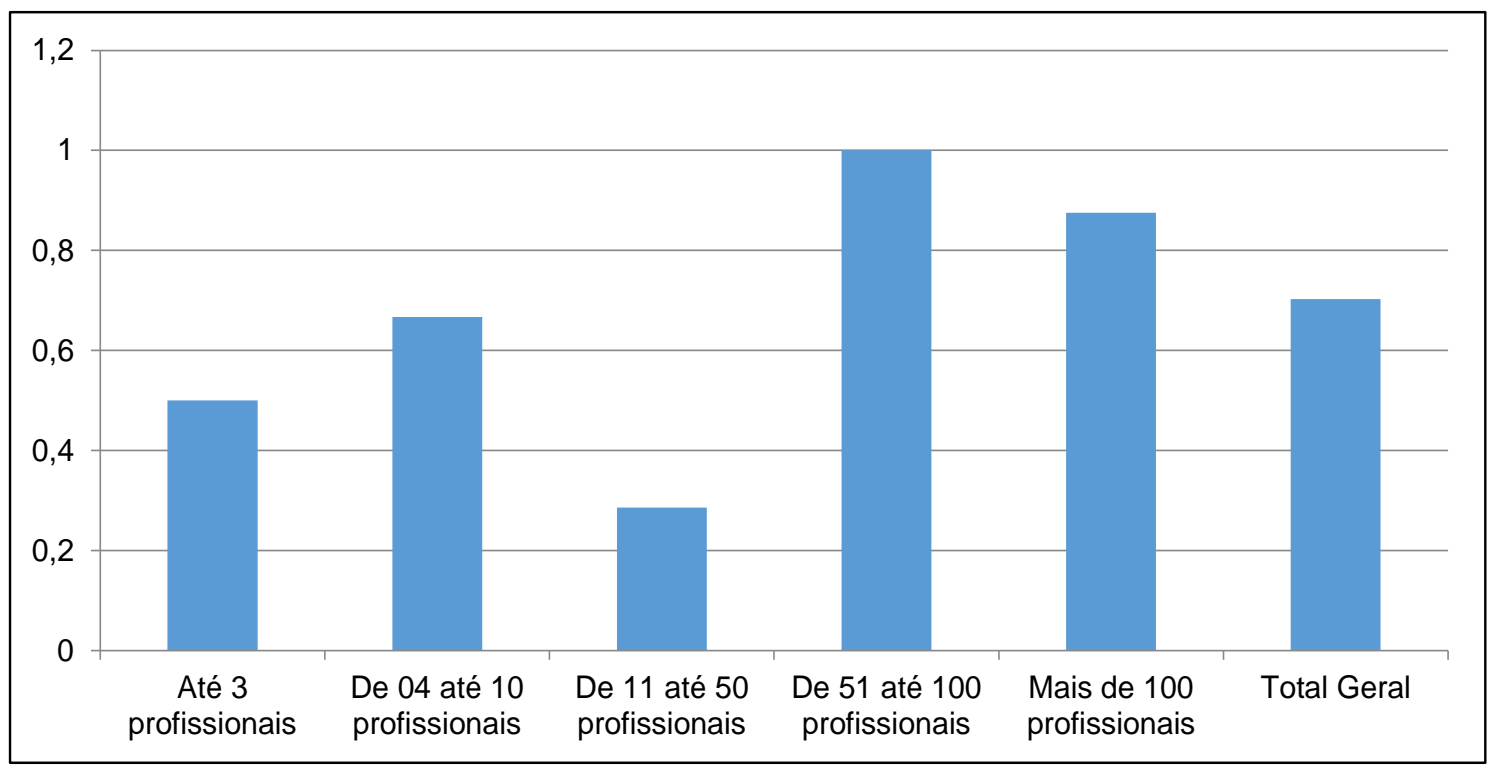

Gráfico 24 Tipo de inovação por tamanho do P\&D - tecnologia aprimorada

A última pergunta do survey era relativa às principais competências atribuídas às áreas internas das empresas envolvidas com P\&D. Os resultados são apresentados no quadro 11 :

Quadro 11 Principais competências das áreas envolvidas com P\&D

\begin{tabular}{|l|c|c|c|c|c|}
\hline \multicolumn{1}{|c|}{ Áreas } & P\&D & $\begin{array}{c}\text { Marketing e } \\
\text { Comercial }\end{array}$ & $\begin{array}{c}\text { Produção e } \\
\text { Operações }\end{array}$ & $\begin{array}{c}\text { Gestão da } \\
\text { Inovação }\end{array}$ & Jurídico \\
\hline $\begin{array}{l}\text { Competência } \\
\text { Técnica }\end{array}$ & 93 & 10 & 49 & 21 & 5 \\
\hline $\begin{array}{l}\text { Competência } \\
\text { Relacional }\end{array}$ & 5 & 21 & 11 & 26 & 8 \\
\hline $\begin{array}{l}\text { Competência } \\
\text { de Negócios }\end{array}$ & 0 & 64 & 11 & 26 & 8 \\
\hline $\begin{array}{l}\text { Competência } \\
\text { de Regulação }\end{array}$ & 0 & 2 & 8 & 3 & 74 \\
\hline $\begin{array}{l}\text { Competência } \\
\text { Organizacional }\end{array}$ & 2 & 2 & 22 & 26 & 5 \\
\hline Total (\%) & 100 & 100 & 100 & 100 & 100 \\
\hline
\end{tabular}


A partir da análise das respostas foi possível agrupar as principais competências atribuídas pelos respondentes, às áreas ligadas ao desenvolvimento de inovações. Na visão dos respondentes, a área de P\&D possui competências mais técnicas, que envolvem a pesquisa e geração de novas ideias, análise de oportunidades no mercado, o desenvolvimento de produtos, processos e tecnologias. Possuem também algumas competências relacionais mais voltadas para formação de parcerias e busca de conhecimentos no ambiente externo, conforme gráfico 25 :

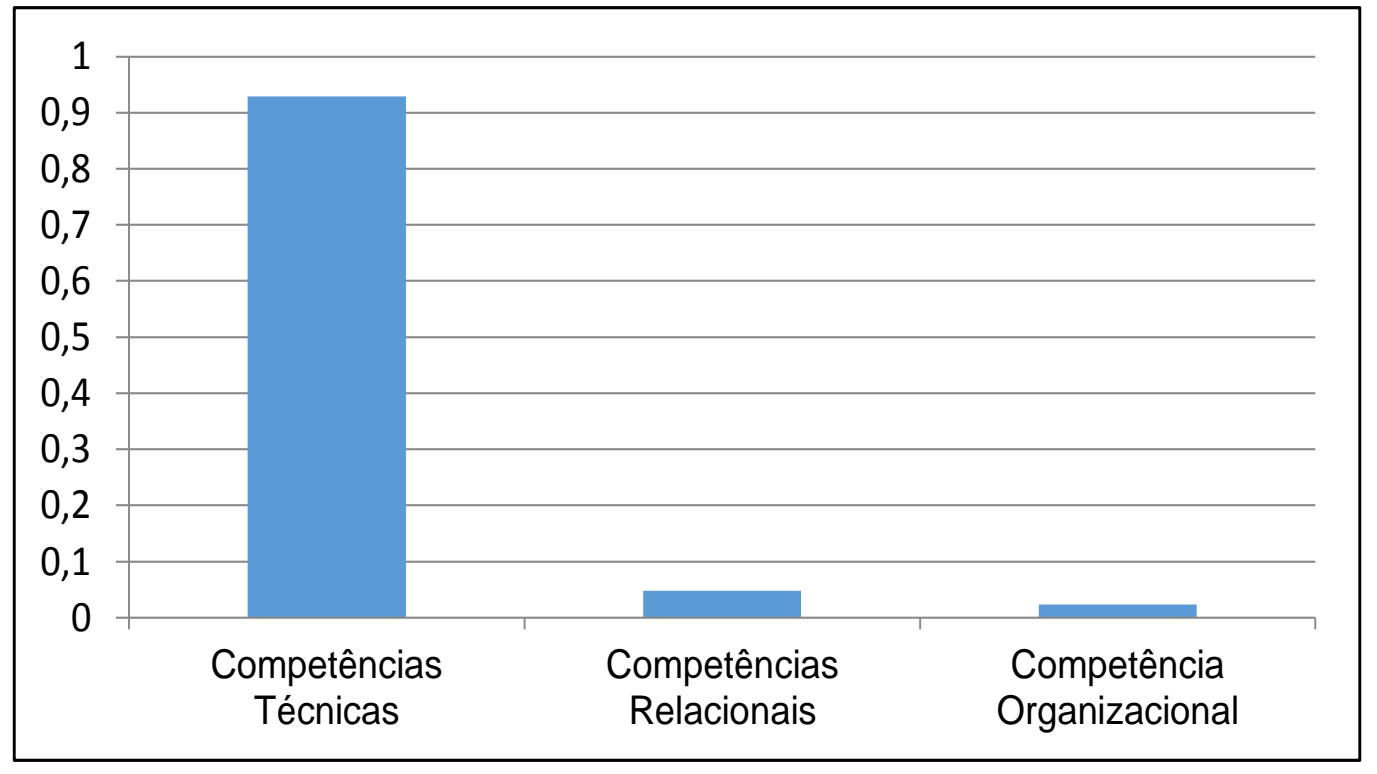

\section{Gráfico 25 Competências esperadas da área de P\&D}

A área de Marketing e Comercial possui competências de negócios, que envolvem a captação e seleção de novos projetos na interface com o mercado, o planejamento estratégico e a captação de fontes de financiamento e também competências relacionais, que envolvem a busca de parcerias e cooperação. Aparece a competência de regulação com menos de $5 \%$ que deve-se à implementação dos produtos, conforme gráfico 26 : 


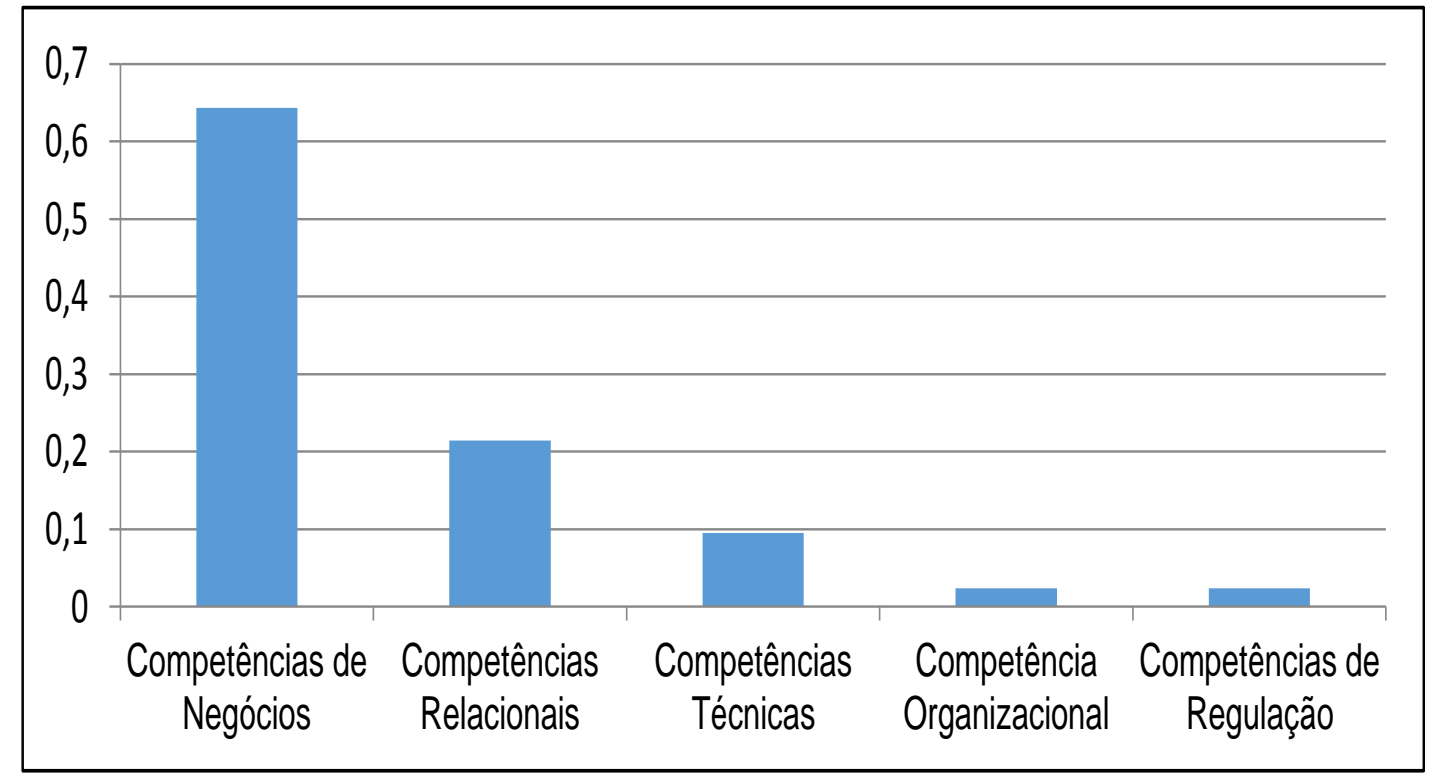

Gráfico 26 Competências esperadas da área de Marketing e Comercial

A área de Produção e Operações possui competências técnicas e também organizacionais, que envolvem a gestão da produção e de pessoal, conforme gráfico 27:

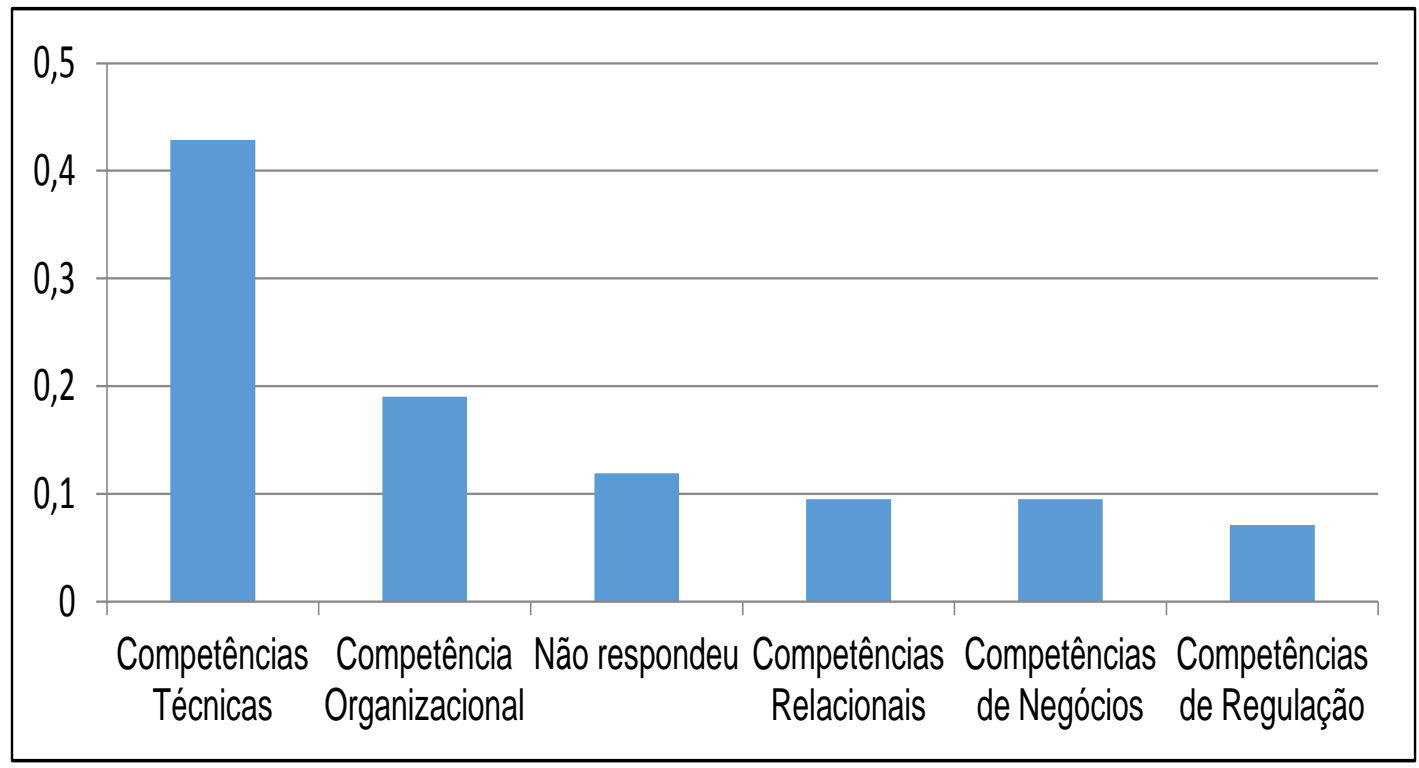

Gráfico 27 Competências esperadas da área de Produção e Operações

A área de Gestão da Inovação possui competências diversas, mas principalmente organizacional, relacional e de negócios, que envolvem desde a 
gestão da informação, a formação de parcerias, a elaboração do planejamento estratégico, a seleção de novos projetos e o controle financeiro, conforme gráfico 28 :

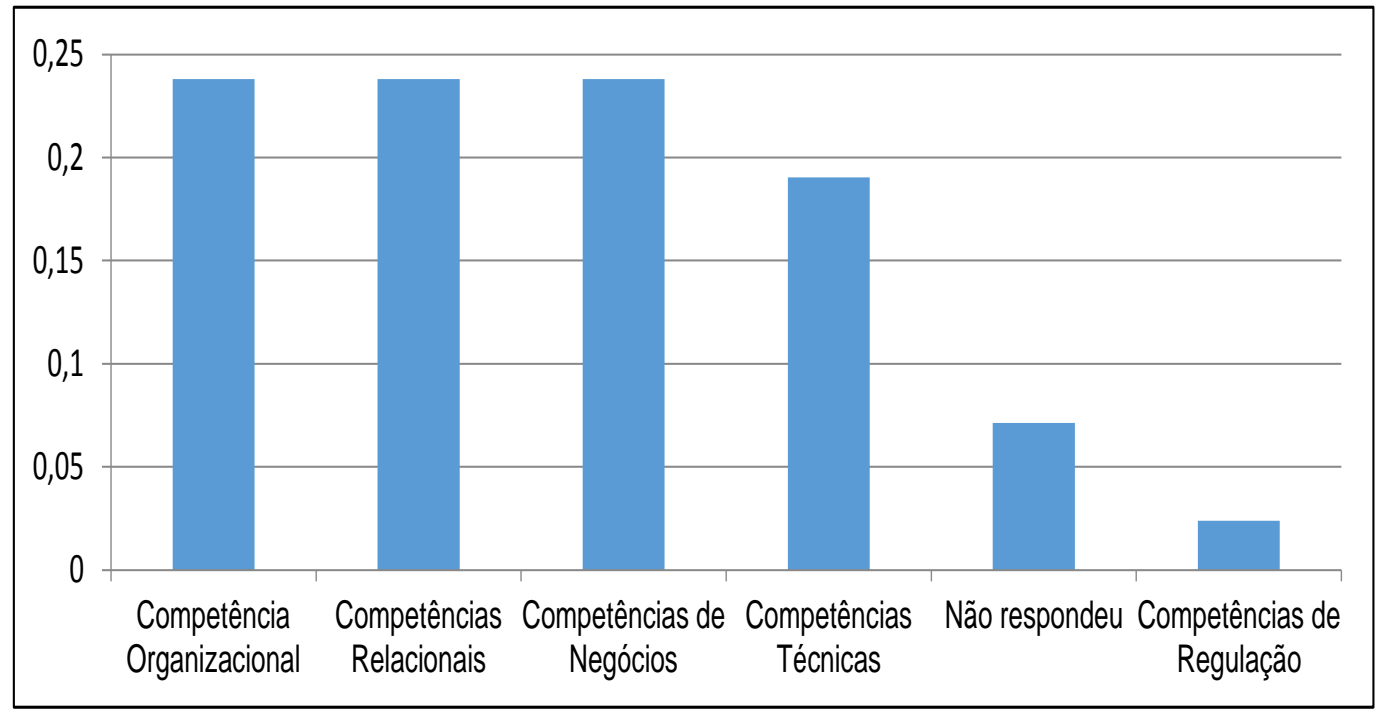

Gráfico 28 Competências esperadas da área de Gestão da Inovação

A área Jurídica possui as competências de regulação, que envolvem a formalização de contratos e licenciamentos, o monitoramento da propriedade intelectual, a análise e controle de riscos de projetos, entre outras, conforme gráfico 29:

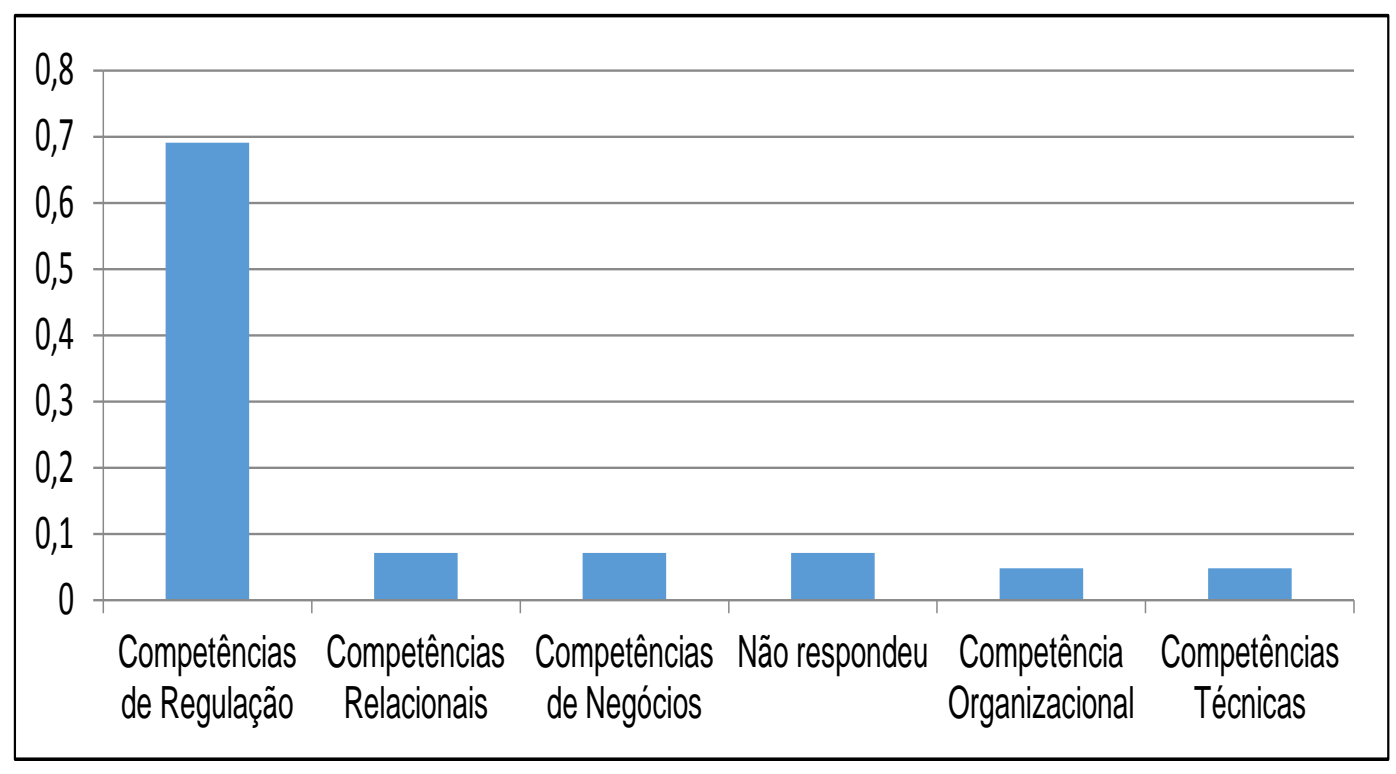

Gráfico 29 Competências esperadas da área Jurídica 


\section{ANÁLISE E DISCUSSÃO dOS CASOS E DAS PROPOSIÇÕES}

Conforme descrito no capítulo 1, o objetivo deste estudo era analisar como a organização do trabalho de pesquisa e desenvolvimento de inovações modifica as competências requeridas para realizar as atividades, exigindo em muitos casos que as empresas busquem as competências não existentes internamente, junto às empresas e instituições externas, para garantir o alcance de resultados.

Os aspectos da organização do trabalho de pesquisa e desenvolvimento de inovações foram investigados através de um estudo de múltiplos casos de empresas de diferentes setores industriais consideradas inovadoras e através de um survey com várias empresas de diversos portes e setores, que responderam um questionário autoaplicado via web.

Os dados coletados através das entrevistas em campo e dos resultados do survey apresentados no capítulo 4 possibilitaram o aprofundamento da discussão sobre as práticas utilizadas para organizar o trabalho de P\&D de inovações e sobre a importância das competências para o sucesso das inovações, bem como o levantamento de evidências para as proposições propostas no capítulo 3. Foi possível perceber a importância das competências desenvolvidas e compartilhadas pelos profissionais, tanto no ambiente interno quanto externo das empresas, para o desenvolvimento e garantia do sucesso das inovações. Ficou evidente o caráter sistêmico da inovação nas cadeias produtivas e seu poder de gerar desenvolvimento para a economia de um país.

Assim, este capítulo traz uma discussão da questão e proposições de pesquisa e sobre os aspectos anteriormente apresentados, partindo-se da pesquisa de campo, dos resultados do survey e do referencial teórico.

A principal contribuição do estudo é analisar como a organização do trabalho de pesquisa e desenvolvimento de inovações se relaciona com as competências requeridas para realizar as atividades, dentro de um contexto de complexidade e mudanças em que as empresas estão inseridas.

A análise considerou desde aspectos relacionados às características das empresas e tipos de negócios desenvolvidos até dados sobre a estrutura da área de 
P\&D destas empresas, com o objetivo de identificar as características organizacionais e estruturais das empresas bem sucedidas no lançamento de inovações.

Para atingir os objetivos, inicialmente foi feita uma revisão bibliográfica com levantamento de publicações na área de gestão e inovação, com análise de teorias clássicas e de abordagens mais atuais que analisam o processo de geração de inovações, as estratégias e formas adotadas para organizar o trabalho de P\&D e a importância do conhecimento e das competências nesse processo. A partir da análise teórica foram desenvolvidas as proposições que orientaram a pesquisa.

A análise das proposições a partir das evidências do estudo de múltiplos casos e do survey realizado geraram resultados importantes.

A primeira proposição desenvolvida para este estudo considerou que:

"uma rede de cooperação forte é um fator importante para viabilizar o sucesso na geração de uma inovação e assim a competência relacional dá sustentação às demais competências”.

Analisando as evidências da pesquisa de campo e do survey, pode-se concluir que a proposição é verdadeira. Verificou-se que as empresas analisadas formaram ao longo do tempo uma rede de cooperação forte com outras instituições e atores envolvidos direta e indiretamente na cadeia produtiva que proporcionam complementaridades de conhecimentos, práticas e competências para alavancar o desenvolvimento das inovações e da própria economia do país. O que diferencia as empresas é o nível de cooperação existente em cada uma delas, que depende da estratégia de internalizar ou externalizar etapas do processo de P\&D e do tipo de produto desenvolvido que pode exigir ou não um maior conteúdo científico e tecnológico, como no caso da empresa farmacêutica e de certa forma, a empresa mineradora.

Pode-se analisar a busca de conhecimentos e competências no ambiente externo, a partir da abordagem de Malerba (1992), que considera que as fontes internas de conhecimento para inovação são importantes, mas as fontes externas têm papel fundamental ao gerarem novos avanços na ciência e tecnologia, seja 
através de instituições de ensino e pesquisa, fornecedores, clientes ou empresas de uma mesma indústria.

Foi possível observar também as diferentes características da cooperação encontradas nas empresas, tais como: a divisão das atividades pelos profissionais de acordo com competências que depois se integram, a divisão do objeto do trabalho de forma simultânea ou não (que pode ser presencial ou à distância), a articulação temporal das ações na busca de cumprir os cronogramas dos projetos, a responsabilidade e autonomia dos profissionais na realização de certas tarefas, a coordenação das atividades entre os profissionais com a participação de um líder ou entre o próprio grupo. Estas características foram apontadas por Barthe (2003) como próprias de atividades cooperativas e apareceram em todas as empresas. Algumas empresas apresentavam estruturas mais hierárquicas, mas na interação com os parceiros e no ambiente externo, a cooperação ultrapassava as fronteiras mesmo geográficas, pois todas as empresas mantinham cooperação com parceiros globais.

Através do survey foi possível verificar as principais fontes de cooperação das empresas e em destaque apareceram os fornecedores, instituições de ensino e pesquisa, clientes e mesmo os concorrentes, embora com menos importância e não evidenciando o que foi proposto por Malerba (1992), ao observar outros países.

Destaca-se que a atuação no mercado global traz novas exigências e requer capacitações que as empresas precisam desenvolver internamente ou através de parcerias, o que desenvolve novas competências. A redução de custos com ativos de tecnologia, com pessoal e com a estrutura foi apontada nas entrevistas como um motivo para cooperar no ambiente externo, mas as evidências do survey revelaram que este não é o motivo principal. A busca por competências específicas ou complementares é que apareceu como o principal motivo. Muitas parcerias são formadas ao longo do tempo, ao criarem relações de confiança, mas no Brasil as empresas ainda estão muito focadas nas questões comerciais e jurídicas envolvidas nas relações. Muitas evidências relacionaram questões contratuais, de direitos de propriedade, segredo industrial, royalties e outras participações no retorno financeiro das inovações. Estas questões acabam inviabilizando algumas parcerias no país 
principalmente quando envolvem instituições públicas, pois as empresas lidam melhor com a parte de formalização dos projetos e das pesquisas.

Para participar da cooperação externa, as empresas precisam desenvolver competências organizacionais e capacidades internamente, de modo que possam acompanhar, escolher e absorver as tecnologias externas. Para acompanhar o desenvolvimento tecnológico no ambiente externo, os profissionais das empresas precisam desenvolver competências que lhes permitam acompanhar patentes, publicações e invenções, identificando oportunidades de novos negócios e novas ideias.

A segunda proposição desenvolvida afirmava que:

"as empresas buscam competências externas devido às especificidades de cada inovação, que exige competências complementares para o alcance de resultados".

A análise dessa proposição nas empresas estudadas toma como base os conceitos desenvolvidos por Rosenberg (1982), que considera o caráter sistêmico das invenções, ao envolver diversos atores que contribuem com diferentes insumos ou outras invenções que complementam uma invenção maior.

Foi possível concluir que a segunda proposição é verdadeira, pois a inovação é um processo sistêmico, que exige integração das cadeias produtivas com empresas participantes em estágio tecnológico semelhante ou empresas que possam desenvolver algumas das competências requeridas nos diferentes estágios do desenvolvimento do P\&D e participar enquanto fornecedoras. O grau da busca por competências externas depende de características dos produtos de cada setor e no setor farmacêutico, por exemplo, o grau de dependência dos parceiros externos é maior, dada a exigência de constantes pesquisas tanto científicas quanto tecnológicas, o alto custo das pesquisas com novos medicamentos e a necessidade de aprimorar os processos de produção para obter ganhos de escala e vantagens competitivas em relação aos concorrentes que são grandes empresas multinacionais. 
Outro aspecto que deve ser considerado e que foi evidenciado nas entrevistas é que a busca por cooperação externa depende da visão de cada empresa sobre a importância estratégica da geração de inovações e isto pode ser observado a partir da estrutura interna para inovação e dos investimentos destinados à $P \& D$ de inovações. Duas das empresas possuem grande estrutura interna voltada para inovação e áreas específicas de gestão da inovação. Além disso, os gestores entrevistados apontaram que a inovação fazia parte dos objetivos estratégicos das empresas. A empresa farmacêutica embora tivesse um tamanho menor, realizava grandes investimentos em $P \& D$, inclusive fomentando os parceiros externos e tinha uma visão da inovação como atividade estratégica, embora estivesse implantando uma área de gestão da inovação.

Embora o volume de investimentos em P\&D e a visão estratégica sobre a inovação sejam importantes, as empresas têm que ter competências para identificar e selecionar os parceiros e suas contribuições na geração de inovações, assim como para novos conhecimentos e tecnologias gerados no mercado. Desta forma, os profissionais das empresas têm que desenvolver competências antigas e novas, de forma que possam acompanhar as novidades no mercado e conseguir internalizar para fazer o desenvolvimento e fabricação. É um processo bem complexo e crucial para o sucesso na geração de inovações, que Cohen e Levinthal (1990) denominaram capacidade de absorção.

Essa capacidade de absorção depende do desenvolvimento de diversas competências individuais e organizacionais. Apesar da dificuldade de medição dessas competências, buscou-se nesta pesquisa avaliar quais são as competências requeridas para o sucesso no lançamento de inovações, a partir da abordagem de Munier e Rondé (2001) que agruparam as competências em: técnicas, organizacionais, relacionais e de meios.

Nas entrevistas foram utilizadas questões para explorar estas competências e os resultados demonstram que:

As competências técnicas são divididas em competências de conteúdo mais científico de pesquisa e prospecção de novas ideias nos ambientes interno e externo e também, competências mais operacionais voltadas para a eficiência dos 
processos e da implantação de tecnologias que melhorem a eficiência da produção. Para todas as empresas, a eficiência mais operacional e tecnológica é de extrema importância, uma vez que precisam obter ganhos de escala para concorrer no mercado e atender rapidamente as demandas dos clientes. Esta etapa de produção é praticamente uma atividade interna das empresas.

As empresas analisadas dependem muito de inovações tecnológicas e estas são produzidas por fornecedores de equipamentos e máquinas ou por parceiros que são desenvolvidos e formados nas empresas nascentes, como no caso da mineradora que precisa desenvolver fornecedores para atender as especificidades de seus negócios. No caso das químicas, petroquímica e da farmacêutica, as demandas por tecnologia são atendidas pelos fornecedores do mercado. Há aqui uma evidência já apontada por Pavitt (1984) de que empresas destes setores embora sejam baseadas em ciência, dependem muito dos fornecedores especializados de tecnologia, pois desenvolver tecnologia não é o foco do negócio. Apenas a mineradora desenvolve e aprimora tecnologias internamente. A partir dos resultados do survey verificou-se que as grandes empresas investem mais em inovações tecnológicas e as menores fazem aprimoramento de tecnologias já existentes, talvez pelo alto custo envolvido. As competências técnicas foram apontadas como competências mais das áreas de P\&D e de Produção \& Operações, pelos respondentes da pesquisa.

As competências organizacionais envolvem de maneira geral, a gestão dos recursos financeiros, materiais e humanos, a gestão do conhecimento e da informação. Nos casos analisados foi possível perceber que estas atividades e competências estão divididas entre as áreas de P\&D, Gestão da Inovação e Produção \& Operações. O que difere entre elas é que algumas estão mais estruturadas, duas delas possuem áreas de Gestão da Inovação ou Centro de PD\&I e uma possui um Conselho Científico. Estas que estão mais estruturadas realizam as análises e controles financeiros dos projetos, análise de viabilidade quanto aos objetivos estratégicos, busca de fontes de financiamentos das inovações e também algumas atividades de regulação e interface com as áreas de $P \& D$, Marketing e Produção. As unidades de negócios têm autonomia para desenvolver os projetos e parcerias, mas em uma empresa química de tamanho menor, a matriz centraliza e 
controla estas ações, mesmo das unidades que a empresa possui em outros países. Nas empresas que não estão tão estruturadas, estas atividades e competências estão divididas entre as áreas de P\&D, Marketing e Produção. Os gestores destas áreas realizam também as atividades de gestão de pessoal, gestão do conhecimento e da informação pertinentes às atividades que realizam.

As competências organizacionais também foram apontadas como competências mais das áreas de Gestão da Inovação e de Produção \& Operações, pelos respondentes da pesquisa.

As competências relacionais envolvem as habilidades de busca de diferentes formas de parcerias e cooperação, bem como atuar no mercado na captação de novas ideias, conhecimentos e tecnologias. São atividades diversas que envolvem diferentes áreas com competências específicas, tais como as atividades de regulação que envolve mais a área jurídica, porém as demais áreas também têm que acompanhar a legislação e normas certificadoras. Há grande fluxo de informações e conhecimentos no ambiente interno das empresas e de suas unidades, que promove a busca por formas e técnicas eficientes de organizar o conhecimento. As empresas relataram o uso de seminários, conferências e reuniões internas, que envolvem funcionários das diferentes unidades, para divulgar novas ideias, conhecimentos e projetos desenvolvidos pela empresa, de forma que não haja redundância nos trabalhos e para tornar mais eficientes as trocas de conhecimentos e técnicas. Participam também de congressos científicos, feiras, seminários, visitas técnicas, no país e no exterior, a fim de mapear o que está sendo produzido de inovações e atualizar conhecimento. A gestão do conhecimento é uma atividade muito importante para a P\&D de inovações e tem dimensões regulatórias, uma vez que envolve direitos de propriedade, segredo industrial, registro de patentes, entre outras. Uma das empresas relatou ter iniciado a técnica de filmagem das reuniões de modo que possa tornar o conhecimento tácito em conhecimento registrado, uma vez que há grande mobilidade dos pesquisadores, inclusive para outras unidades de negócios da própria empresa.

As competências relacionais são muito importantes, mas para que tenham eficácia é necessário que os profissionais tenham desenvolvidas diversas 
competências técnicas, nas suas áreas de atuação (P\&D, Marketing, Jurídico, Produção, Operações) e para isto, deve haver cumulatividade de conhecimentos na organização, que ocorre ao longo do tempo, conforme destacado por Malerba e Orsenigo, (2000). Essa cumulatividade ocorre através dos processos de aprendizagem, como a aprendizagem externa (learning by interacting) nas parcerias e relações com outras instituições, que nos casos estudados envolvem principalmente as instituições de ensino e pesquisa, os fornecedores, os clientes, outras empresas do setor, as consultorias, as ONG's e os centros de capacitação.

As competências relacionais foram identificadas como competências mais das áreas de Gestão da Inovação e de Marketing \& Comercial, nas respostas do survey, embora outras áreas também tenham sido relacionadas como responsáveis por estas atividades.

As competências de meios envolvem aspectos de regulação, tais como formalização de contratos, projetos e licenciamentos, análise e controle de riscos de projeto, monitoramento da propriedade intelectual. Envolve ainda aspectos de negócios, tais como elaboração do planejamento estratégico, seleção de projetos, captação de recursos e análise e controle de custos. Nos casos estudados foi observado que as competências de regulação são atribuídas geralmente ao jurídico, embora outras áreas também tenham sido mencionadas no survey como responsáveis por essas competências, só que em menor grau. A parte de regulação é muito importante para todas as empresas estudadas, tanto nos contratos e parcerias quanto no desenvolvimento e fabricação de produtos e matérias primas que têm que respeitar normas certificadoras, testes, impactos ambientais e no ser humano. Algumas empresas possuem equipe específica para mapear a legislação, realizar análises de tendências em relação ao que a sociedade e ONG's dizem sobre riscos contaminantes de produtos e matérias primas, projetos de lei etc.

As competências de negócios estão divididas entre a área de marketing e a de gestão da inovação, nas empresas que possuem esta segunda área. Verificou-se que a área de gestão da inovação centraliza os orçamentos destinados à P\&D e aos projetos, selecionando e acompanhando aqueles que estão inseridos nos objetivos estratégicos da empresa. É uma área que faz a interface entre a cúpula estratégica 
e as áreas envolvidas com inovação. Realiza ainda a captação de recursos e financiamentos no mercado, o controle dos projetos e a busca por parcerias. Nas empresas que não possuem a área de gestão da inovação ou uma área similar, estas atividades voltadas para o mercado ou de negócios são em grande parte atribuídas à área de marketing, sendo que a área de produção e operações também foi mencionada como responsável por algumas competências e atividades mais ligadas ao controle de custos e orçamentos de materiais e pessoal.

A terceira proposição considerou que:

"a competência de negócios vem ganhando importância em muitas empresas, evidenciando que a competência técnica não tem primazia no processo de inovação, inclusive por causa dos estímulos gerados por programas institucionais de incentivo".

Esta proposição não se confirmou, embora tenha sido mencionado em várias entrevistas que as empresas estavam se organizando e desenvolvendo competências mais jurídicas, no sentido de buscar fontes de financiamento público e benefícios para a geração de inovações, como por exemplo, a Lei do Bem. Os gestores têm domínio sobre todas as fontes e tipos de financiamentos existentes no país e alguns no exterior e conhecem os aspectos positivos e negativos de buscar estes financiamentos.

O ambiente institucional vem favorecendo o desenvolvimento de inovações ao conceder benefícios fiscais para a empresa que inova, então sem inovação não há benefícios fiscais, porém as empresas relataram que a burocracia dificulta os processos e os projetos de inovações têm cronogramas apertados para o desenvolvimento e cada atraso gera custos. O fato de a inovação fazer parte da estratégia das empresas e ter altos custos envolvidos faz com que as empresas busquem eficiência na gestão dos recursos financeiros e por isso, desenvolvem competências de gestão da inovação tal como a gestão de um negócio.

Em muitas empresas, a viabilidade de um projeto de inovação é dada pela adequação ou não aos objetivos estratégicos da empresa e ao seu negócio, então muitos projetos acabam sendo descartados e não recebem orçamento. Porém, a competência técnica é muito importante e tem relação direta com a competência de 
negócios, esta última dá subsídios para que a outra se desenvolva. Além disso, o ambiente empresarial tem um foco na aplicação e comercialização da inovação, diferente de uma pesquisa de caráter científico ou mais acadêmica, mesmo porque a empresa precisa ter o retorno do investimento feito. As pesquisas no setor farmacêutico, por exemplo, demoram anos até a etapa de comercialização e para ter um retorno econômico, sendo que os investimentos nas pesquisas e na estrutura para fabricação são enormes. Vários gestores mencionaram ainda, que há inovações de altíssimo risco, as inovações de ruptura, que as empresas não sabem se ao final elas serão ideias viáveis para comercialização. No país não há financiamento público para este tipo de inovação tal como ocorre em outros países, segundo mencionado por um entrevistado. As empresas não têm estímulos para produzir inovações de ruptura, mesmo as grandes e bem estruturadas.

Uma das empresas, a de extração mineral, apresentou uma visão da inovação dentro de uma perspectiva de sustentabilidade, que envolvia tanto os negócios da empresa quanto o desenvolvimento das comunidades locais, que implica na geração de emprego e renda, no desenvolvimento e construção dos parceiros locais, na preocupação com o impacto ambiental e elaboração de ações para minimizá-lo, na geração de capacitação dos profissionais internos e daqueles que atuam no setor seja no país ou no exterior, no financiamento de projetos que não necessariamente fazem parte dos negócios da empresa, mas que envolvem a comunidade do seu entorno. Este modelo de geração de inovações evidencia que é possível desenvolver inovação com retornos para todos os atores da sociedade e não só para a empresa e que isto pode impulsionar o desenvolvimento econômico do próprio país. 


\section{CONCLUSÃO}

Esta tese de doutorado estudou a organização do trabalho de pesquisa e desenvolvimento de inovações, tendo como foco o desenvolvimento de competências requeridas para realizar as atividades e as relações de cooperação com atores do ambiente externo.

O desenvolvimento de diversas competências é um atributo importante para as empresas que buscam o sucesso na P\&D de inovações, como forma de garantir a competitividade e a sobrevivência no mercado. Nesta pesquisa, buscou-se agrupar as competências em técnicas, organizacionais, relacionais e de meios, adaptandose a tipologia elaborada por Munier e Rondé (2001), que foi fundamental na formulação e análise das proposições de pesquisa e dos objetivos propostos.

A inovação cada vez mais necessita de ativos que estão dispersos geograficamente, sejam de materiais, pessoas, recursos naturais e outros. Desta forma, as empresas precisam formar conexões e criar mecanismos que facilitem os fluxos de conhecimento e informações, agregando valor e desenvolvendo novas competências internamente. Esta interação, que Kline e Rosenberg (1986) chamaram de processo interativo da inovação, é cada vez mais forte e, com cada vez mais frequência, as empresas recebem feedbacks do mercado e de outros agentes envolvidos no processo, sejam clientes, profissionais, fornecedores, institutos de ensino e pesquisa, entre outros.

Nesta visão interativa da inovação, percebe-se que as relações ocorrem através das competências compartilhadas entre os atores, algumas mais explicitamente e outras de maneira tácita, quando não interessa ao profissional que sua competência seja transmitida, seja por não fazer parte do escopo do negócio do seu parceiro ou por questões de sigilo e patente. Neste processo, há fornecedores, compradores, clientes, usuários, agentes reguladores e outros atores envolvidos.

Nesta dinâmica não basta ter o capital e fazer a aquisição de tecnologias, pois é necessário ter o conhecimento para selecionar a melhor tecnologia e depois fazer uso dela de maneira eficiente. Isto é que dará vantagem competitiva à empresa, que só será obtida se os seus profissionais possuírem as competências 
necessárias, desenvolvidas ao longo do tempo, pela cumulatividade de conhecimentos, de técnicas e pela atualização constante para dar conta das mudanças no ambiente externo. A capacidade de absorção de novos conhecimentos e novas técnicas é fundamental para as empresas e é a garantia de que novas competências se formarão ao longo de suas trajetórias.

Além disso, as atividades de pesquisa científica e empírica devem ter 0 máximo de integração, pois uma ideia pode surgir tanto no ambiente acadêmico como no meio empresarial, mas a difusão de conhecimentos gerados precisa necessariamente ocorrer entre os diferentes atores, se a intenção é criar uma inovação.

Portanto, o processo de inovação deve ser considerado como um processo social, em que os atores e as organizações cooperam, seja através de relações contratuais ou de relações de confiança mais duradouras, com um objetivo comum que pode ser uma contribuição científica ou uma aplicação industrial e cada vez mais, as duas devem estar interligadas, como apontam as evidências encontradas na tese e em outras pesquisas que seguem esta mesma linha de análise. Uma forma de alavancar as pesquisas e desenvolver a ciência, sendo que os recursos são cada vez mais escassos, tem que envolver esse aspecto do retorno econômico da inovação.

Uma das contribuições da tese é mostrar que o grau de dependência das competências externas varia muito com as características de cada segmento, das características do próprio negócio e do modelo de inovação de cada empresa.

Para muitas empresas é mais interessante internalizar o máximo de etapas do processo de P\&D e reduzir a dependência de terceiros, mas para outras empresas o importante é focar na sua competência essencial e externalizar algumas etapas. A empresa precisa estar em sintonia com o restante da cadeia e, por isso, deve desenvolver várias competências complementares envolvidas no negócio, até para poder explicitar a sua demanda para o fornecedor.

Algumas instituições têm esse papel de regular as relações e de criar condições para que as pesquisas se desenvolvam no país, com o uso de incentivos (incluindo aqueles que as empresas mais demandam, os incentivos fiscais), mas 
sobretudo investindo em centros de capacitação e formação, na construção de infraestrutura e na própria coordenação dos esforços de cooperação nas cadeias produtivas, de forma que o país possa construir um sistema de C,T\&l forte.

As empresas pesquisadas mostraram-se preocupadas em estruturar a inovação para enfrentar a concorrência global e sobreviver no mercado, independente do setor industrial ou porte da empresa. Até mesmo as grandes empresas que realizam esforços substanciais para acompanhar o mercado e concorrentes globais, defrontam-se com questões como a falta de pessoal altamente qualificado no país para preencher as lacunas existentes nas cadeias produtivas.

O Estado tem papel fundamental no apoio ao desenvolvimento de competências, que não são só organizacionais e das empresas, mas também competências do sistema de inovação do próprio país. O desenvolvimento de um setor gera impulsos para o desenvolvimento em outros setores, pois há uma interdependência muito forte, sejam por descobertas de novos produtos, matérias primas ou insumos, sejam por novas tecnologias ou ainda por inovações em processos.

Em toda pesquisa faz-se necessário realizar escolhas e delimitações e por esse motivo não foram investigadas algumas questões relativas às características organizacionais, por exemplo, a influência da cultura organizacional no processo de $P \& D$ ou se a origem da empresa gera diferenças na forma como se estrutura o P\&D e a própria cooperação interna.

Outra limitação do trabalho que já era evidente na metodologia, é que esta amostra de empresas não era representativa dos setores industriais considerados e, portanto, o estudo não envolveu análises quantitativas e setoriais mais detalhadas, que permitissem generalizações.

No decorrer desta pesquisa, algumas oportunidades para futuros estudos foram identificadas. As futuras pesquisas sobre gestão da inovação podem investigar em profundidade o papel que as instituições possuem no desenvolvimento das competências organizacionais e na inovação, com incentivos que podem determinar a trajetória da indústria nacional. 
Outro tema proposto é a análise mais aprofundada das competências requeridas na P\&D de inovações por setor industrial e dentro das cadeias produtivas. Estudos quantitativos também são viáveis para traçar um panorama com amostras maiores de empresas de diferentes tamanhos, que podem ajudar na construção de teorias na área de inovação e de gestão de competências. Estudos comparativos entre pesquisas desenvolvidas com amostras de empresas de outros países podem enriquecer as análises e gerar a proposição de modelos. 


\section{REFERÊNCIAS}

ABIFINA. Medicamentos - o desafio da produção nacional. Disponível em: http://www.abifina.org.br/abifina midia.asp (acesso em novembro 2013).

ABIQUIFI. Um olhar sobre o mundo. Disponível em: http://www.abiquifi.org.br/publicaçoes (acesso em junho 2012).

ABIQUIM. O desempenho da indústria química brasileira em 2013. Disponível em: $\quad$ http://www.abiquim.org.br/pdf/Livro Desempenho da Industria Quimica.pdf (acesso em janeiro 2014).

ACEMOGLU, D.; JOHNSON, S.; ROBINSON, J. Institutions as the Fundamental Cause of Long-Run Growth, NBER Working Paper 10481, Cambridge, MA (http://www.nber.org/papers/w10481), 2004.

ANDRADE, C. A. A. Inovação e externalização: uma análise de capabilities na indústria farmacêutica. Tese (Doutorado em Engenharia de Produção) - Escola Politécnica, Universidade de São Paulo, São Paulo, 2010.

ANPEl. Como alavancar inovação tecnológica nas empresas. São Paulo, 2004.

ANVISA. Brasil inaugura fábrica de medicamentos. Disponível em: http://s.anvisa.gov.br/wps/s/r/cmjE. (acesso em fevereiro 2014).

BARTHE, B. Elaboration, mise en oeuvre et apport classificatoire d'un cadre d'analyse des aspects collectifs du travail. In: XXXVIIlème Congrès de la SELF. Paris, p. 181-188, 2003.

BERMUDEZ, J. Medicamentos genéricos: uma alternativa para o Mercado brasileiro. Caderno de Saúde Pública, Rio de Janeiro, 10 (3), p. 368-378, jul/set, 1994.

BOYATZIS, R. E.; MCCLELLAND, D. C. Leadership motive pattern and long-term sucess in management. Journal of Applied Psychology, Washington, v. 67, iss. 6, p. 737-744, dec. 1982.

BRASIL. MCT. Constituição. Capítulo IV - Da Ciência e Tecnologia - Artigo 218, 1988. Disponível em: http://www.mct.gov.br/legis. Acesso em 05 de agosto de 2013.

Lei do Bem, 2005. Disponível em: http://www.mct.gov.br. Acesso em 07 de agosto de 2013.

Lei de Inovação, 2004. Disponível em: http://www.mct.gov.br/content. Acesso em 07 de agosto de 2013.

BROWN, S. L.; EISENHARDT, K. M. Product development: past research, present findings, and future directions. Academy of Management Review. v. 20, n. 2, p. 343-378, 1995. 
CAPANEMA, L. X. L.; PALMEIRA FILHO, P. L. Indústria farmacêutica brasileira: reflexes sobre sua estrutura e potencial de investimentos. Relatório BNDES 2006. Disponível em: http://www.bndes.gov.br/site BNDES/export (acesso em outubro 2013).

CAPES. História e Missão. Disponível em: http://www.capes.gov.br/sobre a capes/ historia e missao. Acesso em 30 de julho de 2013.

CNPQ. Criação do CNPq. Disponível em: http://www.cnpq.br/criação. Acesso em 30 de julho de 2013.

COHEN, W. M.; LEVINTHAL, D. A. Absorptive capacity: a new perspective on learning and innovation. Administrative Science Quartely, [lthaca], USA, v. 35, n. 1, p.128-152, March 1990.

COOPER, R. G. Identifying industrial new product success: project NewProd. Industrial Marketing Management, v. 8, p. 124-135, 1979.

COOPER, R. G.; KLEINSCHMIDT, E. J. An Investigation into the New Product Process: Steps, Deficiencies, and Impact. Journal of Product Innovation Management, v . 3, p. 71-85, 1986.

COOPER, R. G.; KLEINSCHMIDT, E. J. Benchmarking the firm's critical success factors in New Product Development. Journal of Product Innovation Management, v. 12, n. 5, p. 374-391, 1995.

COOPER, R. G.; EDGETT, S. J.; KLEINSCHMIDT, E. J. Benchmarking best NPD practices-III. Research Technology Management, v. 47, n. 6, p. 43-55, 2004.

DEJOURS, C. 0 fator humano. Trad. M. I. S. Betiol, M. J. Tonelli. Rio de Janeiro: Editora Fundação Getulio Vargas, 1997.

DOSI, G. Sources, procedures and microeconomic effects of innovation. Journal of Economic Literature, v. 26, n. 3, p. 1120-1171, sep/1988.

DUBOIS, D. D. Competency-based performance improvement. HRD Press, NY: 1993.

EDMONDSON, A. C.; NEMBHARD, I. M. Product development and learning in project teams: the challenges are the benefits. Journal of Product Innovation Management, v . 26, p. 123-138, 2009.

EISENHARDT, K. M. Building Theories from Case Study Research. The Academy of Management Review, v. 14, n. 4, p. 532-550, oct 1989.

FAPESP. Histórico. Disponível em: http://www.agencia.fapesp.br . Acesso em 05 de agosto de 2013.

Nov de 2011-A.

Indicadores FAPESP de Ciência, Tecnologia e Inovação, boletim no 3 , 
Indicadores FAPESP de Ciência, Tecnologia e Inovação, Atividades de Patenteamento no Estado de São Paulo, 2011-B.

Indicadores FAPESP de Ciência, Tecnologia e Inovação, Balanço de Pagamentos Tecnológico, 2010-A.

Indicadores FAPESP de Ciência, Tecnologia e Inovação, Recursos Humanos em P\&D no Estado de São Paulo, 2010-B.

Indicadores FAPESP de Ciência, Tecnologia e Inovação, Inovação Tecnológica no setor empresarial paulista, 2010-C.

FINEP. A Empresa. Disponível em: http://www.finep.gov.br . Acesso em 30 de julho de 2013.

FRANÇOIS J. P.; GOUX, D.; GUELLEC, D.; KABLA, I.; TEMPLE, P. Le développement d'un outil pour mésurer les compétences: l'enquête "Compétence pour Innover". Ministère de I'Industrie, de la Poste et des Télécommunications e Service des statistiques industrielles (SESSI). OECD, 1998.

FREEMAN, C. The 'National System of Innovation' in historical perspective. Cambridge Journal of Economics, v. 19, p. 5-24, 1995.

FURTADO, J. P. M.; URIAS, E. Recursos naturais e desenvolvimento: estudos sobre o potencial dinamizador da mineração na economia brasileira. $1^{1}$. edição. São Paulo: Editora dos autores/IBRAM, 2013.

FURTADO, J. P. M. Padrões de inovação na indústria brasileira, (mimeo), 2008.

FURTADO, A. Difusão tecnológica: um debate superado? In: Pelaez, V. \& Szmrecsányi, T. (orgs.) Economia da Inovação Tecnológica - Ed. HUCITEC, p. 168-192, 2006.

GALBRAITH, J. R. Matrix organization designs - How to combine functional and project forms. Business Horizons, v. 17, n. 1, p. 29-40, feb-1971.

GOMES, G.; DVORSAK, P.; HEIL, T. Indústria petroquímica brasileira: situação atual e perspectivas. BNDES, 2005.

GONÇALVES, E. O padrão espacial da atividade inovadora brasileira: uma análise exploratória. Estudos Econômicos, v. 37, n. 2, p. 405-433, abr/jun-2007.

GRIFFIN, A. PDMA Research on new product development practices: updating trends and benchmarking best practices. Journal of Product Innovation Management, v . 14, n. 6, p. 429-458, 1997.

HODGSON, G.M. What Are Institutions? Journal of Economic Issues, Vol. XL No. 1 March 2006. 
IBRAM. Produção Mineral Brasileira X Mundial (1930-2012). Disponível em: http://www.ibram.org.br/sites (acesso em fevereiro 2014).

INPI. Instituições de pesquisa não acadêmicas brasileiras - utilização do sistema de patentes de 1990 a 2007. Disponível em: http://www.inpi.gov.br/patentes (acesso em junho 2012).

JOHNE, F. A.; SNELSON, P. A. Success factors in product innovation: a selective review of the literature. Journal of Product Innovation Management, v . 5, p. 114$128,1988$.

KAHN, K. B.; BARCZAK, G.; MOSS, R. Perspective: Establishing an NPD best practices Framework. Journal of Product Innovation Management, v. 23, p. 106116, 2006.

KLINE, S. J.; ROSENBERG, N. "An overview of innovation". In R. Landau e N. Rosenberg (eds.) The Positive Sum of Strategy Harnessing Technology for Economic Growth, Washington, DC: National Academy Press, p.275-305, 1986.

KRIEGER, E.; GALEMBECK, F.; GUIMARAES, E.A.; BERTERO, C. O. Ciência e politica no Brasil: uma nova política para um mundo global. SCHWARTZMAN, S. (coordenador). Estudo realizado pela FGV para o Ministério da Ciência e Tecnologia e para o Banco Mundial, 1993.

LAKATOS, E. M.; MARCONI, M. A. Metodologia científica. 4 ed. São Paulo: Atlas, 2004.

LARSON, E. W.; GOBELI, D. H. Organizing for product development projects. . Journal of Product Innovation Management, v . 5, p. 180-190, 1988.

LAWLER III,E. E. From job-based to competency-based organizations. Journal of Organizational Behavior. Chichester, v. 15, iss. 1, p 3-16, Jan-1994.

LE BOTERF, G. De la competénce - Essai sur um attacteur étrange. Paris: Éditions d'Organisation, 1995.

LE BOTERF, G. Repenser la competence. Pour dépasser les idées recues: 15 propositions. 2 ème édition, Paris: Éditions d'Organisation, 2010.

LEEDY, P. D. Practical research: planning and design. Colab. de T. J. Newby e P. A. Ertmer. 6.ed. New Jersey: Prentice Hall, 1997.

MALERBA, F.; ORSENIGO, L. Knowledge, innovative activities and industrial evolution. Industrial and Corporate Change, v. 9 n. 2, p. 289-314, 2000.

MALERBA, F. Learning by firms and incremental technical change. The Economic Journal, v. 102, n. 413, p. 845-859, jul, 1992.

MCCLELAND, D.C. Testing for competence rather than intelligence. American Psychologist, vol. 28, n. 1, p. 1-40 1973. 
MCLANGAN, P. A. Competencies: the next generation. Training and Development, p. 40-47, May 1997.

MCT. O Ministério da Ciência, Tecnologia e Inovação, 2013. Disponível em: http://www.mct.gov.br . Acesso em 07 de agosto de 2013.

MEES, C. E. K. The organization of industrial scientific research. McGraw Hill Book Company, New York, 1920.

METCALFE, J. S. Equilibrium and evolutionary foundations of competition and Technology policy: new perspectives on the division of labour" in Pelikan, $\mathrm{H}$. (ed.) The Evolutionary Analysis of Economic Policy, Edward Elgar Publishers, Cheltenham/Northampton, 2003.

MINTZBERG, H. Criando organizações eficazes: estruturas em cinco configurações. trad. Ciro Bernardes. São Paulo: Atlas, 1995.

MINTZBERG, H. An emerging strategy of "direct" research. Administrative Science Quarterly, v. 24, p. 582-589, dec-1979.

MIRON, M.V.; CAVALCANTI, F. C. B.; WONGTSCHOWSKI, P. Inovação tecnológica e produção no setor químico. Química Nova, v.28, Nov./Dec. 2005.

MUNIER, F. Firm size, technological intensity of sector and relational competencies to innovate: Evidence from French industrial innovating firms. Economics of Innovation and New Technology, $n^{\circ}$ 15, p. 493-505, 2006.

MUNIER, F. Taille de la firme et compétences relationnelles: une vérification empirique sur la base de données individuelles d'entreprises industrielles françaises. Revue Internationale PME, vol. 14, $\mathrm{n}^{\circ}$ 1, 2001.

MUNIER, F. La relation PME - grande entreprise et compétences pour innover: une vérification empirique sur la base de données individuelles de l'industrie française.

Les 4 pages des statistiques industrielles, $n^{\circ} 120$, octobre 1999.

MUNIER, F.; RONDÉ, P. Densité scientifique des régions et compétences pour innover des entreprises: une mise en perspective du concept de "learning region". Révue d'Économie Régionale et Urbaine, n. 4, p. 515-538, 2001.

NAKANO, D. N.; FLEURY, A. C. C. Centralização e descentralização de atividades de engenharia: dois estudos de caso. Gestão e Produção. v. 5, n.2, p. 133143,1998 .

NELSON, R.R. The role of knowledge in R\&D Efficiency. Quarterly Journal of Economics, 93, p. 453-470, 1982.

NELSON, R.R.; ROSENBERG, N. Technical innovation and national systems. In: Nelson, R. (ed.) National innovation systems: a comparative analysis. New York, Oxford: Oxford University, 1993. 
NELSON, R.R.; WINTER, S. An evolutionary theory of economic change. Cambridge: Harvard University Press, 1982.

NONAKA, I.; TAKEUCHI, $\mathrm{H}$. Criação de conhecimento na empresa: como as empresas japonesas geram a dinâmica da inovação. Rio de Janeiro: Campus, 1997.

NORTH, D. Institutions, Institutional Change and Economic Performance, Cambridge: Press Syndicate of the University of Cambridge, 1990.

ORGANISATION FOR ECONOMIC CO-OPERATION AND DEVELOPMENT, OECD. Frascati Manual. Proposed standard practice for surveys on research and experimental development. Paris, 2002.

OECD. OSLO MANUAL - The measurement of scientific and technological activities. Proposed guidelines for collecting and interpreting technological innovation data. Paris, France: OECD - Organisation for Economic Co-operation and Development Publications, 1997.

PANDE, R.; UDRY, C. Institutions and Development: A View from Below, Center Discussion Paper Na. 928, Economic Growth Center, Yale University, New Haven, 2005. http://www.econ.yale.edu/ egcenter/

PAVITT, K. Sectorial patterns of technical change: towards a taxonomy and a theory. Research Policy, v. 13, n. 6, December 1984, p. 343-373, 1984.

PENROSE, E. The Theory of the growth of the firm. Oxford: Basil Blackwell. 1959.

PLONSKI, G. A. Bases para um movimento pela inovação tecnológica no Brasil. São Paulo em Perspectiva, v. 19, n. 1, p. 25-33, 2005.

PLONSKI, G. A. Cooperação universidade-empresa: um desafio gerencial complexo. Revista de Administração da USP, v. 34, n. 4, p. 5-12, out/dez-1999.

PRAHALAD, C. K.; HAMEL, G. The Core Competence of the Corporation. Harvard Business Review, may-june, pp. 79-90, 1990.

RABECHINI JR, R.; CARVALHO, M. M. Gerenciamento de projetos na prática: casos brasileiros. Rabechini Jr, R.; Carvalho, M.M. (org.). São Paulo: Atlas, 2010.

REVISTA FAPESP. Renovação Química. disponível em: www.revistapesquisa.fapesp.br (acesso em novembro de 2013).

Além dos derivados de petróleo. disponível em: www.revistapesquisa.fapesp.br (acesso em setembro de 2012).

RODRIK, D. Growth strategies, Harvard University, John F. Kennedy School of Government, 2003. http://econ.ucsd.edu/seminars/draft_30.pdf. 
ROSENBERG, N. Inside the Black Box: technology and economics. London: Cambridge, 1982.

SCHUMPETER, J. Business Cycles: a theoretical, historical and statistical analysis of the capitalist process. Philadelphia Ed, 1939.

SCHUMPETER, J. A. Capitalismo, Socialismo e Democracia. Rio de Janeiro: Zahar, 1942.

STAL, E. Centros de Pesquisa Cooperativa. Revista de Administração da USP, v. 34, n. 4, p. 71-80, out/dez-1999.

STOKES, D. E. O quadrante de Pasteur: a ciência básica e a inovação tecnológica. Clássicos da Inovação. Tradução de J. E. M. Campinas: Editora UNICAMP, 2005 (original de 1997), p.15-140, 2005.

SIMON, H. A. Bounded rationality and organizational learning. Organization Science, [S.I.], v. 2, n. 1, p.125-134, November 1991.

TAKEUCHI H.; NONAKA, I. The new new product development game. Harvard Business Review, Boston, p. 1-12, JAN-FEV 1986.

TIDD, J.; BESSANT, J.; PAVITT, K. Managing Innovation: Integrating technological, market and organizational change. $3^{\text {rd }}$ edition. England: John Wiley \& Sons Ltd, 2005.

TOLMASQUIM, A. T.; DOMINGUES, H. M.B. Conselho Nacional de Desenvolvimento Científico e Tecnológico (CNPq): mais um acervo para a história da ciência. História, Ciência, Saúde. Manguinhos, vol. 5, n. 1, Rio de Janeiro, mar/june 1998.

URIAS, E. M. P. A indústria farmacêutica brasileira: um processo de coevolução de instituições, organizações industriais, ciência e tecnologia. Dissertação (Mestrado em Política Científica e Tecnológica) - Instituto de Geociências da Universidade Estadual de Campinas, Campinas, 2009.

VALOR ECONÔMICO. Multinacionais Brasileiras. Revista Valor Econômico, n. 4, p. 71, set/2011.

VALLÉRY, G. Relations de service et approche ergonomique : saisir le caractère dynamique et situé de l'activité au travers de l'analyse des interactions "agentclient 》. @ctivités, v. 1, n. 2, p. 121-146, 2004. Disponível em: http://www.activites.org/v1n2/vallery.pdf.

VASCONCELLOS, E; HEMSLEY, J. R. Estrutura das Organizações: estruturas tradicionais, estruturas para inovação e estrutura matricial. $3^{a}$. edição. São Paulo: Pioneira, 1997. 
VOSS, C.; TSIKRIKTSIS, N.; FROHLICH, M. Case research in operations management. International Journal of Operations \& Production Management, v. 22, n. 2, p. 195-219, 2002.

YIN, R. K. The case study crisis: some answers. Administrative Science Quarterly, v. 26 , p. $58-65$, mar- 1981 .

ZARIFIAN, P. Objetivo competência: por uma nova lógica. Trad. Maria Helena C.V. Trylinski. São Paulo: Atlas, 2001. 


\section{APÊNDICE}

APÊNDICE A - Roteiro de entrevista semi-estruturada

APÊNDICE B - Carta de apresentação da pesquisa enviada para as empresas

APÊNDICE C - Questionário aplicado junto aos gestores das empresas pesquisadas 


\section{APÊNDICE A - Roteiro de entrevista semi-estruturada}

Data de realização da entrevista:

Duração:

Nome da Empresa: Ano de Fundação:

Entrevistado:

Formação Acadêmica:

Cargo e Tempo de Empresa:

A - Bloco de Competências Técnicas

1. Poderia descrever o processo de pesquisa e desenvolvimento de inovações?

2. A empresa faz captação de novas tecnologias e novos conhecimentos disponíveis no mercado? Quais são as práticas utilizadas para esta atividade?

3. Poderia comentar como é feita a avaliação e seleção dos projetos de novos produtos e tecnologias?

B - Bloco de Competências Organizacionais

4. Como estão organizadas as diferentes atividades do processo de pesquisa e desenvolvimento de inovações (pesquisa/inovação, pesquisa mercado/clientes, análise de projeto, desenvolvimento do produto/protótipo, testes (produção e mercado), start-up produção e análise financeira / jurídica), entre as áreas da empresa?

5. As diferentes competências requeridas em cada fase alteram a forma como está estruturado o processo de P\&D de inovações? 
6. Como ocorre a coordenação dos diferentes profissionais e áreas envolvidas no processo de $P \& D$ de inovações?

7. Há flexibilidade e mobilidade entre as áreas para trabalhar coletivamente?

8. Qual o grau de autonomia dos funcionários para gerar novas ideias?

9. A empresa estimula e recompensa a geração de novas ideias?

10. Há um plano de desenvolvimento e de carreira para os profissionais envolvidos em pesquisa de inovações?

11. Qual a regularidade dos cursos/capacitações (ao ano) para os funcionários de P\&D?

12. Como ocorre o compartilhamento de informações e conhecimentos entre os membros das equipes? Quais os meios utilizados?

13. Quando surge uma dificuldade que exige maior conhecimento ou competência, como a equipe se organiza para solucioná-la (colegas de outras unidades, outras empresas ou instituições, novas contratações, parcerias externas)?

C - Bloco de Competências Relacionais

14.A empresa pesquisa inovações lançadas e registro de patentes dos concorrentes?

15. As necessidades e expectativas dos clientes são analisadas para a geração de ideias?

16. Há parcerias ou cooperação com outras organizações para inovar? Quais os motivos para cooperar com estas organizações?

D - Bloco de Competências de Negócios 
17. A empresa conhece e busca outras fontes públicas e privadas para financiamento da inovação? Quais são as vantagens e desvantagens dessa prática?

18. Comente como é o processo de comercialização da inovação?

19. A empresa possui uma área específica de gestão da inovação? Quais são as atribuições dessa área?

20. Comente sobre a importância da inovação para a empresa.

E - Bloco de Competências de Regulação

21. A empresa faz controle de riscos contratuais e de projetos?

22. Há uma área específica internamente para realizar as atividades de regulação?

23. Como a empresa controla e defende os direitos de propriedade das inovações? 


\section{APÊNDICE B - Carta de apresentação da pesquisa enviada às empresas}

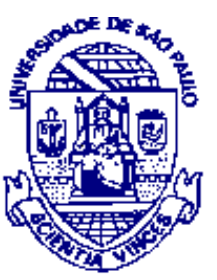

Prezado(a) Sr.(a)

Estamos realizando uma pesquisa sobre práticas de organização do trabalho de P\&D de Inovações em empresas consideradas inovadoras, como etapa de pesquisa de doutorado. Esta pesquisa possui caráter acadêmico, sem fins comerciais, e conta com o apoio da CAPES e USP. Os resultados da pesquisa, observada a confidencialidade dos respondentes, serão publicados e compartilhados com as empresas participantes.

A pesquisa possui 6 perguntas simples, do tipo múltipla escolha, com tempo estimado de resposta de $\mathbf{1 0}$ minutos.

Espera-se que as questões sejam respondidas por Diretores, Gestores ou profissionais responsáveis pela área de P\&D de inovações. Caso não desempenhe uma destas funções, solicitamos a gentileza de encaminhá-la ao(s) profissional(is) desta área.

Para acessar o questionário, clique no link:

\section{https://docs.google.com/forms/d/.../viewform}

Antecipadamente, agradecemos sua valiosa colaboração.

Rosalina Alves S. de Mesquita rosa.mesquita@usp.br ou rosamesquita2000@gmail.com
Prof. Dr. João Furtado joao.furtado@poli.usp.br 


\section{APÊNDICE C - Questionário aplicado junto aos gestores das empresas pesquisadas}

Pesquisa - Levantamento de Melhores Práticas de Desenvolvimento de Inovações

Prezado Gestor,

Esta pesquisa tem como objetivo entender como competências e conhecimentos de diferentes profissionais combinam-se para organizar o trabalho de P\&D de Inovações, tanto no ambiente interno como externo da organização. Solicitamos sua colaboração respondendo o questionário de seis questões, do tipo múltipla escolha. Asseguramos a confidencialidade do nome da empresa e de dados sigilosos ou estratégicos, firmando o compromisso de compartilhar os resultados finais com os participantes. Novamente agradecemos a sua valiosa colaboração.

Rosalina Mesquita

rosa.mesquita@usp.br

ou rosamesquita2000@gmail.com
Prof. Dr. João Furtado joao.furtado@poli.usp.br

Identificação

Nome da Empresa

Cargo do entrevistado 
Estrutura para Inovação

A empresa possui uma área formal de P\&D de Inovações?

$\begin{array}{lll}\circ & \Gamma & \text { Sim } \\ \circ & \square & \text { Não }\end{array}$

Indique que tipo de inovação a empresa implementa ou tem projeto para implementar:

\begin{tabular}{lccc|} 
& Principalmente & Secundariamente & Não se aplica \\
\hline Produto Novo & 0 & 0 & 0 \\
\hline Produto Aprimorado & 0 & 0 & 0 \\
\hline Processo Novo & 0 & 0 & 0 \\
\hline Processo Aprimorado & 0 & 0 & 0 \\
\hline Tecnologia Nova & 0 & 0 & 0 \\
\hline Tecnologia & 0 & 0 & 0 \\
\hline Aprimorada & & & 0 \\
\hline
\end{tabular}

Com quais organizações a empresa mantém cooperação ou interação para inovar?

Regularmente Ocasionalmente Não se aplica

\begin{tabular}{l|c|c|c|}
\hline Universidades & 0 & 0 & 0 \\
\hline Institutos de Pesquisa & 0 & 0 & 0 \\
\hline Clientes & 0 & 0 & 0 \\
\hline Fornecedores & 0 & 0 & 0 \\
\hline Consultorias & 0 & 0 & 0 \\
\hline Concorrentes & 0 & 0 & 0 \\
\hline $\begin{array}{l}\text { Centros de Capacitação } \\
\text { Profissional }\end{array}$ & 0 & 0 & 0 \\
\hline $\begin{array}{l}\text { Instituições certificadoras ou de } \\
\text { testes }\end{array}$ & 0 & 0 & 0 \\
\hline
\end{tabular}




\section{O motivo para a empresa buscar cooperação externa inclui:}

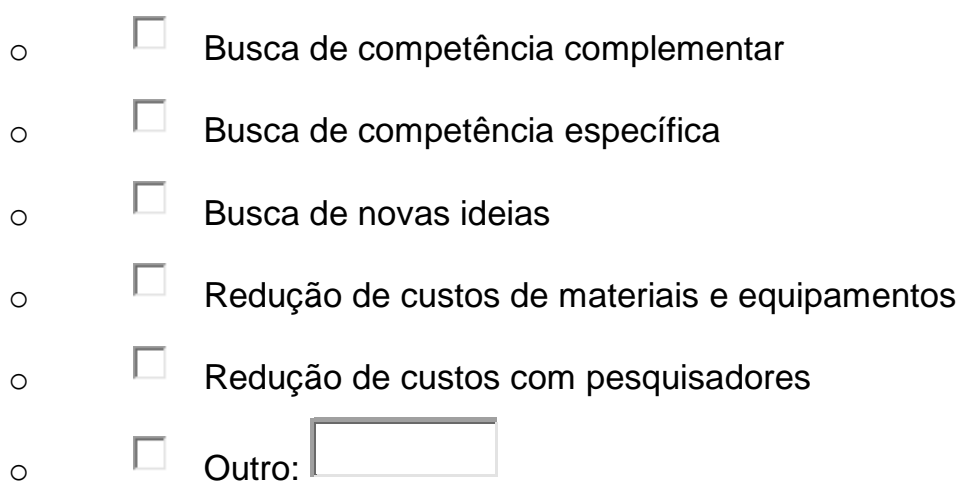

\section{Quantos profissionais trabalham diretamente nos laboratórios de P\&D de Inovações?}

\begin{tabular}{|c|c|}
\hline 6 & Não tem equipe dedicada à $P \& D$ de inovações \\
\hline 0 & Até 3 profissionais \\
\hline 0 & De 4 até 10 profissionais \\
\hline 0 & De 11 até 50 profissionais \\
\hline 0 & De 51 até 100 profissionais \\
\hline 0 & Mais de 100 profissionais \\
\hline
\end{tabular}

Indique que áreas de sua empresa detêm as competências relacionadas abaixo:

Definimos como:

COMPETÊNCIA TÉCNICA ==> as habilidades de geração de novas ideias, análise de oportunidades no mercado, desenvolvimento e produção de inovação;

COMPETÊNCIA RELACIONAL $==>$ as habilidades de busca de parcerias ou cooperação e de conhecimento/competências no mercado;

COMPETÊNCIA DE NEGÓCIOS ==> as habilidades de elaborar planejamento estratégico, selecionar novos projetos, captar recursos e financiamentos, analisar e controlar custos; COMPETÊNCIA DE REGULAÇÃO ==> as habilidades de formalização de contratos e licenciamentos, análise e controle de riscos de projetos, monitorar propriedade intelectual/imitação;

COMPETÊNCIA ORGANIZACIONAL ==> as habilidades de gestão de $\mathrm{RH}$, gestão do conhecimento e da informação. 


\section{Competências Competências Competências Competências Competência \\ Técnicas Relacionais de Negócios de Regulação Organizacional}

\begin{tabular}{lc|c|c|c|c|}
\hline P\&D & O & O & 0 & 0 & 0 \\
\hline $\begin{array}{l}\text { Marketing e } \\
\text { Comercial }\end{array}$ & 0 & 0 & 0 & 0 & 0 \\
\hline $\begin{array}{l}\text { Produção e } \\
\text { Operaçães }\end{array}$ & 0 & 0 & 0 & 0 & 0 \\
\hline $\begin{array}{l}\text { Gestão da } \\
\text { Inovação }\end{array}$ & 0 & 0 & 0 & 0 & 0 \\
\hline Jurídico & 0 & 0 & 0 & 0 & 0 \\
\hline
\end{tabular}

Enviar

Nunca envie senhas em Formulários Google.

Powered by Google Forms

Este conteúdo não foi criado nem aprovado pelo Google.

$\underline{\text { Denunciar abuso - Termos de Serviço - Termos Adicionais }}$ 